Florida International University FIU Digital Commons

$3-22-2010$

\title{
Enhanced Biocompatibility of NiTi (Nitinol) Via Surface Treatment and Alloying
}

Waseem Haider

Florida International University, whaid001@fiu.edu

DOI: $10.25148 /$ etd.FI10041612

Follow this and additional works at: https://digitalcommons.fiu.edu/etd

\section{Recommended Citation}

Haider, Waseem, "Enhanced Biocompatibility of NiTi (Nitinol) Via Surface Treatment and Alloying" (2010). FIU Electronic Theses and Dissertations. 177.

https://digitalcommons.fiu.edu/etd/177

This work is brought to you for free and open access by the University Graduate School at FIU Digital Commons. It has been accepted for inclusion in FIU Electronic Theses and Dissertations by an authorized administrator of FIU Digital Commons. For more information, please contact dcc@fiu.edu. 


\title{
FLORIDA INTERNATIONAL UNIVERSITY
}

Miami, Florida

\section{ENHANCED BIOCOMPATIBILITY OF NITI (NITINOL) VIA SURFACE TREATMENT AND ALLOYING}

\author{
A dissertation submitted in partial fulfillment of the \\ requirements for the degree of \\ DOCTOR OF PHILOSOPHY
}

in

MECHANICAL ENGINEERING

by

Waseem Haider

2010 
To: Dean Amir Mirmiran

College of Engineering and Computing

This dissertation, written by Waseem Haider, and entitled Enhanced Biocompatibility of NiTi (Nitinol) via Surface Treatment and Alloying, having been approved in respect to style and intellectual content, is referred to you for judgment.

We have read this dissertation and recommend that it be approved.

$\begin{array}{r}\hline \text { Kuang-Hsi Wu } \\ \hline \text { W. Kinzy Jones } \\ \hline \text { Anthony J. McGoron } \\ \hline \text { Norman Munroe, Major Professor }\end{array}$

Date of Defense: March 22, 2010

The dissertation of Waseem Haider is approved.

\begin{tabular}{r} 
Dean Amir Mirmiran \\
College of Engineering and Computing \\
\hline Interim Dean Kevin O' Shea \\
University Graduate School
\end{tabular}

Florida International University, 2010 


\section{DEDICATION}

To My Lovely Parents \& Grandparents 


\section{ACKNOWLEDGMENTS}

I am deeply grateful to my Major Professor, Norman Munroe, for his guidance, vision and support throughout the course of my PhD work. I express my special thanks to him for reviewing the research manuscripts and providing constructive comments and criticism during the past years. I also appreciate his constant inspiration and invaluable encouragement for me to become better.

My gratitude is extended to my dissertation committee members for their willingness to participate in his process and provided invaluable support and encouragement.

During these years, the support of my friends has been extremely valuable. I want to thank Yuan Tang for helping and training me with the cell culture studies. I also would like thank my research group members Puneet, Chandan, Sushma, Smit and Dharam. Last but not the least, special thanks to Dr. Tek who spent several hours with me to prepare the metal ion solutions for cytotoxicity assessment.

I sincerely thank Electrobright ${ }^{\circledR}$ for electropolishing and magnetoelectropolishing, Physical Electronics ${ }^{\circledR}$ for XPS analysis and Tatiana Trejos for ICPMS analysis.

I also would like to thank my family for all the love and support especially, to my Father, who is always been supportive to me. Dad, this is for you. To my Mom, thank you for being so understanding and being such a wonderful mother. I appreciate their continuing support in everything I do. I also want to thank my brothers and sisters for their support and encouragement throughout my life.

I wish to express my loving thanks to my wife, without whom this work never could have been success and whose patience and love kept me motivated. I appreciate the 
countless sacrifices (especially those late night trips....) she has made and I am very much looking forward to recapturing the time we have missed! She has been my source of happiness, confidence, and inspiration. Honey, we made it!

I would also like to acknowledge various funding sources, which have enabled the completion of my degree.

Applied Research Center (ARC) at FIU offered me the Enhanced Research Assistant award that covered my expenses during the first one and half year. Later, I was also supported by Dr. Munroe's project (Award Number SC3GM084816) from the National Institute of General Medical Sciences. The University Graduate School (UGS) selected me for the Dissertation Year Fellowship, which covered my tuition and living expenses during my final year.

Finally, I acknowledge my Lord who gave me strength when I was weak, who helped me and guided me in all these hard times. Thank you so much! 


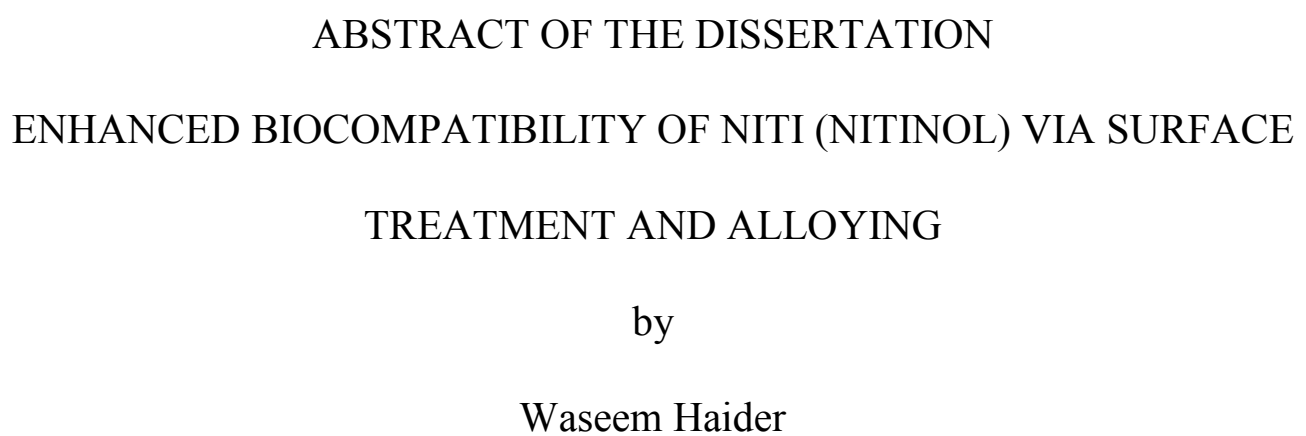

Florida International University, 2010

Miami, Florida

Professor Norman Munroe, Major Professor

It is projected that by 2020 , there will be 138 million Americans over 45 , the age at which the increased incidence of heart diseases is documented. Many will require stents. This multi-billion dollar industry, with over 2 million patients worldwide, $15 \%$ of whom use Nitinol stents have experienced a decline in sales recently, due in part to thrombosis. It is a sudden blood clot that forms inside stents. As a result, the Food and Drug Administration and American Heart Association are calling for a new generation of stents, new designs and different alloys that are more adaptable to the arteries. The future of Nitinol therefore depends on a better understanding of the mechanisms by which Nitinol surfaces can be rendered stable and inert. In this investigation, binary and ternary Nitinol alloys were prepared and subjected to various surface treatments such as electropolishing (EP), magnetoelectropolishing (MEP) and water boiling \& passivation (W\&P). In vitro corrosion tests were conducted on Nitinol alloys in accordance with ASTM F 2129-08. The metal ions released into the electrolyte during corrosion tests were measured by Inductively Coupled Plasma Mass Spectroscopy (ICP-MS). Biocompatibility was assessed by observing the growth of human umbilical vein 
endothelial cells (HUVEC) on the surface of Nitinol alloys. Static and dynamic immersion tests were performed by immersing the Nitinol alloys in cell culture media and measuring the amount of metal ions released in solution. Sulforhodamine B (SRB) assays were performed to elucidate the effect of metal ions on the growth of HUVEC cells. The surfaces of the alloys were studied using Scanning Electron Microscopy (SEM) and X-ray Photoelectron Spectroscopy (XPS) respectively. Finally, wettability and surface energy were measured by Contact Angle Meter, whereas surface roughness was measured by Atomic Force Microscopy (AFM).

All the surface treated alloys exhibited high resistance to corrosion when compared with untreated alloys. SRB assays revealed that $\mathrm{Ni}$ and $\mathrm{Cu}$ ions exhibited greater toxicity than $\mathrm{Cr}$, Ta and Ti ions on HUVEC cells. EP and MEP alloys possessed relatively smooth surfaces and some were composed of nickel oxides instead of elemental nickel as determined by XPS. MEP exhibited lowest surface energy and lowest surface roughness. 


\section{TABLE OF CONTENTS}

CHAPTER

PAGE

1. INTRODUCTION

1.1 Biomaterials

1.2 Shape Memory Alloys (SMAs)

1.2.1 Microstructure of Shape Memory Alloys

1.2.2 Transition Temperature Hysteresis

1.2.3 Shape Memory Effect

1.2.4 Superelasticity

$1.3 \quad$ Nitinol

1.3.1 Cardiovascular Stents Made of Nitinol

$1.4 \quad$ Human Blood Vessels and Role of Endothelium 10

1.5 Restenosis

1.6 Thrombosis

1.7 Toxic Effects of Nickel

1.8 Research Objectives

2. LITERATURE REVIEW

2.1 Surface Treatment of Nitinol 16

$\begin{array}{lll}2.1 .1 & \text { Heat Treatment } & 17\end{array}$

2.1.2 Passivation and Electropolishing (EP) 18

2.1.3 Plasma Ion Immersion Implantation (PIII) 21

2.1.4 Sterilization Techniques 23

$\begin{array}{ll}2.1 .5 & \text { Artificial Coatings }\end{array}$

2.2 Alloying of Nitinol 26

3. CORROSION BEHAVIOR OF MEDICAL IMPLANTS 31

3.1 Introduction $\quad 31$

3.1.1 Pitting Corrosion $\quad 32$

3.1.2 Crevice Corrosion 32

3.2 ASTM F 2129 Standard 35

3.3 Experimental Methods $\quad 37$

$\begin{array}{lll}3.3 .1 & \text { Materials } & 37\end{array}$

3.3.2 Reagents 38

3.3.3 Sample Preparation 38

3.4 Corrosion Testing 39

3.5 Metal Ion Leaching $\quad 52$

4. BIOCOMPATIBILITY ASSESSMENT OF NITINOL ALLOYS 56

4.1 Immersion Tests $\quad 56$ 
4.1.1 Metal Ion Concentration $\quad 58$

4.1.2 Cytotoxicity Assays 59

4.2 Endothelial Cell Proliferation 69

$\begin{array}{lll}4.3 & \text { Exogenous Addition of Metal ions } & 72\end{array}$

4.4 Biological Tolerance of Implant Metals 76

5. SURFACE CHARACTERIZATION OF NITINOL ALLOYS 78

$\begin{array}{lll}5.1 & \text { Scanning Electron Microscopy (SEM) } & 78\end{array}$

5.2 X-ray Photoelectron Spectroscopy (XPS) 82

5.2.1 Depth Profiles 83

5.2.2 Montage Plots 91

$\begin{array}{ll}\text { 5.2.3 Composition of Nitinol Surfaces } & 105\end{array}$

$\begin{array}{lll}5.3 \quad \text { Contact Angle Measurement } & 107\end{array}$

$\begin{array}{ll}\text { 5.3.1 Work of Adhesion } & 110\end{array}$

$\begin{array}{ll}\text { 5.3.2 Surface Energy } & 111\end{array}$

$\begin{array}{lll}5.4 & \text { Roughness Analysis } & 113\end{array}$

6. DISCUSSION 116

6.1 Biocompatibility of Nitinol alloys . . 116

6.1.1 Corrosion Analysis of Nitinol Alloys 116

$\begin{array}{ll}\text { 6.1.2 Endothelialization of Nitinol Alloys } & 118\end{array}$

6.1.3 Cytotoxicity Assessment of Nitinol Alloys 119

$\begin{array}{lll}6.2 & \text { Surface Characterization of Nitinol Alloys } & 120\end{array}$

6.2.1 Scanning Electron Microscopy 120

6.2.2 X-Ray Photoelectron Spectroscopy 121

$\begin{array}{ll}\text { 6.2.3 Contact Angle Measurement } & 122\end{array}$

6.2.4 Atomic Force Microscopy 123

$\begin{array}{ll}\text { CONCLUSIONS } & 125\end{array}$

$\begin{array}{ll}\text { REFERENCES } & 129\end{array}$

$\begin{array}{ll}\text { APPENDICES } & 139\end{array}$

$\begin{array}{ll}\text { VITA } & 149\end{array}$ 


\section{LIST OF TABLES}

TABLES

PAGE

Table 3-1 Alloy Composition (in atomic percent) 38

Table 3-2 Corrosion data for NiTi-untreated alloys 44

Table 3-3 Corrosion data for NiTi-EP alloys 44

Table 3-4 Corrosion data for NiTi-MEP alloys 44

Table 3-5 Corrosion data for NiTi-W\&P alloys 45

Table 3-6 Corrosion data for NiTi10Cr-untreated alloys 45

Table 3-7 Corrosion data for NiTi10Cr-EP alloys 45

Table 3-8 Corrosion data for NiTi10Cr-MEP alloys 45

Table 3-9 Corrosion data for NiTi10Cr-W\&P alloys 46

Table 3-10 Corrosion data for NiTi10Cu-untreated alloys 46

Table 3-11 Corrosion data for NiTi10Cu-EP alloys 46

Table 3-12 Corrosion data for NiTi10Cu-MEP alloys 46

Table 3-13 Corrosion data for NiTi10Cu-W\&P alloys 47

Table 3-14 Corrosion data for NiTi10Ta-untreated alloys 47

Table 3-15 Corrosion data for NiTi10Ta-EP alloys 47

Table 3-16 Corrosion data for NiTi10Ta-MEP alloys 48

Table 3-17 Corrosion data for NiTi10Ta-W\&P alloys 48

Table 3-18 Corrosion data for NiTi5Ta-untreated alloys 48

Table 3-19 Corrosion data for NiTi5Cu-untreated alloys 49

Table 3-20 Corrosion data for NiTi5Cr-untreated alloys 49

Table 3-21 Corrosion data for Nitinol Stents 49 
Table 3-22 ICP-MS analysis for NiTi alloys 54

Table 3-23 ICP-MS analysis for NiTiCr alloys 54

Table 3-24 ICP-MS analysis for NiTiCu alloys 55

Table 3-25 ICP-MS analysis for NiTiTa alloys 55

Table 3-26 ICP-MS analysis for NiTi5Ta, NiTi5Cu and NiTi5Cr alloys 55

Table 4-1 Composition of F-12K medium 57

Table 5-1 Elemental concentrations (at. \%) on the surfaces of Nitinol alloys 106 detected using XPS

Table 5-2 Oxides concentration and thickness on the surfaces of Nitinol alloys 106 detected using XPS

Table 5-3 Contact Angle Test Results for Water 109

Table 5-4 Contact Angle Test Results for Ethylene Glycol 109

Table 5-5 Contact Angle Test Results for Diiodomethane 109

Table 5-6 Kitazaki-Hata Surface Interaction 111

Table 5-7 Kitazaki-Hata Surface Free Energy Components $\left(\mathrm{mJ} / \mathrm{m}^{2}\right) \quad 112$

Table 5-8 Mean surface roughness (Ra) for Nitinol alloys $\quad 113$ 


\section{LIST OF FIGURES}

FIGURE

PAGE

Figure 1-1 Macroscopic and microscopic views of the two phases of SMAs 4

Figure 1-2 Transition temperature hysteresis 5

Figure 1-3 Mechanism of shape memory effect 6

Figure 1-4 Mechanism of superelasticity $\quad 7$

Figure 1-5 Structure of blood vessel found in human body 10

Figure 3-1 Extrinsic factors affecting the corrosion behavior of Nitinol 34

Figure 3-2 Typical cyclic potentiodynamic curves illustrating different corrosion 36 Parameters

$\begin{array}{lll}\text { Figure 3-3 Corrosion cell kit } & 40\end{array}$

Figure 3-4 Cyclic potentiodynamic curves for NiTi alloys 41

Figure 3-5 Cyclic potentiodynamic curves for NiTi10Cr alloys 41

Figure 3-6 Cyclic potentiodynamic curves for NiTi10Cu alloys 42

Figure 3-7 Cyclic potentiodynamic curves for NiTi10Ta alloys 42

Figure 3-8 Cyclic potentiodynamic curves for NiTi5X alloys 43

Figure 3-8 Cyclic potentiodynamic curves for Nitinol stents 43

Figure 4-1 ICPMS data for NiTi alloy after static immersion $\quad 61$

Figure 4-2 SRB data for NiTi alloy after static immersion $\quad 61$

Figure 4-3 ICPMS data for NiTi10Cr alloy after static immersion 62

Figure 4-4 SRB data for NiTi10Cr alloy after static immersion $\quad 62$

Figure 4-5 ICPMS data for NiTi10Cu alloy after static immersion 63

Figure 4-6 SRB data for NiTi10Cu alloy after static immersion 63 
Figure 4-7 ICPMS data for NiTi10Ta alloy after static immersion 64

Figure 4-8 SRB data for NiTi10Ta alloy after static immersion $\quad 64$

Figure 4-9 ICPMS data for NiTi alloy after dynamic immersion 65

Figure 4-10 SRB data for NiTi alloy after dynamic immersion 65

Figure 4-11 ICPMS data for NiTi10Cr alloy after dynamic immersion 66

Figure 4-12 SRB data for NiTi10Cr alloy after dynamic immersion 66

Figure 4-13 ICPMS data for NiTi10Cu alloy after dynamic immersion 67

Figure 4-14 SRB data for NiTi10Cu alloy after dynamic immersion 67

Figure 4-15 ICPMS data for NiTi10Ta alloy after dynamic immersion 68

Figure 4-16 SRB data for NiTi10Ta alloy after dynamic immersion 68

Figure 4-17 Highlighted nuclei on NiTi-untreated alloy 70

Figure 4-18 Highlighted nuclei on NiTiCr-untreated alloy 70

Figure 4-19 Highlighted nuclei on NiTiCu-untreated alloy 71

Figure 4-20 Highlighted nuclei on NiTiTa-untreated alloy 71

Figure 4-21 Highlighted nuclei and mitochondria on NiTi-untreated alloy 71

Figure 4-22 Highlighted nuclei and mitochondria on NiTiCr-untreated alloy 71

Figure 4-23 Highlighted nuclei and mitochondria on NiTiCu-untreated alloy 72

Figure 4-24 Highlighted nuclei and mitochondria on NiTiTa-untreated alloy 72

Figure 4-25 SRB data showing the effect of Ni ions on HUVEC cells 74

Figure 4-26 SRB data showing the effect of Ti ions on HUVEC cells 74

Figure 4-27 SRB data showing the effect of Cr ions on HUVEC cells 75

Figure 4-28 SRB data showing the effect of $\mathrm{Cu}$ ions on HUVEC cells 75

$\begin{array}{lll}\text { Figure 5-1 SEM micrograph of NiTi-untreated } & 78\end{array}$ 
Figure 5-2 SEM micrograph of NiTi-EP $\quad 78$

$\begin{array}{lll}\text { Figure 5-3 SEM micrograph of NiTi-MEP } & 79\end{array}$

Figure 5-4 SEM micrograph of NiTi-W\&P $\quad 79$

Figure 5-5 SEM micrograph of NiTi10Cr-untreated 79

Figure 5-6 SEM micrograph of NiTi10Cr-EP $\quad 79$

Figure 5-7 SEM micrograph of NiTi10Cr-MEP $\quad 80$

Figure 5-8 SEM micrograph of NiTi10Cr-W\&P $\quad 80$

Figure 5-9 SEM micrograph of NiTi10Cu-untreated 80

Figure 5-10 SEM micrograph of NiTi10Cu-EP $\quad 80$

Figure 5-11 SEM micrograph of NiTi10Cr-MEP $\quad 81$

Figure 5-12 SEM micrograph of NiTi10Cu-W\&P 81

Figure 5-13 SEM micrograph of NiTi10Ta-untreated 81

Figure 5-14 SEM micrograph of NiTi10Ta-EP $\quad 81$

Figure 5-15 SEM micrograph of NiTi10Ta-MEP 82

Figure 5-16 SEM micrograph of NiTi10Ta-W\&P 82

Figure 5-17 Depth profile for NiTi-untreated 84

Figure 5-18 Depth profile for NiTi-EP $\quad 84$

Figure 5-19 Depth profile for NiTi-MEP $\quad 85$

Figure 5-20 Depth profile for NiTiCr-untreated 85

Figure 5-21 Depth profile for NiTiCr-EP 86

Figure 5-22 Depth profile for NiTiCr-MEP 86

Figure 5-23 Depth profile for NiTiCr-W\&P $\quad 87$

Figure 5-24 Depth profile for NiTiCu-untreated 87 
Figure 5-25 Depth profile for NiTiCu-EP $\quad 88$

Figure 5-26 Depth profile for NiTiCu-MEP $\quad 88$

Figure 5-27 Depth profile for NiTiCu-W\&P $\quad 89$

Figure 5-28 Depth profile for NiTi10Ta-untreated 89

Figure 5-29 Depth profile for NiTi10Ta-EP 90

Figure 5-30 Depth profile for NiTi10Ta-MEP 90

Figure 5-31 Ti montage plot for NiTi-untreated 92

Figure 5-32 Ti montage plot for NiTi-EP 92

Figure 5-33 Ti montage plot for NiTi-MEP 92

Figure 5-34 Ti montage plot for NiTi10Cr-untreated 93

Figure 5-35 Ti montage plot for NiTi10Cr-EP 93

Figure 5-36 Ti montage plot for NiTi10Cr-MEP 93

Figure 5-37 Ti montage plot for NiTi10Cr-W\&P 93

Figure 5-38 Ti montage plot for NiTi10Cu-untreated 94

Figure 5-38 Ti montage plot for NiTi10Cu-EP 94

Figure 5-40 Ti montage plot for NiTi10Cu-MEP 94

Figure 5-41 Ti montage plot for NiTi10Cu-W\&P 94

Figure 5-42 Ti montage plot for NiTi10Ta-untreated 95

Figure 5-43 Ti montage plot for NiTi10Ta-EP 95

Figure 5-44 Ti montage plot for NiTi10Ta-MEP 95

Figure 5-45 Ni montage plot for NiTi-untreated 96

Figure 5-46 Ni montage plot for NiTi-EP 96

Figure 5-47 Ni montage plot for NiTi-MEP 96 
Figure 5-48 Ni montage plot for NiTiCr-untreated 97

Figure 5-49 Ni montage plot for NiTiCr-EP 97

Figure 5-50 Ni montage plot for NiTiCr-MEP 97

Figure 5-51 Ni montage plot for NiTiCr-W\&P 97

Figure 5-52 Ni montage plot for NiTi10Cu-untreated 98

Figure 5-53 Ni montage plot for NiTi10Cu-EP 98

Figure 5-54 Ni montage plot for NiTi10Cu-MEP 98

Figure 5-55 Ni montage plot for NiTi10Cu-W\&P 98

Figure 5-56 Ni montage plot for NiTi10Ta-untreated 99

Figure 5-57 Ni montage plot for NiTi10Ta-EP 99

Figure 5-58 Ni montage plot for NiTi10Ta-MEP 99

Figure 5-59 Cr montage plot for NiTi10Cr-untreated 101

Figure 5-60 Cr montage plot for NiTi10Cr-EP 101

Figure 5-61 Cr montage plot for NiTi10Cr-MEP 102

Figure 5-62 Cr montage plot for NiTi10Cr-W\&P 102

Figure 5-63 Cu montage plot for NiTi10Cu-untreated 103

Figure 5-64 Cu montage plot for NiTi10Cu-EP 103

Figure 5-65 Cu montage plot for NiTi10Cu-MEP 103

Figure 5-66 Cu montage plot for NiTi10Cu-W\&P 103

Figure 5-67 Ta montage plot for NiTi10Ta-untreated 104

Figure 5-68 Ta montage plot for NiTi10Ta-EP 104

Figure 5-69 Ta montage plot for NiTi10Ta-MEP 104

Figure 5-70 The Kyowa Contact Angle Meter 108 
Figure 5-71 Image of a water droplet for contact angle analysis on NiTi

Figure 5-72 Image of a water droplet for contact angle analysis on NiTiCr-MEP 110

Figure 5-73 Image of a water droplet for contact angle analysis on NiTiTa-MEP 110

Figure 5-74 Typical AFM image of NiTi-untreated 114

Figure 5-75 Typical AFM image of NiTi-EP 114

Figure 5-76 Typical AFM image of NiTi-MEP 114

Figure 5-77 Typical AFM image of NiTi10Cr-EP 114

Figure 5-78 Typical AFM image of NiTi10Cr-MEP 115

Figure 5-79 Typical AFM image of NiTi10Cr-W\&P 115

Figure 5-80 Typical AFM image of NiTi10Cu-EP $\quad 115$ 


\section{CHAPTER 1}

\section{INTRODUCTION}

\subsection{Biomaterials}

D. F. Williams et al. defined the term biomaterial as "a material intended to interface with biological systems to evaluate, treat, augment or replace any tissue, organ or function of the body" (D. F. Williams 1992). Stainless steel was the first material successfully used inside the body for fracture fixation. In the early 1960s, a British orthopedic surgeon, Sir John Charnley pioneered modern total hip arthroplasty (THA) by attempting to link together a stainless steel hip prosthesis and high-density polyethylene with metachrylate bone cement. In the late 1960s, P.I. Branemark et al. introduced titanium into the field of medicine (P. I. Branemark 1969). In the early 1980s, Nitinol was investigated as an implant material for the first time. Since then, various metals, polymers, ceramics and composites have been introduced as biomaterials. Biomaterials are currently being used in various medical devices such as replacement for damaged or infected body parts, orthopedic implants, pacemakers, orthodontic wires, vascular stents, and cardiac defibrillators. The ideal biomaterial should be inert, non-irritative, flexible, resistant to encrustation and infection and possess good electromagnetic frequency characteristics to facilitate visibility and communication to and from the device (N. Balakrishnan 2005).

In the last few decades, biomaterials have been used in a wide range of medical implant devices. However, the choice of biomaterials used has been restricted by the biocompatibility properties of the material in meeting the requirements of the application 
(R. H. S. Trigwell 1998). D. F. Williams et al. further defined the term biocompatibility as "the ability of a material to perform with an appropriate host response in a specific application" (D. F. Williams 1992). This definition can be better understood by looking at three different categories: The first category considers the ability of the implant material or device to interact and perform with the host body rather than just being inert. The second category focuses on the biomaterials responsibility to generate an appropriate response from the body and the last category deals with a nature of response to an implant, which may vary from one situation to another.

Biomaterials play an important role in today's modern world to replace or treat various parts of the human body. Therefore, the development of cost effective biomaterials either by innovation of new materials or improved performance of existing materials by various surface treatments is a novel area of interest and is the main focus of this dissertation.

\subsection{Shape Memory Alloys (SMAs)}

Shape Memory Alloys (SMAs) are a group of metallic materials that demonstrate the ability to return to some previously defined shape or size when subjected to the appropriate thermal procedure. A. Ölander discovered the pseudoelastic behavior of the Au-Cd alloy for the first time in 1932 (A. Ölander 1932). In 1938, Greninger \& Mooradian observed the formation and disappearance of a martensitic phase by decreasing and increasing the temperature of a Cu-Zn alloy. In the early 1960s, Buehler and his co-workers at the U.S. Naval Ordnance Laboratory discovered the shape memory effect in an equiatomic alloy of nickel and titanium (NiTi), which is considered as a 
breakthrough in the field of shape memory materials. Other SMAs includes $\mathrm{Cu}-\mathrm{Al}-\mathrm{Ni}$, $\mathrm{Cu}-\mathrm{Zn}-\mathrm{Al}, \mathrm{Fe}-\mathrm{Mn}-\mathrm{Si}$. However, NiTi is the most common shape memory alloy.

\subsubsection{Microstructure of Shape Memory Alloys}

The atomic changes in SMA are displacive in nature. This means that the atoms are rearranged into a more stable crystal structure during phase changes, but the chemical composition of the matrix remains the same (Duerig et al., 1990). The following provides a brief discussion on the microscopic changes that allow the shape memory and superelastic effects to occur.

The macrostructure and microstructure of the two phases of SMAs are shown in Figure 1-1. There are two independent phases in shape memory alloys: austenite and martensite.

Austenite is a high temperature phase that is hard, strong and highly symmetric. Its crystal structure is body-centered cubic, which is associated with its superelastic behavior. The austentic phase of Nitinol is more stable at high temperature and low stress. 


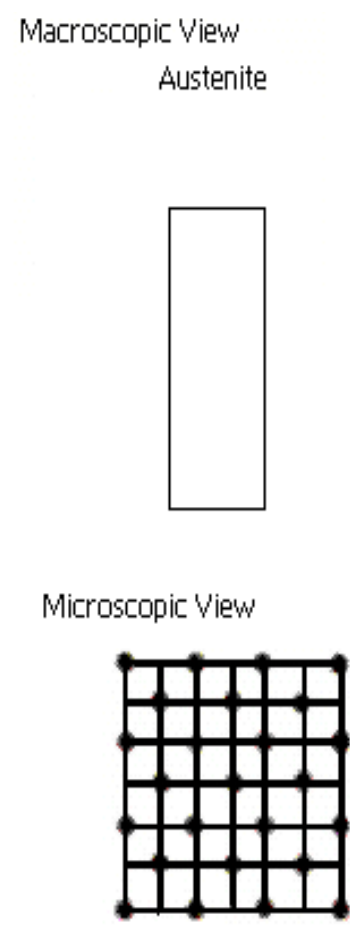

Austenite
Twinned Martensite
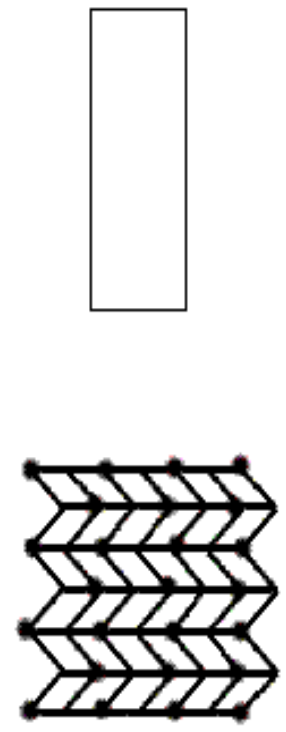

Twinned Martensite

\section{Deformed Martensite}
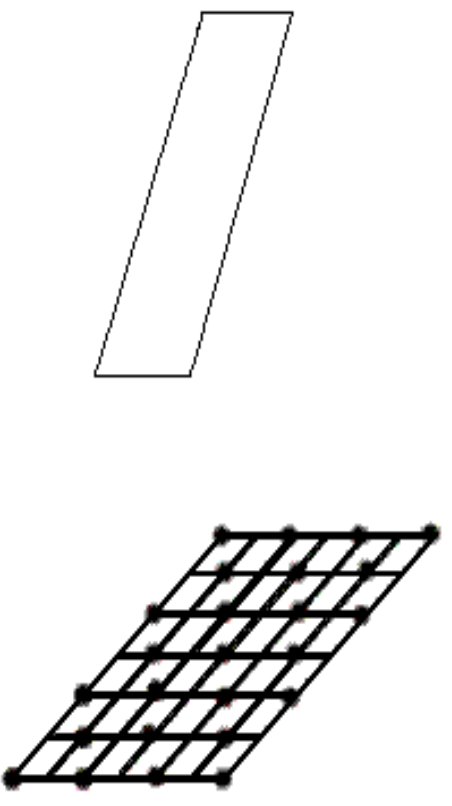

Deformed Martensite

Figure 1-1 Macroscopic and microscopic views of the two phases of SMAs (Ryhänen 1999)

Martensite is a low temperature phase which is soft and ductile. As such, the material can be easily deformed in this phase. It has two stable structures: the twinned form and the deformed form. Martensite exhibits a rhombic geometry which is more stable at low temperature and high stress.

SMAs undergo microstructural phase transformation from martensite to austenite and vice versa, which involves the rearrangement of atoms within the crystal structure of the solid. 


\subsubsection{Transition Temperature Hysteresis}

Hysteresis is the temperature difference between a material's phase transformation upon heating or cooling. Various heat treatments can cause the hysteresis to shift to higher or lower temperature, or become wide. A typical hysteresis curve for SMAs is shown in Figure 1-2.

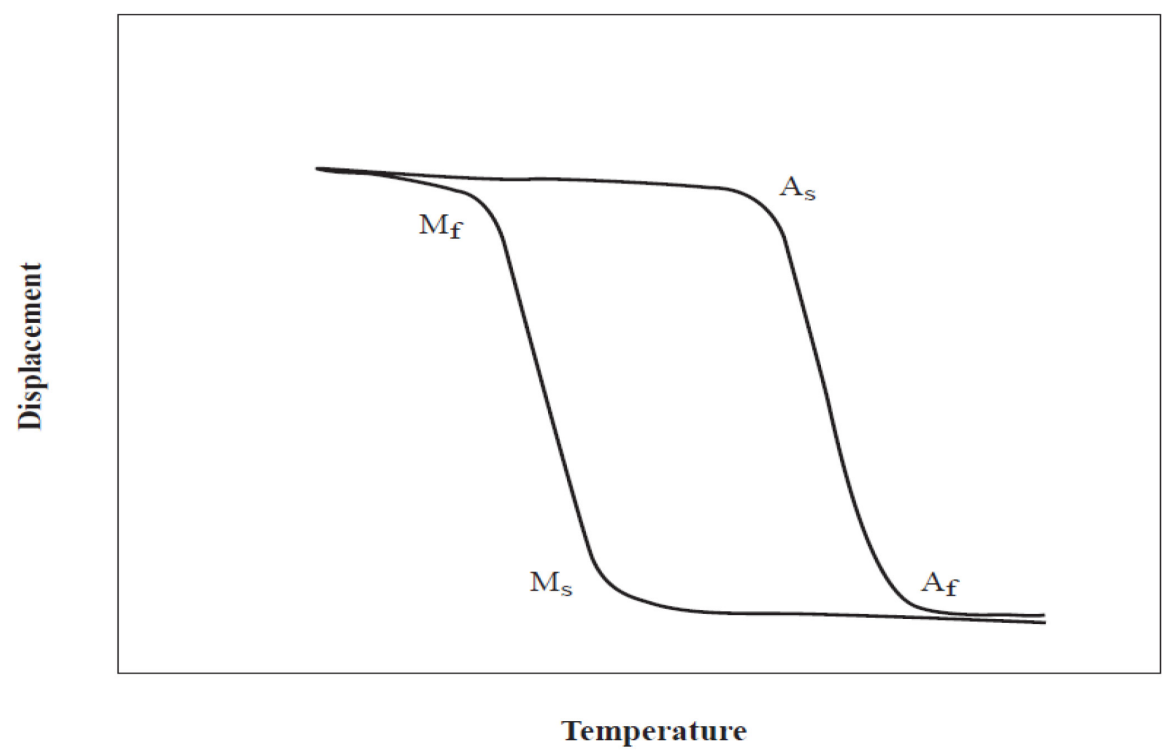

Figure 1-2 Transition temperature hysteresis

where:

$A_{f}$ : The temperature where the material has finished transforming to austenite upon heating

$A_{s}$ : The temperature where the material starts to transform to austenite upon heating $\mathrm{M}_{\mathrm{s}}$ : The temperature where the material starts to transform to martensite upon cooling $\mathrm{M}_{\mathrm{f}}$ : The temperature where the material has finished transforming to martensite upon cooling 


\subsubsection{Shape Memory Effect}

SMAs can be plastically deformed at a relatively low temperature, and upon exposure to some higher temperature, return to their shape prior to the deformation. Materials that exhibit shape memory only upon heating are referred to as having a oneway shape memory. Some materials also undergo a change in shape upon re-cooling. These materials have a two-way shape memory.

Once SMA is deformed in martensitic phase, it will remain deformed until heated to austenite, where it will return to its pre-deformed shape. This phenomenon is known as shape memory effect and is depicted in Figure 1-3.

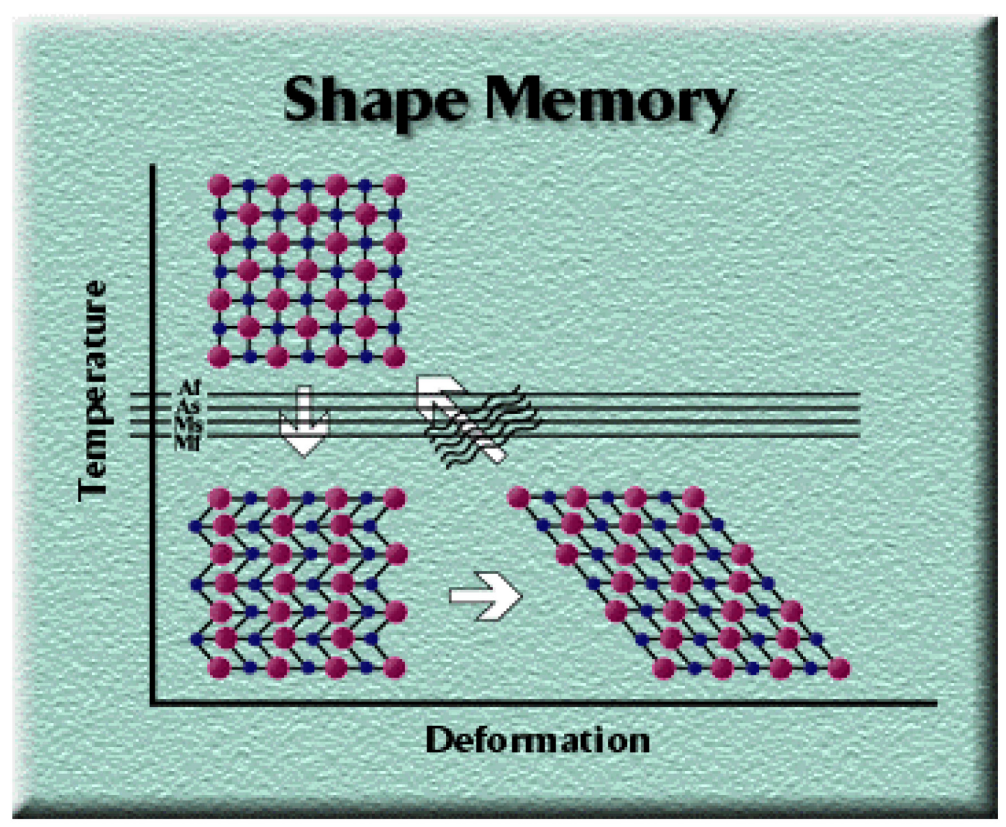

Figure 1-3 Mechanism of shape memory effect (Stoeckel 1995) 
The transition temperature at which martensite is transformed to austentite, varies for different compositions from about $-50{ }^{\circ} \mathrm{C}$ to $166^{\circ} \mathrm{C}$.

\subsubsection{Superelasticity}

Superelasticity is the ability of the material to undergo large elastic deformations. It is the nonlinear recoverable deformation behavior of Nitinol alloys at temperatures above the $A_{f}$ temperature, which arises from the stress-induced martensitic transformation on loading and the spontaneous reversion of the transformation upon unloading. Figure 1-4 illustrates the mechanism of supereleasticity.

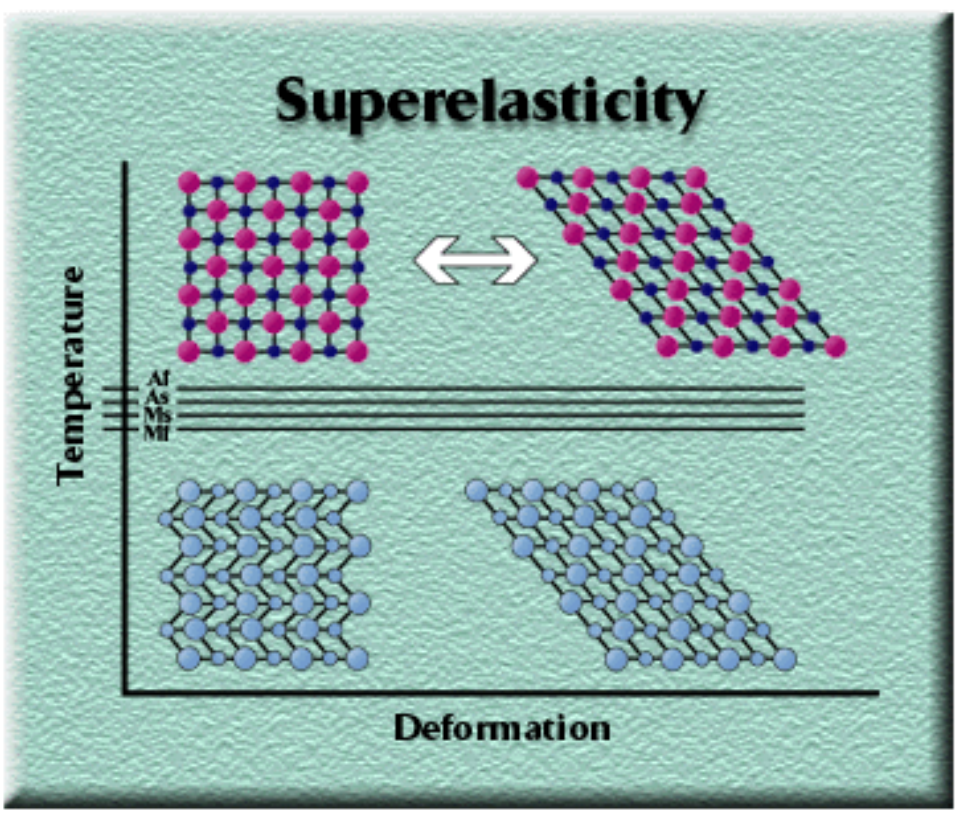

Figure 1-4 Mechanism of superelasticity (Stoeckel 1995) 


\subsection{Nitinol}

Nitinol (an acronym for NiTi Naval Ordnance Laboratory) is a family of nearly equiatomic intermetallic compounds of nickel and titanium. These alloys exhibit many attractive properties, such as superelasticity with large recoverable strain, shape memory effect, high damping properties, corrosion resistance and biocompatibility (D. Vojtech 2008). The combination of shape memory and superelastic properties with excellent kink resistance and MRI compatibility, made Nitinol suitable for many biomedical applications (Wu 2001) (S. A. Shabalovskaya 2002).

Due to Nitinol's malleability and ductility it is manufactured in the form of wires, ribbons, bars, tubes, cylinders and sheets. Common applications in the medical industry include self-expanding stents, graft support systems, orthopedic implants, filters, baskets, surgical tools, orthodontic wires etc. (N. Munroe 2007) (W. Haider 2009).

\subsubsection{Cardiovascular Stents Made of Nitinol}

It is projected that by 2020, there will be 138 million Americans over 45, the age at which the incidence of heart diseases is documented (U.S. Census Bureau 2004). Moreover, over 1 million percutaneous coronary revascularization procedures are performed worldwide annually and approximately $50 \%$ of such patients undergo stent implantation (E. McLuas 2008). The stents are mesh-like tubes that are introduced in blood vessels to prevent occlusion of coronary arteries. It is one of the most effective ways to treat coronary stenosis (narrowing of blood vessels). The development of intracoronary stents has tackled a number of problems associated with percutaneous 
transluminal coronary angioplasty (PTCA). It decreases the necessity for emergency bypass surgery and increases the longevity of the patients' lives (Brian Lin 2009).

Given the superelastic behavior of Nitinol alloys, medical device manufacturers have developed compressible stents for use in arteries where gross deformation can occur. Mainly used in peripheral arteries, Nitinol stents are self expanding upon deployment (Brian Lin 2009).

The procedure to place a stent involves the use of a delivery catheter guided through the femoral artery to the area of deployment. Self expanding stents have a smaller diameter at room temperature and expand to their preset diameter at body temperature. These stents are plastically deformed at room temperature (martensitic phase) and crimped on to the delivery system (Gopinath Mani 2007). After implantation, it regains its original shape (already memorized austenite phase according to the diameter of the target vessel) and conforms to the vessel wall because of the increase in temperature inside the body. The maximum strain recovery is $8.5 \%$ after plastic deformation (Gopinath Mani 2007).

Interventional radiologists use X-ray or fluoroscopy to help guide the catheter and track the location of stent. Stents with thicker struts are more radiopaque than those with thinner struts. Furthermore, less dense NiTi possesses lower inherent radiopacity. As a result, future stents which utilize thinner struts are often made radiolucent (Brian Lin 2009). 


\subsection{Human Blood Vessels and Role of Endothelium}

Human blood vessels are complex tissues composed of three main layers, intima, media and adventitia (J. S. Temenoff 2008) as shown in Figure 1-5. The inner, intima is mainly composed of endothelium. It is a thin heterogeneous layer of endothelial cells that line the interior surface of all blood vessels in the human body. The middle layer, media, is populated by smooth muscles cells (SMCs). The outer layer, adventitia, has connective tissue and fibroblasts.

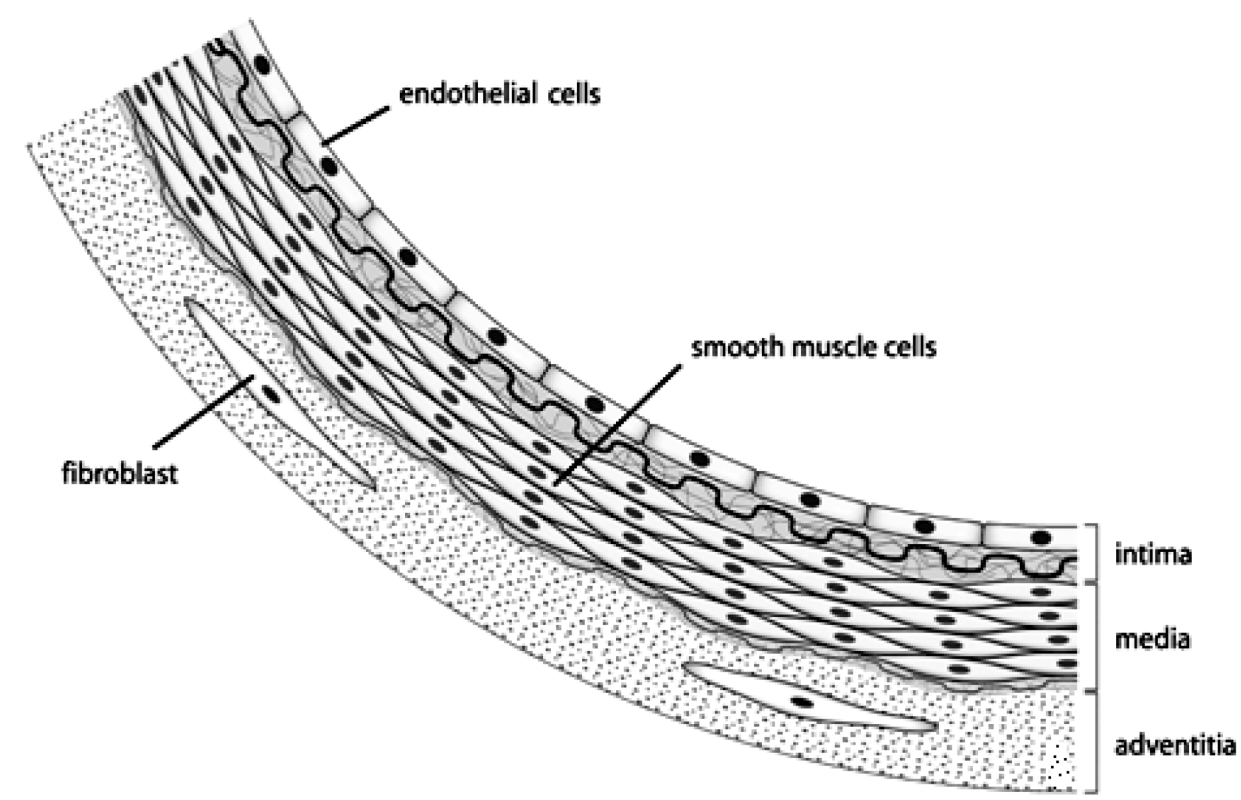

Figure 1-5 Structure of blood vessel found in human body (J. S. Temenoff 2008)

Glycosaminoglycans (GAGs) or Mucopolysaccharides are long unbranched polysaccharides consisting of repeating disaccharide units. GAGs are adsorbed on the endothelial cells and interact with moieties already on the surface to form a glycocalyx, which imparts smoothness to the walls of blood vessels. The surface of the endothelium 
has integrins and other receptors for cell attachment and protein adhesion (J. S. Temenoff 2008).

The endothelium also has a number of anticoagulative properties. The presence of heparan sulfate (GAG) may help angiotensin receptors (AT II) in inhibiting thrombin. Endothelial cells also secrete soluble chemical mediators, such as prostaglandin $\mathrm{I}_{2}\left(\mathrm{PGI}_{2}\right)$, which prevents platelet aggregation, and tissue plasminogen activator (TPA), which activates plasmin, which then dissolves the thrombus (J. S. Temenoff 2008).

\subsection{Restenosis}

Cardiovascular stents have many benefits as described above but they do have some limitations as well. Stent implantation usually results in vessel damage, which triggers inflammatory and repair reactions (Barry O’Brien 2009). Damage to the endothelium layer and exposure of the subendothelial matrix at the site of arterial injury may result in intimal hyperplasia, which leads to in-stent restenosis. Restenosis is defined as repeated narrowing of operating blood vessels with $>50 \%$ luminal closure (J. A. S. Shabalovskaya 2008). Restenosis remains a significant problem, with $15-20 \%$ of patients being affected after primary stenting (E. McLuas 2008). In-stent restenosis can result when smooth muscle cells underlying the endothelium that are exposed due to stent implantation, undergo rapid proliferation and cause a re-narrowing of the artery (Arash Shahryari 2010). It is worth mentioning here that fast endothelialization is better in order to prevent extensive proliferation of smooth muscle cells (J. A. S. Shabalovskaya 2008).

During the last few years, drug-eluting stents have come into the market. Drugeluting stents were designed to cope with restenosis by emitting low dosages of drugs. 
Although the rate of restenosis was reduced, a more serious problem known as thrombosis has emerged. The inhibition of endothelial proliferation by drugs and severe inflammatory responses to the polymer coating are suspected causes of a great delay in healing with drug-eluding stents. It has also been reported that drug-eluding stents did not perform better in inhibiting restenosis in coronary vessels having a diameter larger than 3.2 mm (G. C. Svetlana A. Shabalovskaya 2009).

\subsection{Thrombosis}

Fibrinogen is the most abundant blood serum protein after serum albumin and immunoglobulins. It adsorbs on the surface of stents within minutes of its implantation and triggers a process that evokes the agglomeration of blood platelets, (Arash Shahryari 2010) which leads to coagulation cascade. Platelets are non-nucleated fragments megakaryocytes with a diameter of 3-4 $\mu \mathrm{m}$ that can become activated by a variety of stimuli, such as exposure to soluble factors or interaction with cells or injured vessel walls. In particular, collagen and von Willebrand factor (vWF) are main platelet activators (J. S. Temenoff 2008). Activated platelets adhere near the implant and secrete various bioactive factors for further platelet activation. Platelets cannot proliferate as they do not possess nuclei. Platelets express different receptors for various factors, which forms a complex called prothrombin activator. Later, prothrombin activator is converted into thrombin. Thrombin is an extremely important substance in the cascade, with proand anti-coagulant activities (Bhat 2005). Its main procoagulant role is to cleave fibrinogen. This cleavage results into fibrin monomers, which polymerize to form long fibers and are the basis of a blood clot. The formation of this complex structure 
(thrombus) of fibrin, platelets, adhesive proteins, and other bioactive factors is known as thrombosis (J. S. Temenoff 2008).

Blood compatibility is a property of the material or device that permits it to function in contact with blood without inducing adverse reactions (Buddy D. Ratner 2004). A material or device that induces thrombogenic responses is known as a thrombogenic device, which may induce the accumulation of various blood elements. Subsequent localized preferential concentration of blood elements relative to their concentration in circulating blood, is known as thrombus formation.

The obvious goal for a biomaterials engineer is to design and improve materials used in devices that are more blood compatible. Therefore, there is a need of new generation of stents that are thromboresistant and are more adaptable to the blood vessels.

On these biocompatible stents surfaces, endothelial cells are expected to proliferate, differentiate and release growth factors, which inhibit thrombosis and neointimal hyperplasia (Gopinath Mani 2007).

Despite such a vast array of applications, there still exist major concerns regarding nickel release from the surface of implantable Nitinol alloys. Different stentassociated problems result from the biological, chemical and surface properties of the stent (E. McLuas 2008). Therefore, it is of prime importance to study and understand these properties in order to alleviate adverse effects of implanted medical devices.

\subsection{Toxic Effects of Nickel}

The Nickel ions can act as cofactors or inhibitors in enzymatic processes involved in protein synthesis and cell replication, modify cell morphology, destroy cell organelles 
and even decrease cell numbers (Chun-Che Shih 2000). Studies of the role of Ni in the human environment have shown that $\mathrm{Ni}^{+2}$ can act as an antagonist to the essential metal ions such as $\mathrm{Mg}^{+2}, \mathrm{Ca}^{+2}$ and $\mathrm{Zn}^{+2}$ and thereby disturb the biological processes (J. W. S. A. Shabalovskaya 1995).

$\mathrm{Ni}$ ions in solution have been reported to cause expression of inflammatory mediators, such as interleukin-1 $\beta$ (IL-1 $\beta$ ), tumor necrosis factor- $\alpha$ (TNF- $\alpha$ ), and intercellular adhesion molecules (ICAMs) from keratinocytes, monocytes, and endothelial cells (J. C. Wataha 2000). Nickel ions at a concentration of about $10 \mu \mathrm{g} / \mathrm{ml}$ $(10,000 \mathrm{ppb})$ have been shown to activate ICAM-1, vascular cell adhesion molecules, VCAM-1, and endothelium leukocyte adhesion molecule, ELAM-1 on endothelial cells (J. C. Wataha 2000). The expression of ICAM-1 on endothelial cells is particularly important as these cells are the primary sites for the recruitment of inflammatory cells from the blood stream (J. C. Wataha 2000). Moreover, these adhesion molecules play a major role in leukocyte recruitment in post implantation pathways (E. McLuas 2008).

Nickel has also been found to cause gene alteration expression profiles for a range of genes. It includes activation of hypoxia regulated gene, thrombospondin, transcription factor 1 and cap 43 (E. McLuas 2008).

As nickel is capable of eliciting toxic and allergic responses, it is vital to understand the factors that may lead to excessive release of nickel in the body when using Nitinol as a biomaterial. In order to gain wider acceptance of Nitinol as an implantable material, it is necessary to improve the surface morphology and structure to inhibit nickel release. Many surface treatments involve removing the less protective oxide layer and replacing it with a more stable uniform $\mathrm{TiO}_{2}$ oxide layer (B. Clarke 2006). Additionally, 
the physical and chemical properties of the oxide film and their effect on Nitinol's biocompatibility will have to be further elucidated.

\section{$1.8 \quad$ Research Objectives}

The following were the main objectives of this research:

- Improve corrosion resistance of the Nitinol alloys

- Reduce metal ion leaching from the Nitinol alloys

- Develop a stable, uniform and passive film with low Ni concentration on the surface of the alloys

- Reduce the cytotoxicity of the alloys on human endothelial cells by reducing metal ion release

- Promote endothelial cell proliferation on the Nitinol alloys

- Achieve low surface energy on the Nitinol alloys (Thromboresistant surfaces) 


\section{CHAPTER 2}

\section{LITERATURE REVIEW}

\subsection{Surface Treatment of Nitinol}

Recently a lot of interest has been generated in the fabrication of films and coatings for the inhibition of nickel release from Nitinol. The surface treatment of Nitinol plays a critical role in enhancing its corrosion resistance and biocompatibility. Several surface treatments have been used among which are; mechanical and electrochemical treatments, chemical etching, heat treatments, conventional and plasma ion immersion implantation, laser and electron-beam irradiation and application of bioactive surfaces (J. A. S. Shabalovskaya 2008). The main intent of most of these techniques is to produce a uniform, stable and highly adherent $\mathrm{TiO}_{2}$ layer.

Mechanically polished surfaces usually have a thin oxide layer of about $10 \mathrm{~nm}$ which acts as a protective barrier between the alloy surface and the corrosive biological environment. The protectiveness of this passive film is determined by the rate of ion transfer through the film and by the stability of the film against dissolution (S. Virtanen 2008). However, a thick oxide layer of about $100 \mathrm{~nm}$ appears to be a more reliable barrier for Ni release (J. V. S. Shabalovskaya 2008) (J. A. S. Shabalovskaya 2008) (G. C. Svetlana A. Shabalovskaya 2009). Furthermore, surface properties such as heterogeneity, chemical composition, crystallinity, roughness, and wettability, are also of great importance to the stability of the $\mathrm{TiO}_{2}$ layer and thus, the life of the biomedical implant (S. Shabalovskaya 2001) (J. A. S. Shabalovskaya 2008). 


\subsubsection{Heat Treatment}

Studies (J. A. S. A. Shabalovskaya 2003) (F. Sun 2008) have indicated that a controlled surface oxidation in various liquids or gaseous media produces a thin, compact and adherent oxide, which helps to reduce nickel release into the surrounding tissue. The surface chemistry of most materials depends on the media in which they are exposed such as air, water/steam, hydrogen peroxide, etc. [13], the temperature, pressure and the duration of the exposure. Vojtech D. et al. investigated the formation of passive layers on Nitinol wire (50.9 at.\% Ni, $0.2 \mathrm{~mm}$ diameter) when subjected to air at $25{ }^{\circ} \mathrm{C}, 480{ }^{\circ} \mathrm{C}$ and $530{ }^{\circ} \mathrm{C}$ for 10 minutes where oxide layers of about $10 \mathrm{~nm}, 70 \mathrm{~nm}$ and $140 \mathrm{~nm}$, were obtained respectively (D. Vojtech 2008).

Firstov G. S. et al. reported different oxidation behaviors below and above $500{ }^{\circ} \mathrm{C}$ during the heat treatment of $\mathrm{NiTi}$. Below $500^{\circ} \mathrm{C}$, a layer of $\mathrm{TiO}$ and metallic nickel were formed beneath a $\mathrm{TiO}_{2}$ layer. The oxidation rate was fairly low and the oxide layer was smooth. At $600{ }^{\circ} \mathrm{C}$ and above, rutile (the most stable form of $\mathrm{TiO}_{2}$ ) was formed at the air/oxide interface. The oxide layer was rough and became porous at $800{ }^{\circ} \mathrm{C}(\mathrm{G}$. S. Firstov 2002). However, the oxidation of NiTi in air at temperatures close to $500{ }^{\circ} \mathrm{C}$ produced a nickel-free smooth oxide layer, which is conducive to good biocompatibility (T. Duerig 1999). In another study, it was reported that air oxidation of equiatomic NiTi at $500{ }^{\circ} \mathrm{C}$ for 60 minutes produced a protective $\mathrm{TiO}_{2}$ layer (M. C. Chen 2009).

Photoelectrocatalytic oxidation (PEO) on NiTi produced a Ni-free zone near the surface and a sturdy $\mathrm{TiO}_{2}$ layer, as reported by C.L. Chu. This layer suppressed Ni leaching in simulated body fluids (C. G. C. L. Chu 2009). 
Munroe et al. also reported a Ni-free surface when porous Nitinol (PNT) was subjected to water boiling at $132{ }^{\circ} \mathrm{C}$ for 30 minutes (N. D. Munroe 2009). Furthermore, when PNT was dry-heated at $132{ }^{\circ} \mathrm{C}$ in a tubular furnace in a continuous supply of air for 1 hour, then passivated by immersion in $20 \%$ conc. $\mathrm{HNO}_{3}$ at $80{ }^{\circ} \mathrm{C}$ for 20 minutes, a decrease in the corrosion resistance $\left(\mathrm{E}_{\mathrm{b}}-\mathrm{E}_{\mathrm{r}}=1.1708\right)$ was obtained as compared with that of water boiled and passivated PNT $\left(E_{b}-E_{r}=1.2530\right)$ (N. D. Munroe 2009).

In other studies, mechanically polished Nitinol surfaces exhibited various $\mathrm{Ti} / \mathrm{Ni}$ ratios, which sometimes equated to 5 times more $\mathrm{Ti}$ on the surface as compared with $\mathrm{Ni}$ (S. Shabalovskaya 2001) (Ryhänen 1999) (J. A. S. A. Shabalovskaya 2003) (N. D. Munroe 2009) . Also, Nitinol when boiled or autoclaved in water exhibited an increase in Ti/Ni ratio of 23-33 at its surface (Ryhänen 1999) (G. C. Svetlana A. Shabalovskaya 2009). Moreover, when it is immersed in neutral electrolyte solution for 30 days, the Ti/Ni ratio at the surface increased up to 91 (Ryhänen 1999). Aging of NiTi in boiling water was found to be much more effective for surface oxidation than exposure to pure oxygen (J. A. S. A. Shabalovskaya 2003).

\subsubsection{Passivation and Electropolishing (EP)}

Passivation is a non-electrical process that chemically removes exogenous ions from the surface of a material without significantly affecting the bulk of the underlying material. A homogenous $\mathrm{TiO}_{2}$ layer, which is flexible during implantation, is usually formed in this process (G. Tepe 2006).

EP is a standard surface treatment process employed as a final finish in the manufacture of Nitinol devices. An electric potential and current are applied, which result 
in ionic dissolution from the surface. In this process, the surface chemistry and morphology of the material are altered while surface imperfections are removed as dissolved metal ions. Simultaneously, titanium is oxidized to $\mathrm{TiO}_{2}$, which protects the underlying material from further corrosion (G. Tepe 2006). Generally, electropolishing removes the native oxide layer and forms a more homogeneous and stable passive film. During this process, the amount of nickel on the surface of the alloy decreases (R. S. S. Mändl 2003) (G. S. Firstov 2002).

According to American Society of Testing and Materials (ASTM) standard, ASTM F 86, electropolishing and nitric acid passivation are two main techniques recommended for surface treatment of medical devices to remove deformed native oxide layers and replace them with more uniform ones (ASTM F 86 2009).

Chu C. L. et al. reported a new surface modification technique, which encompassed EP pretreatment and PEO on Nitinol (C. G. C. L. Chu 2009). His study showed a sturdy $\mathrm{Ni}$-free $\mathrm{TiO}_{2}$ layer and a graded interfacial structure between the $\mathrm{TiO}_{2}$ layer and the NiTi substrate. This surface modification proved to be very effective in suppressing nickel leaching in a 10 week immersion test.

Trepanier et. al. studied nitric acid EP-passivation and heat treatment on NiTi stents. The XPS spectrum for EP-passivated samples revealed three dominant peaks, which were assigned to $\mathrm{Ti}^{0}, \mathrm{Ti}^{3+}$ and $\mathrm{Ti}^{4+}$ (Christine Trépanier 1999) (S. Shabalovskaya 2001). However, only one peak was observed in the XPS spectrum of heat treated samples, and it was assigned to $\mathrm{Ti}^{4+}$.

Chu C. L. et al. reported that anodic oxidation of Nitinol in $1 \mathrm{~mol} / \mathrm{L} \mathrm{H}_{2} \mathrm{SO}_{4}$ at $5 \mathrm{~A}$ for 60 minutes resulted in the formation of a porous $\mathrm{TiO}_{2}$ film, which was void of any $\mathrm{Ni}$ 
(R. M. C. L. Chu 2008). This film was considered to be very effective in inhibiting the diffusion of Ni from the interior of the alloy to the surface when immersed in simulated body fluids (SBF) despite the fact that the $\mathrm{TiO}_{2}$ layer was very porous.

In another study, Chu C. L. et al investigated the effect of chemical polishing (CP) and EP of Ti-58 at.\% Ni on wettability, blood compatibility and thromboresistance (C.L. Chu 2008). The solution employed for $\mathrm{CP}$ consisted of $\mathrm{H}_{2} \mathrm{O}, \mathrm{HF}$, and $\mathrm{HNO}_{3}$ in a 5:1:4 ratio, whereas, the electrolyte for EP consisted of 21 vol. \% perchloric acid and 73 vol. \% acetic acid. A constant voltage of $10 \mathrm{~V}$ for 6 minutes was employed for the latter. The EP samples were found to exhibit better wettability, blood compatibility and thromboresistance as compared with $\mathrm{CP}$ samples. Hemolysis ratio and water contact angle for EP samples were $1.40 \% \pm 0.10 \%$ and $45.3^{\circ} \pm 4.8^{\circ}$, respectively and that for $\mathrm{CP}$ samples were $4.26 \% \pm 0.02 \%$ and $65.5^{\circ} \pm 5.8^{\circ}$, respectively. Similarly, the platelets on EP samples formed a single layer and were isolated, whilst accumulation and pseudopodium of platelets were observed on $\mathrm{CP}$ samples. No major difference in cytocompatibility was observed on samples from both processes.

B. O'Brien et al. heat treated commercially available binary Nitinol wires at 500 ${ }^{\circ} \mathrm{C}$ using a fluidized bath, with air as the fluidizing gas prior to passivation (B. O' Brien 2002). Passivation was performed using $20 \%$ nitric acid solution at $80{ }^{\circ} \mathrm{C}$ for 20 minutes. XPS analysis revealed that heat treatment increased the oxide thickness, which did not significantly change with subsequent passivation. Significant improvement in corrosion resistance after passivation was therefore primarily attributed to a reduction in the surface concentration of $\mathrm{Ni}$ and an increase in the nature, thickness and continuity of surface $\mathrm{TiO}_{2}$ content. 
A relatively new technology called magnetoelectropolishing (MEP) was introduced by Hryniewicz T. et al., which was performed using a mixture of sulfuric, hydrofluoric and nitric acid in the presence of a constant external magnetic field of up to $500 \mathrm{mT}$ (T. Hryniewicz 2009). The surface roughness obtained after MEP was less than that observed after standard EP and mechanical polishing (MP). Also, it was observed that the corrosion resistance of MEP Ti samples was much higher than that of samples subjected to EP and MP. SEM analysis of MEP samples revealed a unique nanostructured surface (pore-like features - $50 \mathrm{~nm}$ in diameter), which has been reported to be conducive to osteointegration.

\subsubsection{Plasma Ion Immersion Implantation (PIII)}

A number of interesting processes for surface modification based on plasma discharges have been developed and implemented over the last three decades. It has been reported (J. W. S. Mändl 2005) (Y. Shen 2009) (R. A. Yankov 2007) that the corrosion resistance and biocompatibility of Nitinol can be improved using oxygen, argon, nitrogen ion implantation. A nickel-free Nitinol surface can be achieved with $\mathrm{Ar}^{+}$and/or $\mathrm{N}^{+}$ implantation at $20-40 \mathrm{keV}$ and fluences of (3-5) $\times 10^{17} \mathrm{~cm}^{-2}$ by means of PIII (F. Sun 2008).

S. Mändl et. al described the formation of a layered sequence of $\mathrm{TiO}_{2}-\mathrm{Ni}_{3} \mathrm{Ti}-\mathrm{NiTi}$ on flat Nitinol (Ti-49.2 at.\% Ni), after removing the native oxide layer using Ar ion sputtering at $5 \mathrm{kV}$, with an incident dose of $6 \times 10^{17}$ ions $/ \mathrm{cm}^{2}$ prior to oxygen PIII. The PIII experiments were performed in a high vacuum chamber (base pressure, 1 x $10^{-5} \mathrm{~Pa}$; working pressure, 0.2 Pa; helix plasma source, $150 \mathrm{~W}, 40.68 \mathrm{MHz}$ ). The layered 
sequence of $\mathrm{TiO}_{2}-\mathrm{Ni}_{3} \mathrm{Ti}-\mathrm{NiTi}$ after oxygen PIII was indicative of the diffusion of $\mathrm{Ni}$ towards the bulk of the alloy. (J. W. S. Mändl 2005). This phenomenon was confirmed by J. Lutz et. al using non-radioactive isotope markers, $60 \mathrm{Ni}$ and $56 \mathrm{Ti}$ at $400-550{ }^{\circ} \mathrm{C}$ where the layered sequence was $\mathrm{TiO}_{2}-\mathrm{Ni}_{3} \mathrm{Ti}-\mathrm{NiTi} 60 \mathrm{Ni}$. Marker implantation therefore enabled a clear identification of $\mathrm{Ni}$ as the mobile species within an immobile $\mathrm{Ti}$ matrix ( $\mathrm{S}$. Shabalovskaya 2001).

In another investigation, S. Mändl et. al studied PIII treatment on Ti rods $(0.9 \mathrm{~mm}$ diameter) in a high vacuum chamber (base pressure, $2 \times 10^{-6}$ mbar; working pressure, $3 \times 10^{-3}$ mbar; oxygen flow, $45 \mathrm{sccm}$ ). Improved biocompatibility was observed for oxygen PIII Ti rods implanted in rats as compared with untreated Ti. This is primarily attributed to the smooth $\mathrm{TiO}_{2}$ surface layer (J. W. S. Mändl 2005) (R. S. S. Mändl 2003).

X.M. Liu et. al investigated water PIII as a commonly used technique to implant oxygen species such as $\mathrm{H}_{2} \mathrm{O}^{+}, \mathrm{HO}^{+}$and $\mathrm{O}^{+}$into the materials with minimal energy spread as compared with oxygen, PIII which introduces $\mathrm{O}^{+}$and $\mathrm{O}^{2+}$ (X. M. Liu 2007). Thus, water PIII yielded a better $\mathrm{TiO}_{2}$ surface layer. Water PIII (RF power, $1000 \mathrm{~W}$; sample voltage, $40 \mathrm{kV}$; pulse width, $30 \mu \mathrm{s}$; frequency, $100 \mathrm{~Hz}$; pulse duration, $240 \mathrm{~min}$; base pressure, $1 \times 10^{-5}$ Torr; working pressure, $3.4 \times 10^{-4}$ Torr) produced a $\mathrm{TiO}_{2}$ surface layer of $40 \mathrm{~nm}$ thick as compared to the untreated material, which was only a few nanometers thick.

Yankov et. al studied PIII on Nitinol (50.85 at.\% Ni) that was first cleaned by Argon sputtering at $2 \mathrm{keV}$ for $10 \mathrm{~min}$. Oxygen PIII (base pressure, $<8 \times 10^{-4} \mathrm{~Pa}$; oxygen pressure, $0.2 \mathrm{~Pa}$; temperature, $<250{ }^{\circ} \mathrm{C}$, voltage, $40 \mathrm{kV}$ ) resulted in the formation of a rutile $\mathrm{TiO}_{2}$ surface layer with a $\mathrm{Ni}$ content below 1 at.\%. The thickness of oxide layer 
depended on both the ion fluence and the substrate temperature. Moreover, the thickness of the oxide layer was controlled by the degree of sputtering and diffusion during highfluence PIII (R. A. Yankov 2007).

\subsubsection{Sterilization Techniques}

Sterilization is required for all devices in contact with the human body. The surface of Nitinol alloys can be significantly modified during sterilization. Since this is the final process prior to implantation, the resulting surface characteristics of an implant material must be clearly understood. The formerly used steam and dry sterilization have been replaced by more advanced techniques, such as exposure to ethylene oxide, peracetic acid, UV light, hydrogen peroxide, plasma, electron and gamma irradiation (Davis 2003). Nevertheless, the effect of sterilization is as significant on the surface chemistry of Nitinol as any of the previously mentioned surface treatments (J. A. S. Shabalovskaya 2008).

B. Thierry et al. performed different sterilization processes on NiTi alloy and described the production of $\mathrm{TiO}_{2}$ layers of various thickness, chemical composition and roughness. Varying concentrations of nickel in the $\mathrm{TiO}_{2}$ surface layer were also observed. Dry heated, steam autoclaved, and ethylene oxide treated Nitinol surfaces possessed thicker oxide layers with slightly higher amounts of nickel as compared with nonsterilized Nitinol. It was also observed that among all sterilization treatments, the plasmabased sterilization had the least effect on $\mathrm{TiO}_{2}$ surface layer thickness and roughness (M. T. B. Thierry 2000). 
In another investigation, B. Thierry et al. studied the effect of sterilization on corrosion resistance of nearly equiatomic electropolished NiTi discs (12 $\mathrm{mm}$ in diameter) employing ethylene oxide (EO) and hydrogen peroxide plasma (PS). It was observed that either technique did not result in any appreciable difference in the corrosion resistance in terms of breakdown potential $(1.07 \pm 0.04 \mathrm{~V} / \mathrm{SCE}$ for EO and $1.02 \pm 0.04 \mathrm{~V} / \mathrm{SCE}$ for PS as compared with unsterilized EP Nitinol, $0.99 \pm 0.05$ V/SCE) (M. T. B. Thierry 2000). Alavi et al. investigated the effect of dry-heat and steam sterilization on the bending properties of Nitinol wires. Dry-heat sterilization was performed in a sterilized oven at $160{ }^{\circ} \mathrm{C}$ for 120 minutes, whereas steam sterilization consisted of exposure of the implant material to saturated steam at $15 \mathrm{psi}$ at $121{ }^{\circ} \mathrm{C}$ for 24 minutes in an autoclave. Sterilization resulted in a decrease of the applied force for both loading and unloading phases (decreased superelasticity) (S. Alavi 2009).

According to Thierry et. al, the sterilization by steam autoclaving of EP Nitinol for about 4 minutes at $270{ }^{\circ} \mathrm{F}$ at $30 \mathrm{psi}$ resulted in an $8 \mathrm{~nm}$ thick $\mathrm{TiO}_{2}$ oxide layer (M. T. B. Thierry 2000). Similarly, EP Nitinol alloys treated with ethylene oxide for 2 hour and 10 minutes at $130{ }^{\circ} \mathrm{F}$ under the pressure of $\sim 10$ psi yielded a $7.5 \mathrm{~nm}$ thick $\mathrm{TiO}_{2}$ layer (M. T. B. Thierry 2000).

Dinca et. al also investigated the effect of sterilization on surface roughness of NiTi thin films on Ti substrate when placed in non-pyrogenic glass vessels and sterilized in a dry heat autoclave at $180{ }^{\circ} \mathrm{C}$ for 1 hour. The surface of the film was analyzed with AFM before and after sterilization procedure and the RMS values of surface roughness were $25 \mathrm{~nm}$ and $55 \mathrm{~nm}$ respectively. (V. C. Dinca 2006). 


\subsubsection{Artificial Coatings}

Different polymeric coatings are currently being explored for improved vascular compatibility and drug delivery. Tepe G. et al. investigated that mechanically polished stents coated with siloxane-based polyurethane co-polymer have shown to be extremely biocompatible and showed superior results regarding coagulation and inflammation compared to non-coated stents (G. Tepe 2006). In another study, Flamini D. O. et al. electrodeposited polypyrrole films on NiTi alloy employing sodium bis (2-ethylhexyl)sulfosuccinate (Aerosol OT) solutions. The polypyrrole coating protected Nitinol against localized corrosion substrate under OCP conditions in chloride solution (D. O. Flamini 2010).

$\mathrm{Xu}$ J. L. et al. reported that rough and porous $\mathrm{Al}_{2} \mathrm{O}_{3}$ coating containing $\mathrm{Ca}$ and $\mathrm{P}$ on Ti-50.8 at.\% Ni by micro arc oxidation produced corrosion resistance almost two orders of magnitude higher than that of uncoated NiTi alloy (J. L. Xu 2009). Similarly, the concentration of nickel released from coated NiTi (12.3 ppb) was much lower than that of uncoated NiTi (84.9 ppb) after three weeks immersion in Hank's Solution at $37^{\circ} \mathrm{C}$ (J. L. Xu 2009).

Liu C. et al. coated Nitinol with highly corrosion resistant and biocompatible diamond like carbon (DLC). DLC coated Nitinol improved the corrosion resistant of NiTi alloy in Tyrode's simulated body fluid $(\mathrm{pH}=7.4)(\mathrm{C}$. Liu 2006). The thickness of the $\mathrm{Si} / \mathrm{SiC}$ graded layer is an important factor to determine the adhesion strength and corrosion behavior. It was reported that the adhesion strength was found to be best for the functionally graded DLC coating with a $150 \mathrm{~nm}$ thick graded layer. Graded layer thicker than $150 \mathrm{~nm}$ had a reverse effect on adhesion strength (D. O. Flamini 2010). 
Muhonen et al. reported that Ni-44.3 wt. \% Ti wires were coated with sol-gelderived $\mathrm{TiO}_{2}-\mathrm{SiO}_{2}$. The coated wires showed enhanced bone-implant attachment and the biocompatibility. In addition, $\mathrm{TiO}_{2}-\mathrm{SiO}_{2}$ did not crack or peel during the bending (R. M. C. L. Chu 2008). Similarly, in another study, Zhang et al. reported that TiN coating on mechanical polished Nitinol wires having 50.6 at.\% Ni of $0.09 \mathrm{~mm}$ diameter could reduce the corrosion current in simulated blood plasma by $50 \%$ and nickel leaching by $35 \%$. However, when these wires were pulled and monitored by optical microscopy, the coating cracked when deformation was larger than 4\% (D. Zhang 2009).

Different prominent surface modification techniques that have been driven by clinical needs of implantable materials were described above eliminates the chemical heterogeneity and provides a stable $\mathrm{TiO}_{2}$ coating on Nitinol surface. Such needs have led to the development of surface treatments for improved corrosion resistance, reduced metal ion leaching and enhanced biocompatibility.

\subsection{Alloying of Nitinol}

The degree of passivity is highly influenced by alloy composition. Stainless steel is a classic example of passivity enhanced by alloying. The addition of $\mathrm{Cr}$ in an amount greater than 12 wt.\% to iron significantly improves the corrosion resistance of the stainless steel (Fontana 1986). Similarly, molybdenum is also known for promoting passivity. Because of the prime importance of passivity as a means of corrosion control in engineered Nitinol alloys, it is essential to have a detailed understanding how alloying elements affect passivity and its breakdown (W. Haider 2009). 
To extend the specific usage of Nitinol in biomedical industry, some NiTiX ternary alloys still need to be developed and studied. The addition of the third element to replace $\mathrm{Ti}$ and/or Ni in NiTi alloys has a substantial effect on their phase transformation behavior. Martensite start temperature $\left(\mathrm{M}_{\mathrm{s}}\right)$ increases when $\mathrm{Ni}$ is replaced with $\mathrm{Au}, \mathrm{Pd}$ or Pt in amounts not less than 15-20 at.\%. Similarly $\mathrm{M}_{\mathrm{s}}$ decreases following the substitution of Ni with Cr, V, Fe, Al, Mn and Co (S. F. Hsieh 2009). Brian Lin et al showed that the addition of Pt or Pd to NiTi up to 10 at.\% decreased the transformation temperature. However, transformation temperature increased linearly with Pt or Pd addition of more than 10 at.\%. The slight decrease in transformation temperatures with Pt addition is desirable from the standpoint of maintaining superelasticity at body temperature (Brian Lin 2009). Moreover, the Pt and Pd doped NiTi alloys exhibited reasonable strain recovery when deformed below $\mathrm{M}_{\mathrm{f}}$ and heated to room temperature, with little dependence on the percentage of alloying element. NiTiPt alloys deployed much smaller stress hysteresis and smaller temperature dependence of the transformation stress when compared with binary Nitinol alloys. However, NiTiPt or NiTiPd are significantly more expensive than NiTi.

The relative chemical affinity of alloying element, $\mathrm{X}$ (where $\mathrm{X}$ is $\mathrm{Cr}, \mathrm{Cu}, \mathrm{Ta}, \mathrm{V}$, $\mathrm{Au}, \mathrm{Pd}, \mathrm{Pt}$ etc), to $\mathrm{Ni}$ and $\mathrm{Ti}$ within the NiTi matrix is another important factor in determining the specific site where $\mathrm{X}$ will reside. If $\mathrm{X}$ has strong affinity for $\mathrm{Ti}$, which is represented by a large negative enthalpy of formation, but has only a weak affinity to $\mathrm{Ni}$, this alloying element tends to substitute for Ni. Furthermore, $\mathrm{X}$ will have similar chemical properties as Ni. For example, Co and Fe will substitute Ni atoms as they have shown weak affinity for Ni. Another important factor in determining site preference is 
atomic size. If other factors are the more or less same, alloying element tends to substitute for species of the similar size (K. Otsuka 2005).

Vanadium, chromium, manganese, copper and gold seem to have less preference for a particular site; their occupancy fractions are strongly affected by the formula of the ternary alloying element. For example, if $\mathrm{Cu}$ is added according to the formula $\mathrm{Ti}_{0.5} \mathrm{Ni}_{0.5-}$ ${ }_{c} \mathrm{X}_{\mathrm{c}}$, the $\mathrm{Cu}$ will have a preference to enter into a $\mathrm{Ni}$ site. However, if $\mathrm{Cu}$ is added according to the formula $\mathrm{Ti}_{0.5-\mathrm{c}} \mathrm{Ni}_{0.5} \mathrm{X}_{\mathfrak{c}}$, it gives the prior preference for $\mathrm{Cu}$ to enter into a Ti-site. There is only about $34 \% \mathrm{Cu}$ entering into a Ni site. This is quite different from the well-accepted postulation that $\mathrm{Cu}$ only goes to Ni-sites (K. Otsuka 2005).

To monitor the location of implants, it is necessary to estimate the exact position and orientation of each component using radiography. Small stents, guide wires and catheters are quite thin and their detection becomes very difficult. One method to enhance the visibility under X-ray is the addition of noble metals and/or coating with gold, etc. Although the gold plated Nitinol components have achieved radiopacity by means of electroplating technique, other problems such as risks of galvanic corrosion, biocompatibility and hydrogen embrittlement still remain a problem. The alloying of Nitinol with other heavy elements is an alternative solution to improve the inherent radiopacity of Nitinol. Possible ternary elements include iridium, platinum, rhenium, tungsten, palladium, rhodium, tantalum, silver, ruthenium or hafnium. Adding hafnium or zirconium as a ternary element increases fracture strength but decreases ductility (Brian Lin 2009). However, tantalum metal has successfully been used for implants. Since the galvanic potentials of tantalum and Nitinol are very similar, the galvanic corrosion effect is almost immeasurable (Y. Cheng 2006). Moreover, tantalum has an excellent corrosion 
resistance because of its highly stable surface oxide layer, which prevents electron exchange between metal and the adsorbed biological species. It has excellent fluoroscopic visibility because of its high density. It is an MRI compatible material as it produces no significant artifacts because of its non-ferromagnetic properties. Tantalum also improves the endothelialization rate (Gopinath Mani 2007).

The mechanical properties of NiTiCr alloys are of interest for medical applications, especially with regard to its higher torqueability and stiffness when compared to binary Nitinol alloys. In addition, $\mathrm{Cr}$ increases the yield stress and results in strengthening of the alloy (J. B. M. Frotscher 2009). According to Horvath and Uhlig, the addition of $\mathrm{Cr}$ increased the affinity of the alloy for oxygen rather than chloride (Uhlig 1968). Hence the appropriate $\mathrm{Cr}$ content is expected to increase the corrosion resistance as compared with that of binary Nitinol alloys.

NiTi10Cu exhibits one stage B2-B19' (B2: cubic, austentite; B19’: monoclinic, martensite) transformation when $\mathrm{Cu}$ concentration is less than 5 at.\%. Increasing the $\mathrm{Cu}$ content to 10 at.\%, B2-B19' transformation is suppressed and B19 (orthorhombic, martensite) appears. This is followed by the two stage B2-B19-B19' transformation. B2B19 transformation is very attractive because of its smaller hysteresis when compared with B2-B19' (Jae-hwa Lee 2006). However, NiTi having more than 10 at.\% Cu spoils the alloy's formability (Tomasz Goryczka 2008) (M. Es-Souni 2001).

Copper addition results in increasing the characteristic temperature of martensitic transformation, as compared with a binary Nitinol alloy. Moreover, copper imparts good corrosion resistance, stability to the characteristic transformation temperature and narrow transformation hysteresis ( $40 \mathrm{~K}$ for the binary alloy to $11 \mathrm{~K}$ for NiTi-10at.\%Cu), decreases 
stress of the superelastic hysteresis, increases fatigue resistance during thermal cycling and prevent $\mathrm{Ti}_{3} \mathrm{Ni}_{4}$ precipitation. Less dependence on concentration variations and lower martensitic yield strength are actually beneficial for many applications such as orthodontics wires, orthopedics devices and cardiovascular stents (E. S. F. J. Gil 2004). Composition sensitivity of martensitic start temperature (Ms) is also significantly reduced by $\mathrm{Cu}$ addition (Tomasz Goryczka 2008). 


\section{CHAPTER 3}

\section{CORROSION BEHAVIOR OF MEDICAL IMPLANTS}

\subsection{Introduction}

Corrosion is the result of an electrochemical reaction of a metal with its environment. Electrochemical deterioration of the metal occurs as the positive metal ions are released from the anode and electrons are available to flow towards the cathode (Davis 2003). Common anodic and cathodic reactions are shown below (Fontana 1986)

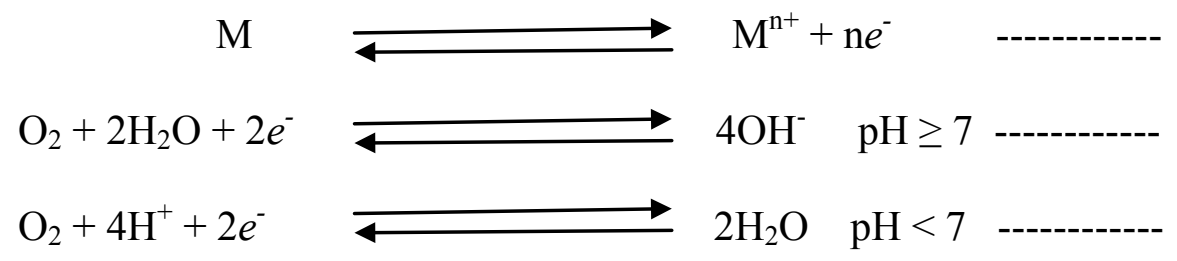

Equation (1) represents oxidation of a metal, equation (2) is the reduction process in neutral or basic conditions while equation (3) is also a reduction process in acidic conditions.

There are the types of corrosion in which there is intense attack at localized sites on the surface of an implant whilst the rest of the surface is corroding at a much lower rate, either because of the formation of a protective oxide film or because of some physiological conditions. 


\subsubsection{Pitting Corrosion}

Pitting corrosion is a severe form of localized corrosion that is caused by local dissolution of the passive film and the formation of pits surrounded by an intact passivated layer (S. Virtanen 2008). Pit is a cavity or hole with the surface diameter about the same or less than its depth (Fontana 1986). Pits may be isolated or so closed together that they look like a rough surface. Pitting corrosion can cause an implant device to fail because of perforation with only a small percent weight loss of the entire implant. Pitting corrosion is usually difficult to predict because of the small pit size and often these pits are covered with corrosion products. Pitting usually occurs in halide containing solutions. It is an autocatalytic process i.e. corrosion processes within the pit produce conditions which are necessary for the continuing activity of the pit. In this process fast dissolution occurs within the pit and oxygen reduction takes place on adjacent surfaces. Rapid dissolution produces an excess of positive charge which attracts Chloride ion to maintain electro-neutrality. Both chloride and hydrogen ions stimulate the dissolution of metals. This process accelerates with time. Extremely low concentration of the oxygen is available within the pit so no oxygen reduction occurs. Oxygen reduction on the adjacent surfaces tends to suppress corrosion and in that way pits cathodically protects the rest of the alloy surface (Fontana 1986).

\subsubsection{Crevice corrosion}

Crevice corrosion is also a type of localized corrosion which occurs preferentially in the region on the metal surface where the mass transfer is limited, e.g. in the narrow crevices, voids, gaps and under deposits. The concentration of chloride ions, decrease in 
$\mathrm{pH}$ value and depletion of oxygen in these narrow crevices can lead to activation of the surface (S. Virtanen 2008). Crevice corrosion is initiated by the depletion of oxygen in the crevice. During the crevice corrosion, the metallic surface inside the crevice acts as anode and the bulk metallic surface acts as cathode. As the reaction starts, the concentration of metal ions in the crevice increases due to anodic dissolution. To maintain the electrical neutrality, these metal ions in the crevice attract the chloride ions from the bulk solution and forms unstable metallic chlorides, which then hydrolyze to produce $\mathrm{H}^{+}$ions, thus decrease the $\mathrm{pH}$. The increase in acidity increases the dissolution rate of the metal, thus attracting more chloride ions and further lowers the $\mathrm{pH}$. This is an autocatalytic process and the solution in the crevice is becoming more and more aggressive as the concentration of $\mathrm{Cl}^{-}$and $\mathrm{H}^{+}$ions increase. Passive metallic materials are susceptible to crevice corrosion in chloride or hydrogen ions containing environment (F. T. Cheng 2007) (Fontana 1986).

The performance of a biomedical implant is determined by its chemical, physical and biological properties. The most important issue in the use of metallic implant materials is their corrosion behavior. The corrosion of the biomaterial is influenced by various intrinsic and extrinsic factors. Intrinsic factors include its chemical composition, microstructure, surface energy, wettability, thickness and stability of passivating oxide film etc. Extrinsic factors as shown in Figure 3-1, include temperature, $\mathrm{pH}$, dissolved oxygen content, amino acids, biomolecules and chloride ions in the surrounding environment (S. Virtanen 2008). Tissue fluids in the human body also present a very corrosive environment for implant devices. Furthermore, the regeneration of a passivating oxide film is delayed since the concentration of dissolved oxygen in body fluids is 
approximately one fourth of that in the air (A. Balamurugan 2008). Additionally, the concentration of chloride ion (the prime species in the initiation of pitting corrosion) in serum and interstitial fluid is 113 and $117 \mathrm{mEq} / \mathrm{L}$ respectively (A. Balamurugan 2008). Chloride ions induce pitting at sites where the passive film is breached. This is followed by the propagation of the pit, at a rate that sometimes increases with time, because of the increasing acidity inside the pit (Revie 2000). In addition to inorganic species in the body fluid, different types of biomolecules and cells may attach to the implant surface and affect its surface chemistry. Infact, there is sufficient evidence to support the premise that protein adsorption varies in direct proportion to $\mathrm{Ni}$ and $\mathrm{Ti}$ surface concentration (Sevtlana A. Shabalovskaya 2004) and that the presence and adsorption of proteins can influence the rate of corrosion of implant materials (V. C. Dinca 2006) (S. Shabalovskaya 2001) (Ryhänen 1999).

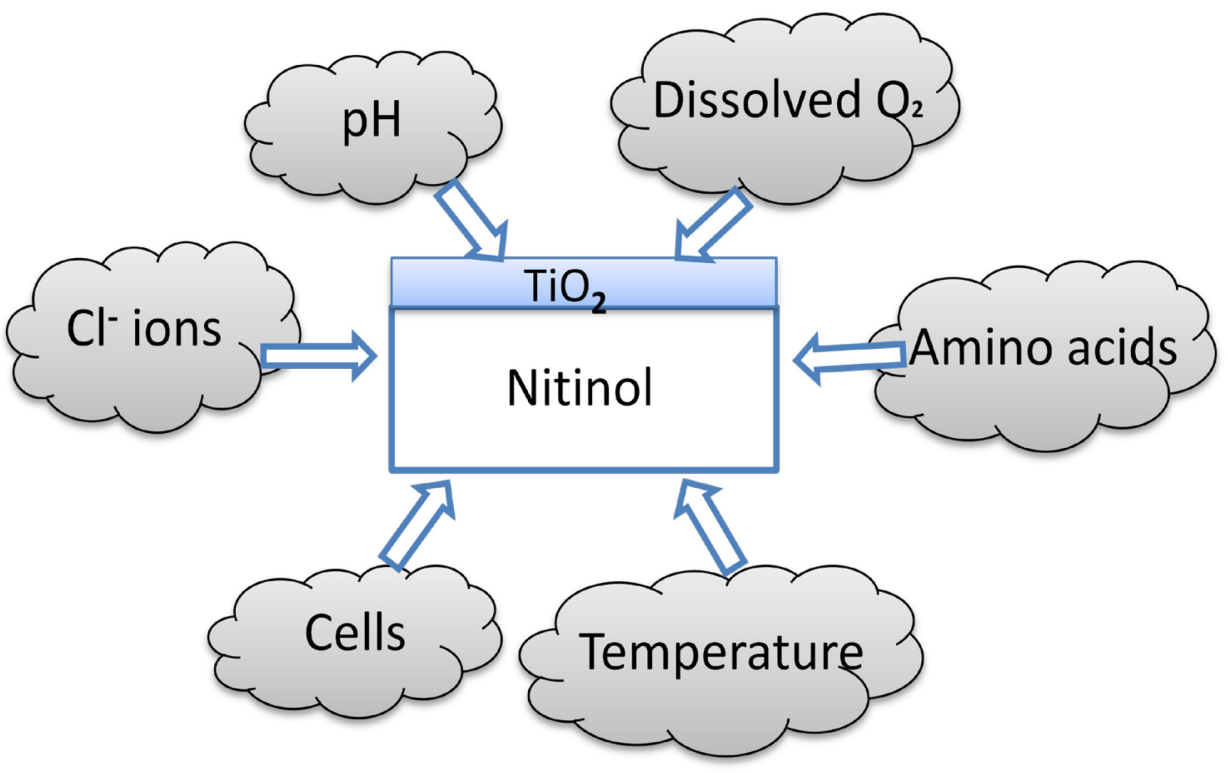

Figure 3-1 Extrinsic factors affecting the corrosion behavior of Nitinol 
Another significant factor determining the corrosion behavior of Nitinol is the $\mathrm{pH}$ of the environment. The $\mathrm{pH}$ of the tissue surrounding a Nitinol implant has been reported (S. Virtanen 2008) to decrease to 5 , after which it increases to 7.4 within a few weeks. Such an environment imposes strict material requirements on surface homogeneity and stability (V. C. Dinca 2006) (N. Munroe 2007) (J. A. S. A. Shabalovskaya 2003) because in service demands such as bending, strain from fatigue, abrasion, or wear may eventually damage the passive film. This film is normally composed of $\mathrm{TiO}_{2}$, which has a larger thermodynamic driving force of formation over that of nickel (S. Virtanen 2008). Any surface damage to the $\mathrm{TiO}_{2}$ can expose the underlying metal which could lead to the release of nickel into the physiological environment.

The study of corrosion resistance of medical implants is a quite complicated subject. Part of the complication in characterizing the corrosion resistance is the inherent stochastic nature of corrosion. Long term reliability of implantable materials requires assuring low corrosion and low metal ion leaching. Corrosion determines the structural integrity of the implant device and metal ion leaching has been associated with adverse immunological reactions. (Warner 2009).

\subsection{ASTM F 2129 Standard}

Application of the cyclic polarization tests to implantable devices is described in the American Society of Testing and Materials - ASTM F 2129 Standard. The original version was introduced in 2001 but updated versions were released in 2003, 2004, 2006 and 2008. The ASTM F 2129-08 standard was adopted in this study. It is basically a test procedure for measuring the corrosion susceptibility of small metallic implants using 
cyclic potentiodynamic polarization. It is a modification of reference test methods G 5 and G 61. The Food and Drug Administration (FDA) requires medical-device manufacturers to provide corrosion data to ensure that their device possess sufficient corrosion resistance. ASTM F 2129 is frequently used to satisfy this FDA requirement. However, neither the FDA nor ASTM F 2129 provides any guidance about the acceptance criterion for the polarization results (Lawrence E. Eiselstein 2009). Although no minimum criteria have been defined for ASTM F 2129, these corrosion tests are designed to enable the researcher to rank materials (Warner 2009). Two typical cyclic potentiodynamic curves are shown below in Figure 3-2, where $E_{b}, E_{p}, E_{r}, E_{v}$ represent the breakdown potential, protection potential, rest potential and vertex potential respectively.

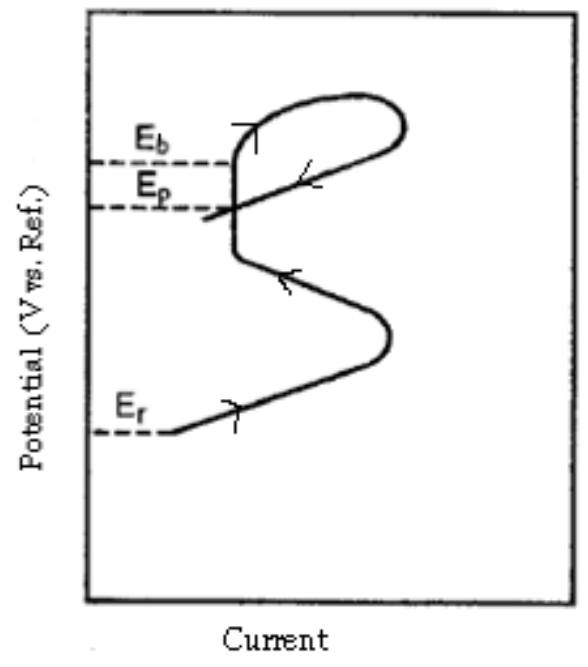

(a)

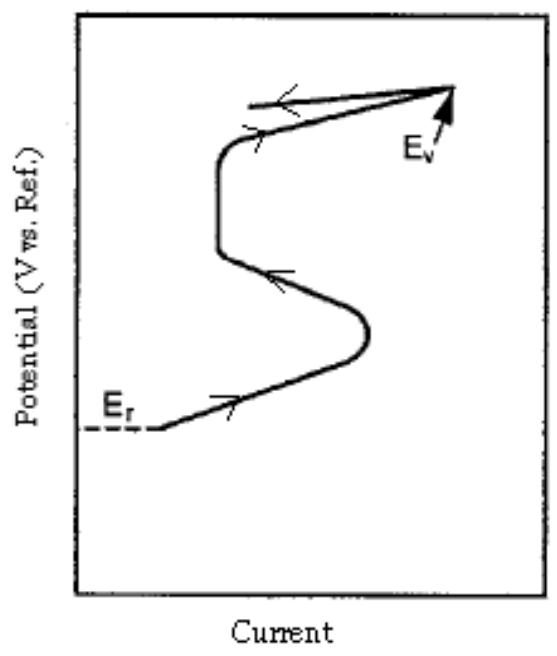

(b)

Figure 3-2 Typical cyclic potentiodynamic curves illustrating different corrosion parameters (ASTM F 2129 2008) 
Breakdown potential $\left(\mathbf{E}_{\mathbf{b}}\right)$ is the least noble potential at which pitting or crevice corrosion or both will initiate.

Protection potential $\left(\mathbf{E}_{\mathbf{p}}\right)$ is the potential at which the reverse scan intersects the forward scan at a value that is less noble than $\mathrm{E}_{\mathrm{b}}$.

Rest potential $\left(\mathbf{E}_{\mathbf{r}}\right)$ is the potential of the working electrode relative to the reference electrode measured under virtual open-circuit conditions.

Vertex potential $\left(\mathbf{E}_{\mathbf{r}}\right)$ is the potential at which the scan is reversed.

In general, three common methodologies exist as possibilities for an acceptance criterion (Lawrence E. Eiselstein 2009). The first is that the $\mathrm{E}_{\mathrm{b}}$ of an implantable device should have similar or better corrosion resistance than approved devices currently in the market with no known corrosion problems. The second methodology that has been proposed is that the $\mathrm{E}_{\mathrm{b}}$ of the implantable device should be more than some threshold value. It is generally agreed that a Nitinol implantable device should have an $E_{b}$ greater than $0.600 \mathrm{~V}$ with respect to the saturated calomel electrode (SCE). The third methodology is to use the difference between the breakdown potential $\left(\mathrm{E}_{\mathrm{b}}\right)$ and the rest potential $\left(E_{r}\right),\left(E_{b}-E_{r}\right)$, as a measure of corrosion resistance.

\subsection{Experimental Methods}

\subsubsection{Materials}

Binary and ternary Nitinol alloys were prepared by arc melting (AM) method at the National Institute of Standards and Technology (NIST). The composition of these alloys is shown in Table 1 where $\mathrm{X}$ represents the ternary element, tantalum (Ta), 
chromium $(\mathrm{Cr})$ and copper $(\mathrm{Cu})$. Samples were prepared by cutting the cylindrical ingots with a high-speed saw into cylindrical discs of dimension $(1 \mathrm{~cm} \times 2 \mathrm{~mm})$.

Binary Nitinol stents were obtained from stent manufacturers and were used for corrosion analysis.

Table 3-1 Alloy Composition (in atomic percent)

\begin{tabular}{|c|c|c|}
\hline $\mathbf{N i}$ & $\mathbf{T i}$ & $\mathbf{X}$ \\
\hline 51 & 49 & 0 \\
\hline 48.45 & 46.55 & 5 \\
\hline 45.90 & 44.10 & 10 \\
\hline
\end{tabular}

\subsubsection{Reagents}

Phosphate Buffered Saline (PBS), a reagent grade chemical conforming to the specifications of the Committee on Analytical Reagents of the American Chemical Society was used as the standard test solution for corrosion analysis. Also, distilled water was used for water boiling and nitric acid $\left(\mathrm{HNO}_{3}\right)$ was used as the passivation reagent.

\subsubsection{Sample Preparation}

All the samples were polished with a series of 200, 320 and 600 grit SiC paper. The samples were then degreased ultrasonically with acetone, rinsed in distilled water and air-dried. Three surface treatments were performed on these samples namely, electropolishing (EP), magnetoelectropolishing (MEP) and water boiling \& passivation (W\&P). Electropolishing and magnetoelectropolishing were performed by 
Electrobright ${ }^{\circledR}$ (Macungie, PA, USA). Because of its proprietary nature, information on electropolishing and magnetoelectropolishing has not been disclosed by Electrobright ${ }^{\circledR}$. Water boiling was performed by boiling the samples in distilled water at $132{ }^{\circ} \mathrm{C}$ for 30 minutes followed by passivation, which is the immersion of water boiled samples in $20 \%$ $\mathrm{HNO}_{3}$ at $80{ }^{\circ} \mathrm{C}$ for 20 minutes.

\subsection{Corrosion Testing}

The corrosion cell kit used in this investigation is shown in Figure 3-3. The cell was first cleaned with deionized water, rinsed with PBS solution and filled with approximately $70 \mathrm{ml}$ of PBS. The cell with PBS solution was brought up to $37{ }^{\circ} \mathrm{C}$ by placing it in a controlled temperature water bath. The PBS solution was purged with ultra high purity nitrogen for 30 minutes prior to immersion of the test sample. A saturated calomel electrode was used as the reference electrode and it was inserted into a Luggin Capillary. The Luggin Capillary was mounted as close as possible to the Nitinol sample in order to minimize the junction potential and thus, ensure accurate readings. The surface area of the sample in contact with PBS was carefully calculated and it was $1 \mathrm{~cm}^{2}$. The entire test setup was then placed in the water bath. The working, reference and counter electrodes were connected to the potentiostat. The cyclic polarization option was then selected on a GAMRY® potentiostat (G-750) equipped with a Instrument Framework Software. Tests were conducted using phosphate buffer saline (PBS) as the electrolyte at $37{ }^{\circ} \mathrm{C}$ employing a scan rate of $1 \mathrm{mV} / \mathrm{s}$ over a potential range of -0.5 to 2.2 $\mathrm{V}_{\mathrm{SCE}}$, where SCE is standard calomel electrode. 


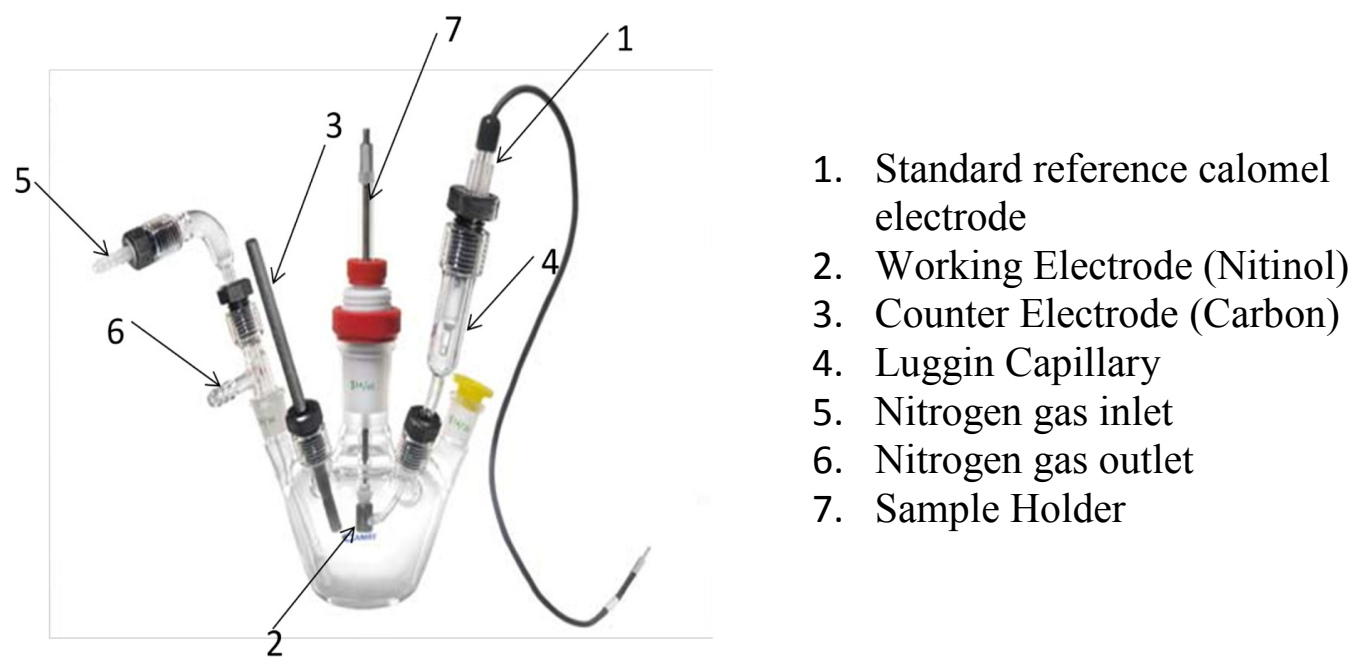

Figure 3-3 Corrosion cell kit

Cyclic potentiodynamic polarization curves for Nitinol alloys depicted in figures 3-4 to 3-9 reveal two distinct features - a positive and a negative hysteresis. For example, the reverse scan at the vertex potential for NiTi, NiTiCu, NiTiTa alloys and Nitinol stents loop in a clockwise direction (positive hysteresis), i.e., initially towards a high current density region, whereas, for NiTiCr alloys the reverse scan loops in an anti-clockwise direction (negative hysteresis), i.e., initially towards a low current density.

For the alloys and stents showing the positive hysteresis, the pitting corrosion resistance may be evaluated by the difference between the breakdown and rest potentials $\left(\mathrm{E}_{\mathrm{b}}-\mathrm{E}_{\mathrm{r}}\right)$, whereas, crevice corrosion resistance may be evaluated by the protection potential $\left(\mathrm{E}_{\mathrm{p}}\right)$. A large hysteresis loop area is associated with a greater disruption of the passive film and lower restoration in surface passivity, which leads to greater risk of localized corrosion. For alloys that exhibit a negative hysteresis, the corrosion resistance may be evaluated by the vertex potential $\mathrm{E}_{\mathrm{v}}$. 


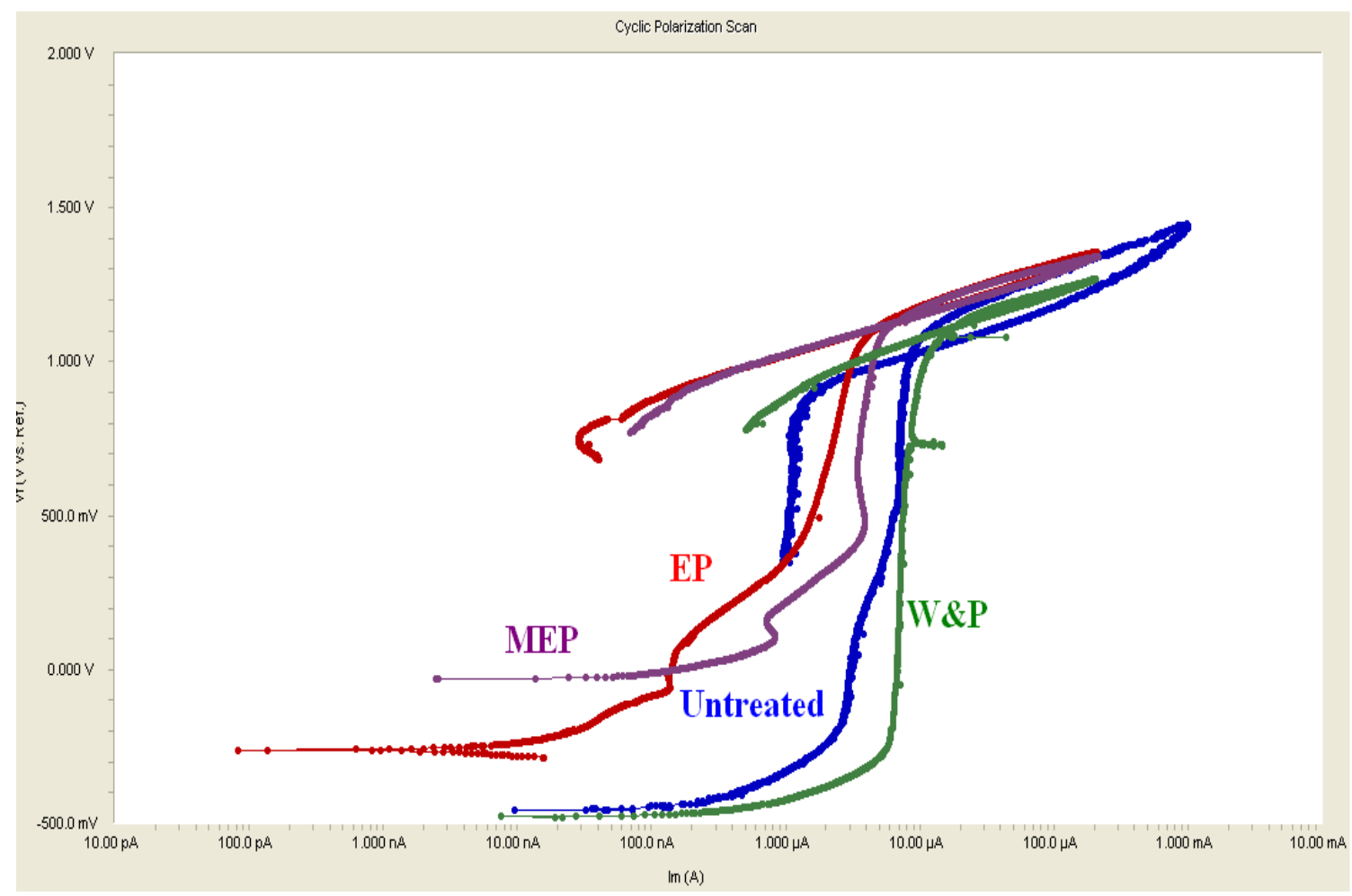

Figure 3-4 Cyclic potentiodynamic curves for NiTi alloys

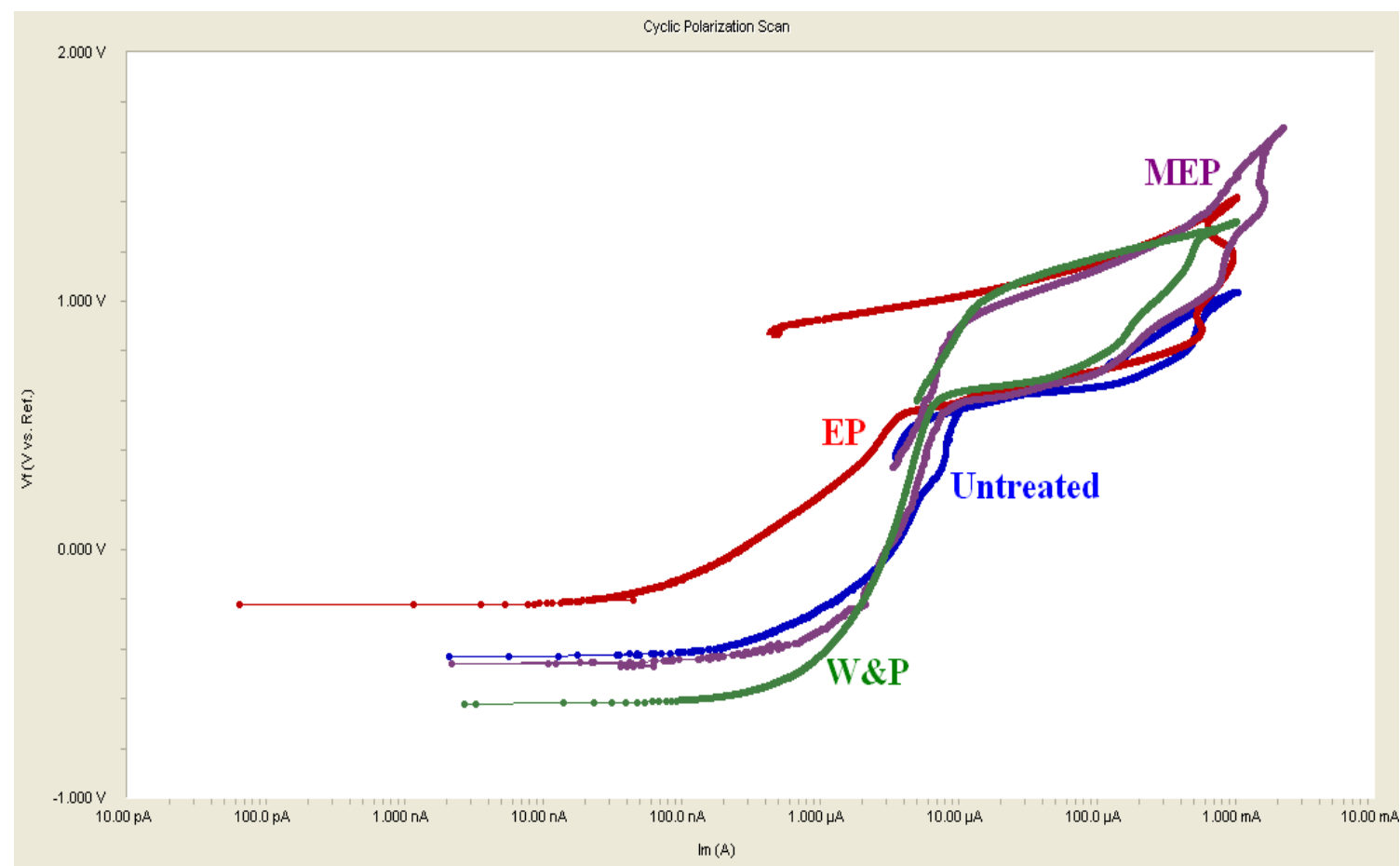

Figure 3-5 Cyclic potentiodynamic curves for NiTi10Cr alloys 


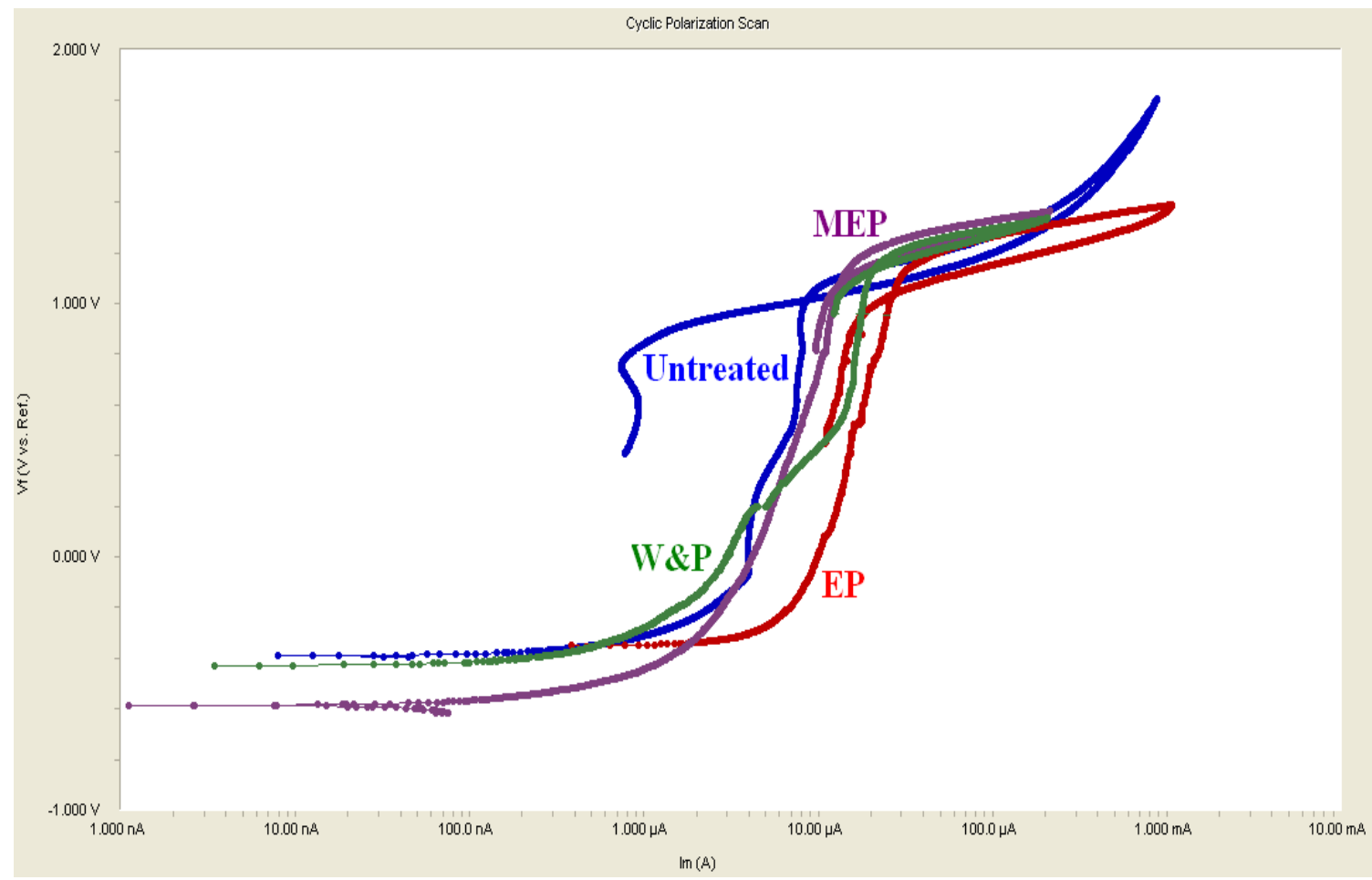

Figure 3-6 Cyclic potentiodynamic curves for NiTi10Cu alloys

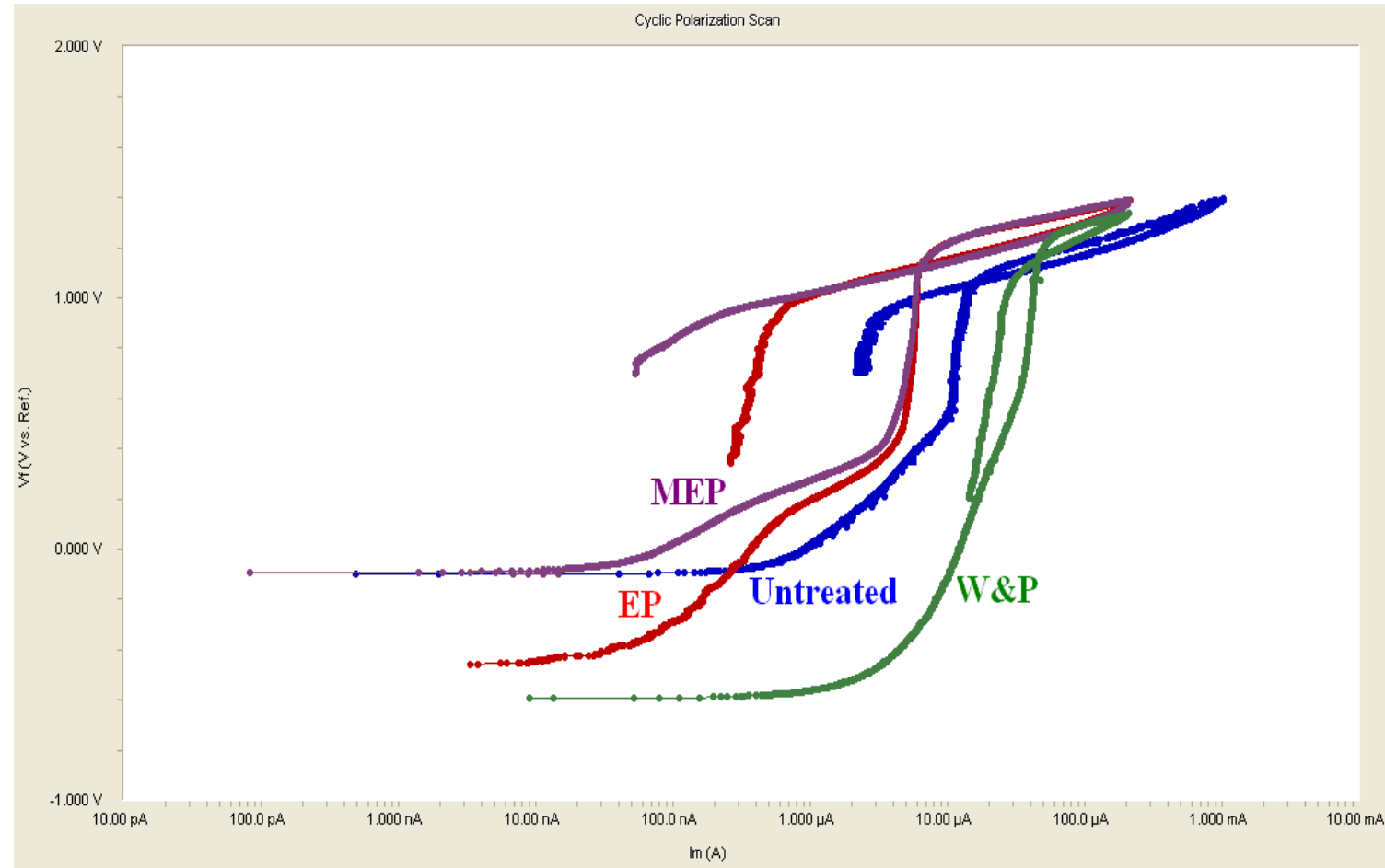

Figure 3-7 Cyclic potentiodynamic curves for NiTi10Ta alloys 


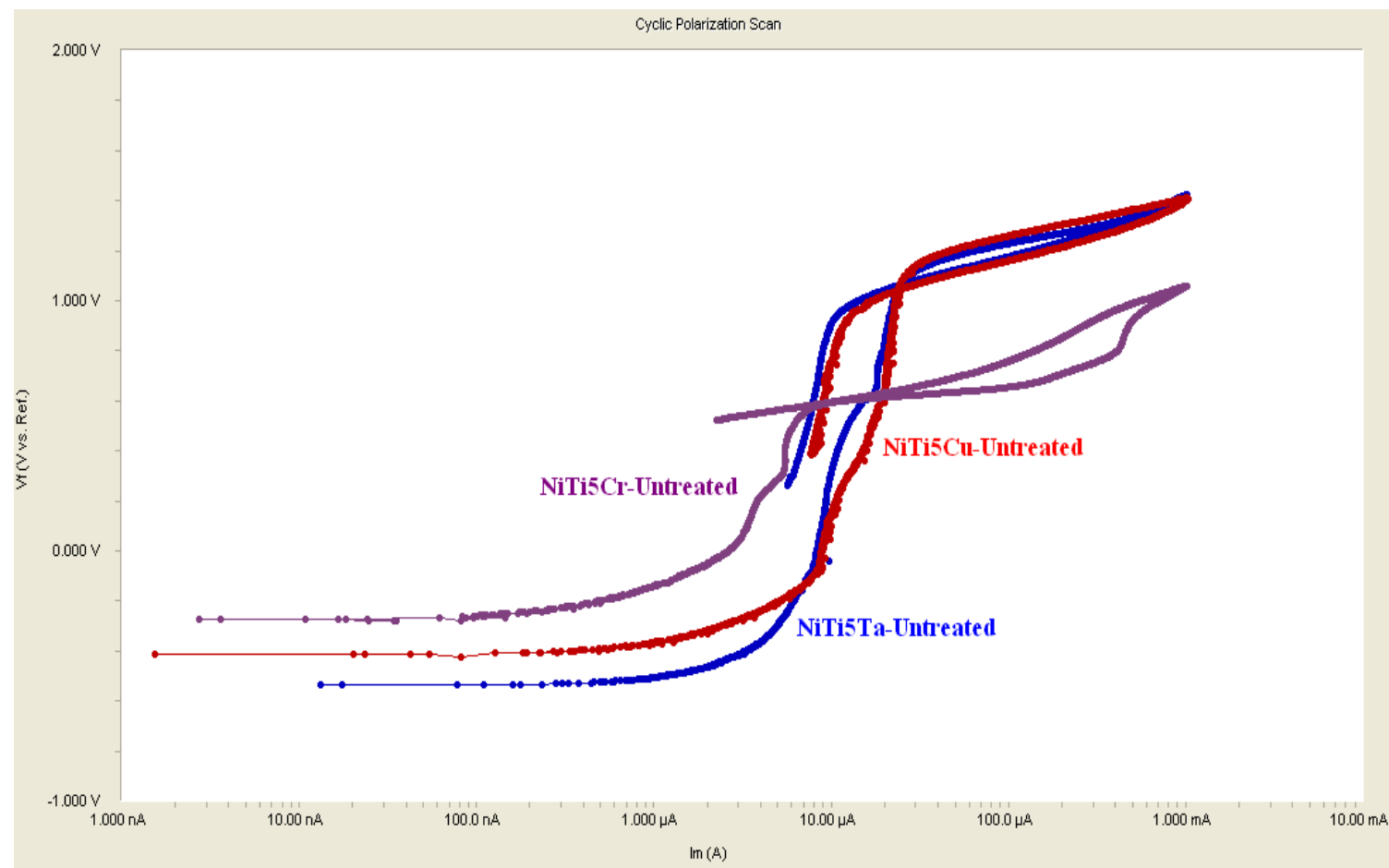

Figure 3-8 Cyclic potentiodynamic curves for NiTi5X alloys

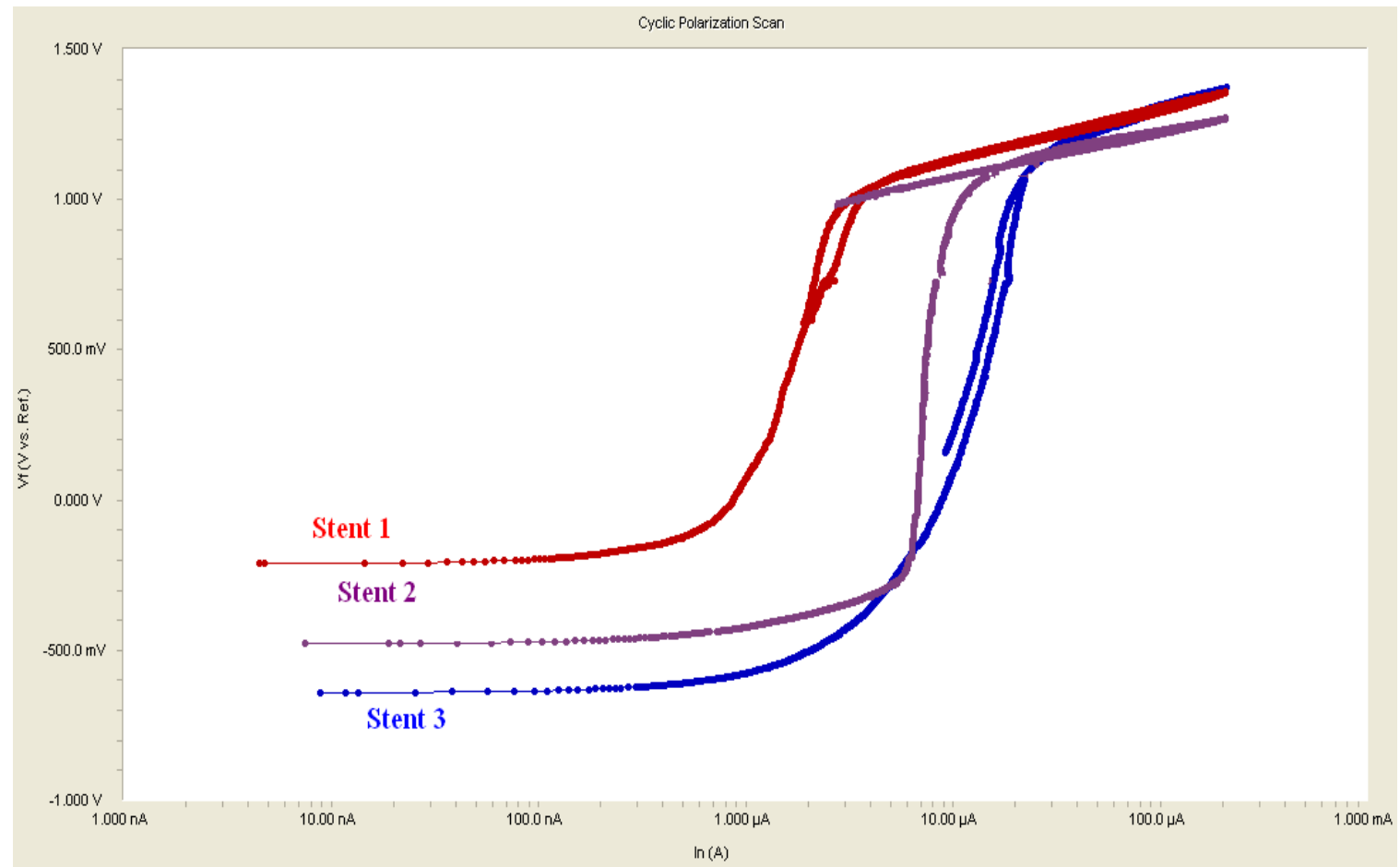

Figure 3-8 Cyclic potentiodynamic curves for Nitinol Stents 
The cyclic potentiodynamic polarization method is very useful for determining the susceptibility of an alloy to pitting and crevice corrosion. The corrosion parameters such as $E_{p}, E_{b}, E_{v}, E_{r}$, and $E_{b}-E_{r}$ obtained during cyclic potentiodynamic tests for various Nitinol alloys and stents are given in tables 3-2 to 3-21.

Table 3-2 Corrosion data for NiTi-untreated alloys

\begin{tabular}{|c|c|c|c|c|c|c|}
\hline $\begin{array}{c}\text { Corrosion } \\
\text { Parameters }\end{array}$ & Sample 1 & Sample 2 & Sample 3 & Sample 4 & Sample 5 & Average \\
\hline $\mathbf{E}_{\mathbf{b}}$ (Volts) & 1.082 & 1.060 & 1.070 & 1.016 & 1.110 & 1.067 \\
\hline $\mathbf{E}_{\mathbf{r}}$ (Volts) & -0.492 & -0.458 & -0.508 & -0.541 & -0.536 & -0.507 \\
\hline $\mathbf{E}_{\mathbf{p}}$ (Volts) & 1.010 & 1.026 & 1.007 & 0.891 & 1.076 & 1.002 \\
\hline $\mathbf{E}_{\mathbf{b}}-\mathbf{E}_{\mathbf{r}}$ (Volts) & 1.574 & 1.518 & 1.578 & 1.557 & 1.646 & 1.574 \\
\hline
\end{tabular}

Table 3-3 Corrosion data for NiTi-EP alloys

\begin{tabular}{|c|c|c|c|c|c|c|}
\hline $\begin{array}{c}\text { Corrosion } \\
\text { Parameters }\end{array}$ & Sample 1 & Sample 2 & Sample 3 & Sample 4 & Sample 5 & Average \\
\hline $\mathbf{E}_{\mathbf{b}}$ (Volts) & 1.010 & 1.141 & 1.145 & 1.156 & 1.149 & 1.120 \\
\hline $\mathbf{E}_{\mathbf{r}}$ (Volts) & -0.297 & -0.495 & -0.249 & -0.636 & -0.631 & -0.461 \\
\hline $\mathbf{E}_{\mathbf{p}}$ (Volts) & 0.984 & 1.095 & 1.109 & 1.105 & 1.104 & 1.079 \\
\hline $\mathbf{E}_{\mathbf{b}}-\mathbf{E}_{\mathbf{r}}$ (Volts) & 1.307 & 1.636 & 1.394 & 1.792 & 1.780 & 1.581 \\
\hline
\end{tabular}

Table 3-4 Corrosion data for NiTi-MEP alloy

\begin{tabular}{|c|c|c|c|c|c|c|}
\hline $\begin{array}{c}\text { Corrosion } \\
\text { Parameters }\end{array}$ & Sample 1 & Sample 2 & Sample 3 & Sample 4 & Sample 5 & Average \\
\hline $\mathbf{E}_{\mathbf{b}}$ (Volts) & 1.199 & 1.144 & 1.113 & 1.101 & 1.101 & 1.131 \\
\hline $\mathbf{E}_{\mathbf{r}}$ (Volts) & -0.334 & -0.097 & -0.495 & -0.615 & -0.676 & -0.443 \\
\hline $\mathbf{E}_{\mathbf{p}}$ (Volts) & 1.124 & 0.965 & 1.101 & 1.016 & 1.009 & 1.043 \\
\hline $\mathbf{E}_{\mathbf{b}}-\mathbf{E}_{\mathbf{r}}$ (Volts) & 1.533 & 1.241 & 1.608 & 1.716 & 1.777 & 1.574 \\
\hline
\end{tabular}


Table 3-5 Corrosion data for NiTi-W\&P alloys

\begin{tabular}{|c|c|c|c|c|c|c|}
\hline $\begin{array}{c}\text { Corrosion } \\
\text { Parameters }\end{array}$ & Sample 1 & Sample 2 & Sample 3 & Sample 4 & Sample 5 & Average \\
\hline $\mathbf{E}_{\mathbf{b}}($ Volts) & 1.219 & 1.140 & 1.102 & 1.111 & 1.001 & 1.114 \\
\hline $\mathbf{E}_{\mathbf{r}}($ Volts) & -0.256 & -0.472 & -0.413 & -0.621 & -0.457 & -0.444 \\
\hline $\mathbf{E}_{\mathbf{p}}($ Volts) & 1.208 & 1.112 & 1.077 & 1.101 & 0.989 & 1.097 \\
\hline $\mathbf{E}_{\mathbf{b}}-\mathbf{E}_{\mathbf{r}}($ Volts) & 1.475 & 1.632 & 1.515 & 1.732 & 1.458 & 1.558 \\
\hline
\end{tabular}

Table 3-6 Corrosion data for NiTi10Cr-untreated alloys

\begin{tabular}{|c|c|c|c|c|c|c|}
\hline $\begin{array}{c}\text { Corrosion } \\
\text { Parameters }\end{array}$ & Sample 1 & Sample 2 & Sample 3 & Sample 4 & Sample 5 & Average \\
\hline $\mathbf{E}_{\mathbf{v}}($ Volts) & 1.060 & 1.036 & 1.001 & 1.252 & 1.021 & 1.074 \\
\hline $\mathbf{E}_{\mathbf{r}}$ (Volts) & -0.277 & -0.428 & -0.408 & -0.354 & -0.215 & -0.336 \\
\hline
\end{tabular}

Table 3-7 Corrosion data for NiTi10Cr-EP alloys

\begin{tabular}{|c|c|c|c|c|c|c|}
\hline $\begin{array}{c}\text { Corrosion } \\
\text { Parameters }\end{array}$ & Sample 1 & Sample 2 & Sample 3 & Sample 4 & Sample 5 & Average \\
\hline $\mathbf{E}_{\mathbf{v}}($ Volts) & 1.447 & 1.416 & 1.404 & 1.510 & 1.496 & 1.454 \\
\hline $\mathbf{E}_{\mathbf{r}}($ Volts) & -0.215 & -0.221 & -0.569 & -0.411 & -0.310 & -0.345 \\
\hline
\end{tabular}

Table 3-8 Corrosion data for NiTi10Cr-MEP alloys

\begin{tabular}{|c|c|c|c|c|c|c|}
\hline $\begin{array}{c}\text { Corrosion } \\
\text { Parameters }\end{array}$ & Sample 1 & Sample 2 & Sample 3 & Sample 4 & Sample 5 & Average \\
\hline $\mathbf{E}_{\mathbf{v}}$ (Volts) & 1.733 & 1.821 & 1.721 & 1.809 & 1.754 & 1.767 \\
\hline $\mathbf{E}_{\mathbf{r}}$ (Volts) & -0.034 & -0.097 & -0.315 & -0.496 & -0.475 & -0.283 \\
\hline
\end{tabular}


Table 3-9 Corrosion data for NiTi10Cr-W\&P alloys

\begin{tabular}{|c|c|c|c|c|c|c|}
\hline $\begin{array}{c}\text { Corrosion } \\
\text { Parameters }\end{array}$ & Sample 1 & Sample 2 & Sample 3 & Sample 4 & Sample 5 & Average \\
\hline $\mathbf{E}_{\mathbf{v}}($ Volts) & 1.060 & 1.443 & 1.322 & 1.411 & 1.239 & 1.295 \\
\hline $\mathbf{E}_{\mathbf{r}}$ (Volts) & -0.416 & -0.364 & -0.619 & -0.402 & -0.689 & -0.498 \\
\hline
\end{tabular}

Table 3-10 Corrosion data for NiTi10Cu-untreated alloys

\begin{tabular}{|c|c|c|c|c|c|c|}
\hline $\begin{array}{c}\text { Corrosion } \\
\text { Parameters }\end{array}$ & Sample 1 & Sample 2 & Sample 3 & Sample 4 & Sample 5 & Average \\
\hline $\mathbf{E}_{\mathbf{b}}$ (Volts) & 1.030 & 1.058 & 1.082 & 1.066 & 1.050 & 1.057 \\
\hline $\mathbf{E}_{\mathbf{r}}$ (Volts) & -0.392 & -0.345 & -0.270 & -0.252 & -0.267 & -0.335 \\
\hline $\mathbf{E}_{\mathbf{p}}$ (Volts) & 1.013 & 1.036 & 1.060 & 1.040 & 1.037 & 1.037 \\
\hline $\mathbf{E}_{\mathbf{b}}-\mathbf{E}_{\mathbf{r}}$ (Volts) & 1.422 & 1.403 & 1.352 & 1.318 & 1.317 & 1.392 \\
\hline
\end{tabular}

Table 3-11 Corrosion data for NiTi10Cu-EP alloys

\begin{tabular}{|c|c|c|c|c|c|c|}
\hline $\begin{array}{c}\text { Corrosion } \\
\text { Parameters }\end{array}$ & Sample 1 & Sample 2 & Sample 3 & Sample 4 & Sample 5 & Average \\
\hline $\mathbf{E}_{\mathbf{b}}$ (Volts) & 1.111 & 1.093 & 1.091 & 1.101 & 1.192 & 1.117 \\
\hline $\mathbf{E}_{\mathbf{r}}$ (Volts) & -0.165 & -0.194 & -0.351 & -0.331 & -0.394 & -0.287 \\
\hline $\mathbf{E}_{\mathbf{p}}$ (Volts) & 1.022 & 1.012 & 1.036 & 1.087 & 1.096 & 1.050 \\
\hline $\mathbf{E}_{\mathbf{b}}-\mathbf{E}_{\mathbf{r}}$ (Volts) & 1.276 & 1.287 & 1.442 & 1.432 & 1.586 & 1.404 \\
\hline
\end{tabular}

Table 3-12 Corrosion data for NiTi10Cu-MEP alloys

\begin{tabular}{|c|c|c|c|c|c|c|}
\hline $\begin{array}{c}\text { Corrosion } \\
\text { Parameters }\end{array}$ & Sample 1 & Sample 2 & Sample 3 & Sample 4 & Sample 5 & Average \\
\hline $\mathbf{E}_{\mathbf{b}}$ (Volts) & 1.084 & 1.170 & 1.104 & 1.176 & 1.181 & 1.143 \\
\hline $\mathbf{E}_{\mathbf{r}}$ (Volts) & -0.063 & -0.081 & -0.203 & -0.569 & -0.585 & -0.300 \\
\hline $\mathbf{E}_{\mathbf{p}}$ (Volts) & 1.019 & 1.140 & 1.051 & 1.077 & 1.130 & 1.083 \\
\hline $\mathbf{E}_{\mathbf{b}}-\mathbf{E}_{\mathbf{r}}$ (Volts) & 1.147 & 1.251 & 1.307 & 1.745 & 1.766 & 1.443 \\
\hline
\end{tabular}


Table 3-13 Corrosion data for NiTi10Cu-W\&P alloys

\begin{tabular}{|c|c|c|c|c|c|c|}
\hline $\begin{array}{c}\text { Corrosion } \\
\text { Parameters }\end{array}$ & Sample 1 & Sample 2 & Sample 3 & Sample 4 & Sample 5 & Average \\
\hline $\mathbf{E}_{\mathbf{b}}$ (Volts) & 1.189 & 1.177 & 1.188 & 1.201 & 1.191 & 1.189 \\
\hline $\mathbf{E}_{\mathbf{r}}$ (Volts) & -0.133 & -0.412 & -0.301 & -0.322 & -0.222 & -0.278 \\
\hline $\mathbf{E}_{\mathbf{p}}$ (Volts) & 1.141 & 1.129 & 1.130 & 1.131 & 1.102 & 1.126 \\
\hline $\mathbf{E}_{\mathbf{b}}-\mathbf{E}_{\mathbf{r}}$ (Volts) & 1.322 & 1.589 & 1.489 & 1.523 & 1.413 & 1.467 \\
\hline
\end{tabular}

Table 3-14 Corrosion data for NiTi10Ta-untreated alloys

\begin{tabular}{|c|c|c|c|c|c|c|}
\hline $\begin{array}{c}\text { Corrosion } \\
\text { Parameters }\end{array}$ & Sample 1 & Sample 2 & Sample 3 & Sample 4 & Sample 5 & Average \\
\hline $\mathbf{E}_{\mathbf{b}}$ (Volts) & 1.106 & 1.109 & 1.127 & 1.103 & 1.108 & 1.110 \\
\hline $\mathbf{E}_{\mathbf{r}}$ (Volts) & -0.511 & -0.254 & -0.288 & -0.347 & -0.082 & -0.296 \\
\hline $\mathbf{E}_{\mathbf{p}}$ (Volts) & 1.093 & 1.099 & 1.107 & 1.078 & 1.077 & 1.090 \\
\hline $\mathbf{E}_{\mathbf{b}}-\mathbf{E}_{\mathbf{r}}$ (Volts) & 1.617 & 1.363 & 1.415 & 1.450 & 1.190 & 1.407 \\
\hline
\end{tabular}

Table 3-15 Corrosion data for NiTi10Ta-EP alloys

\begin{tabular}{|c|c|c|c|c|c|c|}
\hline $\begin{array}{c}\text { Corrosion } \\
\text { Parameters }\end{array}$ & Sample 1 & Sample 2 & Sample 3 & Sample 4 & Sample 5 & Average \\
\hline $\mathbf{E}_{\mathbf{b}}$ (Volts) & 1.146 & 1.140 & 1.149 & 1.141 & 1.152 & 1.145 \\
\hline $\mathbf{E}_{\mathbf{r}}$ (Volts) & -0.456 & -0.412 & -0.542 & -0.433 & -0.387 & -0.466 \\
\hline $\mathbf{E}_{\mathbf{p}}$ (Volts) & 1.127 & 1.122 & 1.130 & 1.123 & 1.134 & 1.127 \\
\hline $\mathbf{E}_{\mathbf{b}}-\mathbf{E}_{\mathbf{r}}$ (Volts) & 1.602 & 1.552 & 1.691 & 1.574 & 1.539 & 1.611 \\
\hline
\end{tabular}


Table 3-16 Corrosion data for NiTi10Ta-MEP alloys

\begin{tabular}{|c|c|c|c|c|c|c|}
\hline $\begin{array}{c}\text { Corrosion } \\
\text { Parameters }\end{array}$ & Sample 1 & Sample 2 & Sample 3 & Sample 4 & Sample 5 & Average \\
\hline $\mathbf{E}_{\mathbf{b}}$ (Volts) & 1.144 & 1.159 & 1.157 & 1.145 & 1.155 & 1.152 \\
\hline $\mathbf{E}_{\mathbf{r}}$ (Volts) & -0.099 & -0.288 & -0.245 & -0.674 & -0.596 & -0.380 \\
\hline $\mathbf{E}_{\mathbf{p}}$ (Volts) & 1.114 & 1.149 & 1.148 & 1.138 & 1.148 & 1.139 \\
\hline $\mathbf{E}_{\mathbf{b}}-\mathbf{E}_{\mathbf{r}}$ (Volts) & 1.243 & 1.447 & 1.402 & 1.819 & 1.751 & 1.532 \\
\hline
\end{tabular}

Table 3-17 Corrosion data for NiTi10Ta-W\&P alloys

\begin{tabular}{|c|c|c|c|c|c|c|}
\hline $\begin{array}{c}\text { Corrosion } \\
\text { Parameters }\end{array}$ & Sample 1 & Sample 2 & Sample 3 & Sample 4 & Sample 5 & Average \\
\hline $\mathbf{E}_{\mathbf{b}}$ (Volts) & 1.181 & 1.179 & 1.187 & 1.175 & 1.178 & 1.180 \\
\hline $\mathbf{E}_{\mathbf{r}}$ (Volts) & -0.595 & -0.619 & -0.411 & -0.522 & -0.165 & -0.462 \\
\hline $\mathbf{E}_{\mathbf{p}}$ (Volts) & 1.152 & 1.142 & 1.137 & 1.130 & 1.130 & 1.138 \\
\hline $\mathbf{E}_{\mathbf{b}}-\mathbf{E}_{\mathbf{r}}$ (Volts) & 1.776 & 1.798 & 1.598 & 1.697 & 1.343 & 1.642 \\
\hline
\end{tabular}

Table 3-18 Corrosion data for NiTi5Ta-untreated alloys

\begin{tabular}{|c|c|c|c|c|c|c|}
\hline $\begin{array}{c}\text { Corrosion } \\
\text { Parameters }\end{array}$ & Sample 1 & Sample 2 & Sample 3 & Sample 4 & Sample 5 & Average \\
\hline $\mathbf{E}_{\mathbf{b}}$ (Volts) & 1.101 & 1.102 & 1.132 & 1.123 & 1.131 & 1.117 \\
\hline $\mathbf{E}_{\mathbf{r}}$ (Volts) & -0.565 & -0.485 & -0.592 & -0.501 & -0.451 & -0.518 \\
\hline $\mathbf{E}_{\mathbf{p}}$ (Volts) & 0.996 & 1.070 & 1.078 & 1.029 & 1.044 & 1.043 \\
\hline $\mathbf{E}_{\mathbf{b}}-\mathbf{E}_{\mathbf{r}}$ (Volts) & 1.666 & 1.587 & 1.724 & 1.624 & 1.582 & 1.635 \\
\hline
\end{tabular}


Table 3-19 Corrosion data for NiTi5Cu-untreated alloys

\begin{tabular}{|c|c|c|c|c|c|c|}
\hline $\begin{array}{c}\text { Corrosion } \\
\text { Parameters }\end{array}$ & Sample 1 & Sample 2 & Sample 3 & Sample 4 & Sample 5 & Average \\
\hline $\mathbf{E}_{\mathbf{b}}($ Volts) & 1.116 & 1.080 & 1.123 & 1.016 & 1.110 & 1.089 \\
\hline $\mathbf{E}_{\mathbf{r}}($ Volts) & -0.531 & -0.398 & -0.474 & -0.541 & -0.536 & -0.496 \\
\hline $\mathbf{E}_{\mathbf{p}}($ Volts) & 1.101 & 1.016 & 1.041 & 0.891 & 1.076 & 1.025 \\
\hline $\mathbf{E}_{\mathbf{b}}-\mathbf{E}_{\mathbf{r}}$ (Volts) & 1.647 & 1.478 & 1.597 & 1.557 & 1.646 & 1.585 \\
\hline
\end{tabular}

Table 3-20 Corrosion data for NiTi5Cr-untreated alloys

\begin{tabular}{|c|c|c|c|c|c|c|}
\hline $\begin{array}{c}\text { Corrosion } \\
\text { Parameters }\end{array}$ & Sample 1 & Sample 2 & Sample 3 & Sample 4 & Sample 5 & Average \\
\hline $\mathbf{E}_{\mathrm{v}}$ (Volts) & 1.011 & 0.936 & 0.911 & 1.023 & 1.001 & 0.976 \\
\hline $\mathbf{E}_{\mathbf{r}}$ (Volts) & -0.251 & -0.317 & -0.307 & -0.411 & -0.384 & -0.334 \\
\hline
\end{tabular}

Table 3-21 Corrosion data for Nitinol Stents

\begin{tabular}{|c|c|c|c|}
\hline Corrosion Parameters & Stent 1 & Stent 2 & Stent 3 \\
\hline $\mathbf{E}_{\mathbf{b}}$ (Volts) & 1.101 & 1.137 & 1.140 \\
\hline $\mathbf{E}_{\mathbf{r}}$ (Volts) & -0.229 & -0.455 & -0.615 \\
\hline $\mathbf{E}_{\mathbf{p}}$ (Volts) & 1.071 & 1.102 & 1.097 \\
\hline $\mathbf{E}_{\mathbf{b}}-\mathbf{E}_{\mathbf{r}}$ (Volts) & 1.330 & 1.592 & 1.755 \\
\hline
\end{tabular}

Tables 3-2 to 3-5 display the results of cyclic polarization tests on untreated and treated NiTi alloys, where it can be seen that the $E_{p}, E_{b}$ and $E_{b}-E_{r}$ for the latter were higher. Among all surface treated NiTi alloys, NiTi-EP exhibited the highest resistance to pitting corrosion $\left(\mathrm{E}_{\mathrm{b}}-\mathrm{E}_{\mathrm{r}}=1.581 \mathrm{~V}\right)$. However, NiTi-W\&P exhibited the highest resistance to crevice corrosion $\left(\mathrm{E}_{\mathrm{p}}=1.097 \mathrm{~V}\right)$ and NiTi-untreated had the least resistance to crevice $\operatorname{corrosion}\left(\mathrm{E}_{\mathrm{p}}=1.002 \mathrm{~V}\right)$. 
The results of cyclic polarization tests on untreated and treated NiTi10Cr alloys are displayed in Tables 3-6 to 3-9. In this case, a stable oxide film is formed during the forward scan, from $E_{\mathrm{r}}$ to $\mathrm{E}_{\mathrm{v}}$ (Figure 3-2(b) and Figure 3-5). This type of cyclic polarization behavior is known to resist localized corrosion (Rahul Bhola 2009) (Silverman 1998). Among all the NiTi10Cr alloys, NiTi10Cu-MEP had the highest vertex potential followed by NiTi10Cr-EP, NiTi10Cr-W\&P and NiTi10Cr-untreated as shown in Figure 3-5. The significant increase in $E_{v}$ of the electropolished and magentoelectroploished NiTi10Cr may be attributed to the fact that both $\mathrm{Ti}$ and $\mathrm{Cr}$ are highly passivating elements. During these surface treatments, $\mathrm{Ni}$ is primarily stripped out of the lattice structure, which results in a highly passivating surface with relative surface enrichment of Ti and Cr atoms (G. S. S. Trigwell 2007). The low $\mathrm{E}_{\mathrm{v}}$ recorded for the NiTi10Cr-untreated was attributed to the tendency of $\mathrm{Cr}$ atoms to replace $\mathrm{Ni}$ in the crystal lattice (J. B. M. Frotscher 2007). The formation of the $\mathrm{TiO}_{2}$ and $\mathrm{Cr}_{2} \mathrm{O}_{3}$ as a result of MEP are further described in Chapter 5 in XPS montage plots and depth profile.

Tables 3-10 to 3-13 list the results of cyclic polarization tests on untreated and treated NiTi10Cu alloys, where it can be seen that the $\mathrm{E}_{\mathrm{p}}, \mathrm{E}_{\mathrm{b}}$ and $\mathrm{E}_{\mathrm{b}}-\mathrm{E}_{\mathrm{r}}$ for the latter were higher. Among all the surface treatments on NiTi10Cu alloys, NiTi10Cu-W\&P had the highest resistance to pitting $\left(\mathrm{E}_{\mathrm{b}}-\mathrm{E}_{\mathrm{r}}=1.467 \mathrm{~V}\right)$ and crevice corrosion $\left(\mathrm{E}_{\mathrm{p}}=1.126 \mathrm{~V}\right)$ followed by NiTi10Cu-MEP, NiTi10Cu-EP and NiTi10Cu-untreated. High corrosion resistance of NiTi10Cu-W\&P is due to the fact that stable and uniform titanium oxide film is formed during passivation. It is further described in Chapter 5.

The results of cyclic polarization tests on untreated and treated NiTi10Ta alloys are shown in Table 3-14 to 3-17, where it can be seen that the $E_{p}, E_{b}$ and $E_{b}-E_{r}$ for the 
latter were higher. Among all the surface treated NiTi10Ta alloys, NiTi10Ta-W\&P possessed the highest resistance to pitting $\left(\mathrm{E}_{\mathrm{b}}-\mathrm{E}_{\mathrm{r}}=1.642 \mathrm{~V}\right)$ followed by NiTi10Ta-EP, NiTi10Ta-MEP and NiTi10Ta-untreated. However, NiTi10Ta-MEP possessed the highest resistance to crevice corrosion $\left(\mathrm{E}_{\mathrm{p}}=1.145 \mathrm{~V}\right)$ followed by NiTi10Ta-W\&P, NiTi10Ta-EP and NiTi10Ta-untreated.

Tables 3-18 to 3-20 display the corrosion data for NiTi5Ta-untreated, NiTi5Cruntreated and NiTi5Cu-untreated alloys. The resistance to pitting corrosion for NiTi5Ta $\left(E_{b}-E_{r}=1.635 V\right)$ and NiTi5Cu $\left(E_{b}-E_{r}=1.585 V\right)$ was higher than NiTi-untreated $\left(E_{b}-E_{r}\right.$ $=1.574 \mathrm{~V})$. Similarly, the resistance to crevice corrosion for NiTi5Ta $\left(\mathrm{E}_{\mathrm{p}}=1.043 \mathrm{~V}\right)$ and NiTi5Cu $\left(E_{p}=1.025 \mathrm{~V}\right)$ was higher than NiTi-untreated $\left(E_{p}=1.002 \mathrm{~V}\right)$.

Table 3-21 displays the corrosion data for Nitinol stents obtained from three different stent manufacturers. Stent 1 corrosion data was the average values obtained for two stents while stent 2 and stent 3 corrosion data were based on a single stent. The $E_{b}-E_{r}$ value varies from one stent to another. The resistance to pitting corrosion is highest for stent $3\left(E_{b}-E_{r}=1.755 V\right)$ while that of stent 3 is lowest $\left(E_{b}-E_{r}=1.330 V\right)$. The cyclic potentiodynamic curves of stents also exhibited minimal hysteresis loop area.

It should be noted that $E_{\mathrm{r}}$ values varied significantly for different samples of the same Nitinol alloy. This can be expected since the $\mathrm{E}_{\mathrm{r}}$ obtained depends on various factors such as surface morphology, surface energy and duration of immersion etc. These factors could be significantly different from one sample to another. Variation in $\mathrm{E}_{\mathrm{r}}$ values may also be attributed to the stochastic nature of corrosion test results 


\subsection{Metal Ion Leaching}

Inductively coupled plasma mass spectroscopy (ICP-MS) is highly sensitive and one of the most promising analytical techniques used for elemental analysis. ICP-MS is based on coupling together an inductively coupled plasma as a method of producing ions with a mass spectrometer as a method of separating and detecting the ions.

The ICP-MS (Perkin Elmer Sciex, model ELAN DRC-II) was used to determine the concentration of dissolved metal ions in PBS solution after each corrosion test. Five corrosion tests were conducted with each alloy. After each corrosion test, $5 \mathrm{ml}$ of PBS was collected and sent for ICP-MS analysis. The average concentration of metal ions in three replicates of each sample was determined by ICP-MS and standard deviation (SD) was calculated.

Table 3-22 displays the average concentrations of dissolved metal ions in the electrolyte after corrosion tests of binary NiTi alloys. A large amount of nickel (69.93 $\mu \mathrm{g} / \mathrm{L})$ was observed for NiTi-untreated alloy. However, surface treated samples did not show any metal ion leaching. This is attributed to the fact that electropolishing and passivation are known to be efficient for the elimination of defective surface layers. It should be noted that the enthalpy of formation of Ti oxide is higher than that of Ni oxide. Therefore, the preferential oxidation of Ti on Nitinol surface always occurs. Similarly, water boiling assists in atomic diffusion by providing the ions with an appropriate medium for release during the heat treatment. It also provides conditions for oxygen diffusion, which results in a more stable and stoichiometric oxide composition with reduced Ni concentration (0-1 at.\%) on the surface of the alloy (J. A. S. Shabalovskaya 
2008). Consequently, the $\mathrm{TiO}_{2}$ formed serves as a protective barrier, which restricts further Ni release (A. Michiardi 2005).

The ICP-MS data of NiTi10Cr alloys is displayed in Table 3-23. Although no nickel was observed in the PBS solution after corrosion test, it should be noted that relatively large amounts of chromium were observed. This was attributed to surface enrichment of the alloy by highly passivating element, chromium, which leached out during the corrosion tests.

The average concentration of dissolved metal ions in the electrolyte after corrosion tests of NiTi10Cu alloys is displayed in Table 3-24. A large amount of Ni $(65.74 \mu \mathrm{g} / \mathrm{L})$ was observed for NiTi10Cu-W\&P alloy while no other surface treated alloy showed any Ni release. However, among all the surface treated NiTi10Cu alloys, NiTi10Cu-MEP showed the highest $\mathrm{Cu}$ release $(38.35 \mu \mathrm{g} / \mathrm{L})$, followed by NiTi10CuW\&P, NiTi10Cu-EP and NiTi10Cu-untreated.

Table 3-25 displays the concentration of dissolved metal ions in the electrolyte for NiTi10Ta alloys. $\mathrm{TiO}_{2}$ and $\mathrm{Ta}_{2} \mathrm{O}_{5}$, which are strong passive layers, act as a protective barrier against metal ion leaching.

Oxide layers $\left(\mathrm{TiO}_{2}, \mathrm{Cr}_{2} \mathrm{O}_{3}\right.$ and $\left.\mathrm{Ta}_{2} \mathrm{O}_{5}\right)$ serve as strong barriers between the Nitinol alloy and the physiological environment. The main function of these layers is (1) to increase the stability of surface layers by protecting the bulk material form corrosion and (2) to create a physical and chemical barrier against nickel release. Depending on the chemical composition of the alloy, slight differences in metal ion release could be expected. The metal ion release is not necessarily related to the elemental composition of 
the alloy but is more dependent on compactness, stability, thickness and regeneration potential of the oxide film

The subsequent treatment of Nitinol alloys in boiling water produced better results in terms of metal ion leaching except NiTi10Cu-W\&P as compared with untreated surfaces, providing the ions an appropriate medium for release. Consequently, as the oxide is protective and acts as an ion barrier, there is no more release possible. It should be noted that an optimal time for boiling the alloy in water should be investigated in order to limit the amount of Ni released (A. Michiardi 2005).

Table 3-22 ICP-MS analysis for NiTi alloys

\begin{tabular}{|l|c|c|c|c|c|c|c|c|}
\hline \multirow{2}{*}{ Element } & \multicolumn{2}{|c|}{ NiTi-untreated } & \multicolumn{2}{c|}{ NiTi-EP } & \multicolumn{2}{c|}{ NiTi-MEP } & \multicolumn{2}{c|}{ NiTi-W\&P } \\
\cline { 2 - 8 } & $\begin{array}{c}\text { Average } \\
\text { Conc. }(\mu \mathrm{g} / \mathrm{L})\end{array}$ & SD & $\begin{array}{l}\text { Average } \\
\text { Conc. }(\mu \mathrm{g} / \mathrm{L})\end{array}$ & SD & $\begin{array}{c}\text { Average } \\
\text { Conc. }(\mu \mathrm{g} / \mathrm{L})\end{array}$ & SD & $\begin{array}{c}\text { Average } \\
\text { Conc. }(\mu \mathrm{g} / \mathrm{L})\end{array}$ & SD \\
\hline $\mathbf{N i}$ & 69.93 & 0.35 & ND & & ND & & ND & \\
\hline Ti & ND & & ND & & ND & & ND & \\
\hline
\end{tabular}

ND: Not detected (below detection limit after background subtraction)

Table 3-23 ICP-MS analysis for NiTi10Cr alloys

\begin{tabular}{|l|c|c|c|c|c|c|c|c|}
\hline Element & \multicolumn{2}{|c|}{ NiTi10Cr-untreated } & \multicolumn{2}{c|}{ NiTi10Cr-EP } & \multicolumn{2}{c|}{ NiTi10Cr-MEP } & \multicolumn{2}{c|}{ NiTi10Cr-W\&P } \\
\hline & $\begin{array}{c}\text { Average } \\
\text { Conc. }(\mu \mathrm{g} / \mathrm{L})\end{array}$ & SD & $\begin{array}{l}\text { Average } \\
\text { Conc. }(\mu \mathrm{g} / \mathrm{L})\end{array}$ & SD & $\begin{array}{c}\text { Average } \\
\text { Conc. }(\mu \mathrm{g} / \mathrm{L})\end{array}$ & SD & $\begin{array}{c}\text { Average } \\
\text { Conc. }(\mu \mathrm{g} / \mathrm{L})\end{array}$ & SD \\
\hline $\mathbf{N i}$ & ND & & ND & & ND & & ND & \\
\hline $\mathbf{T i}$ & ND & & ND & & ND & & ND & \\
\hline $\mathbf{C r}$ & 300 & 23 & 354 & 0.3 & 1492 & 6 & 513 & 1.3 \\
\hline
\end{tabular}

ND: Not detected (below detection limit after background subtraction) 
Table 3-24 ICP-MS analysis for NiTi10Cu alloys

\begin{tabular}{|l|c|c|c|c|c|c|c|c|}
\hline Element & \multicolumn{2}{|l|}{ NiTi10Cu-untreated } & \multicolumn{2}{l|}{ NiTi10Cu-EP } & \multicolumn{2}{c|}{ NiTi10Cu-MEP } & \multicolumn{2}{c|}{ NiTi10Cu-W\&P } \\
\hline & $\begin{array}{c}\text { Average } \\
\text { Conc. }(\mu \mathrm{g} / \mathrm{L})\end{array}$ & SD & $\begin{array}{l}\text { Average } \\
\text { Conc. }(\mu \mathrm{g} / \mathrm{L})\end{array}$ & SD & $\begin{array}{c}\text { Average } \\
\text { Conc. }(\mu \mathrm{g} / \mathrm{L})\end{array}$ & SD & $\begin{array}{c}\text { Average } \\
\text { Conc. }(\mu \mathrm{g} / \mathrm{L})\end{array}$ & SD \\
\hline Ni & ND & & ND & & ND & & 65.74 & 0.1 \\
\hline Ti & 1.63 & 0.17 & ND & & ND & & ND & \\
\hline Cu & 13.77 & 0.33 & 28.47 & 0.1 & 38.35 & 0.5 & 30.87 & 0.1 \\
\hline
\end{tabular}

ND: Not detected (below detection limit after background subtraction)

Table 3-25 ICP-MS analysis for NiTi10Ta alloys

\begin{tabular}{|l|c|c|c|c|c|c|c|c|}
\hline Element & \multicolumn{2}{|c|}{ NiTi10Ta-untreated } & \multicolumn{2}{c|}{ NiTi10Ta-EP } & \multicolumn{2}{c|}{ NiTi10Ta-MEP } & \multicolumn{2}{c|}{ NiTi10Ta-W\&P } \\
\hline & $\begin{array}{c}\text { Average } \\
\text { Conc. }(\mu \mathrm{g} / \mathrm{L})\end{array}$ & SD & $\begin{array}{l}\text { Average } \\
\text { Conc. }(\mu \mathrm{g} / \mathrm{L})\end{array}$ & SD & $\begin{array}{c}\text { Average } \\
\text { Conc. }(\mu \mathrm{g} / \mathrm{L})\end{array}$ & SD & $\begin{array}{c}\text { Average } \\
\text { Conc. }(\mu \mathrm{g} / \mathrm{L})\end{array}$ & SD \\
\hline $\mathbf{N i}$ & ND & & ND & & ND & & ND & \\
\hline Ti & 10.92 & 0.59 & ND & & ND & & ND & \\
\hline Ta & ND & & ND & & ND & & ND & \\
\hline
\end{tabular}

ND: Not detected (below detection limit after background subtraction)

Table 3-26 ICP-MS analysis for NiTi5Ta, NiTi5Cu and NiTi5Cr alloys

\begin{tabular}{|l|c|c|l|l|l|l|l|c|}
\hline Element & \multicolumn{2}{|c|}{ NiTi5Ta-untreated } & Element & \multicolumn{2}{l|}{ NiTi5Cu-untreated } & \multicolumn{2}{l|}{ Element } & \multicolumn{2}{l|}{ NiTi5Cr-untreated } \\
& $\begin{array}{c}\text { Average } \\
\text { Conc. }(\mu \mathrm{g} / \mathrm{L})\end{array}$ & SD & & $\begin{array}{l}\text { Average } \\
\text { Conc. }(\mu \mathrm{g} / \mathrm{L})\end{array}$ & SD & & $\begin{array}{c}\text { Average } \\
\text { Conc. }(\mu \mathrm{g} / \mathrm{L})\end{array}$ & SD \\
\hline $\mathbf{N i}$ & 57.90 & 0.3 & $\mathbf{N i}$ & 135 & 0.2 & $\mathbf{N i}$ & 2.43 & 0.13 \\
\hline $\mathbf{T i}$ & 11.75 & 0.2 & $\mathbf{T i}$ & 4.01 & 0.18 & $\mathbf{T i}$ & 2.17 & 0.04 \\
\hline Ta & ND & 23 & $\mathbf{C u}$ & 47.9 & 0.04 & $\mathbf{C r}$ & 389 & 0.4 \\
\hline
\end{tabular}

ND: Not detected (below detection limit after background subtraction) 


\section{CHAPTER 4}

\section{BIOCOMPATIBILITY ASSESSMENT OF NITINOL ALLOYS}

\subsection{Immersion Tests}

The cell culture media was prepared by adding 10\% Fetal Bovine Serum (FBS), $1 \%$ penicillin, $0.1 \mathrm{mg} / \mathrm{ml}$ heparin and $0.03 \mathrm{mg} / \mathrm{ml}$ Endothelial Cell Growth Supplement (ECGS) into F-12K medium. The composition of F-12K medium is listed in Table 4-1. Nitinol alloys (NiTi, NiTi10Cr, NiTi10Cu, NiTi10Ta) were immersed in six-well cell culture plate in $15 \mathrm{ml}$ of cell culture media (Static Immersion). The cell culture plate was placed in an incubator at $37{ }^{\circ} \mathrm{C}$ having $5 \% \mathrm{CO}_{2}$. Similarly, the second set of Nitinol alloys (NiTi, NiTi10Cr, NiTi10Cu, NiTi10Ta) were also immersed in $15 \mathrm{ml}$ cell culture media in polypropylene centrifuge bottles. Each sample was placed at the bottom of the bottle, which was tightly closed before placement on a shaking plate (Dynamic Immersion). Bottles along with the shaking plate were placed in the incubator at $37{ }^{\circ} \mathrm{C}$ having 5\% $\mathrm{CO}_{2}$. After every $1,3,7,15,28$ and 42 days, cell culture media was collected (from static and dynamic immersion tests) and the Nitinol alloys were placed in fresh cell culture media. The collected cell culture media was used for the determination of dissolved metal ions content and also for the cytotoxicity measurement using sulforhodamine B (SRB) assays. 
Table 4-1 Composition of F-12K medium

\begin{tabular}{|c|c|c|c|c|c|c|c|c|c|}
\hline Inorganic Salts & g/Liter & Amino Acids & g/Liter & $\begin{array}{l}\text { Amino } \\
\text { Acids }\end{array}$ & g/Liter & Vitamins & g/Liter & Other & g/Liter \\
\hline $\mathrm{CaCl}_{2} \cdot 2 \mathrm{H}_{2} \mathrm{O}$ & 0.13524 & $\begin{array}{l}\text { L-Arginine (free } \\
\text { base) }\end{array}$ & 0.42140 & $\begin{array}{l}\text { L- } \\
\text { Phenylalanine }\end{array}$ & 0.00991 & D-Biotin & 0.0000733 & D-Glucose & 1.26000 \\
\hline $\mathrm{CuSO}_{4} \cdot 5 \mathrm{H}_{2} \mathrm{O}$ & 0.000002 & L-Alanine & 0.01782 & L-Proline & 0.06906 & Choline Chloride & 0.01396 & $\begin{array}{l}\text { Phenol Red, } \\
\text { Sodium Salt }\end{array}$ & 0.00332 \\
\hline $\mathrm{FeSO}_{4} \cdot 7 \mathrm{H} 2 \mathrm{O}$ & 0.000834 & L-Asparagine $\cdot \mathrm{H}_{2} \mathrm{O}$ & 0.03020 & L-Serine & 0.02102 & Folic Acid & 0.00132 & $\begin{array}{l}\text { Sodium } \\
\text { Pyruvate }\end{array}$ & 0.22000 \\
\hline $\begin{array}{l}\mathrm{MgSO}_{4} \\
\text { (anhydrous) }\end{array}$ & 0.19264 & $\begin{array}{l}\text { L- } \\
\text { Cysteine } \cdot \mathrm{HCl} \cdot \mathrm{H}_{2} \mathrm{O}\end{array}$ & 0.07024 & L-Tryptophan & 0.00408 & Myo-Inositol & 0.01802 & & \\
\hline $\mathrm{KCl}$ & 0.28329 & L-Glutamic Acid & 0.02942 & $\begin{array}{l}\text { L-Tyrosine } \\
\text { (free base) }\end{array}$ & 0.01087 & Nicotinamide & 0.0000366 & & \\
\hline $\begin{array}{l}\mathrm{KH}_{2} \mathrm{PO}_{4} \\
\text { (anhydrous) }\end{array}$ & 0.05852 & L-Glutamine & 0.29220 & L-Valine & 0.02342 & $\begin{array}{l}\text { D-Pantothenic } \\
\text { Acid }\end{array}$ & 0.000477 & & \\
\hline $\mathrm{NaHCO}_{3}$ & 1.50000 & Glycine & 0.01501 & & & Putrescine $\cdot 2 \mathrm{HCl}$ & 0.000322 & & \\
\hline $\mathrm{NaCl}$ & 7.59720 & L-Isoleucine & 0.00782 & & & Riboflavin & 0.0000376 & & \\
\hline \multirow[t]{3}{*}{$\mathrm{ZnSO}_{4} \cdot 7 \mathrm{H}_{2} \mathrm{O}$} & 0.000144 & L-Leucine & 0.02624 & & & Thiamine $\cdot \mathrm{HCl}$ & 0.000337 & & \\
\hline & & L-Lysine $\cdot \mathrm{HCl}$ & 0.07304 & & & Thymidine & 0.000727 & & \\
\hline & & L-Methionine & 0.00895 & & & Vitamin B-12 & 0.001355 & & \\
\hline
\end{tabular}




\subsubsection{Metal Ion Concentration}

Metal ion concentration in the cell culture media was determined by ICPMS analysis. As the cell culture media contained amino acids, sugars, vitamins and lipoic acid, these samples were digested prior to ICPMS analysis, following the procedure described below:

First, $2 \mathrm{ml}$ of $\mathrm{HNO}_{3}$-optima grade, (diluted with distilled water in a 1:1 dilution) was added to $2 \mathrm{ml}$ of the each sample. Samples were covered with reflux caps and were heated in a hot block (open vessel digestion system) at $100{ }^{\circ} \mathrm{C}$ for 20 minutes. Later, samples were allowed to cool down and then $2 \mathrm{ml}$ of concentrated $\mathrm{HNO}_{3}$-optima grade was added. Samples were then heated to $100{ }^{\circ} \mathrm{C}$ for 30 minutes. They were heated again for an additional 30 minutes without allowing the sample to evaporate. Samples were taken out from the hot block and allowed to cool down. $1.0 \mathrm{ml}$ of $30 \% \mathrm{H}_{2} \mathrm{O}_{2}$-optima grade was added drop wise. An exothermic reaction took place for approximately 5 minutes. The samples were again placed in a hot block and $1.0 \mathrm{ml}$ of $30 \% \mathrm{H}_{2} \mathrm{O}_{2}$-optima grade was added to each sample. Samples were allowed to evaporate. Each sample was analyzed in 3 replicates by ICP-MS analysis. The average values of 3 replicates along with the standard deviation error bar are drawn as dotted lines while the cumulative release of metal ions over the period of time are shown as solid lines in Figures 4-1, 4-3, 4-5, 4-7, 4-9, 4-11, 4-13 and 4-15.

The rate of $\mathrm{Ni}$ release is higher during the first few days an asymptotically approaches some equilibrium concentration over time. The initial rate of Ni release for binary Nitinol under static condition was $12.43 \mu \mathrm{g} /$ day which decreases to $0.707 \mu \mathrm{g} /$ day after 42 days of immersion. Similarly, initial Ni release rate for binary Nitinol under 
dynamic condition was $23.47 \mu \mathrm{g} /$ day which decreases to $1.02 \mu \mathrm{g} /$ day after 42 days of immersion.

\subsubsection{Cytotoxicity Assays}

Cell culture media was prepared by adding $10 \%$ FBS, $1 \%$ penicillin, $0.1 \mathrm{mg} / \mathrm{ml}$ heparin and $0.03 \mathrm{mg} / \mathrm{ml}$ Endothelial Cell Growth Supplement (ECGS) into F-12K medium for culturing human umbilical vein endothelial cells (HUVEC) cells in a 96-well cell culture plate. $200 \mu \mathrm{L}$ of cell culture media were placed into each well at a concentration of $1 \times 10^{5}$ cells $/ \mathrm{ml}$ (approx. 20,000 cells/well). The culture plate was placed in an incubator at $37{ }^{\circ} \mathrm{C}$ that was maintained at $100 \%$ humidity and an atmosphere of $5 \%$ $\mathrm{CO}_{2}$. The HUVEC cells were allowed to grow for 24 hours. Cell culture media collected after a static and dynamic immersion test was added to the cells in order to conduct cytotoxicity analyses. Fresh cell culture media was also added to the cells for baseline comparison serve as a control. The cells were allowed to incubate for 24 hours, after which, SRB assay was performed. This assays measures total biomass (total numbers of cells) based on cellular protein content. Briefly, $50 \mu \mathrm{L}$ of trichloro acetic acid (TCA), which is used to fix the cells to the bottom of the plate, was added to each well. The well plate was held at room temperature for 30 minutes. The cell culture plates were then washed using deionized water and allowed to air dry. $100 \mu \mathrm{L}$ of SRB solution was placed into each well and allowed to sit for 30 minutes (SRB binds to protein). The plates were then rinsed with $1 \%$ acetic acid to remove unbound SRB and again left to air dry. $200 \mu \mathrm{L}$ of tris base solution were now added to each well to dissolve SRB bound to the protein. The Plates were then placed into a TECAN GENios multiplate reader for reading of the 
absorbance of the sulforhodamine. Each experiment was repeated 3 times and the results obtained were normalized with respect to cell grown in fresh cell culture media. Average values of 3 tests along with the standard deviation error bar are shown in Figures 4-2, 4-4, 4-6, 4-8, 4-10, 4-11, 4-14 and 4-16.

A comparative analysis was made of the cytotoxicity assemement of NiTi and three ternary alloys, NiTi10Cr, NiTi10Ta and NiTi10Cu in cell culture media. ICPMS analysis indicated the presence of dissolved metal ions in the cell culture media. The highest concentration of dissolved ions observed was $\mathrm{Ti}(34.62 \mu \mathrm{g} / \mathrm{L})$ followed by $\mathrm{Ni}$ $(23.47 \mu \mathrm{g} / \mathrm{L})$ for all of the alloys immersed in culture media. The binary Nitinol alloys released a large amount of $\mathrm{Ni}$ after 1 day of immersion in cell culture media under static $(12.43 \mu \mathrm{g} / \mathrm{L})$ and dynamic $(23.47 \mu \mathrm{g} / \mathrm{L})$ conditions as compared with ternary Nitinol alloys (varied between 1-10 $\mu \mathrm{g} / \mathrm{L}$ ). After 42 days of immersion in cell culture media, all Nitinol alloys revealed a significant decrease in the amount of $\mathrm{Ni}$ ions released from their surfaces (varied between $0-3 \mu \mathrm{g} / \mathrm{L}$ ) when compared with $\mathrm{Ni}$ ions released after 1 day of immersion.

NiTi10 $\mathrm{Cu}$ alloys showed higher $\mathrm{Cu}$ leaching under static conditions when compared with NiTi10Cu alloy under dynamic conditions. Similarly, NiTi10Cr alloys showed higher $\mathrm{Cr}$ leaching under static conditions when compared with NiTi10Cr alloy under dynamic conditions. NiTi10Ta alloys under static and dynamic conditions showed a very low amount of Ta leaching, which varied between 0 to $1.61 \mu \mathrm{g} / \mathrm{L}$. 


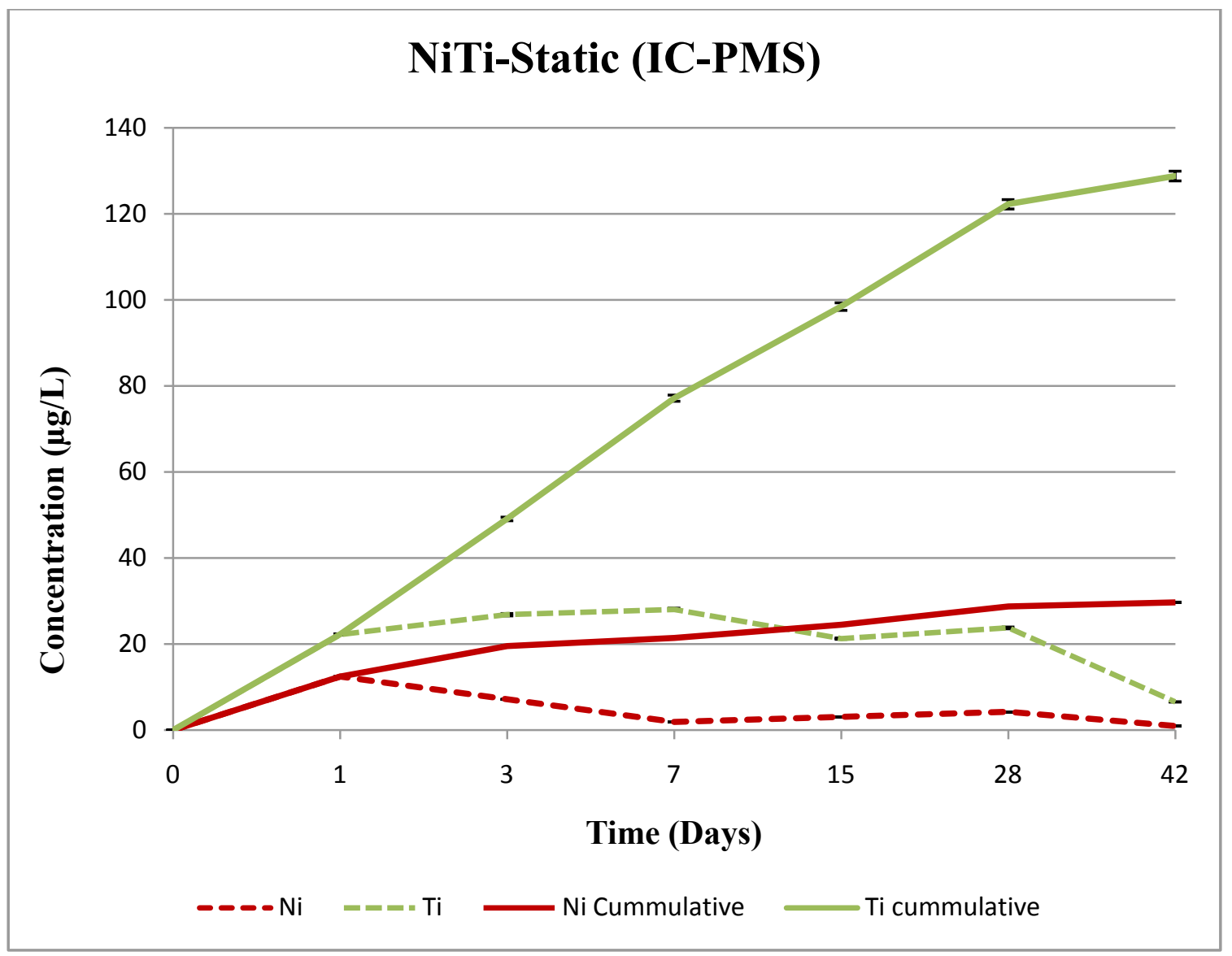

Figure 4-1 ICPMS data for NiTi alloy after static immersion

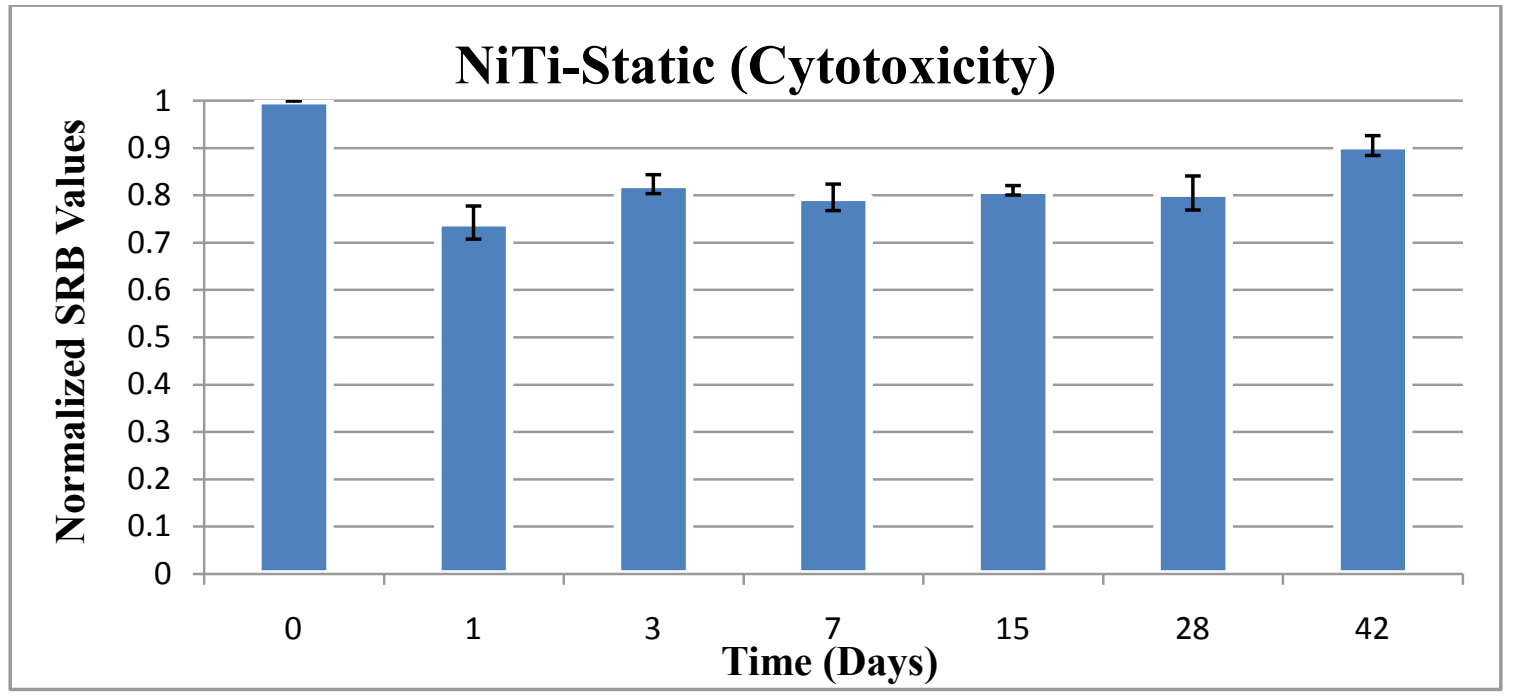

Figure 4-2 SRB data for NiTi alloy after static immersion (mean $\pm \mathrm{SD}, \mathrm{n}=3$ ) 


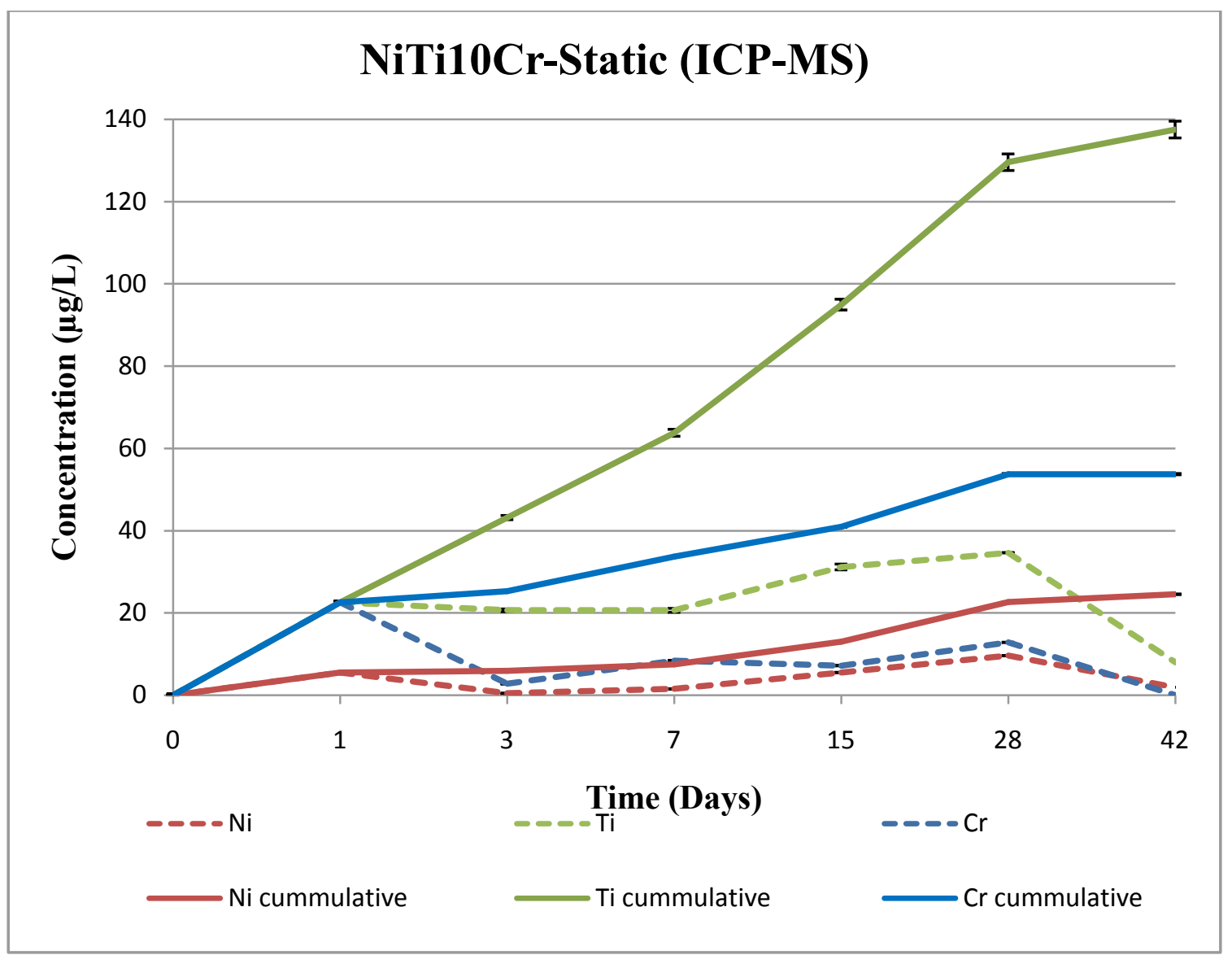

Figure 4-3 ICPMS data for NiTi10Cr alloy after static immersion

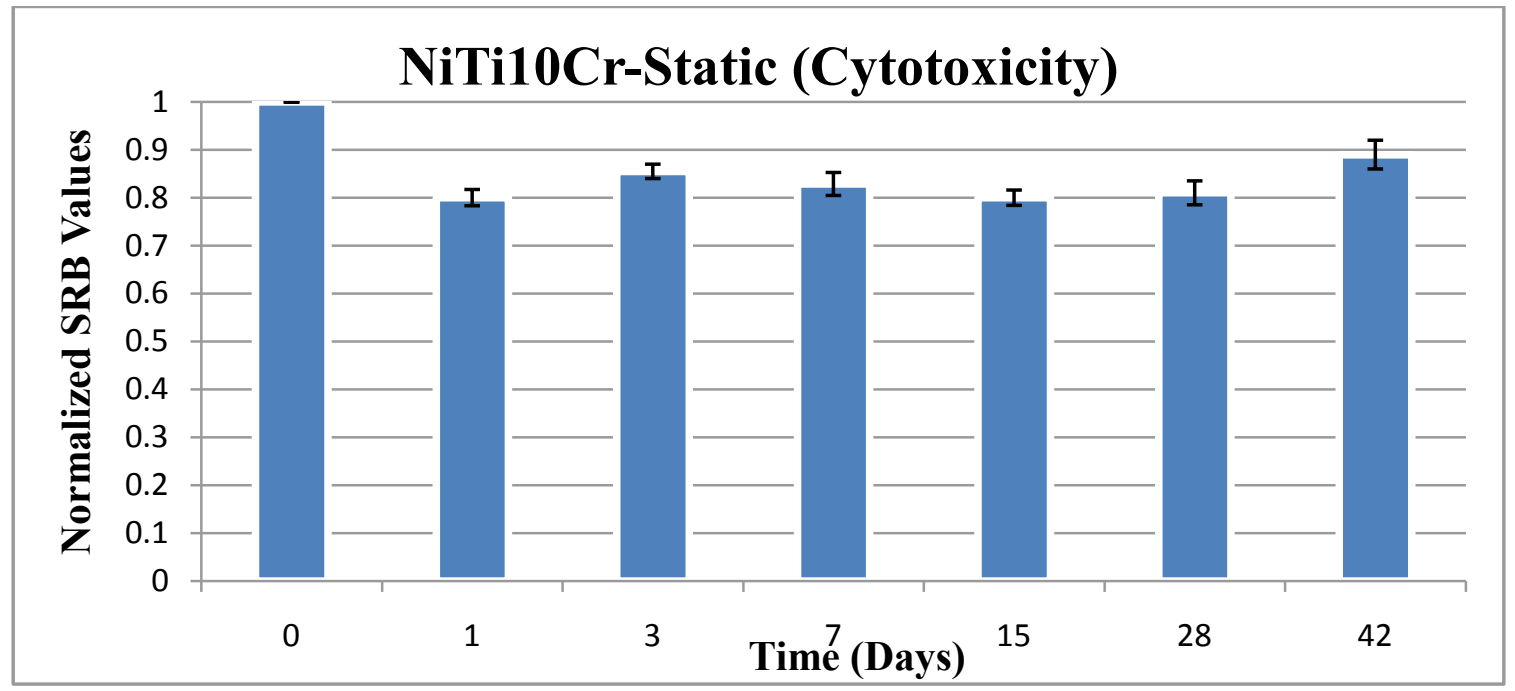

Figure 4-4 SRB data for NiTi10Cr alloy after static immersion (mean $\pm \mathrm{SD}, \mathrm{n}=3$ ) 


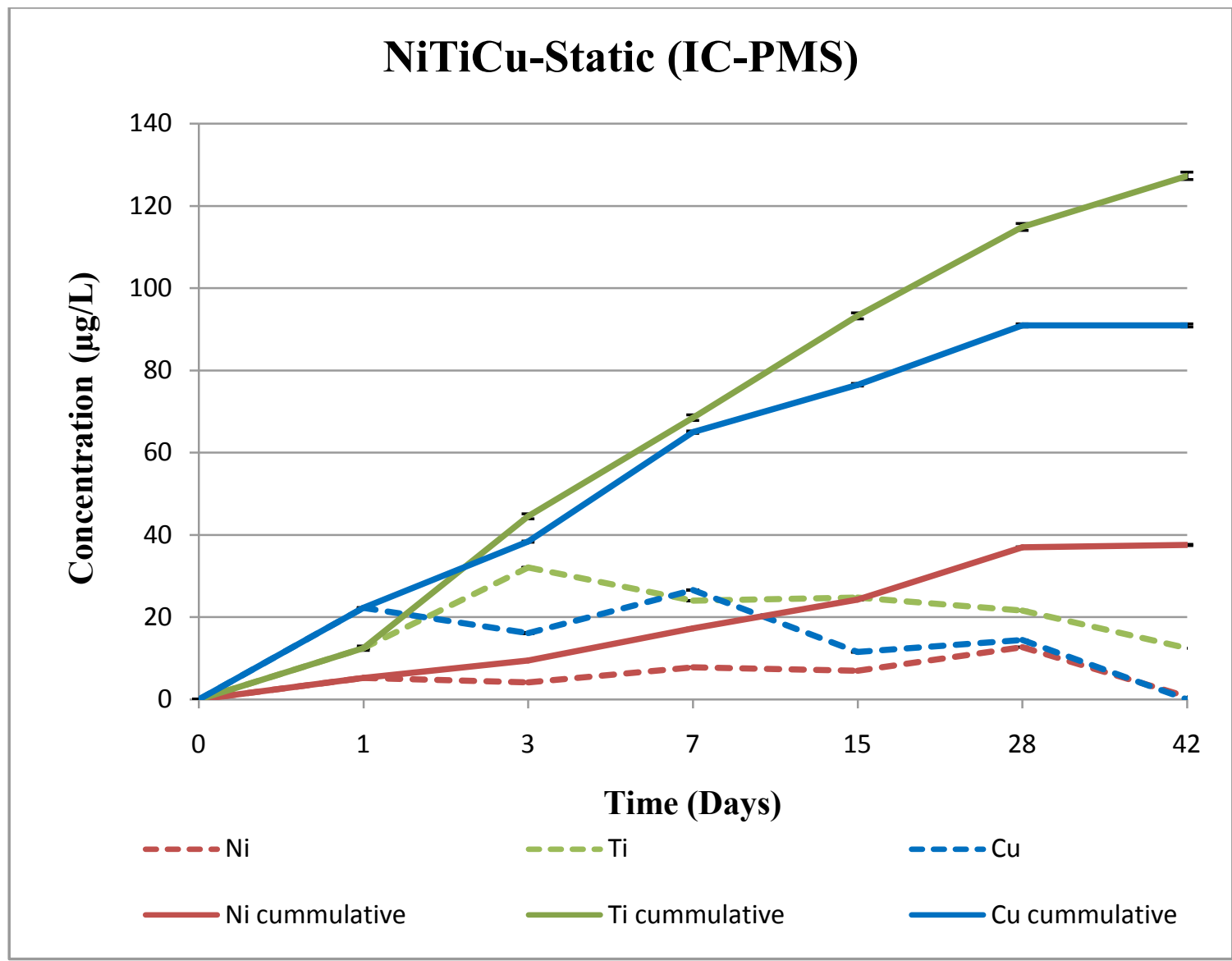

Figure 4-5 ICPMS data for NiTi10Cu alloy after static immersion

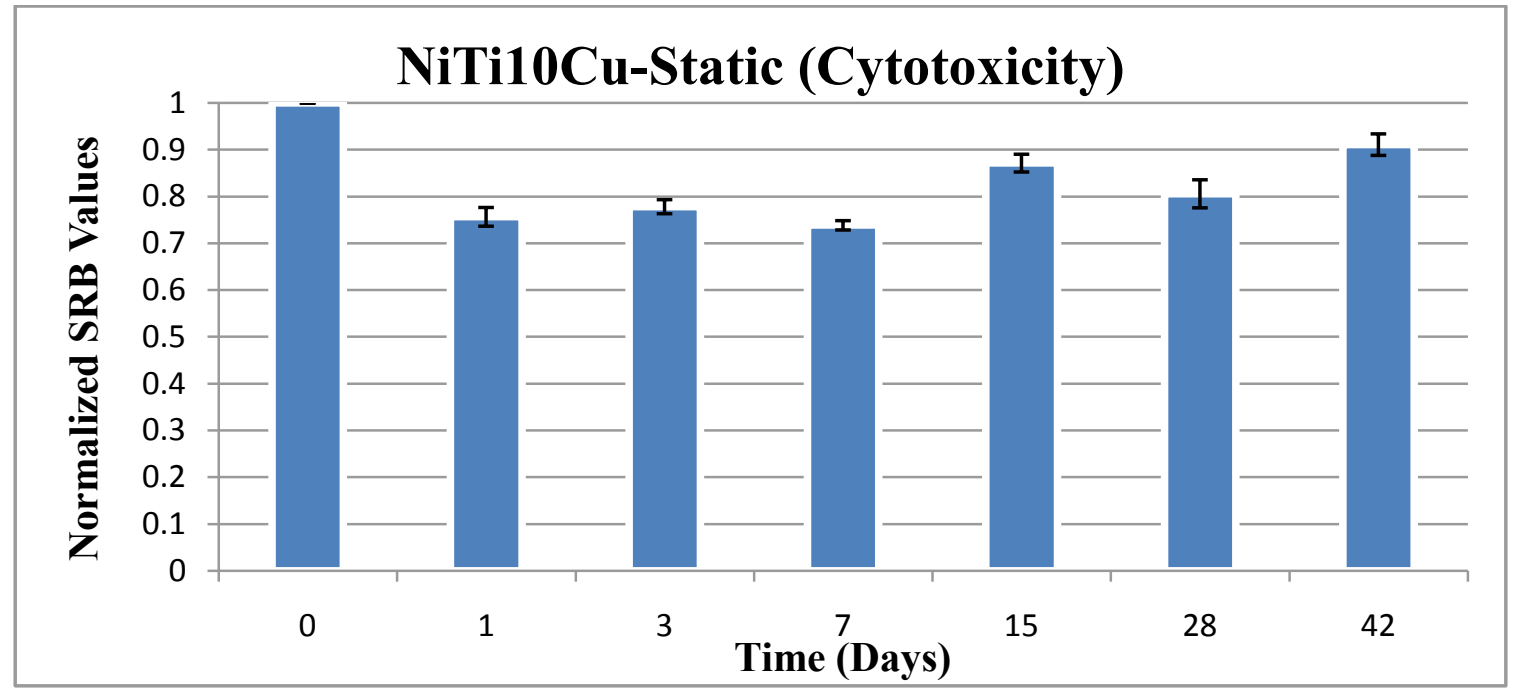

Figure 4-6 SRB data for NiTi10Cu alloy after static immersion (mean $\pm \mathrm{SD}, \mathrm{n}=3$ ) 


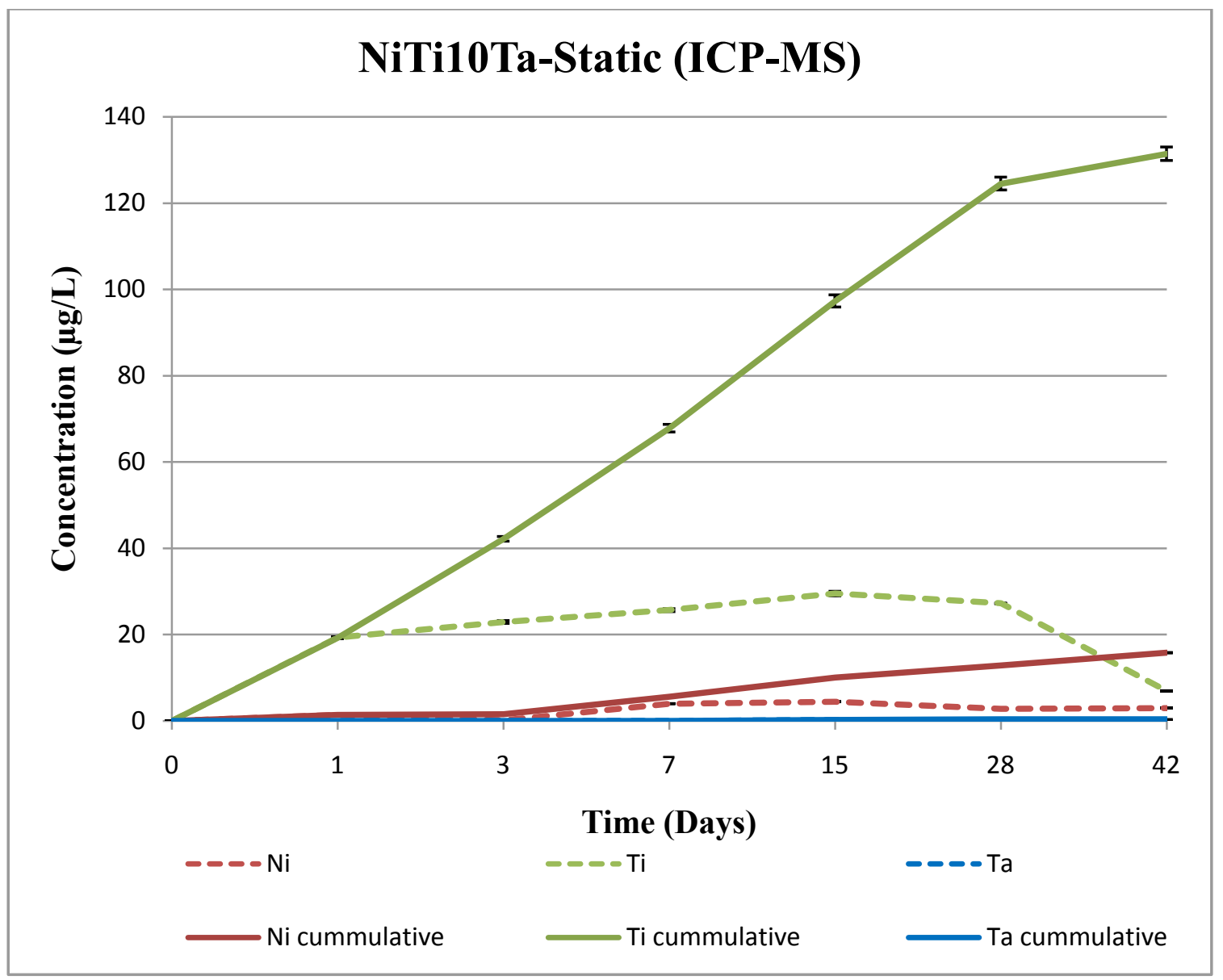

Figure 4-7 ICPMS data for NiTi10Ta alloy after static immersion

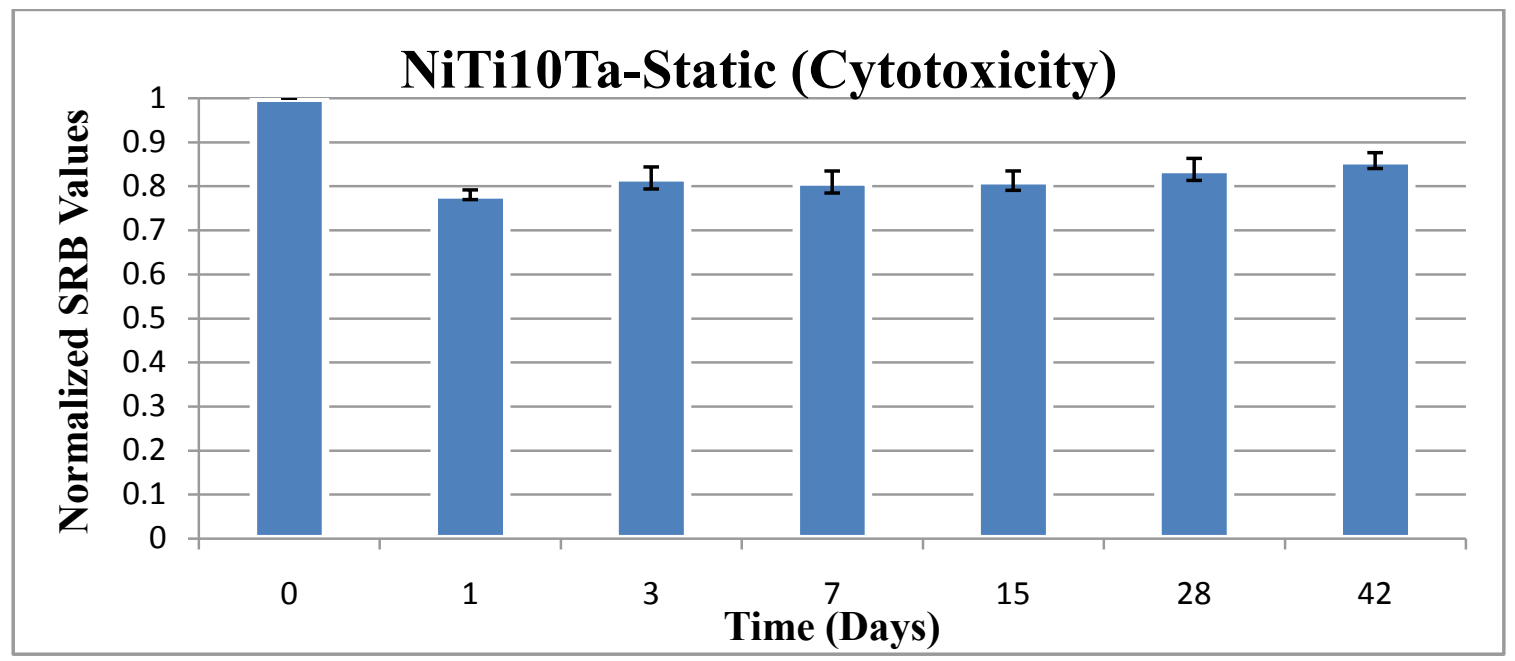

Figure 4-8 SRB data for NiTi10Ta alloy after static immersion (mean $\pm \mathrm{SD}, \mathrm{n}=3$ ) 


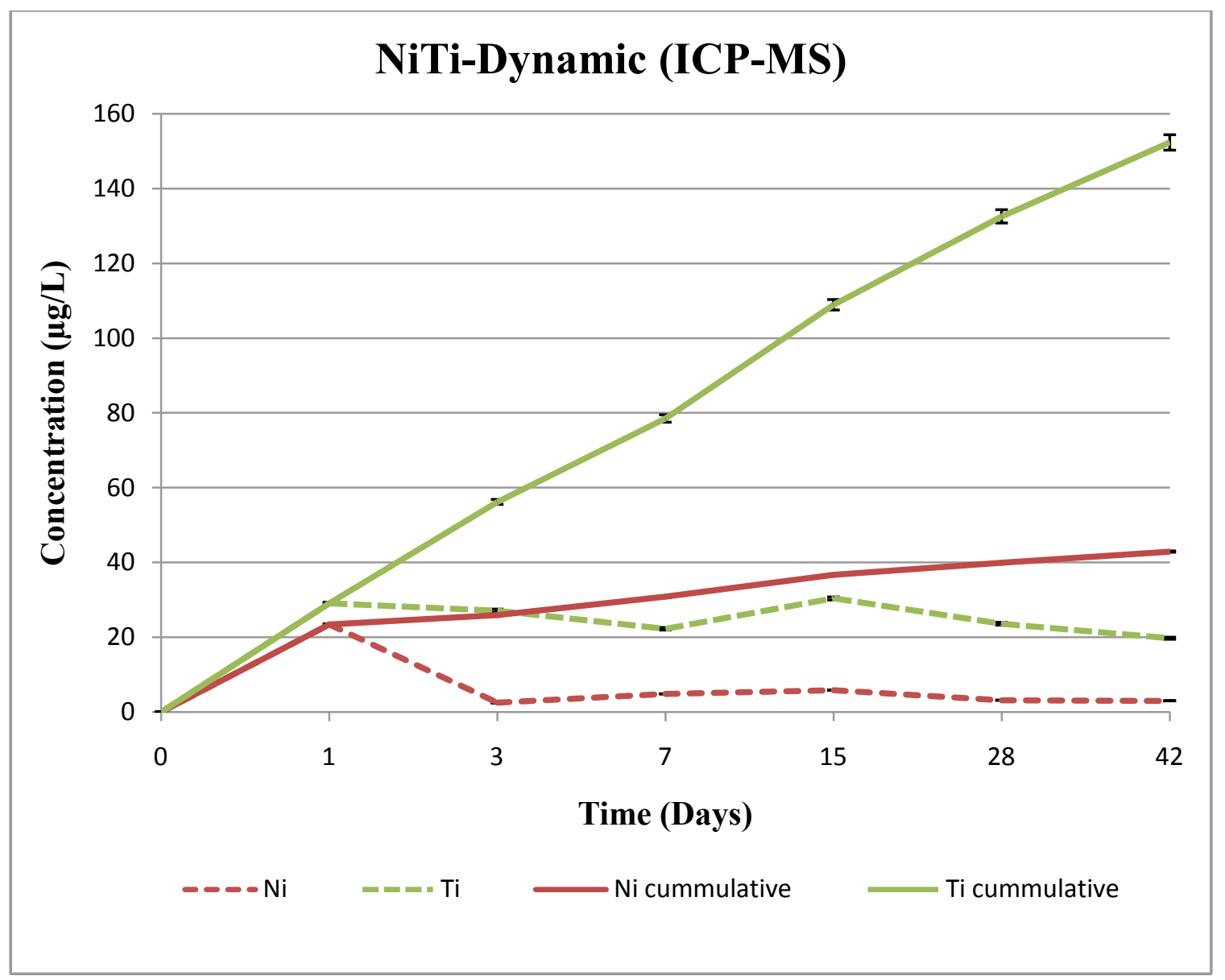

Figure 4-9 ICPMS data for NiTi alloy after dynamic immersion

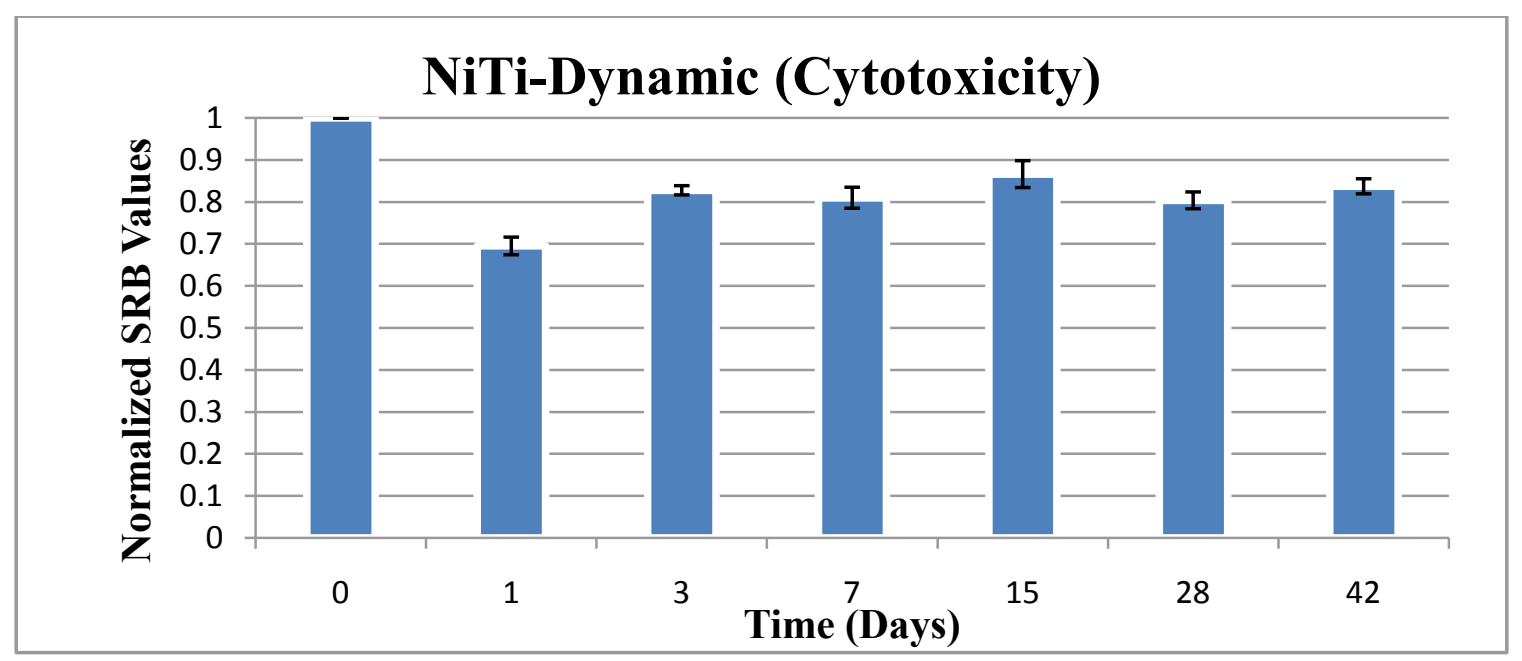

Figure 4-10 SRB data for NiTi alloy after dynamic immersion (mean $\pm \mathrm{SD}, \mathrm{n}=3$ ) 


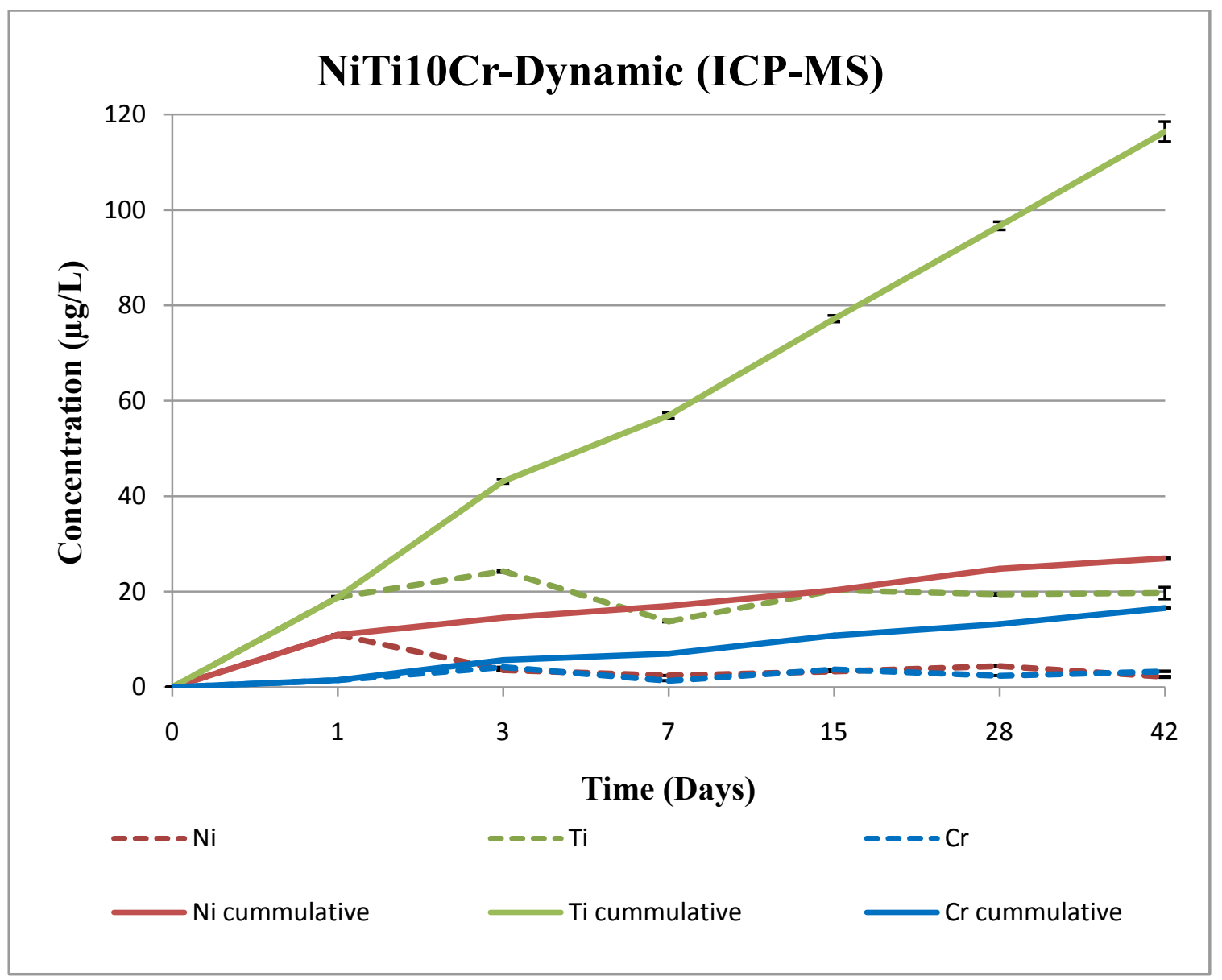

Figure 4-11 ICPMS data for NiTi10Cr alloy after dynamic immersion

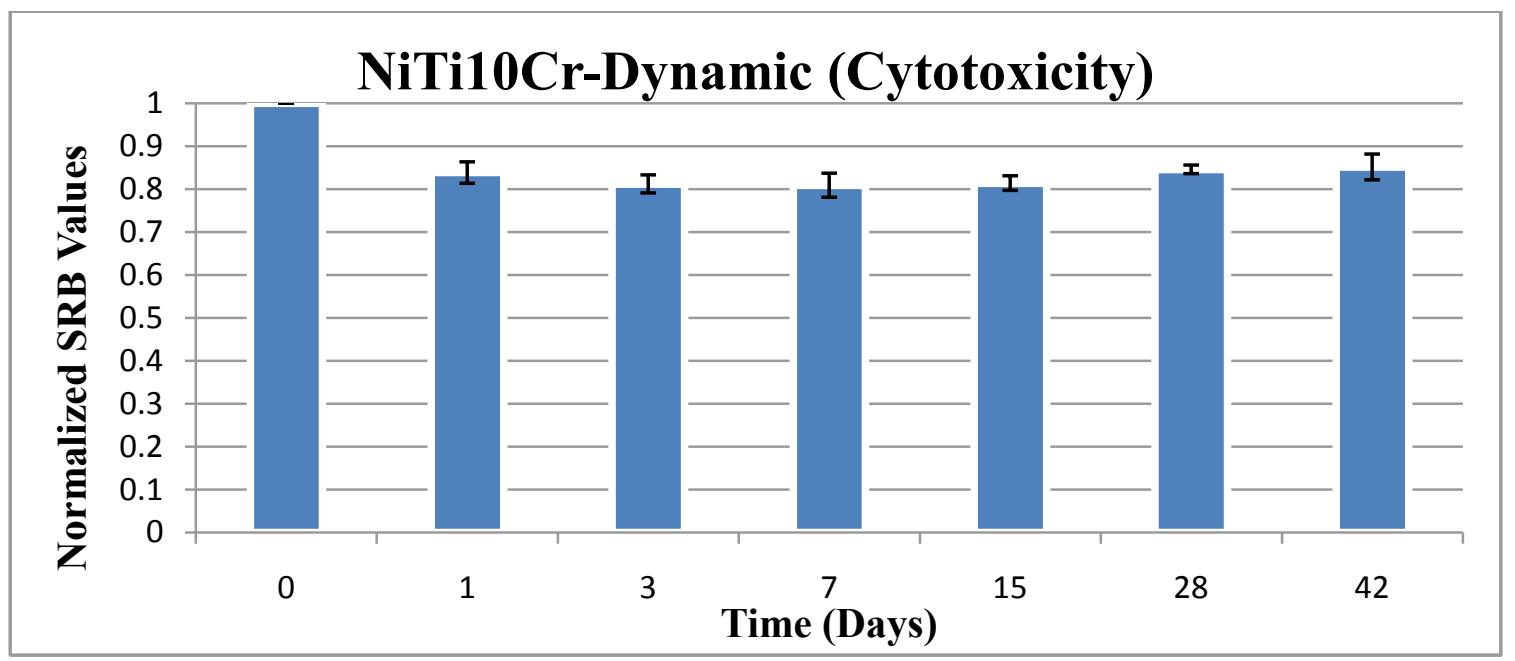

Figure 4-12 SRB data for NiTi10Cr alloy after dynamic immersion (mean $\pm \mathrm{SD}, \mathrm{n}=3$ ) 


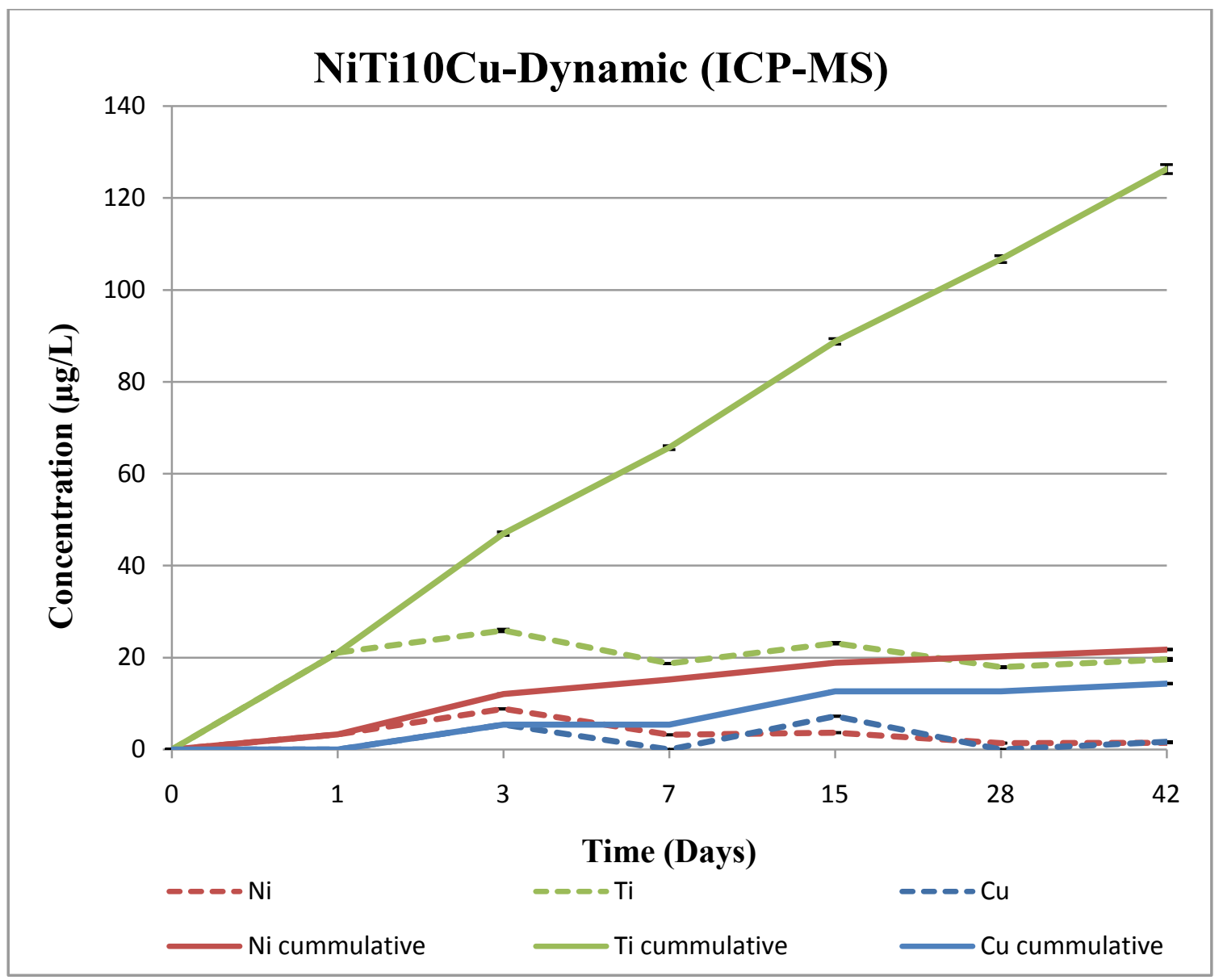

Figure 4-13 ICPMS data for NiTi10Cu alloy after dynamic immersion

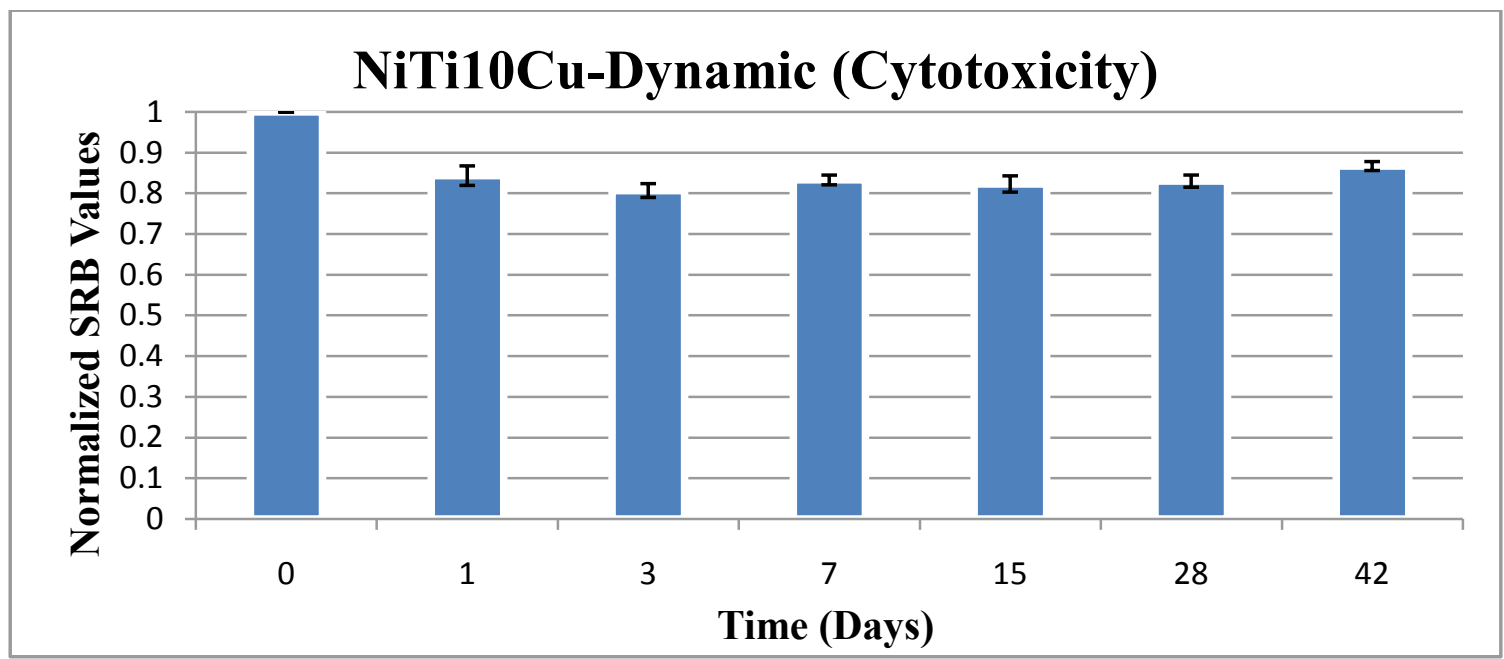

Figure 4-14 SRB data for NiTi10Cu alloy after dynamic immersion (mean $\pm \mathrm{SD}, \mathrm{n}=3$ ) 


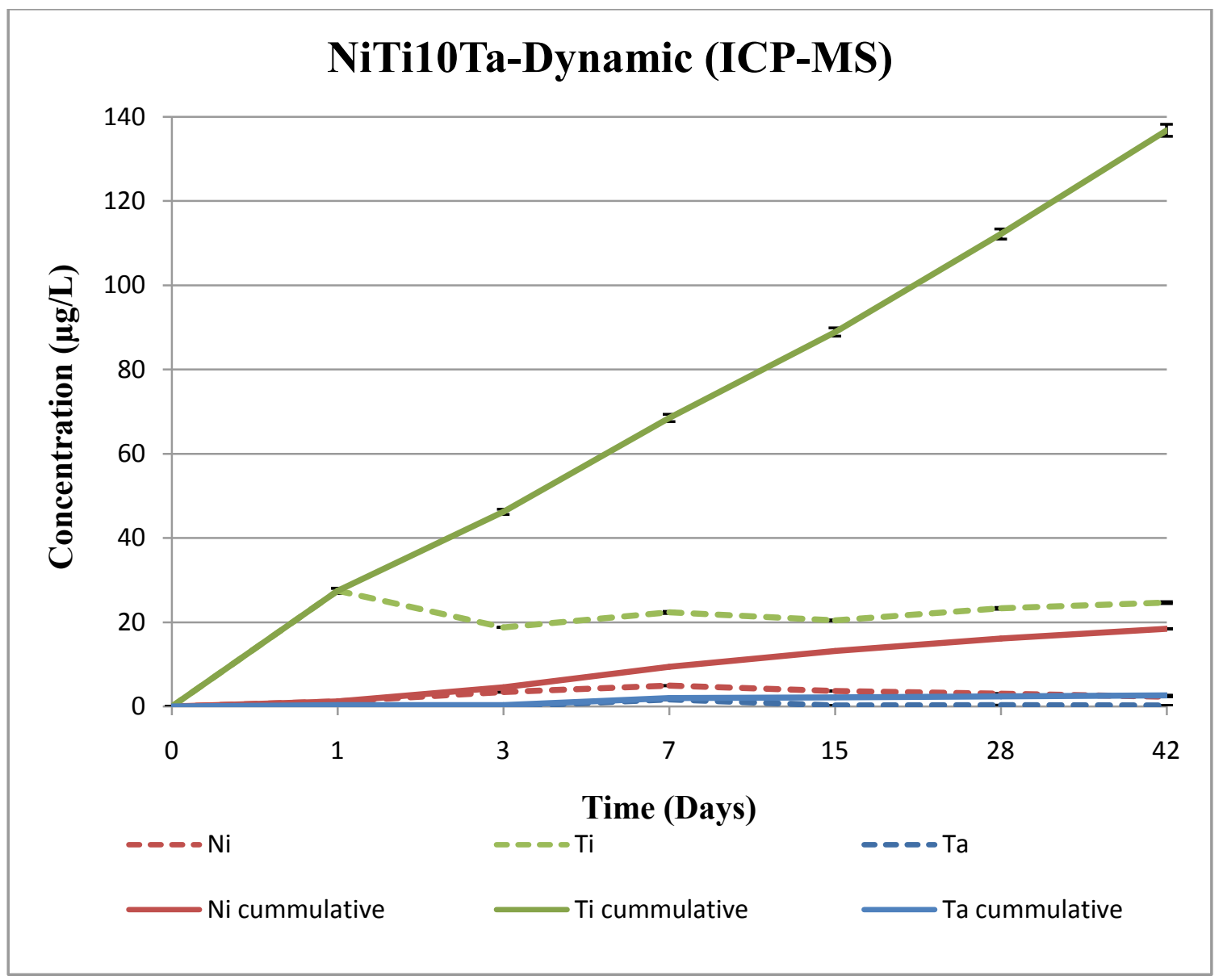

Figure 4-15 ICPMS data for NiTi10Ta alloy after dynamic immersion

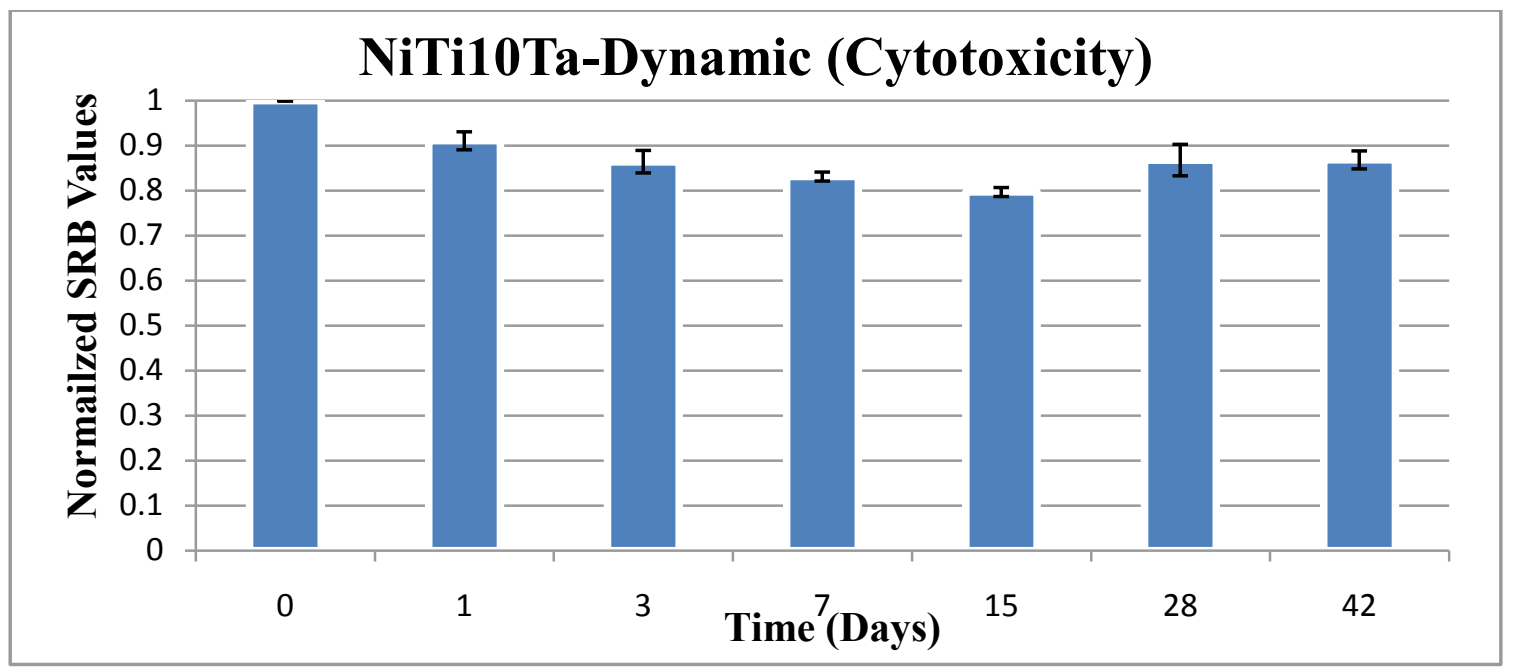

Figure 4-16 SRB data for NiTi10Ta alloy after dynamic immersion (mean $\pm \mathrm{SD}, \mathrm{n}=3$ ) 
All SRB assay results were normalized with respect to fresh media. The SRB assay results revealed that $\mathrm{Ni}$ and $\mathrm{Cu}$ ions exhibited greater toxicity on HUVEC cells than $\mathrm{Cr}$, Ti or Ta ions. In general, as the relative proportion of dissolved metal ion increased, the greater was the degree of toxicity. NiTi alloys showed low SRB values after 1 day of immersion under static (0.742) and dynamic (0.695) conditions. However, NiTi alloys showed higher SRB values after 42 days of immersion under static (0.933) and dynamic (0.836) conditions because of low concentration of metal ions released.

\subsection{Endothelial Cell Proliferation}

In-stent restenosis (ISR) is the major risk following stent implantation (Y. Shen 2009). During implantation the endothelium ruptures resulting in extensive proliferation of smooth muscle cells. (Arash Shahryari 2010). Endothelialization of vascular stents can prevent the proliferation and migration of smooth muscle cells (J. A. S. Shabalovskaya 2008) and significantly reduces the risk of ISR.

The growth of HUVEC cells on the surface of Nitinol alloys was assessed using the ISO 10993 protocols for biological evaluation of medical devices. This was accomplished by using an Olympus IX81 fluorescent microscope. HUVEC cells were maintained in accordance with the instructions provided by the commercial source (American Type Culture Collection, ATCC). The cells were first cultured in a $75 \mathrm{~cm}^{2}$ cell culture flask using F-12K as the medium. When confluency was achieved by the cells, they were trypsinized, centrifuged and re-suspended in culture media for cell counting and cell seeding. 
In order to assess the endothelial cell proliferation, Nitinol alloys $(1 \mathrm{~cm} \times 2 \mathrm{~mm})$ were placed into a 24 -well plate and seeded with $50 \times 10^{3}$ cells per well. Cell culture plates with Nitinol alloys were incubated for 72 hours at $37^{\circ} \mathrm{C}, 5 \% \mathrm{CO}_{2}$ in cell culture media. Later, cell culture media was removed and the Nitinol alloys were gently washed with DPBS. $2 \mathrm{ml}$ of Hoechst dye $(5 \mu \mathrm{M})$ and Mitotracker Red dye (100nM) were added into the wells. Hoechst dye was used to highlight the nuclei of the cells, while Mitotracker Red dye was used to highlight the mitochondria of the cells. The plates were again incubated for 20 minutes, after which the Nitinol alloys were washed 3 times with DPBS. Finally, the cells were fixed on the surface of the alloys with $10 \%$ formaldehyde and covered by glass slides. Highlighed cell nuclei are presented in Figures 4-17 to 4-20 while highlighted cell nuclei and cell mitochondria are presented in Figures 4-21 to 4-24.
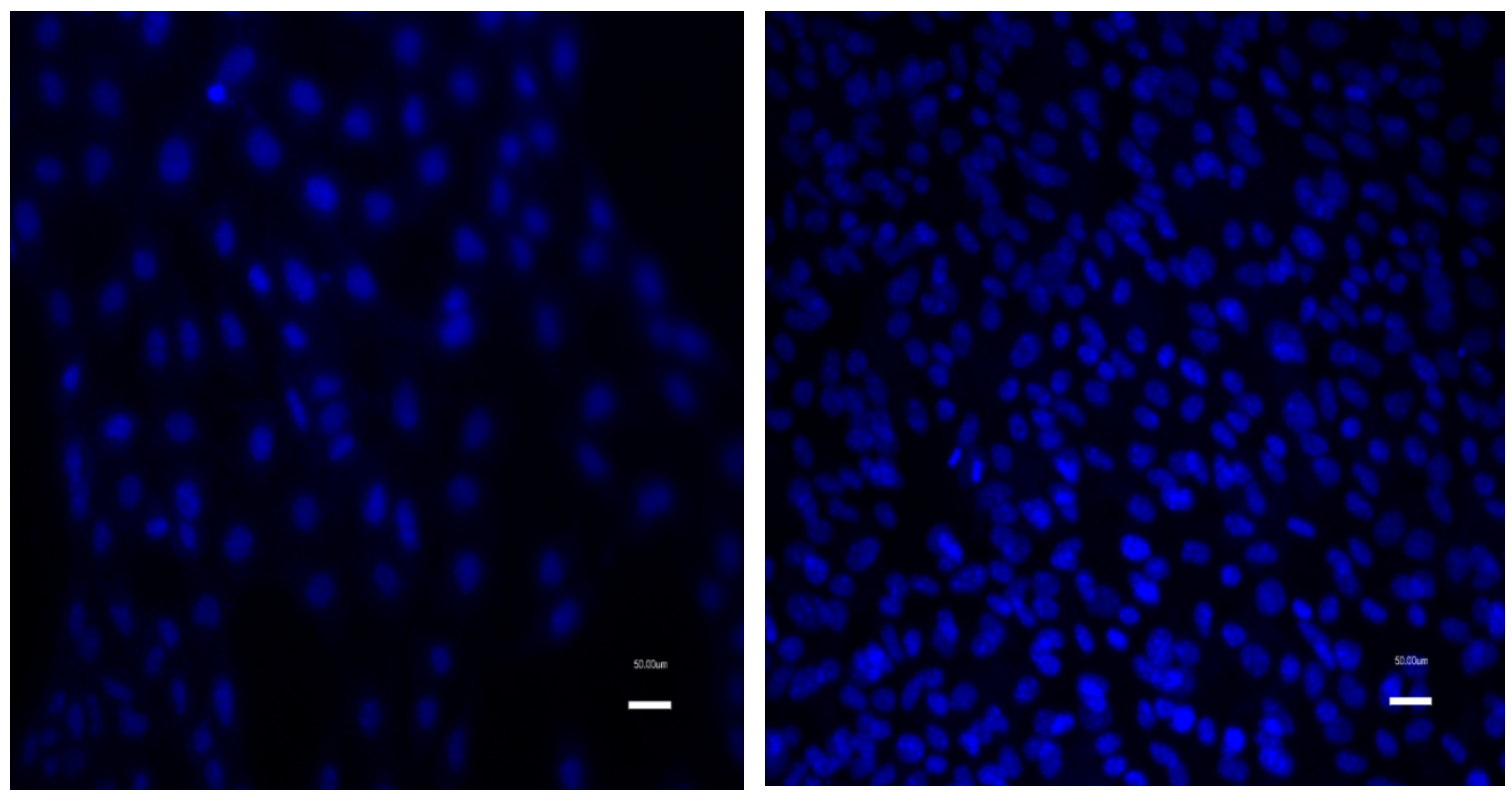

Figure 4-17 Highlighted nuclei on NiTi- Figure 4-18 Highlighted nuclei on untreated alloy NiTi10Cr-untreated alloy 

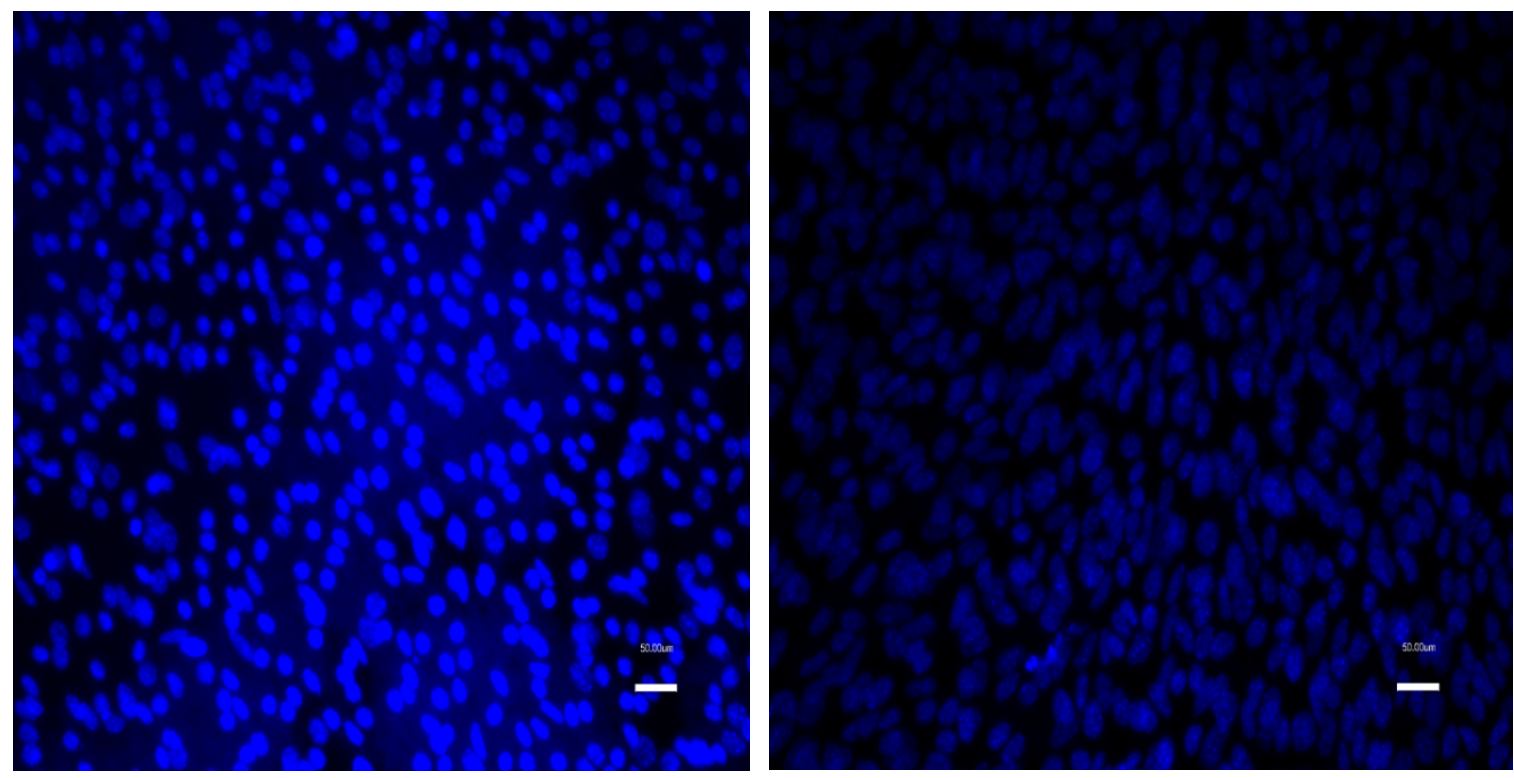

Figure 4-19 Highlighted nuclei on Figure 4-20 Highlighted nuclei on NiTi10Cu alloy NiTi10Ta-untreated alloy
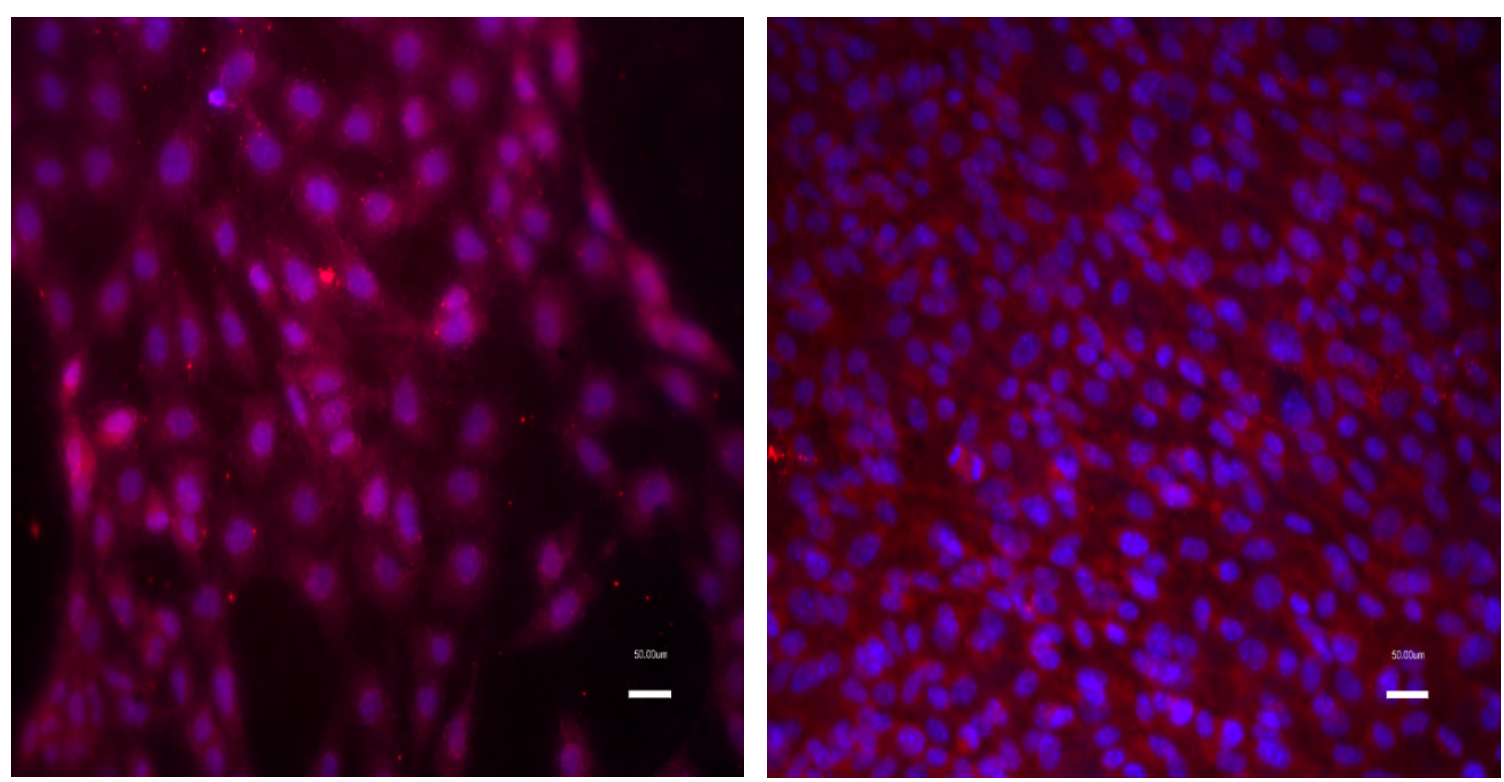

Figure 4-21 Highlighted nuclei and Figure 4-22 Highlighted nuclei and mitochondria on NiTi-untreated alloy mitochondria on NiTi10Cr-untreated alloy 

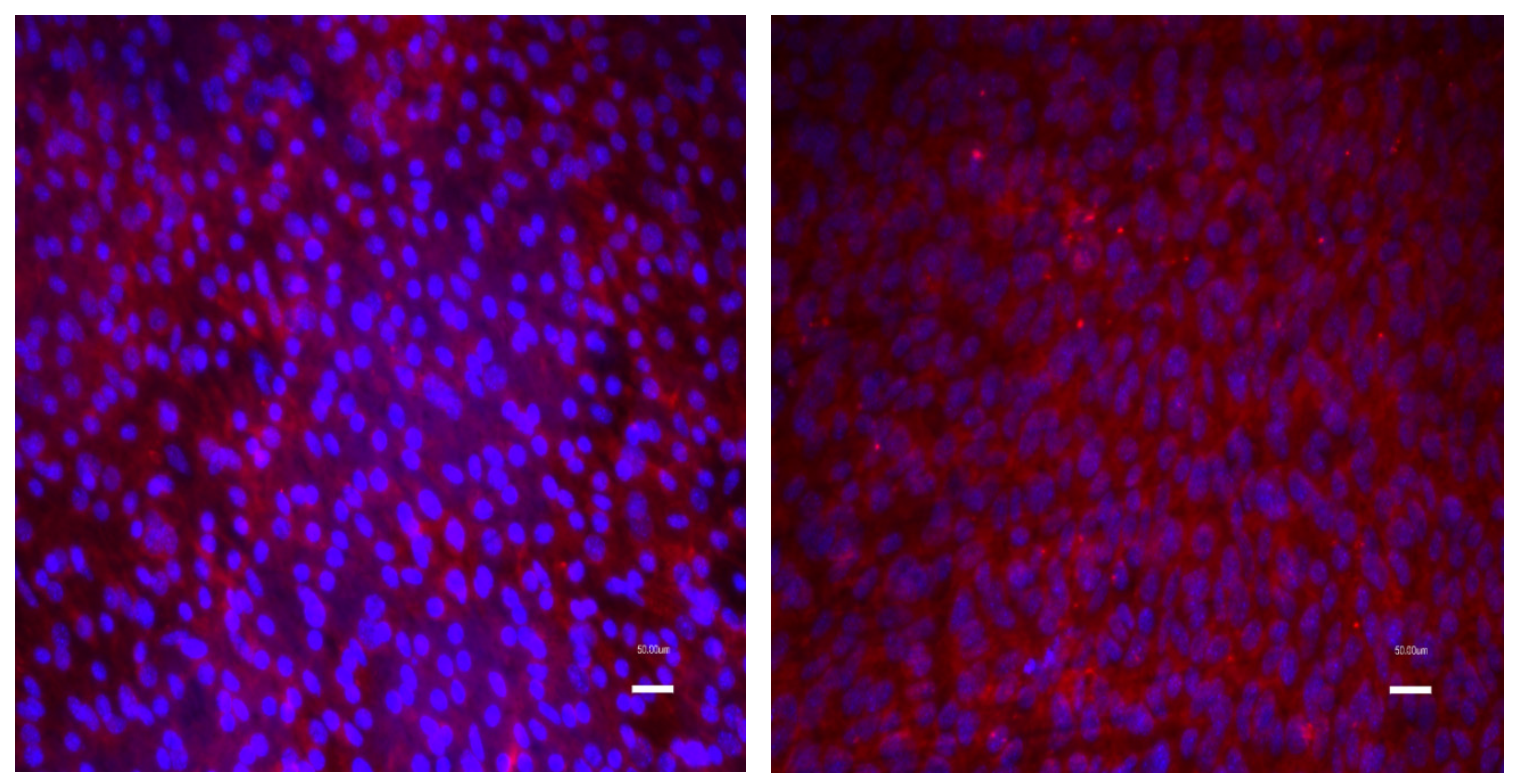

Figure 4-23 Highlighted nuclei and Figure 4-24 Highlighted nuclei and mitochondria on NiTi10Cu-untreated alloy mitochondria on NiTi10Ta-untreated alloy

A confluent monolayer of well defined cells exhibiting cell-to-cell contact was indicative of a non-cytotoxic response. The cells appeared to be healthy and the growth was prolific. It should be noted that the diameter of endothelial cell nuclei were larger in size on NiTi-untreated as compared with those on ternary Nitinol alloys.

\subsection{Exogenous Addition of Metal ions}

Cytotoxicity studies were also performed by conducting SRB assays in the presence of exogenously added metal ions. The stock solutions of metal salts $\left(\mathrm{NiCl}_{2} \cdot 6 \mathrm{H}_{2} \mathrm{O}, \mathrm{CrCl}_{3} \cdot 6.4 \mathrm{H}_{2} \mathrm{O}, \mathrm{TiCl}_{4}, \mathrm{CuCl}_{2}\right)$ were separately prepared in sterilized deionized-water in $25 \mathrm{ml}$ volumetric flasks having an initial concentration of $2 \times 10^{6} \mu \mathrm{g}$ 
of metal ions per liter $\left(2 \times 10^{6} \mathrm{ppb}\right)$. Dilutions of stock solutions in cell culture media were performed using the formula $\mathrm{C}_{1} \mathrm{~V}_{1}=\mathrm{C}_{2} \mathrm{~V}_{2}$ :

where

$\mathrm{C}_{1}$ is the initial concentration

$\mathrm{V}_{1}$ is the initial volume

$\mathrm{C}_{2}$ is the final concentration

$\mathrm{V}_{1}$ is the final volume

$50 \mu \mathrm{L}$ of the stock solution was added to $9.950 \mathrm{ml}$ of cell culture media in a $10 \mathrm{ml}$ sterile voulmetric flask for the first dilution (to prepare $10000 \mu \mathrm{g} / \mathrm{L}$ ). Other diluted concentrations were $5000 \mu \mathrm{g} / \mathrm{L}, 1000 \mu \mathrm{g} / \mathrm{L}, 500 \mu \mathrm{g} / \mathrm{L}, 100 \mu \mathrm{g} / \mathrm{L}, 10 \mu \mathrm{g} / \mathrm{L}, 1 \mu \mathrm{g} / \mathrm{L}, 0.1$ $\mu \mathrm{g} / \mathrm{L}$.

$200 \mu \mathrm{L}$ of fresh cell culture media were placed into each well of 96-well plate at a concentration of $1 \times 10^{5}$ cells/ml (approx. 20,000 cells/well). The culture plate was placed in an incubator at $37^{\circ} \mathrm{C}$ that was maintained at a high humidity and an atmosphere of $5 \%$ $\mathrm{CO}_{2}$. The endothelial cells were allowed to grow for 24 hours, after which media was removed from the wells and media having different concentrations of metal ions were added to the wells. Cells were again allowed to grow for 24 hours. SRB assays were performed in the presence of exogenously added metal ions. Each experiment was repeated 3 times and the results obtained were normalized with respect to fresh cell culture media having no metal ions. The average values of 3 tests along with the standard deviation error bar as shown in Figures 4-25 to 4-28. 


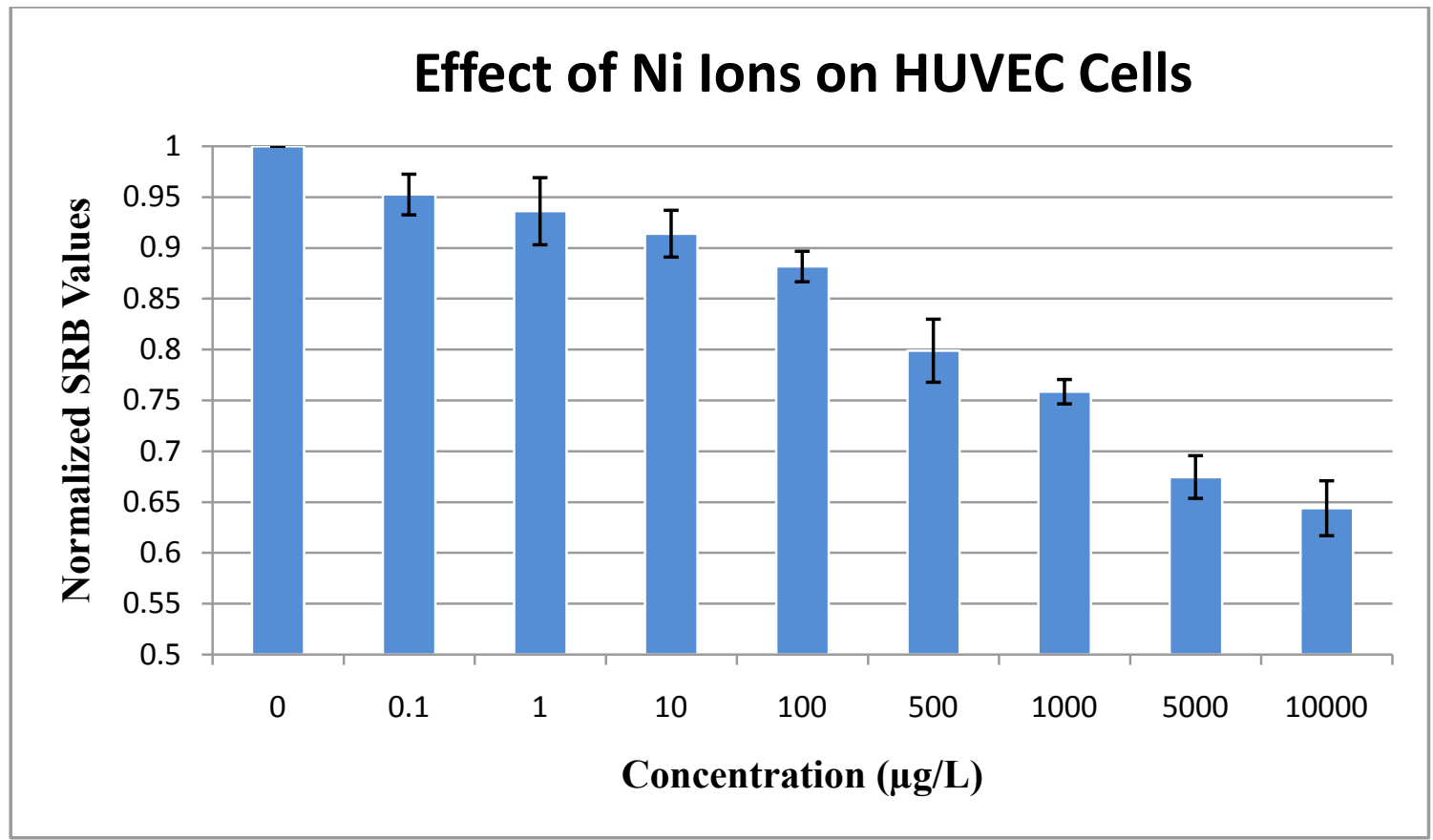

Figure 4-25 SRB data showing the effect of Ni ions on HUVEC cells

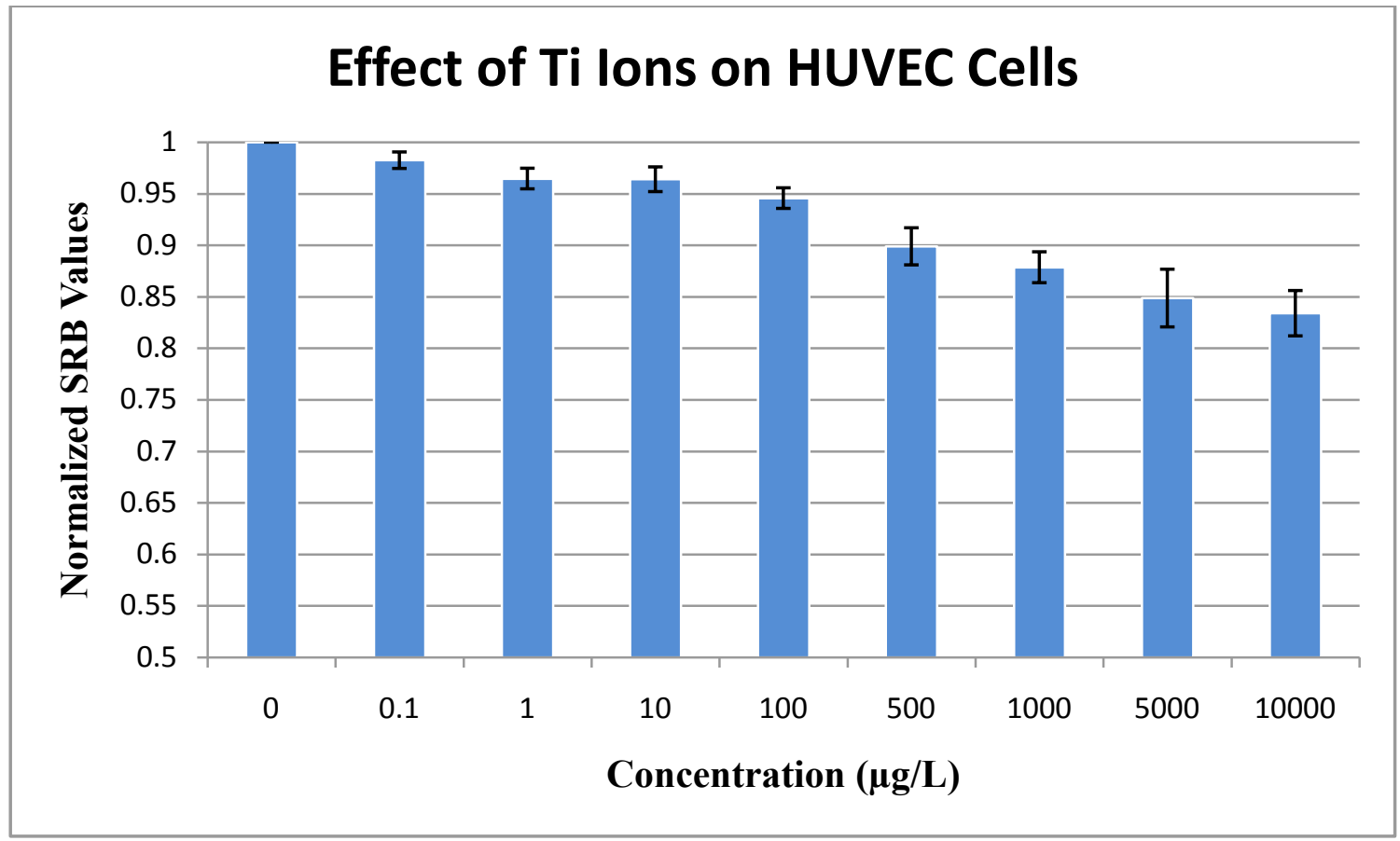

Figure 4-26 SRB data showing the effect of Ti ions on HUVEC cells (mean $\pm \mathrm{SD}, \mathrm{n}=3$ ) 


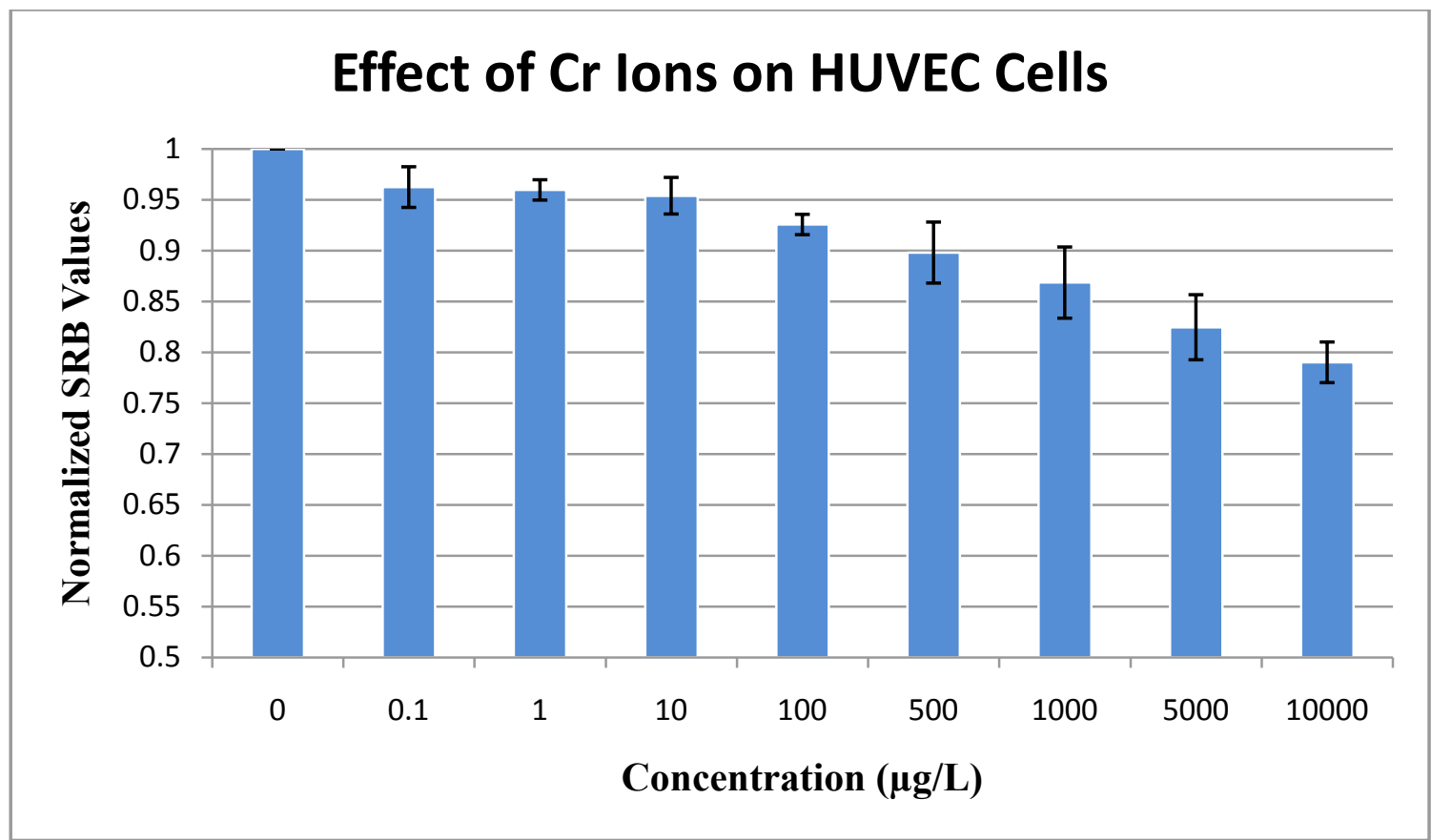

Figure 4-27 SRB data showing the effect of Cr ions on HUVEC cells (mean $\pm \mathrm{SD}, \mathrm{n}=3$ )

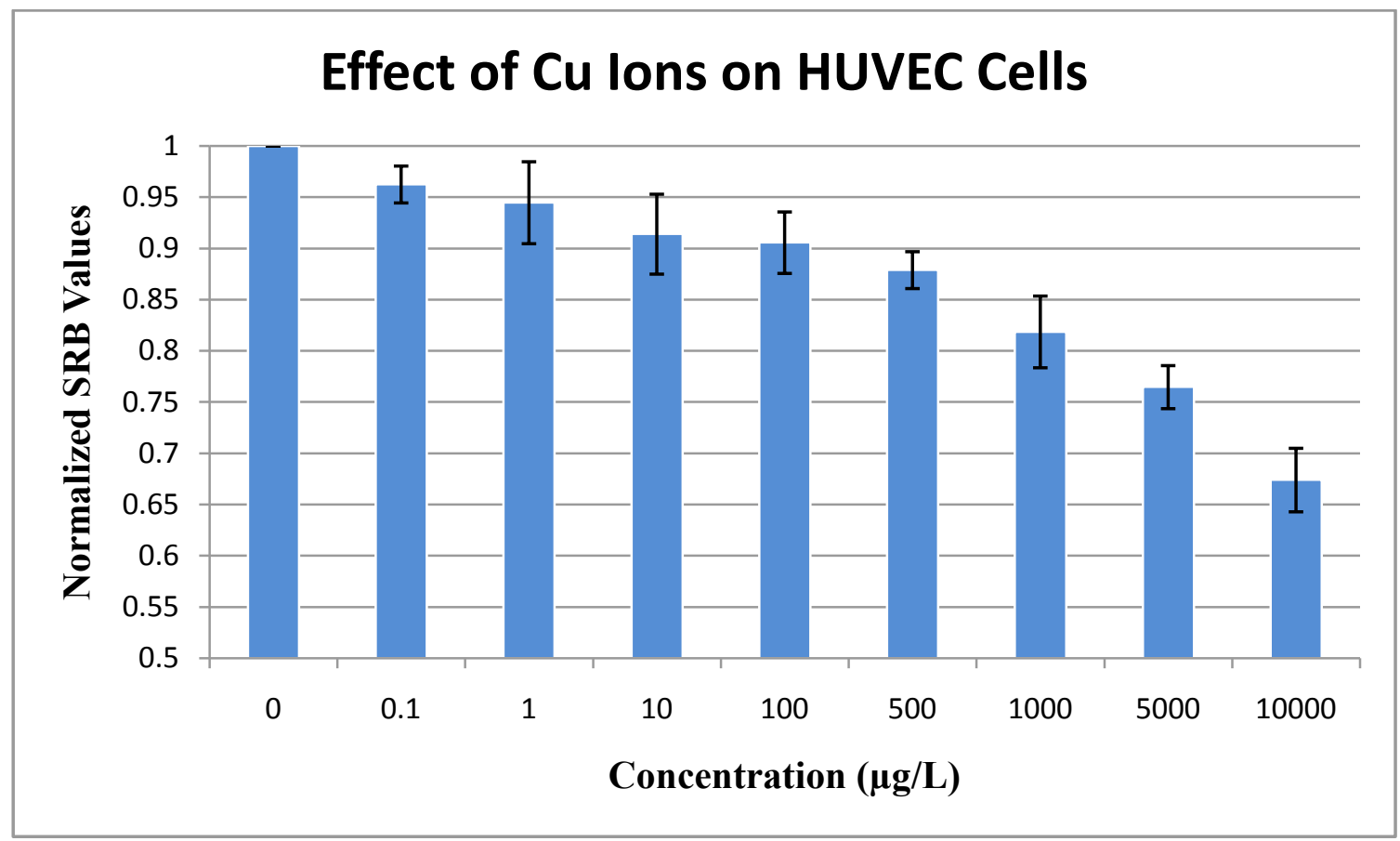

Figure 4-28 SRB data showing the effect of $\mathrm{Cu}$ ions on HUVEC cells (mean $\pm \mathrm{SD}, \mathrm{n}=3$ ) 
It was observed that $\mathrm{Ni}$ and $\mathrm{Cu}$ ions exhibited greater toxicity on HUVEC cells as compared with Ti and Cr ions. As shown in Figures 4-25 to 4-28 the SRB values at the concentration of $10000 \mu \mathrm{g} / \mathrm{L}$ were the highest in the case of $\mathrm{Ti}$ (0.833), followed by $\mathrm{Cr}$ (0.790), $\mathrm{Cu}(0.673)$ and $\mathrm{Ni}(0.643)$. It should be noted that as the concentration of metal ion in the cell culture media increased, the degree of toxicity on the cells was also increased.

\subsection{Biological Tolerance of Implant Metals}

\section{Nickel}

The use of nickel is widespread in everyday materials such as coins, jewellery, buttons, batteries etc. As such, traces of Ni can be found in food and drinking water. In fact, $\mathrm{Ni}$ is involved in many metabolic processes such as protein synthesis and sulfur amino acids metabolism. Diets high in chocolate, nuts, dried beans, peas and grains can provide a daily intake of about $900 \mu \mathrm{g} \mathrm{Ni} / \mathrm{day}$ (Mohammed Es-Souni 2005). The provisional WHO guideline concentration for $\mathrm{Ni}$ in drinking water is $0.02 \mathrm{mg} / \mathrm{L}$ (or 20 ppb) and the average dietary intake of $\mathrm{Ni}$ is $200-300 \mu \mathrm{g} / \mathrm{L}$ (Wojciech Chrzanowski 2008). However, nickel in some diets can be as high as $900 \mu \mathrm{g} /$ day (C. Cabrera 2003). Nevertheless, 300-500 ppb is the critical concentration of $\mathrm{Ni}$ ions at which allergic reactions are induced (M. Diaz 2008). The average concentration of Ni in human serum is $0.2 \mu \mathrm{g} / \mathrm{L}$ and between 1 and $3 \mu \mathrm{g} / \mathrm{L}$ in the urine of healthy humans (Mohammed Es-Souni 2005). It should be noted that $\mathrm{Ni}$ release during corrosion tests or immersion tests conducted in this study were well below the critical concentration of $\mathrm{Ni}$ ions which can induce allergic reactions. 


\section{Titanium}

The concentration of titanium in drinking water is $50 \mathrm{ng} / \mathrm{ml}(50 \mathrm{ppb})$ (E. S. F. J. Gil 2004). Titanium and its compounds have not been found to be carcinogenic in experiment conducted in animals or in humans (Bhat 2005). Linnainmaa K. et al investigated that ultra fine titanium oxide $\left(\mathrm{TiO}_{2}\right)$ samples were non-toxic to rat liver epithelial cells (RLE) (K. Linnainmaa 1997).

\section{Chromium}

Chromium is widely distributed throughout the food supply. It is involved in carbohydrate and lipid metabolism. The daily intake of $\mathrm{Cr}$ is $50-200 \mu \mathrm{g} / \mathrm{day}$ (C. Cabrera 2003), whereas, the average concentration of $\mathrm{Cr}$ in urine of healthy adults is typically $0.22 \mu \mathrm{g} / \mathrm{L}$ (D. C. Paschal 1998).

\section{Copper}

Organ meats, sea food, nuts and seeds are the major contributors of dietary copper. Copper can be found in many enzymes, some of which are essential for iron metabolism (1.5-3 mg/day) (C. Cabrera 2003). The recommended dietary allowance (RDA) of $\mathrm{Cu}$ for adult men and women is $900 \mu \mathrm{g} /$ day $(900 \mathrm{ppb})$. The median intake of $\mathrm{Cu}$ from food in the United States is approximately 1.0 to $1.6 \mathrm{mg} /$ day $(1000-1600 \mathrm{ppb})$, but the tolerable upper intake (UL) for adults is $10 \mathrm{mg} /$ day $(10000 \mathrm{ppb})$. The $\mathrm{Cu}$ concentration in drinking water is $15 \mathrm{ng} / \mathrm{ml}$ (15 ppb) (E. S. F. J. Gil 2004).

Consequently, the release of metal ions from implants at levels close to daily recommended intake is of major concern, because of the nature of the release. The local concentration of metal ions in the vicinity of an implant is far higher than the amount ingested and distributed throughout the body (Wojciech Chrzanowski 2008) 


\section{CHAPTER 5}

\section{SURFACE CHARACTERIZATION OF NITINOL ALLOYS}

\subsection{Scanning Electron Microscopy (SEM)}

Microstructures of Nitinol alloys were studied by using Scanning Electron microscopy (JEOL JSM 6330F). SEM provides both qualitative and quantitative data regarding the morphology of Nitinol alloys. Surface treated Nitinol alloys produced significantly different morphologies when compared with untreated ones.

SEM micrographs for different binary and ternary Nitinol alloys are shown in Figures 5-1 to 5-16. EP and MEP treatments produced ultra smooth surfaces as depicted in Figures 5-2, 5-3, 5-6, 5-7, 5-10, 5-11, 5-14 and 5-15. However, W\&P treatment produced rough and pitted surface as shown in Figures 5-4, 5-8, 5-12 and 5-16.

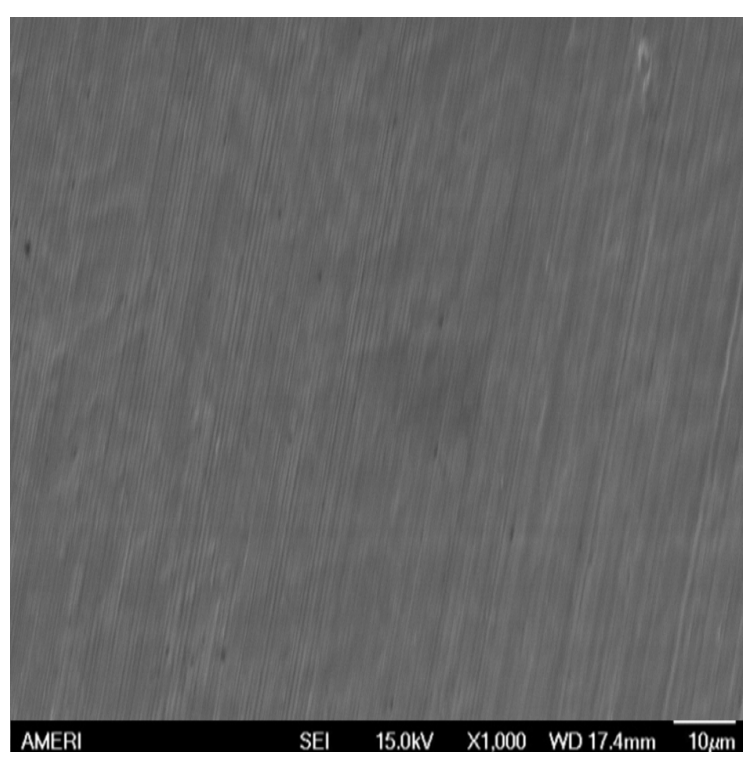

Figure 5-1 SEM micrograph of NiTi-

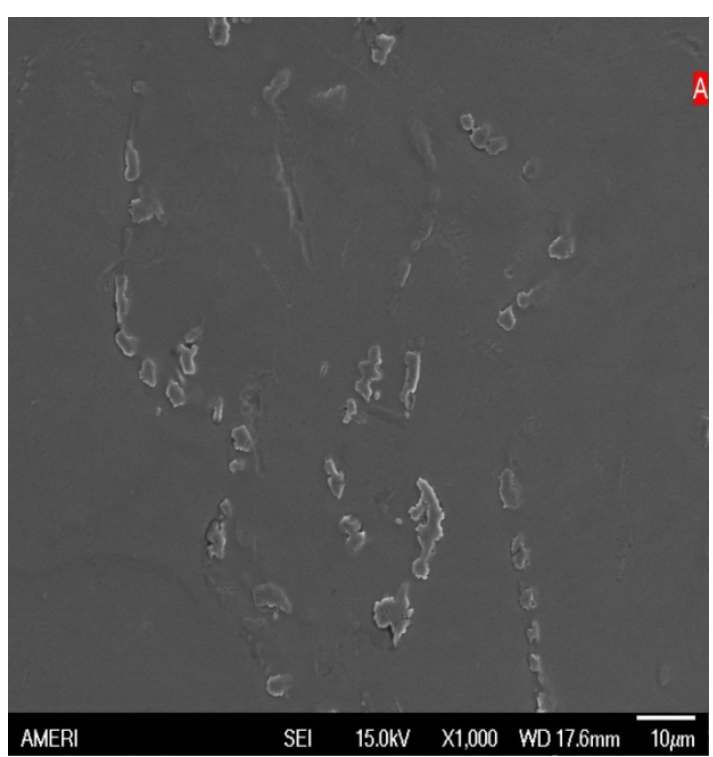

Figure 5-2 SEM micrograph of NiTi-EP

untreated 


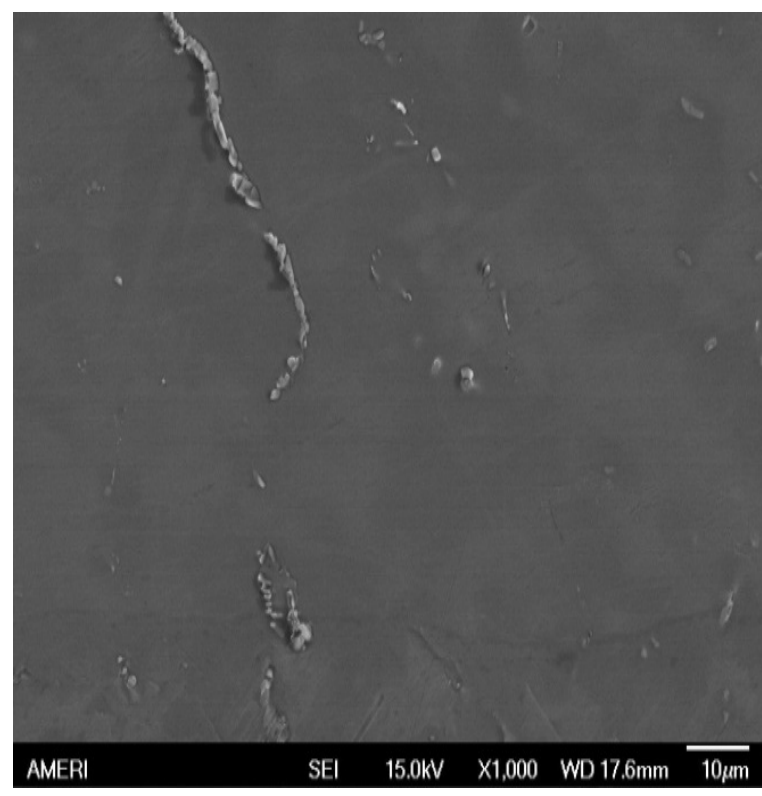

Figure 5-3 SEM micrograph of NiTi-MEP

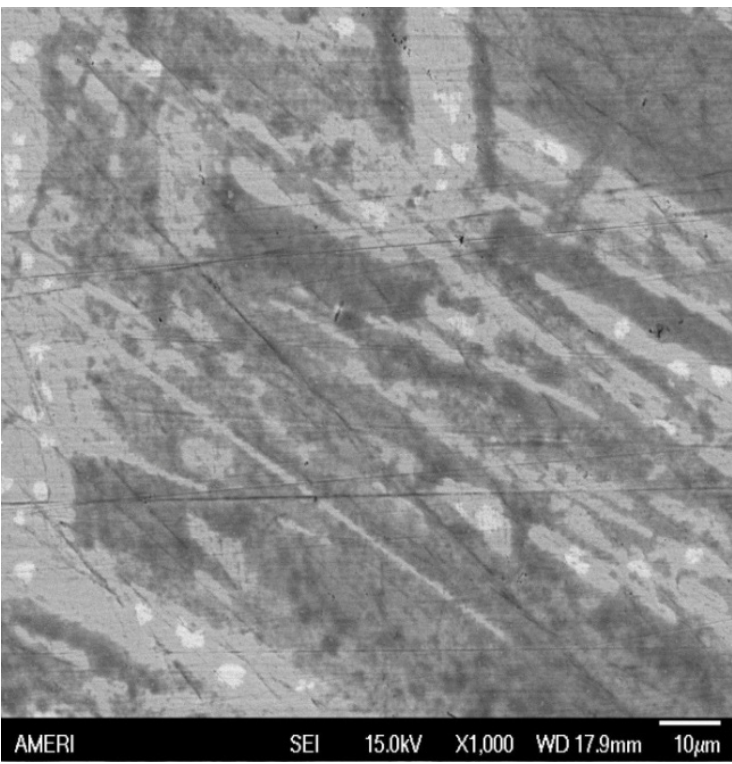

Figure 5-5 SEM micrograph of NiTi10Cruntreated

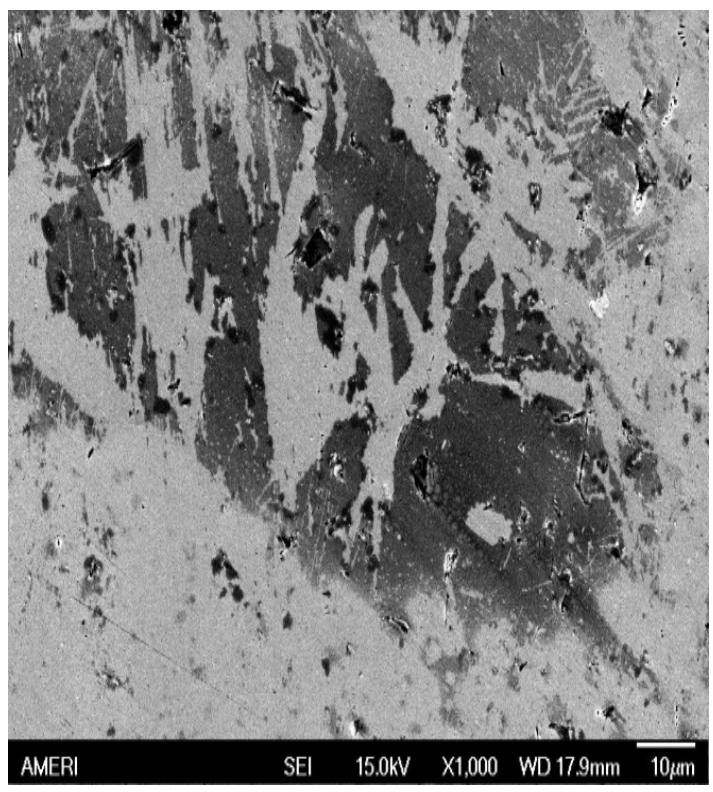

Figure 5-4 SEM micrograph of NiTi-

$\mathrm{W} \& \mathrm{P}$

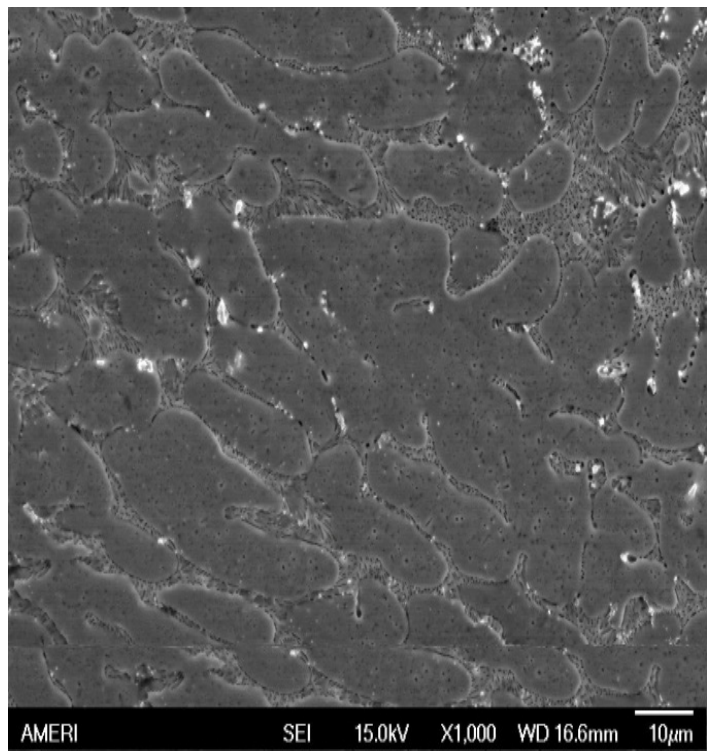

Figure 5-6 SEM micrograph of

NiTi10Cr-EP 


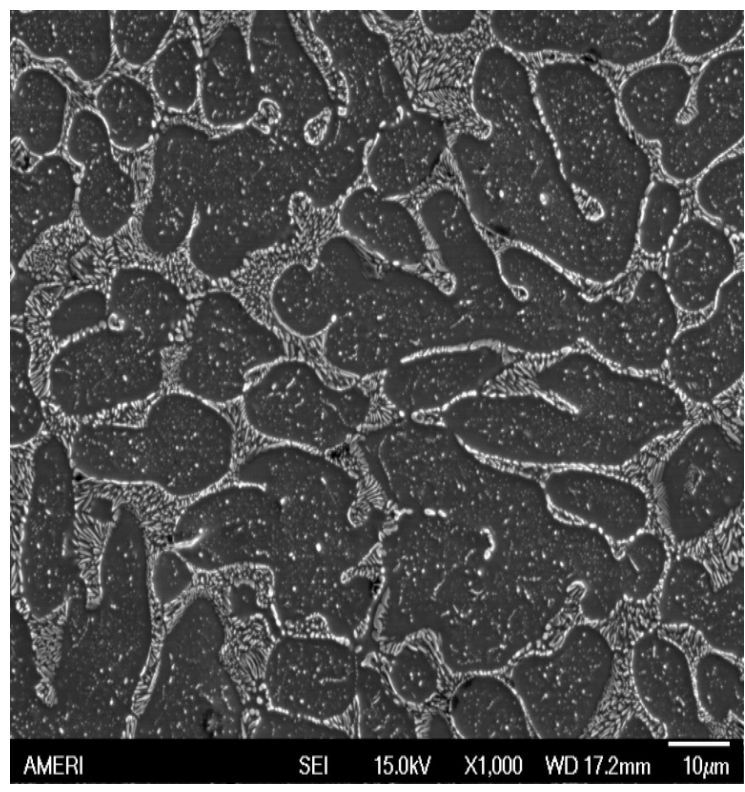

Figure 5-7 SEM micrograph of NiTi10CrMEP

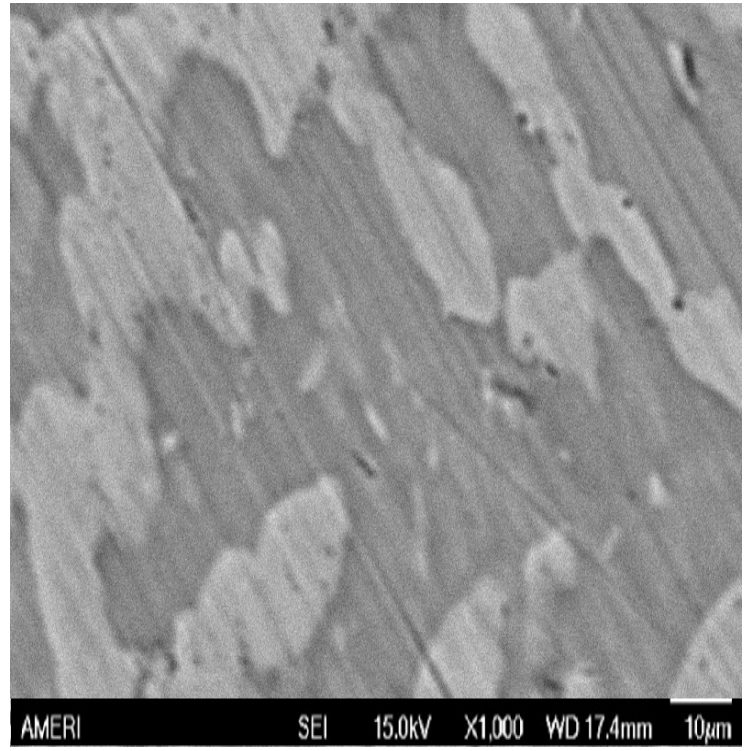

Figure 5-9 SEM micrograph of NiTi10Cuuntreated

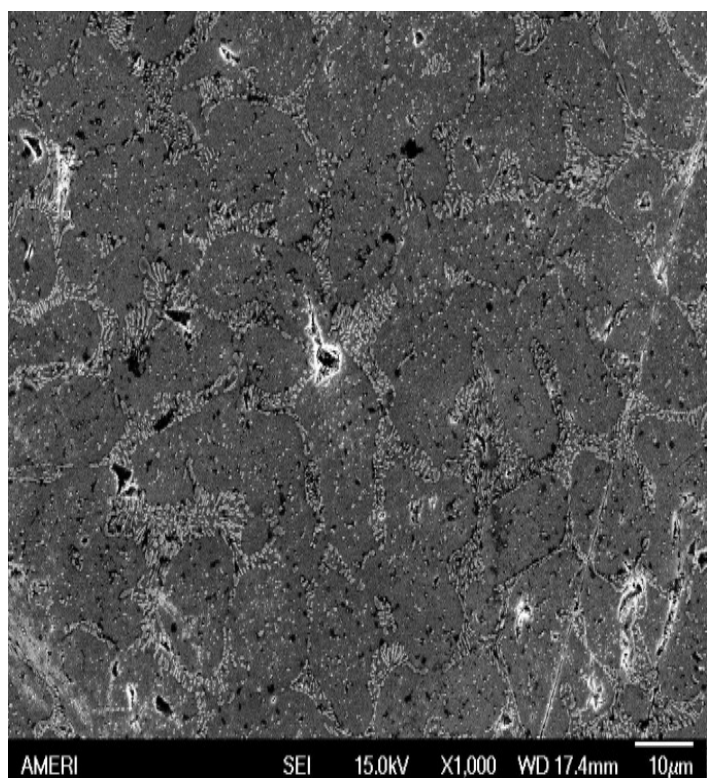

Figure 5-8 SEM micrograph of NiTi10Cr-W\&P

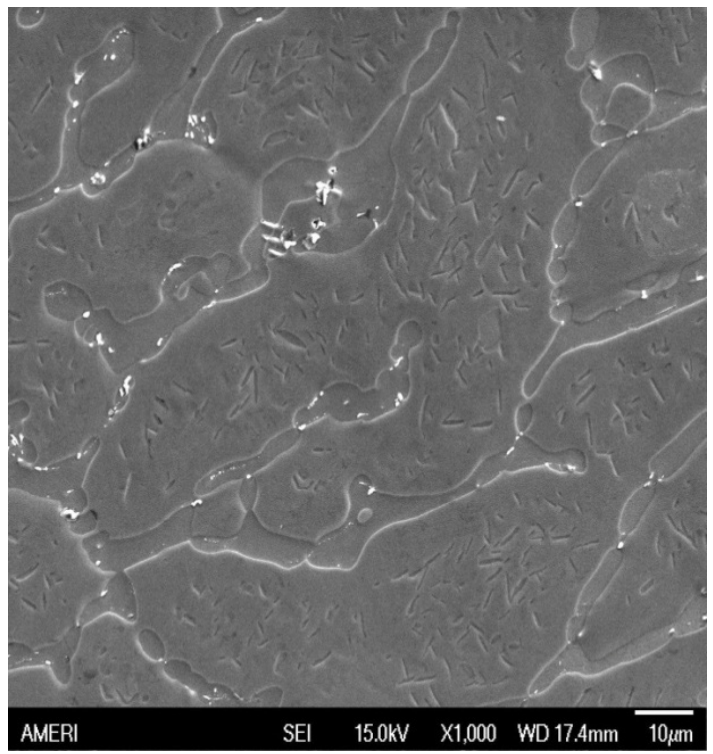

Figure 5-10 SEM micrograph of NiTi10Cu-EP 


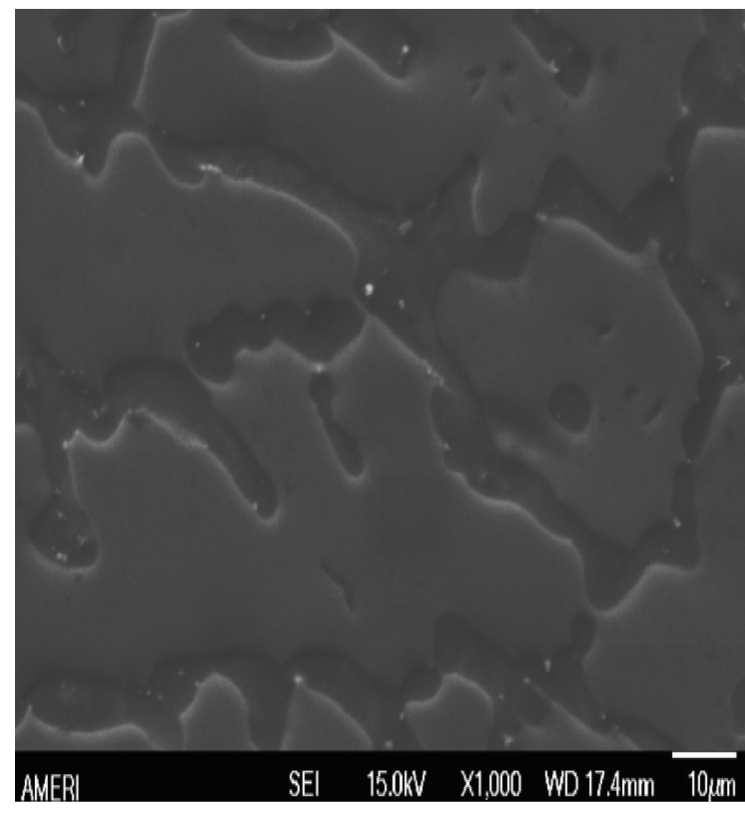

Figure 5-11 SEM micrograph of NiTi10CuMEP

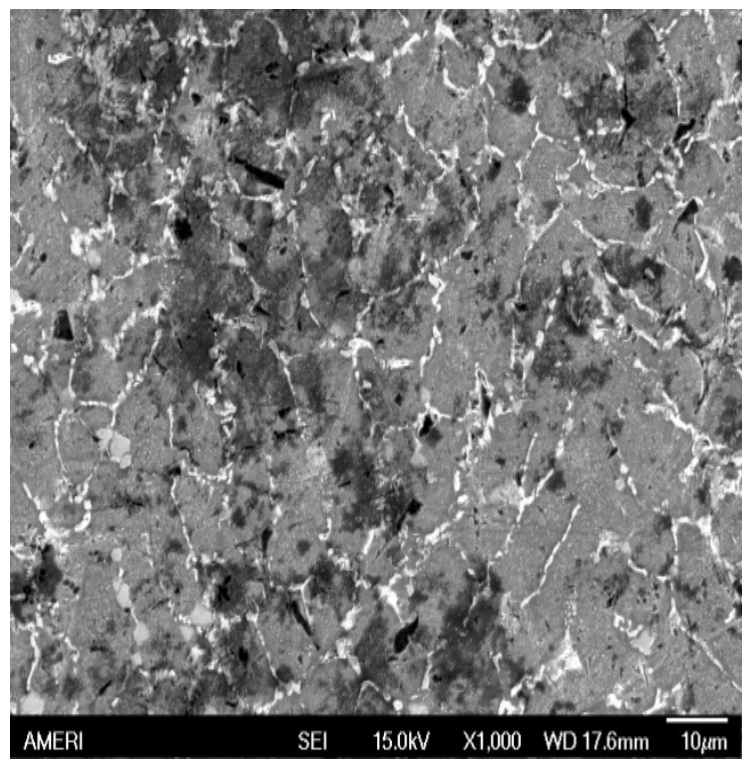

Figure 5-13 SEM micrograph of NiTi10Tauntreated

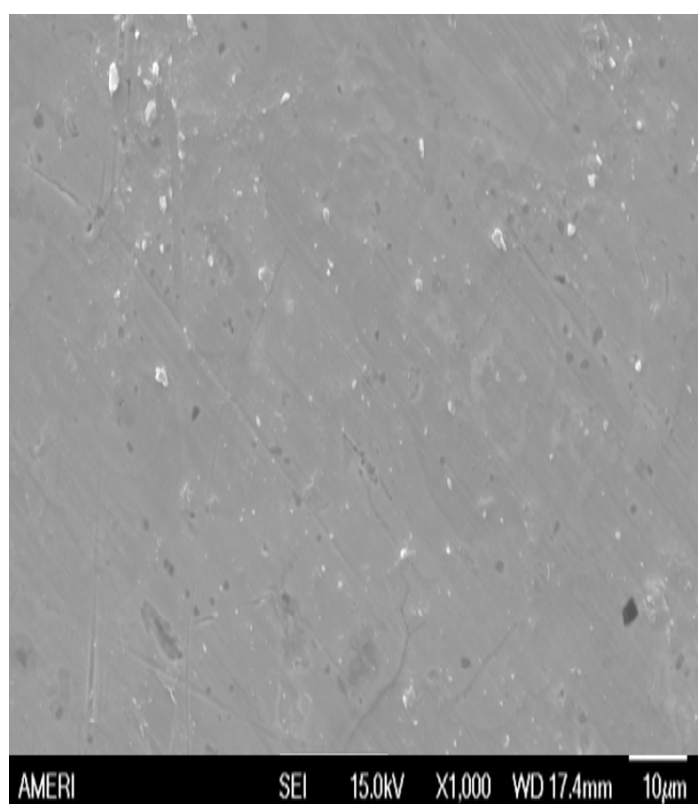

Figure 5-12 SEM micrograph of NiTi10Cu-W\&P

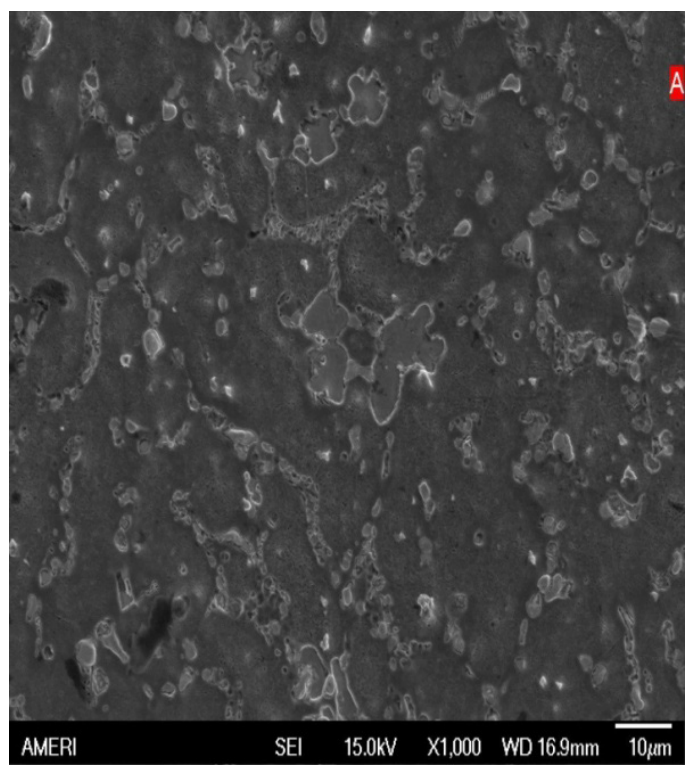

Figure 5-14 SEM micrograph of

NiTi10Ta-EP 


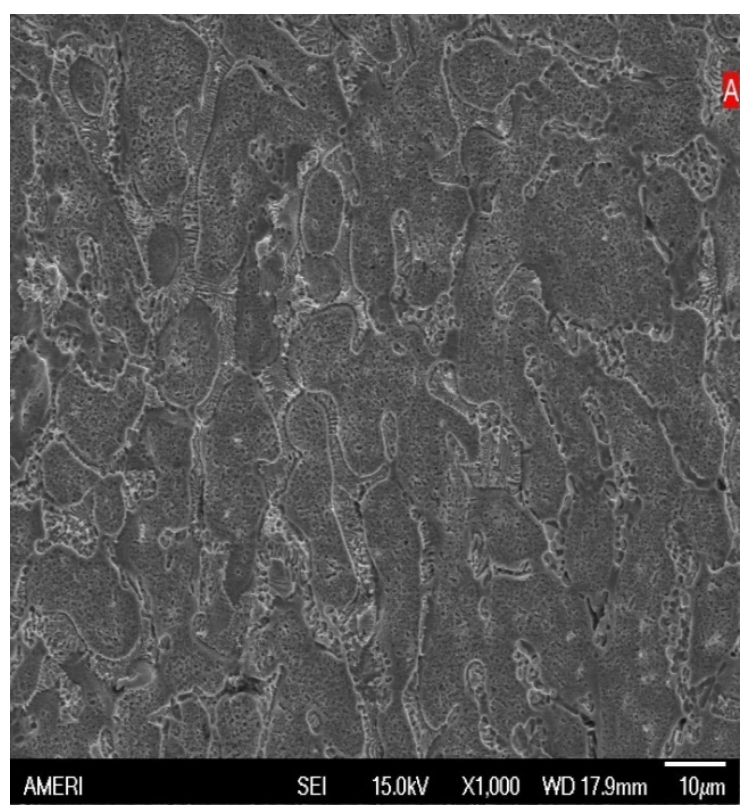

Figure 5-15 SEM micrograph of NiTi10TaMEP

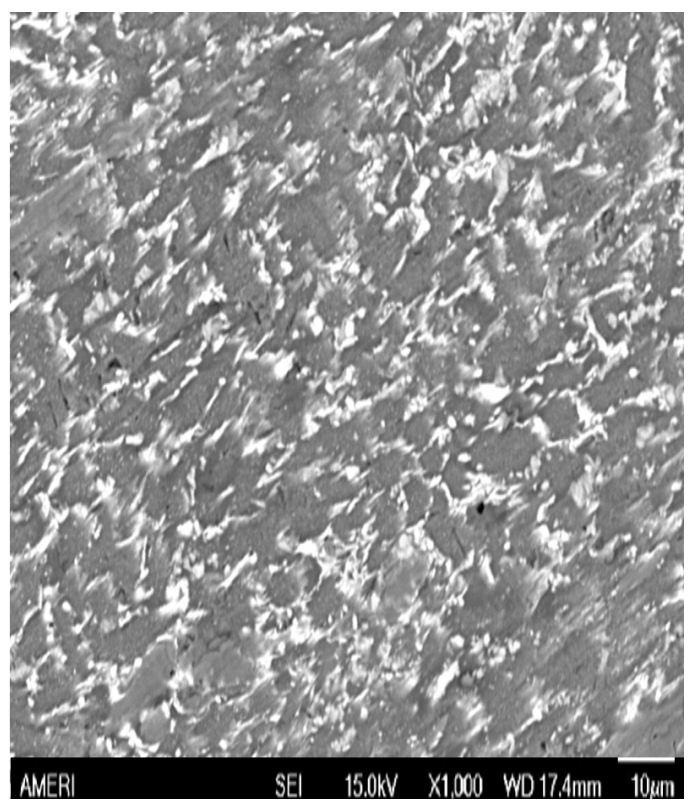

Figure 5-16 SEM micrograph of NiTi10TaW\&P

\subsection{X-ray Photoelectron Spectroscopy (XPS)}

XPS is a sensitive surface characterization technique, which provides both qualitative and quantitative analysis about the presence of different elements at the surface of a material. The elucidation of elemental composition, speciation, depth profile and thickness of the surface film on implant materials are very critical for assessing their biocompatibility.

The surface chemistry of the Nitinol alloys was examined using a PHI Quantera, scanning XPS microprobe, employing monochromatic Al Ka X-ray radiation. High resolution Ti-2p, Ni-2p, Cr-2p, Cu- $2 \mathrm{p}$ and Ta-4f spectra were acquired at $55 \mathrm{eV}$ pass energy in order to determine their chemical states and concentrations. Wide energy survey spectra were collected in a large area analysis mode to determine which elements 
were present at the surface. The large area analysis mode probes an area of $200 \mu \mathrm{m}$ in diameter with a $50 \mathrm{~W}$ monochromatic Al Ka x-ray beam. Sputter depth profiles were obtained using the large area analysis mode and $2 \mathrm{kV}$ argon ions rastered over a $3 \times 3 \mathrm{~mm}$ area. The sputter etch rate of $6.5 \mathrm{~nm} / \mathrm{min}$ was determined using a $\mathrm{SiO}_{2}$ film of known thickness.

\subsubsection{Depth Profiles}

Depth profile analysis of Nitinol alloys are depicted in Figures 5-17 to 5-30. The dominant surface elements were always oxygen and carbon, the inevitable surface components. The XPS montage plots for carbon and oxygen are shown in Appendix B and Appendix C, respectively. The presence of carbon on all of the samples can be attributed to surface contamination by carbon-containing molecules absorbed from the atmosphere. In the depth profile analysis, the oxygen profile exhibited a peak close to the surface and then decreased sharply. However, $\mathrm{Ni}, \mathrm{Ti} \mathrm{Cr}, \mathrm{Cu}$ and Ta profiles indicated the lowest concentration near the surface and then increased rapidly to a steady state value.

On the other hand, different metal oxides exhibited maximum concentration near the surface which then decreased to zero.

Nickel was present in the elemental form on the surface of NiTi-untreated and NiTi-EP alloys as depicted in Figures 5-17 and 5-17. However, nickel was present in the oxide form on NiTi-MEP alloys as illustrated in Figure 5-19. 


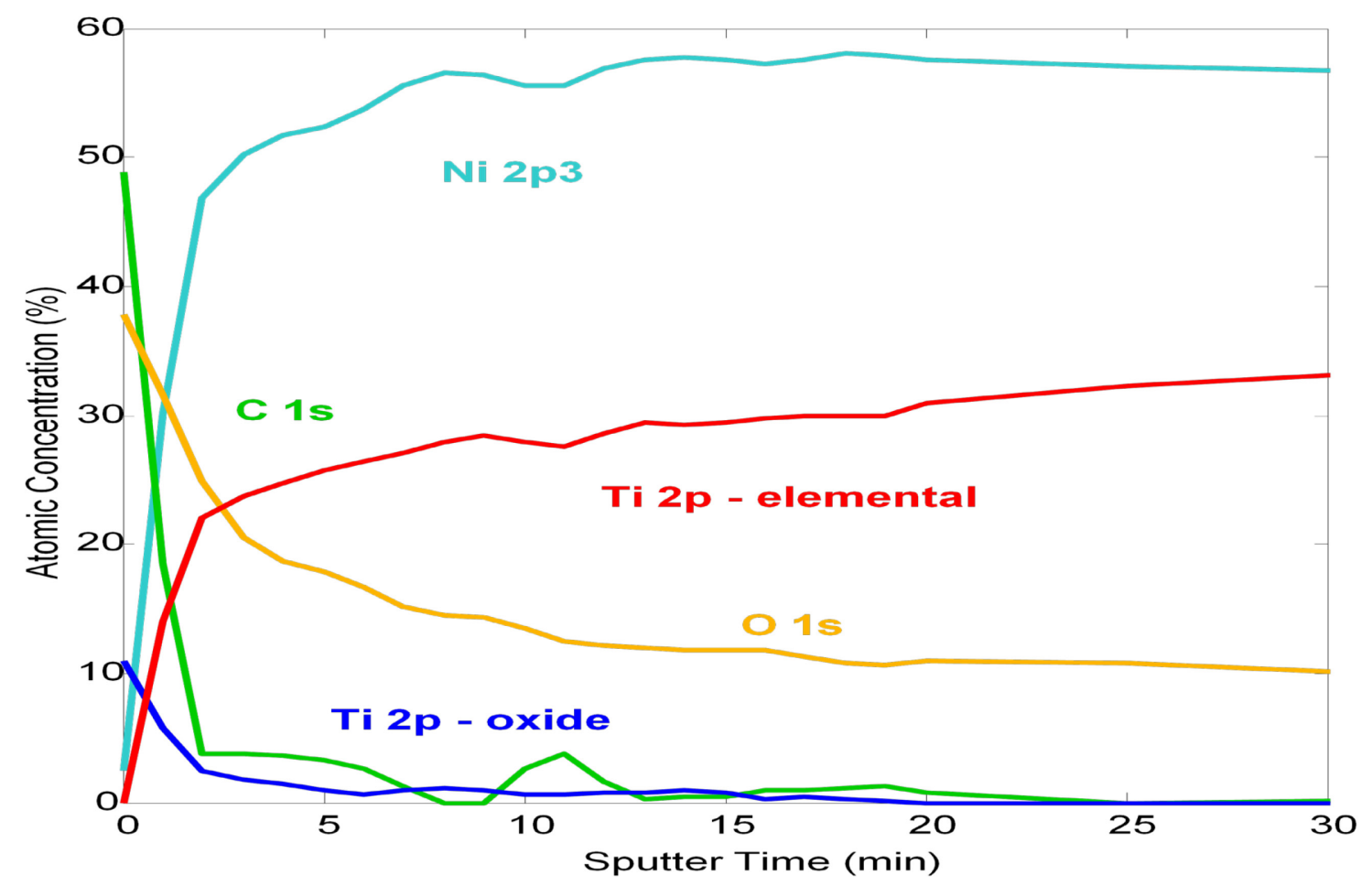

Figure 5-17 Depth profile for NiTi-untreated

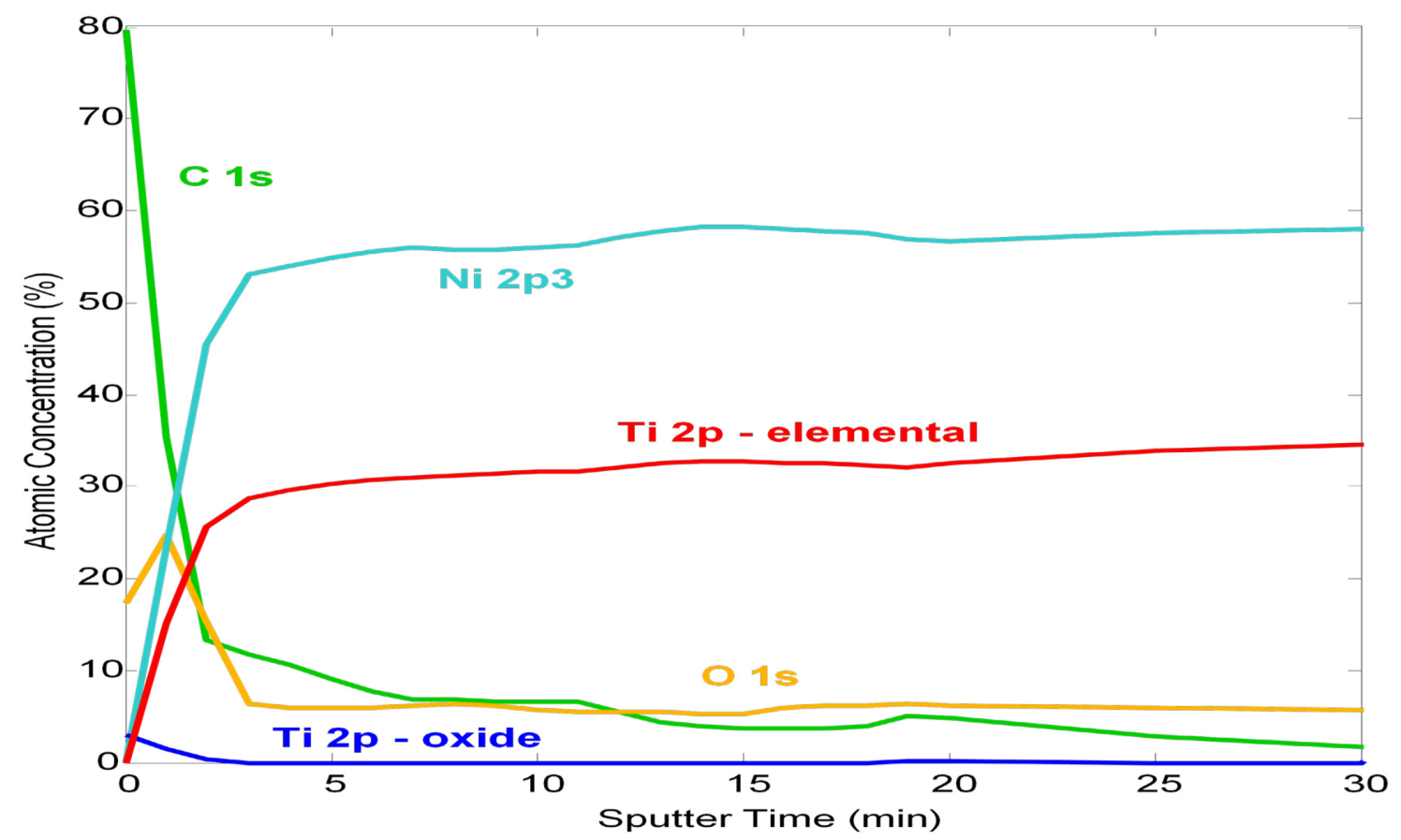

Figure 5-18 Depth profile for NiTi-EP 


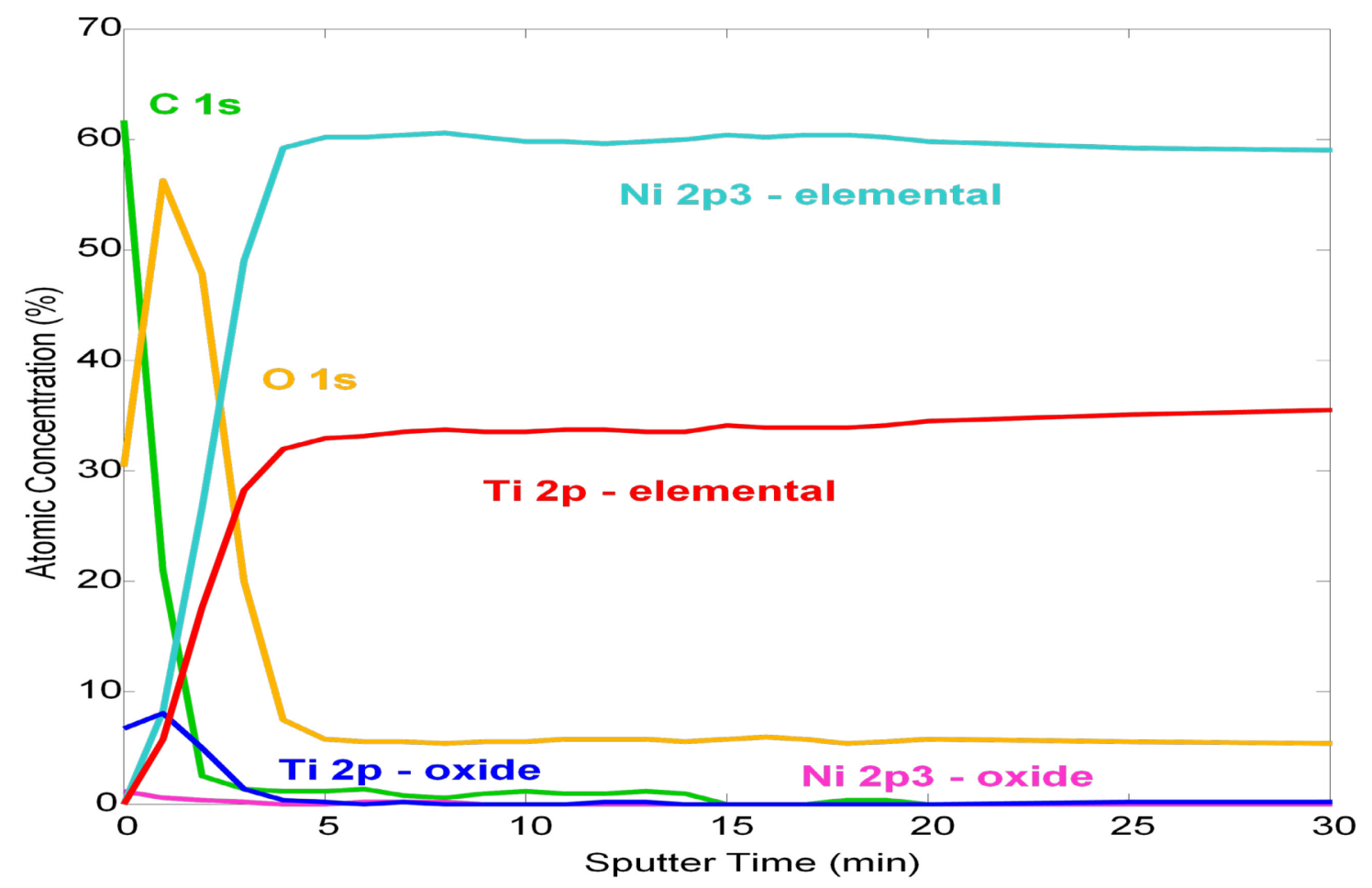

Figure 5-19 Depth profile for NiTi-MEP

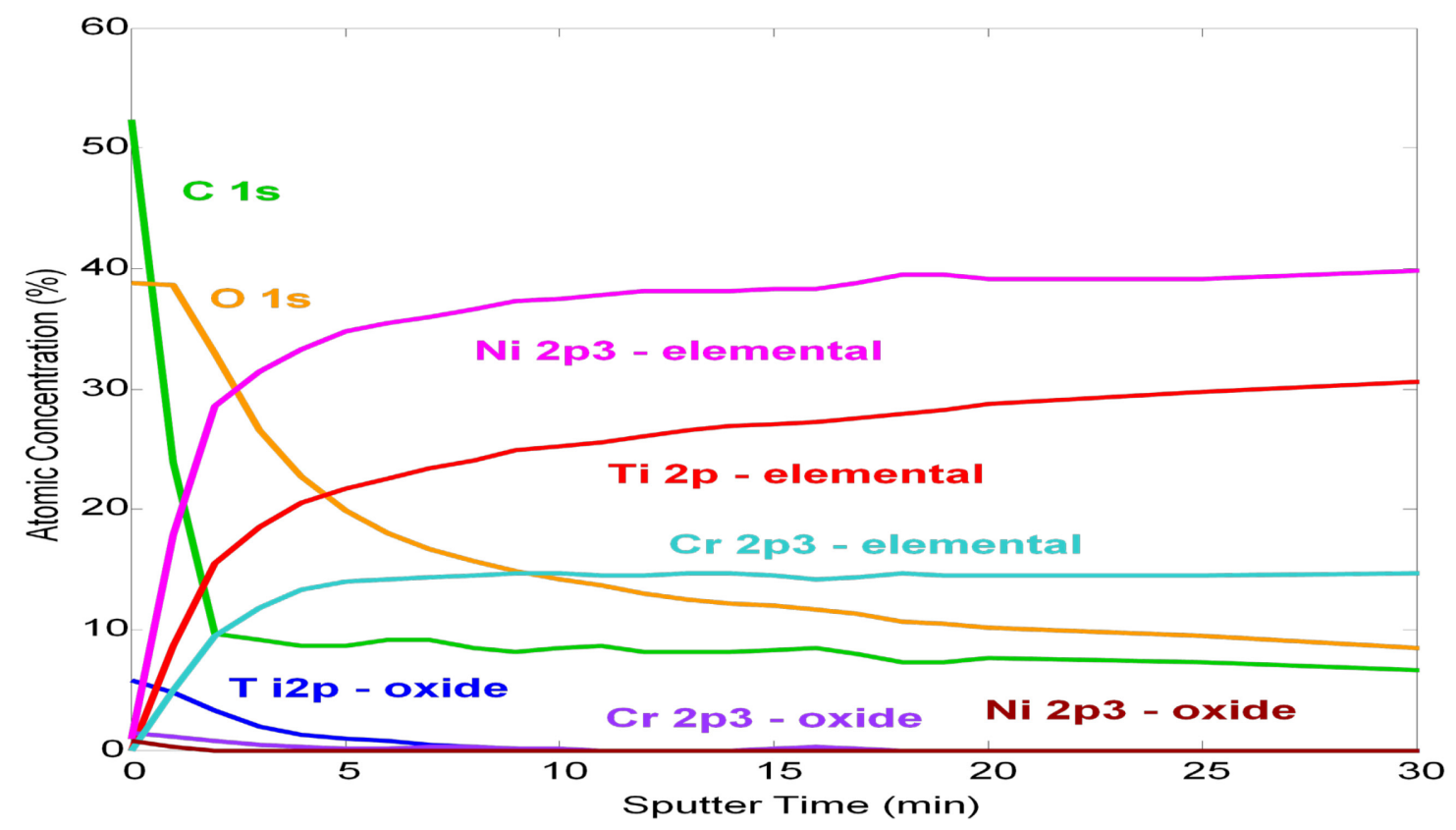

Figure 5-20 Depth profile for NiTi10Cr-untreated 


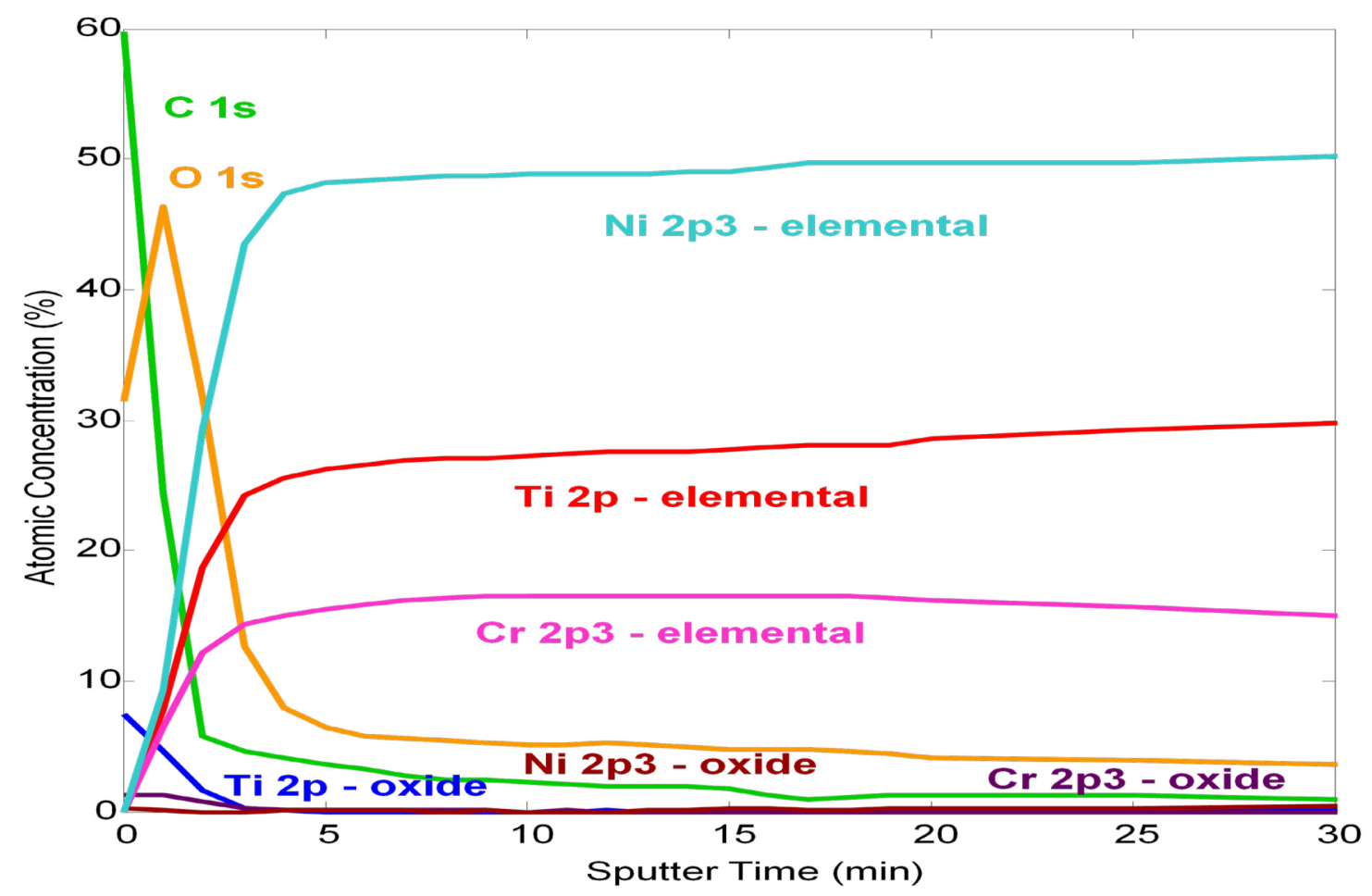

Figure 5-21 Depth profile for NiTi10Cr-EP

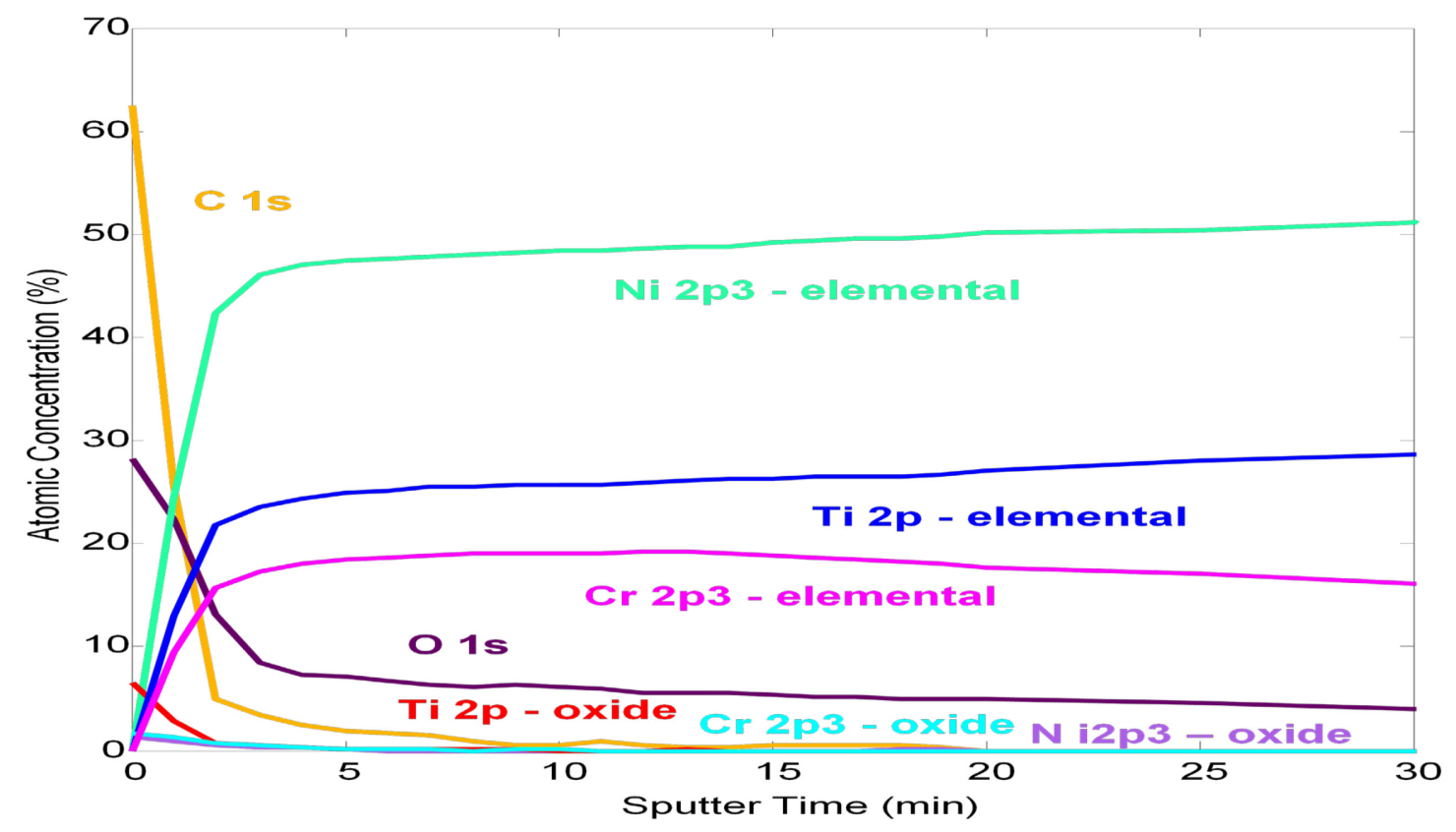

Figure 5-22 Depth profile for NiTi10Cr-MEP 


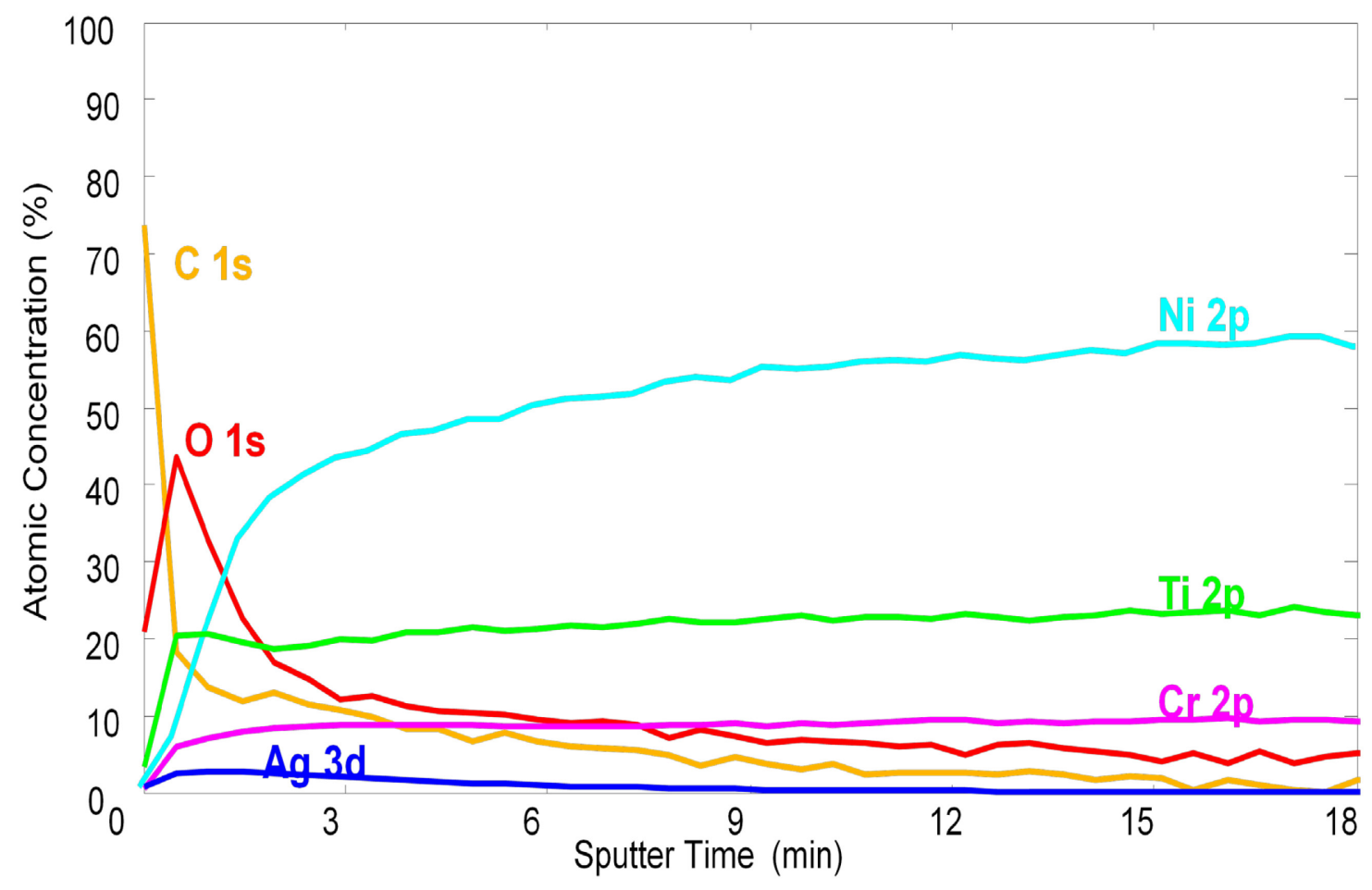

Figure 5-23 Depth profile for NiTi10Cr-W\&P

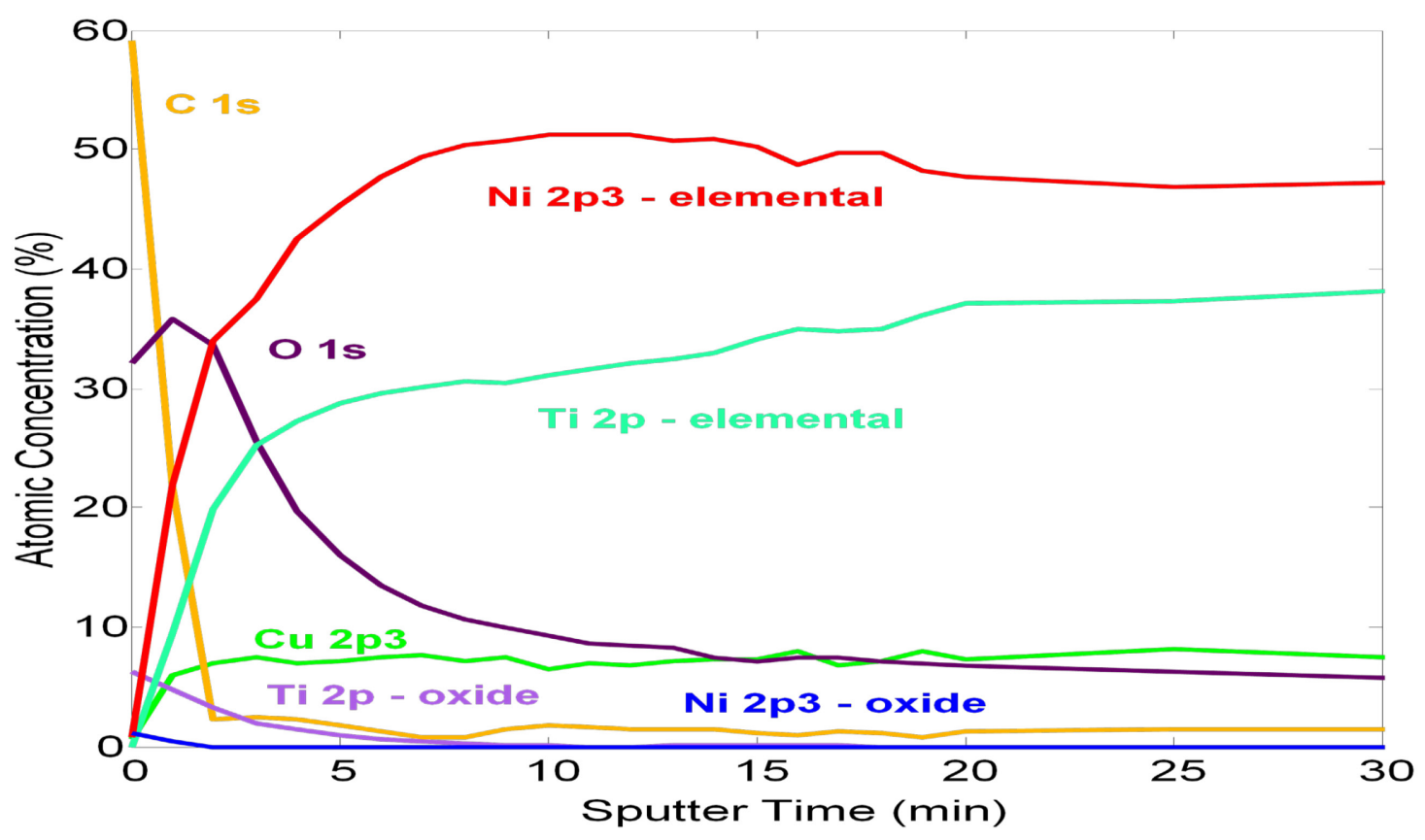

Figure 5-24 Depth profile for NiTi10Cu-untreated 


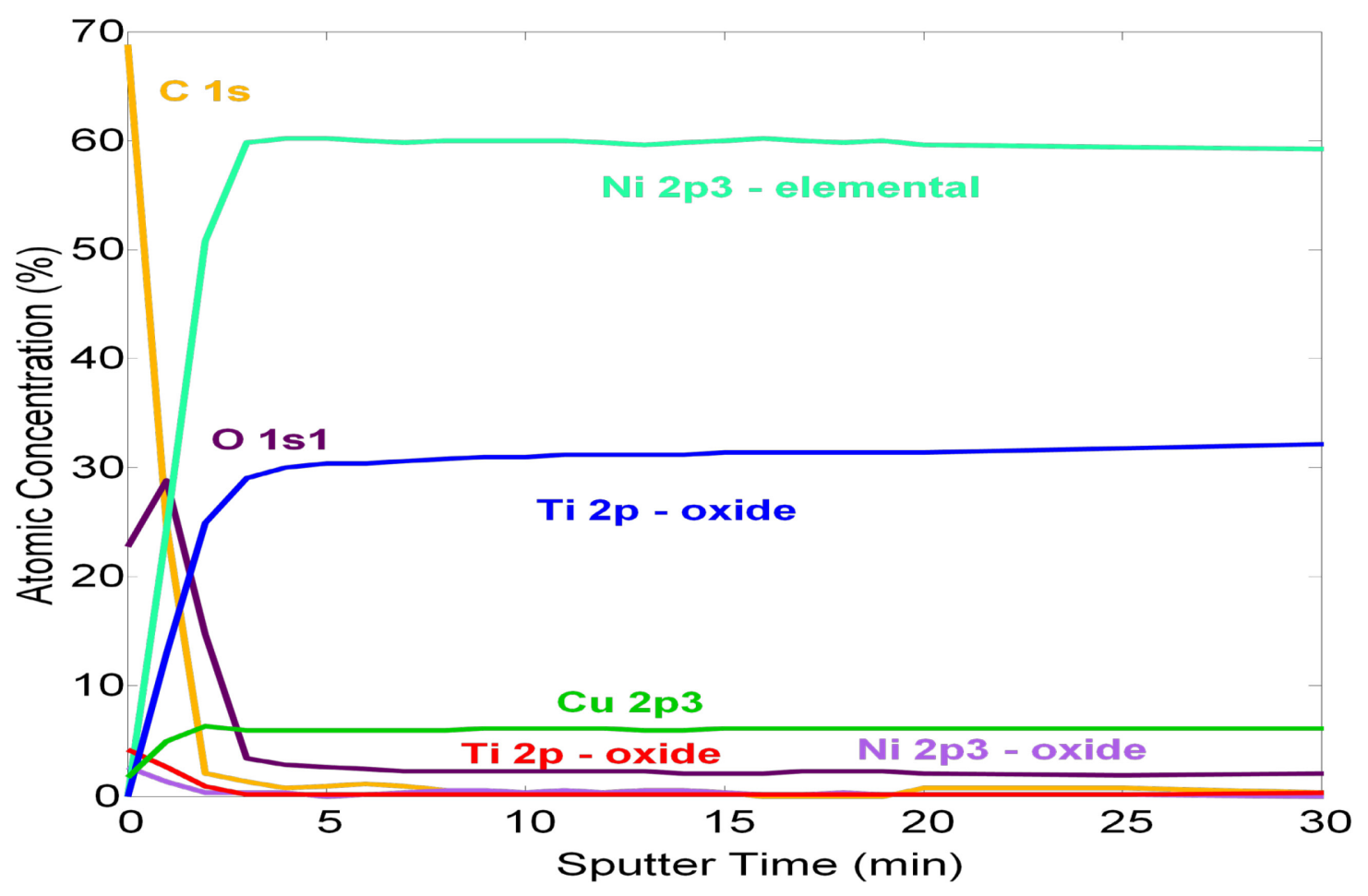

Figure 5-25 Depth profile for NiTi10Cu-EP

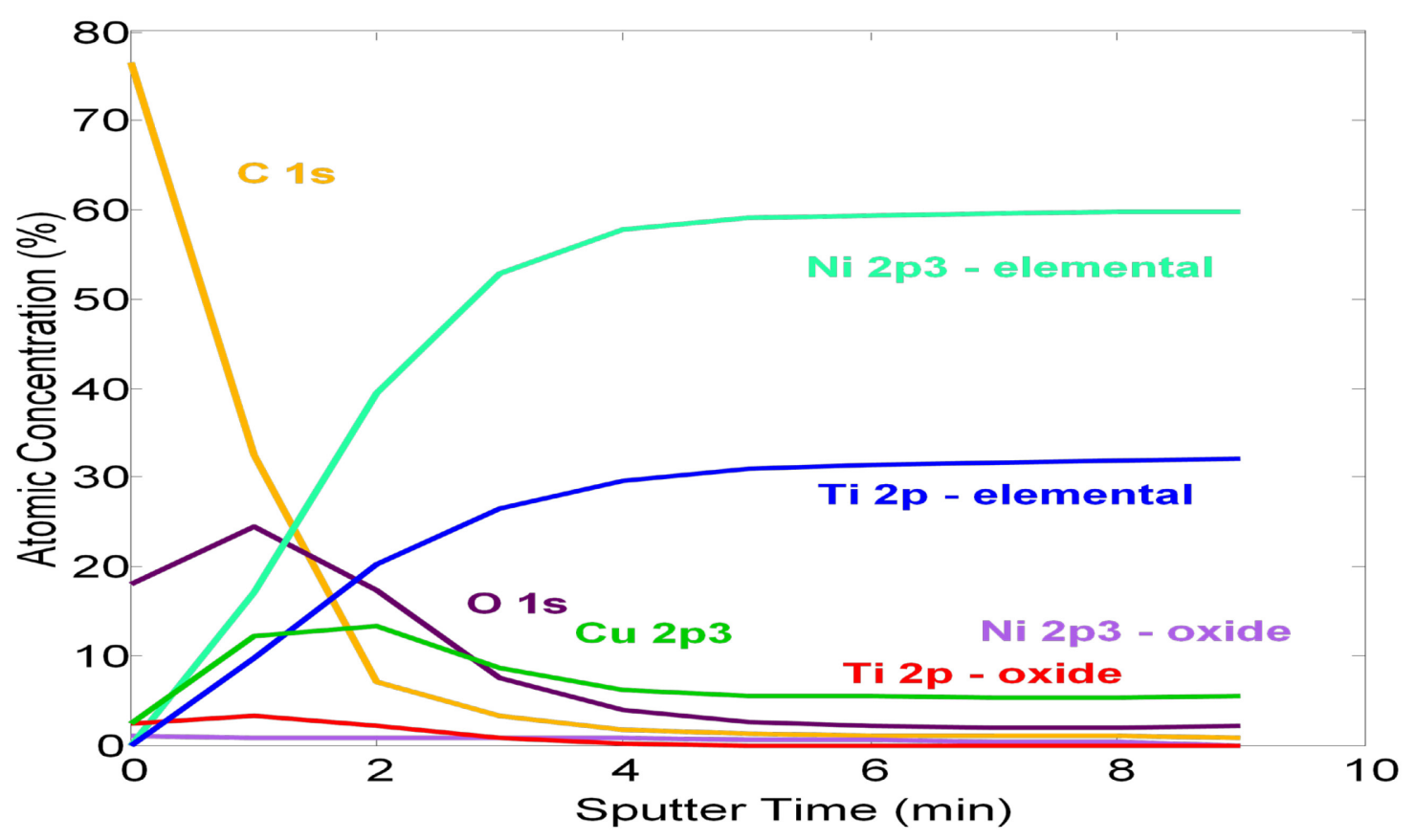

Figure 5-26 Depth profile for NiTi10Cu-MEP 


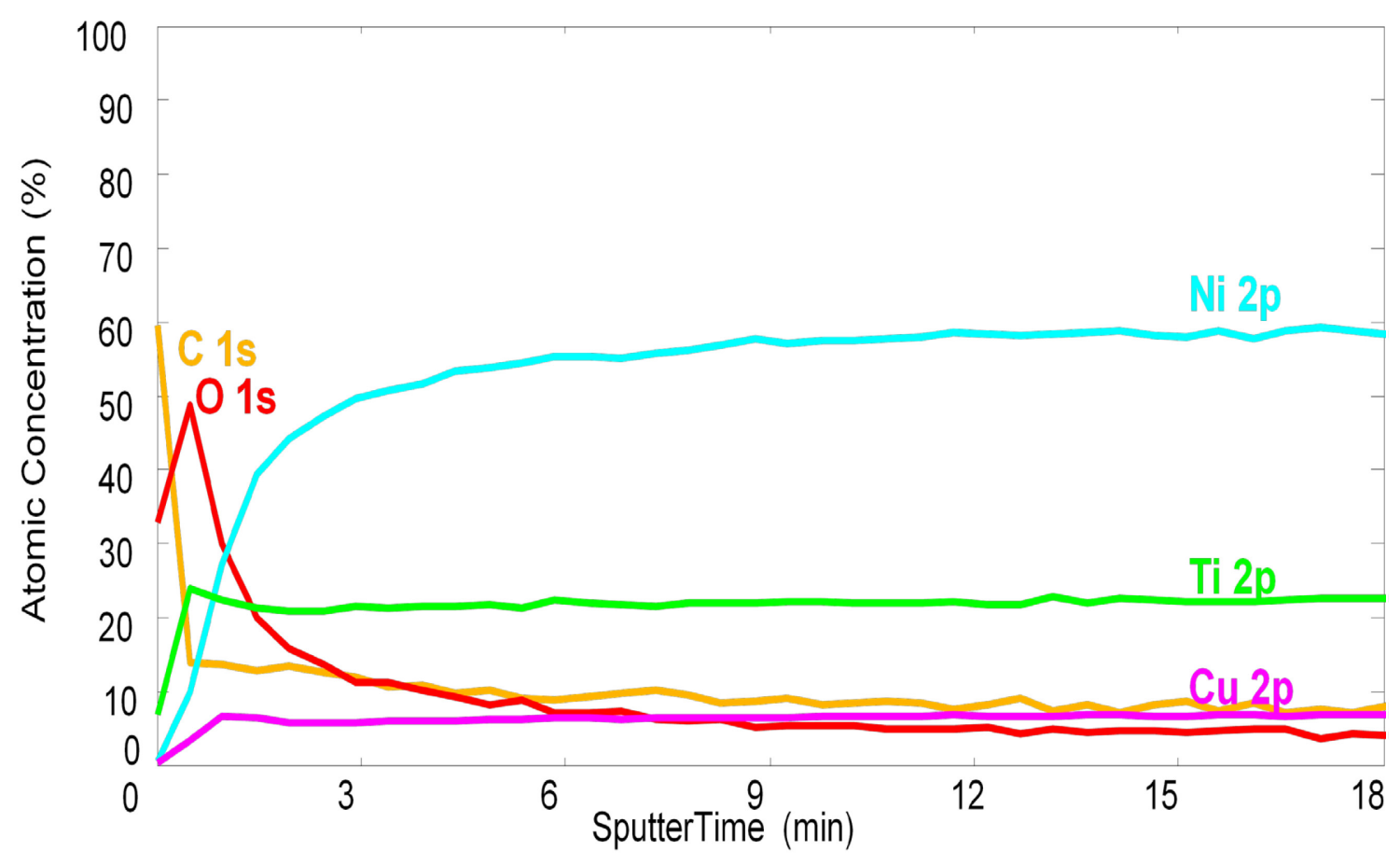

Figure 5-27 Depth profile for NiTi10Cu-W\&P

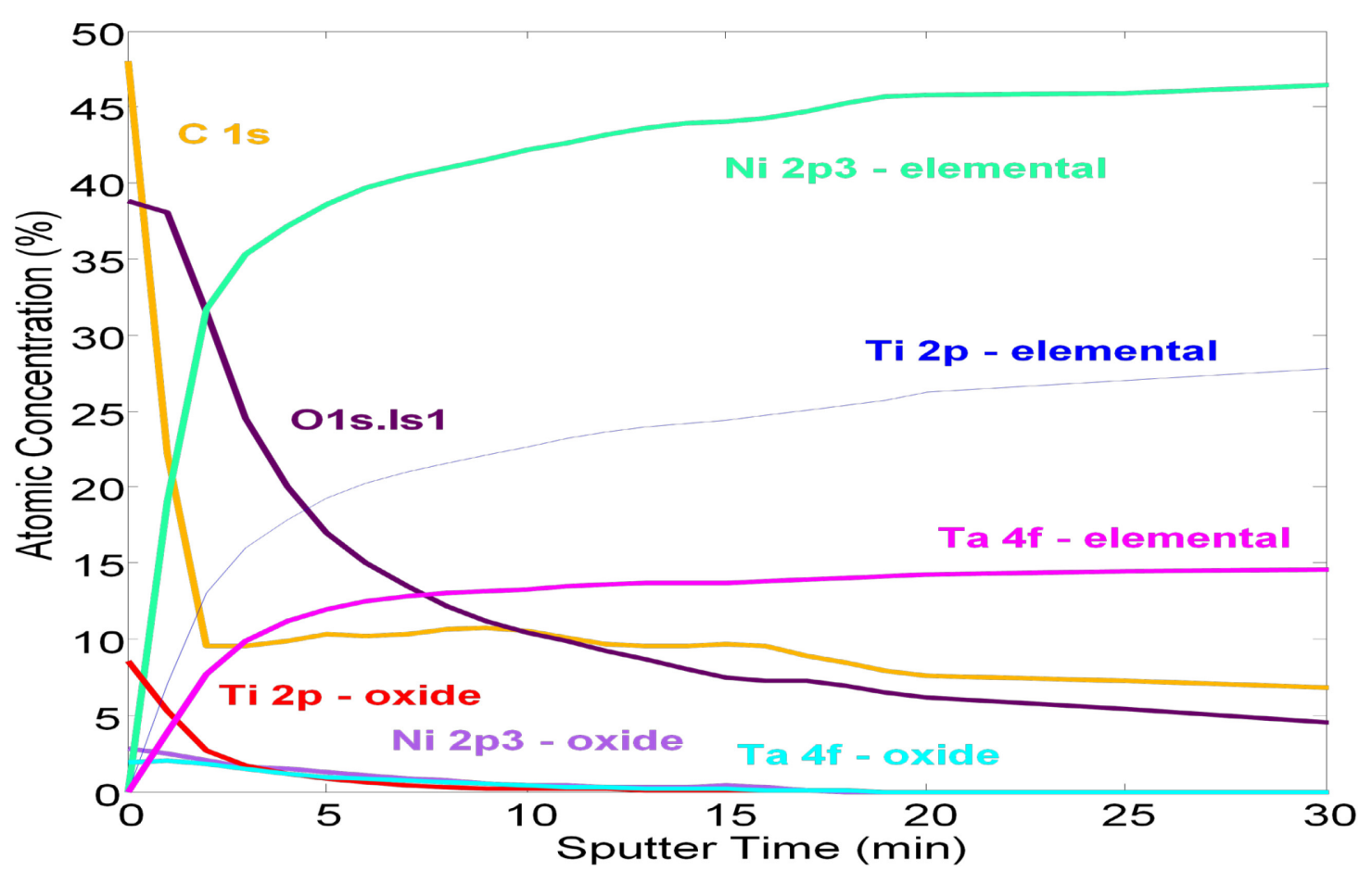

Figure 5-28 Depth profile for NiTi10Ta-untreated 


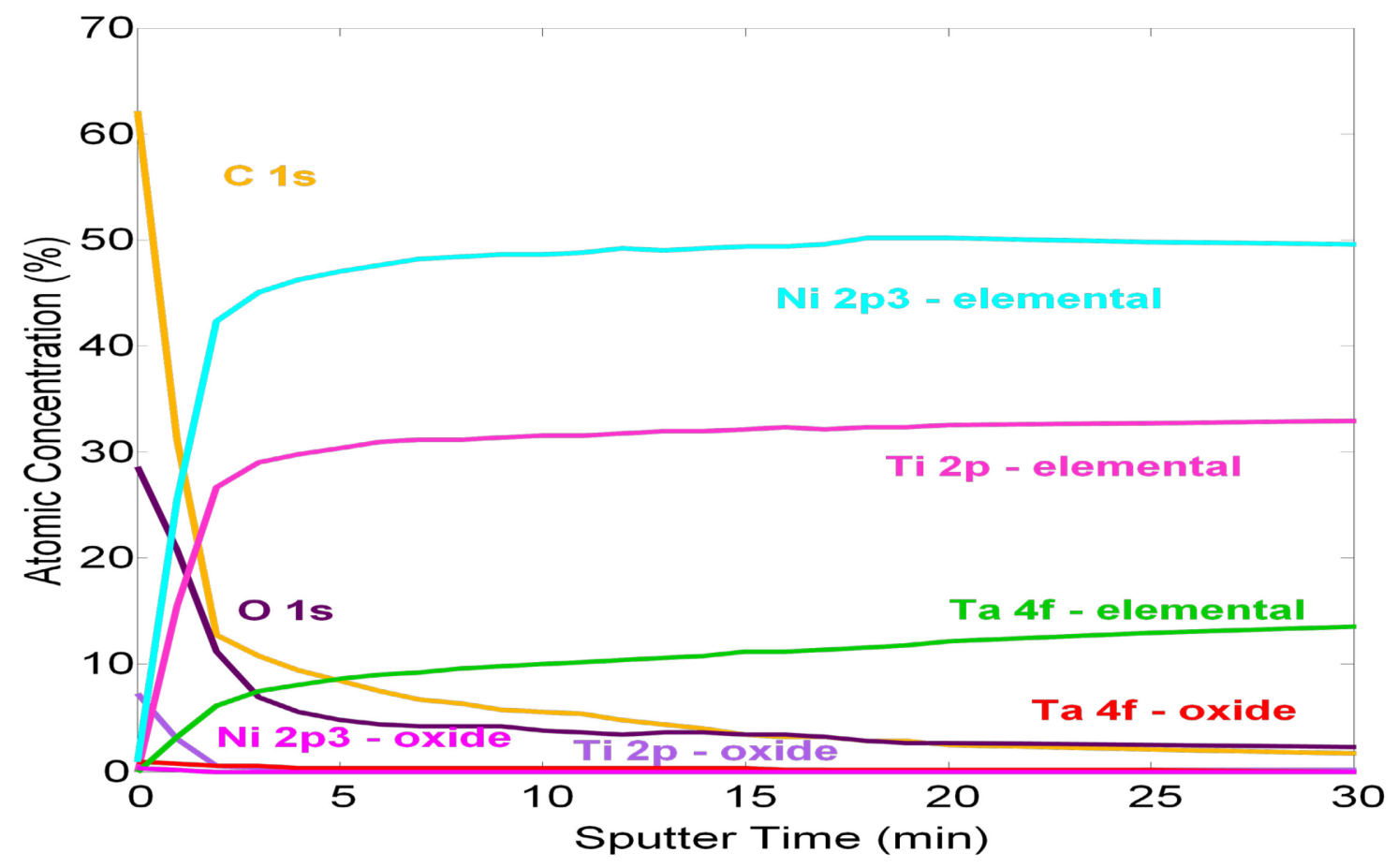

Figure 5-29 Depth profile for NiTi10Ta-EP

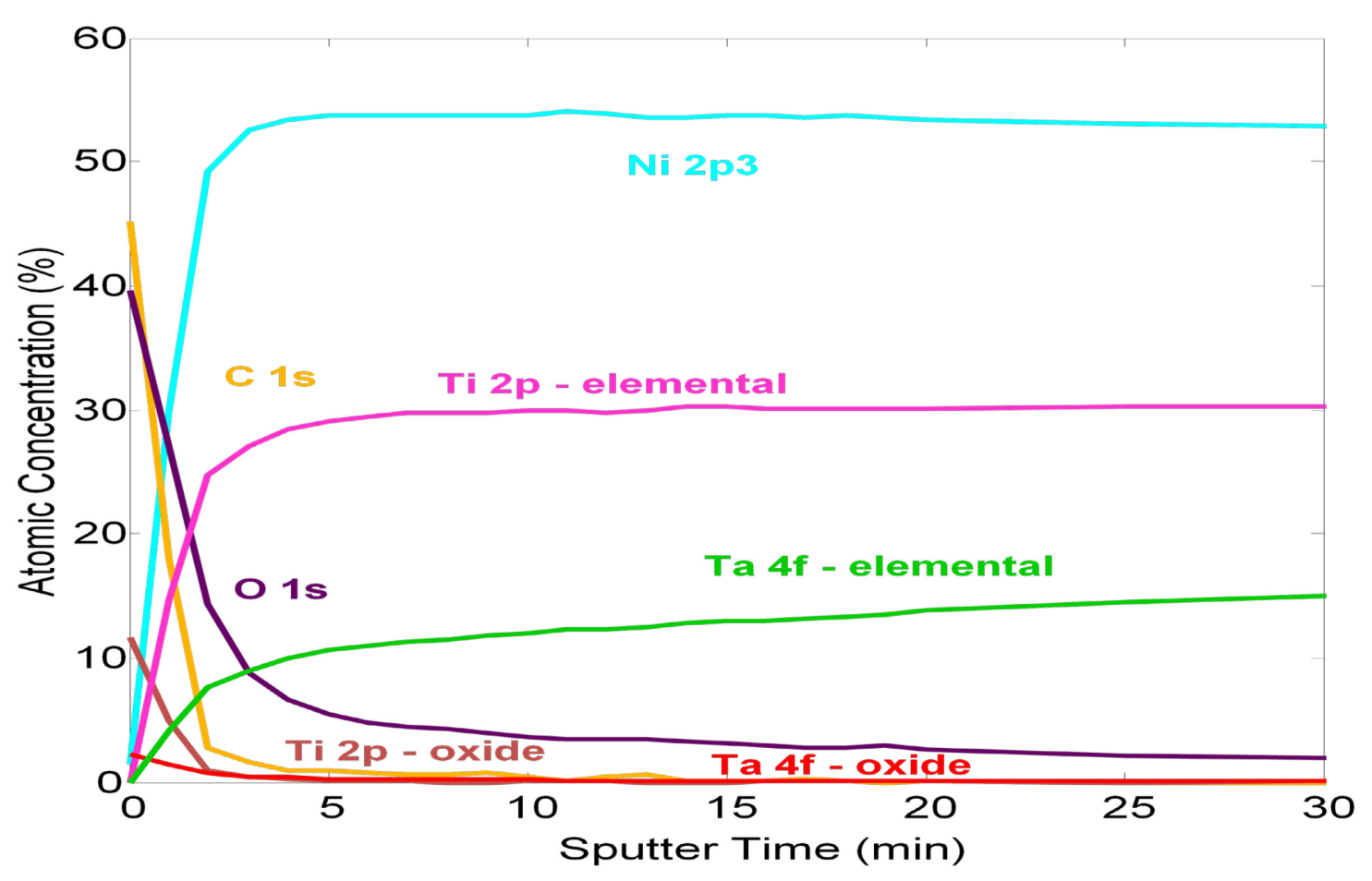

Figure 5-30 Depth profile for NiTi10Ta-MEP 
Depth profiles for NiTi10Cr alloys confirmed the presence of nickel oxides, titanium oxides and chromium oxides on the surface. However, depth profiles of NiTi10Cu alloys depicted the presence of the nickel oxide and titanium oxide while copper was present in the elemental form. Similarly, depth profiles of NiTi10Tauntreated and NiTi10Ta-EP alloys confirmed the presence of titanium oxide, nickel oxide and tantalum oxide while that of NiTi10Ta-MEP reported the presence of only titanium oxide and tantalum oxide as shown in Figure 5-28 to 5-30.

\subsubsection{Montage Plots}

\section{Titanium}

The titanium oxide film on Nitinol appears to be primarily tetravalent titanium, as shown in Ti montage plots, Figure 5-31 to 5-34. This valency $\left(\mathrm{Ti}^{4+}\right)$ appeared relatively independent of surface treatment, as observed in previous studies (Schroeder 2008) (R. H. S. Trigwell 1998). The intensity of the Ti peaks over background depends on the surface treatment, likely because of oxide film thickness. $\mathrm{The}^{+{ }^{+4}}$ peak, which occurs at 458.9 - $459.1 \mathrm{eV}$ was weak for a thin $\mathrm{TiO}_{2}$ layer (Schroeder 2008). $\mathrm{Ti}^{0}$ had a peak at $453.5-454.1 \mathrm{eV}$ (X.-Y. Li 1997). The Ti $2 \mathrm{p}$ peak was a doublet consisting of the $2 \mathrm{p}_{1 / 2}$ and $2 p_{3 / 2}$ peaks with binding energies of 460.8 and $454.6 \mathrm{eV}$, respectively. All Ti spectra were dominated by a peak at $458.9 \mathrm{eV}$, which was assigned to the $\mathrm{Ti}^{+4}\left(\mathrm{TiO}_{2}\right)$. The minor peak observed at $456.8 \mathrm{eV}$ is assigned to $\mathrm{Ti}^{+3}$ species $\left(\mathrm{Ti}_{2} \mathrm{O}_{3}\right)$. The later was only detected in NiTi-MEP, NiTi10Cr-untreated, NiTi10Cr-EP, NiTi10Cr-W\&P and NiTi10Cu-W\&P. 

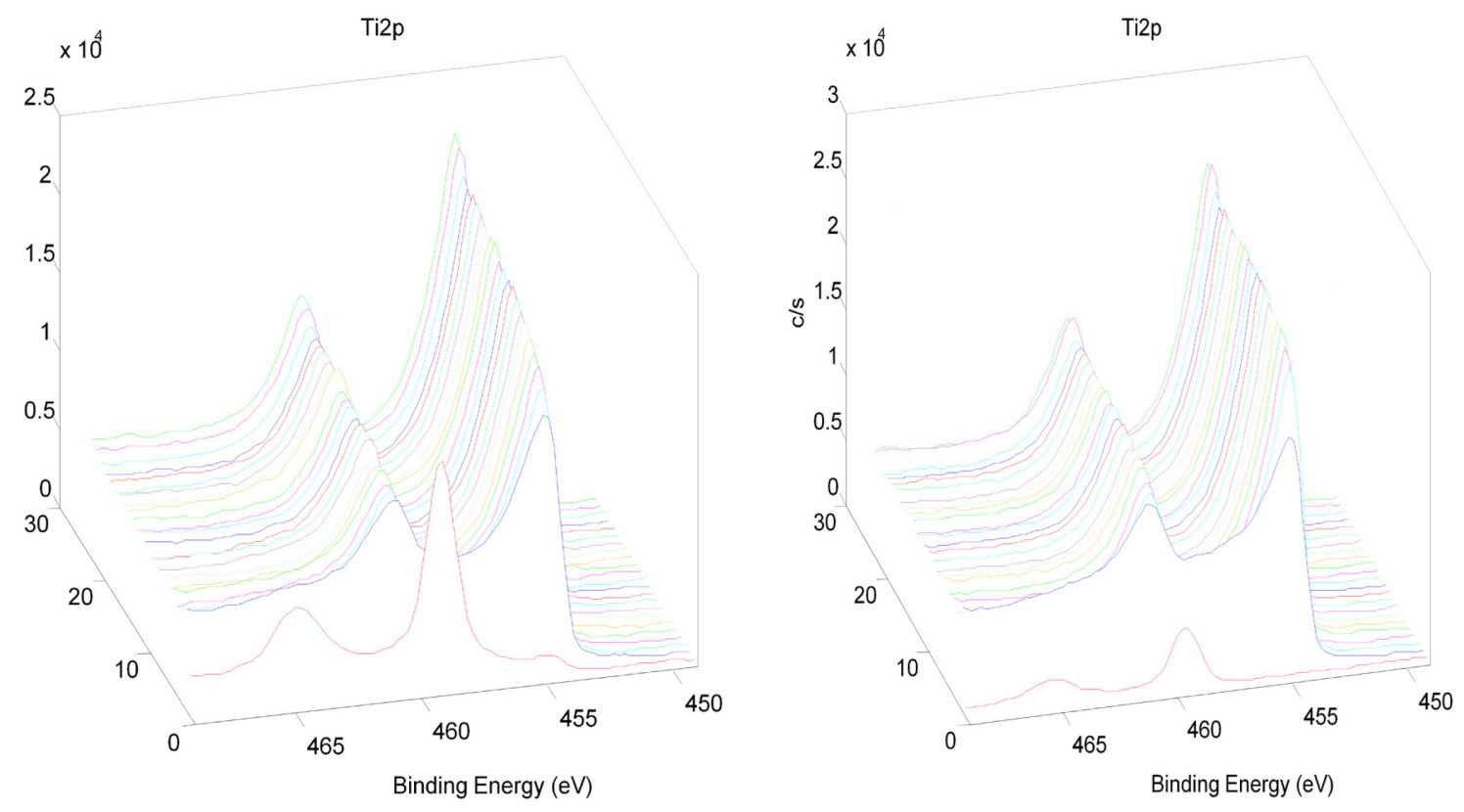

Figure 5-31 Ti montage plot for NiTi- Figure 5-32 Ti montage plot for NiTi-EP untreated

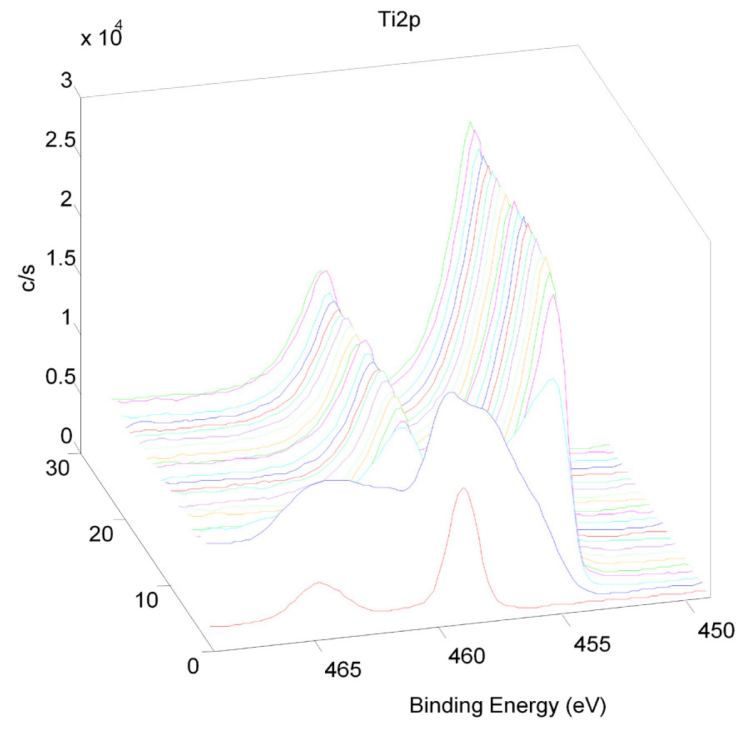

Figure 5-33 Ti montage plot for NiTi-MEP 


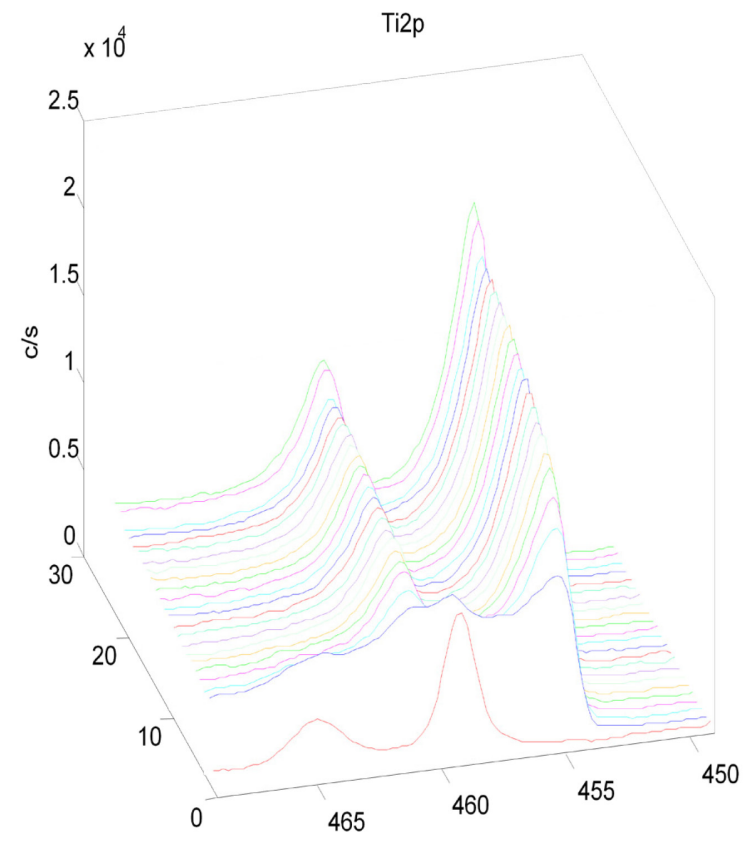

Figure 5-34 Ti montage plot for NiTi10Cruntreated

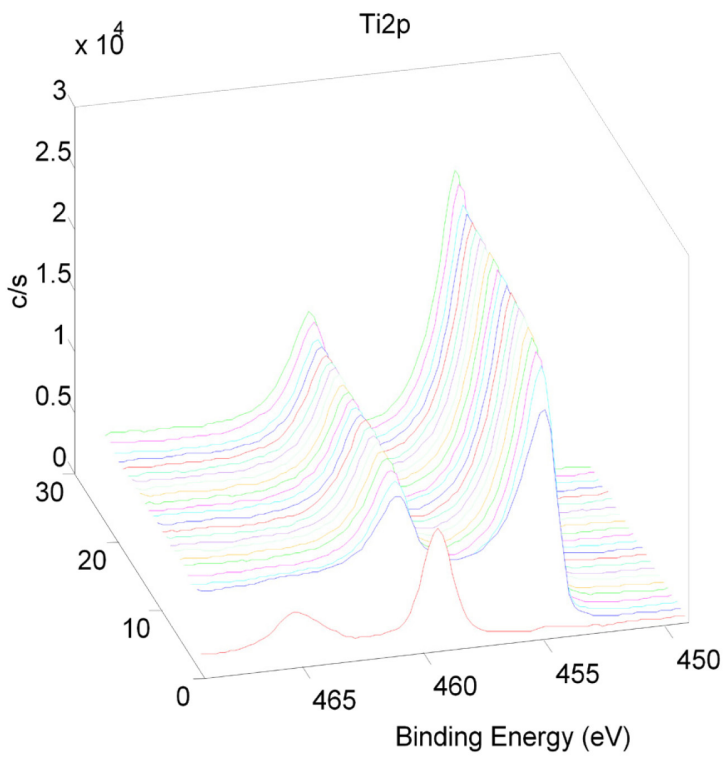

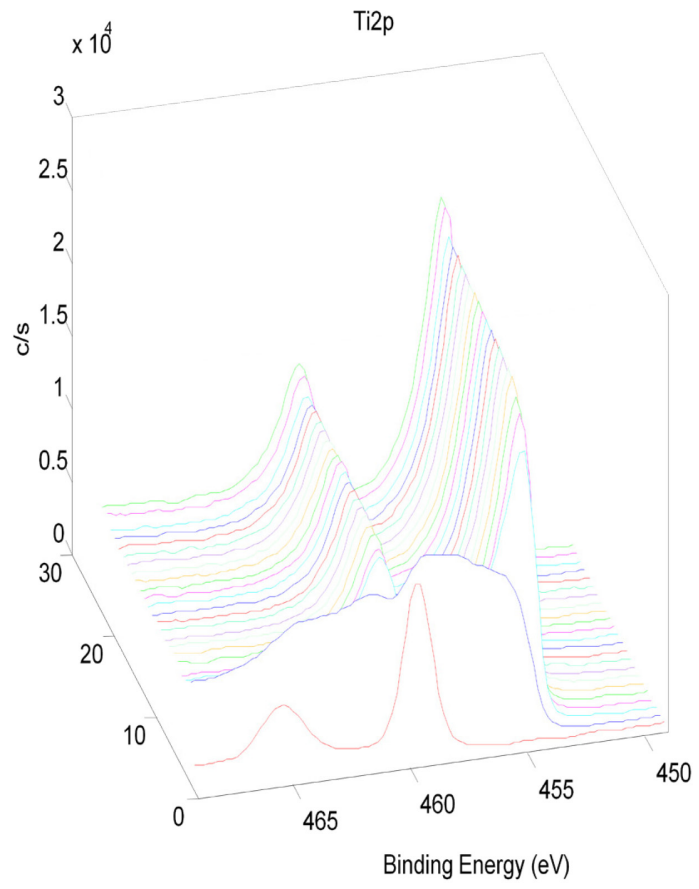

Figure 5-35 $\mathrm{Ti}$ montage plot for NiTi10Cr-EP

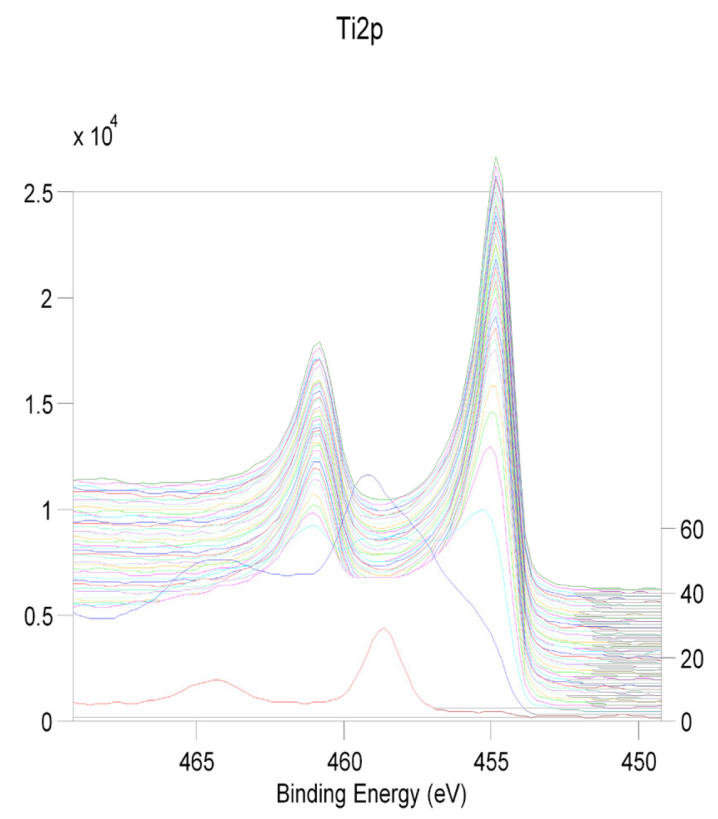

Figure 5-37 Ti montage plot for NiTi10Cr-W\&P 

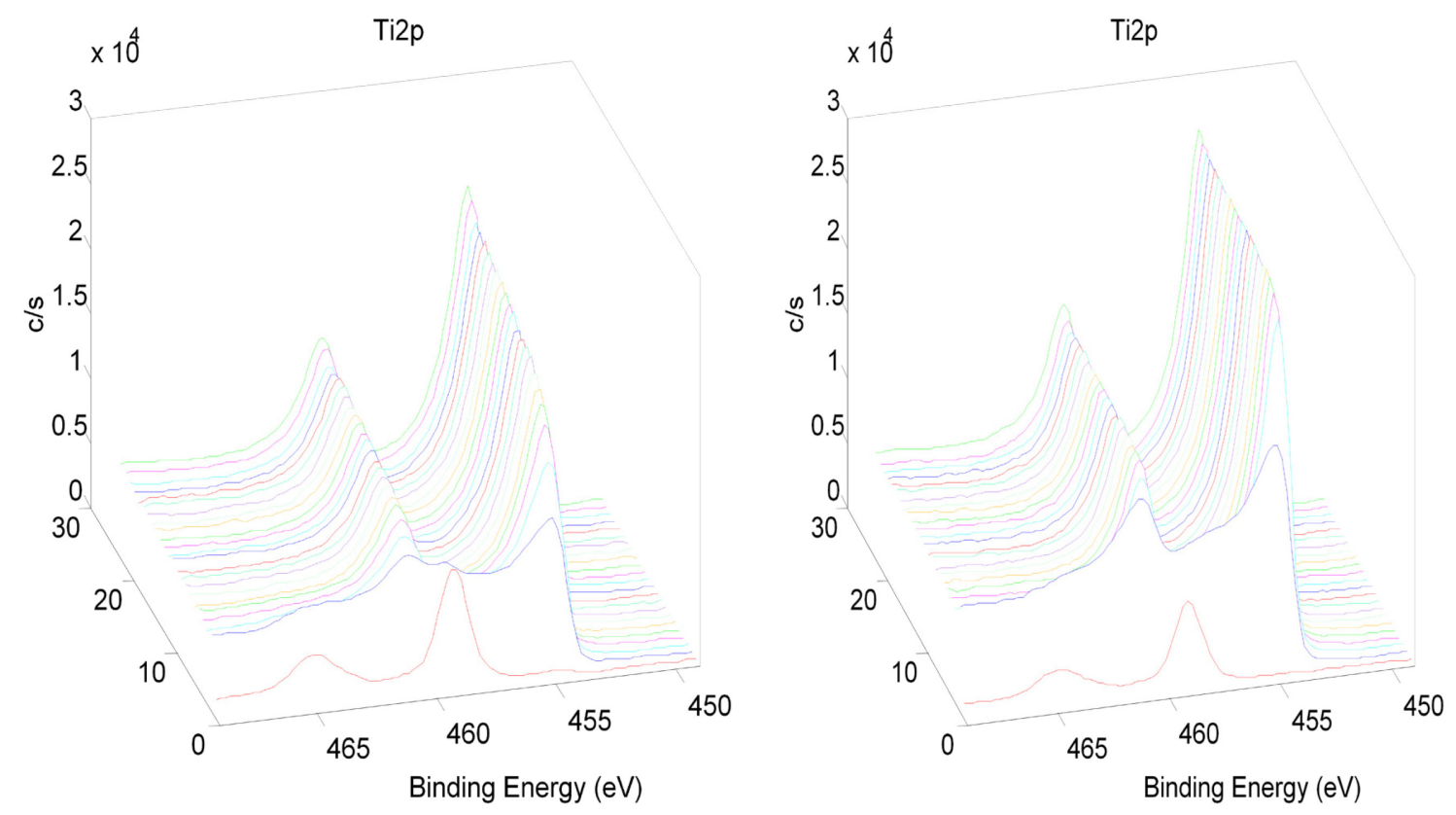

Figure 5-38 Ti montage plot for NiTi10Cu- Figure 5-39 $\mathrm{Ti}$ montage plot for untreated NiTi10Cu-EP
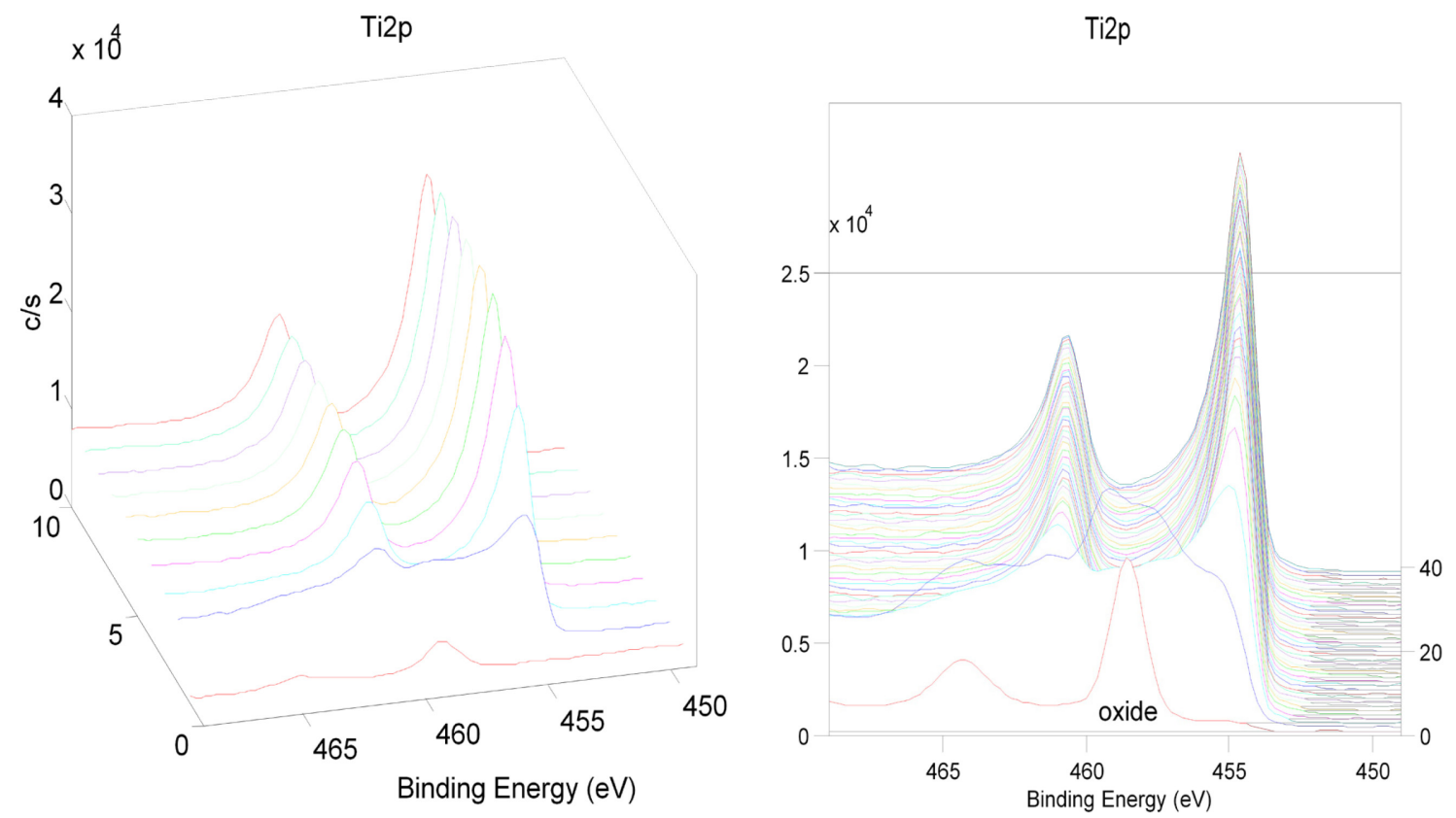

Figure 5-40 Ti montage plot for NiTi10Cu-

Figure 5-41 $\mathrm{Ti}$ montage plot for MEP NiTi10Cu-W\&P 

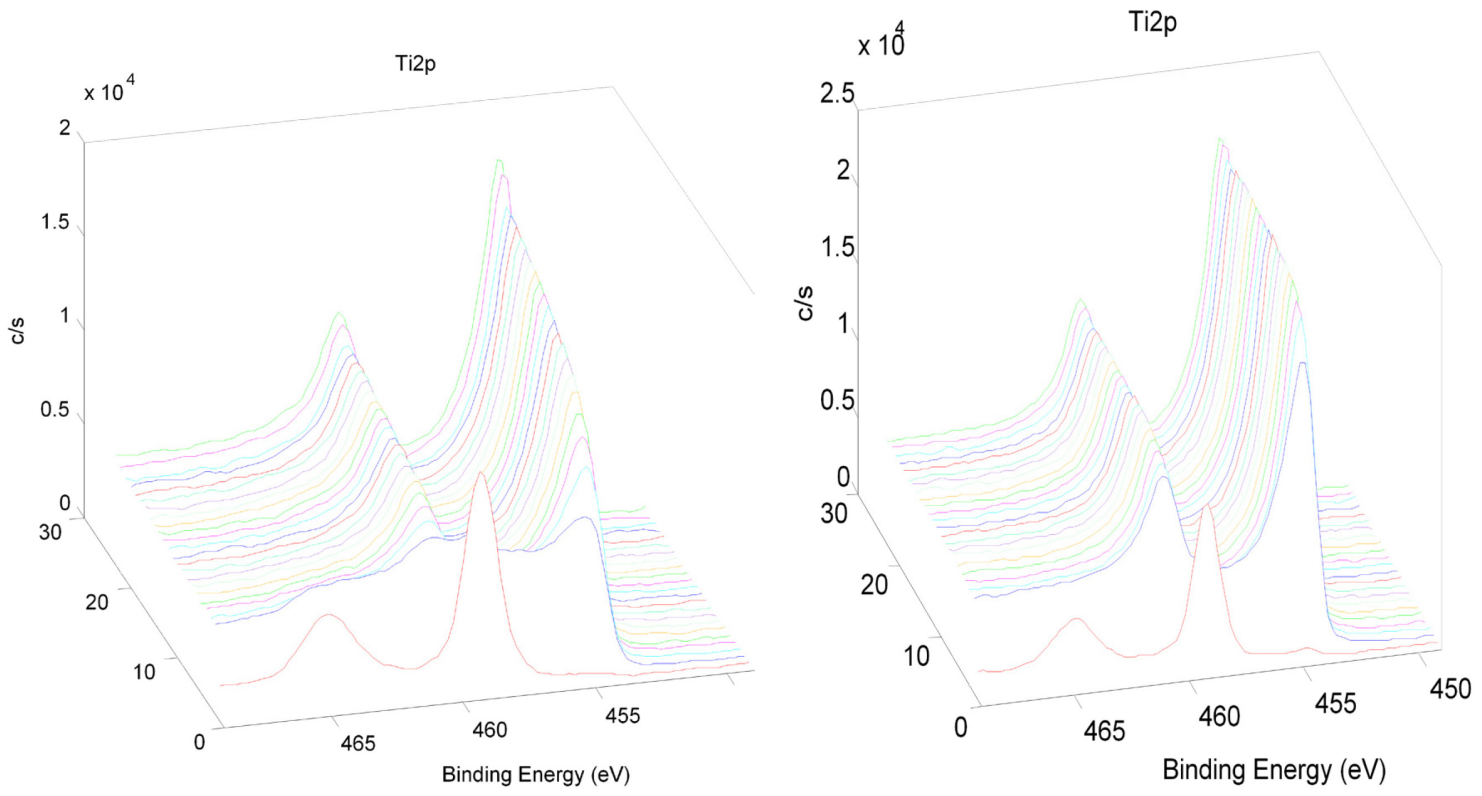

Figure 5-42 Ti montage plot for NiTi10Ta- Figure 5-43 Ti montage plot for untreated NiTi10Ta-EP

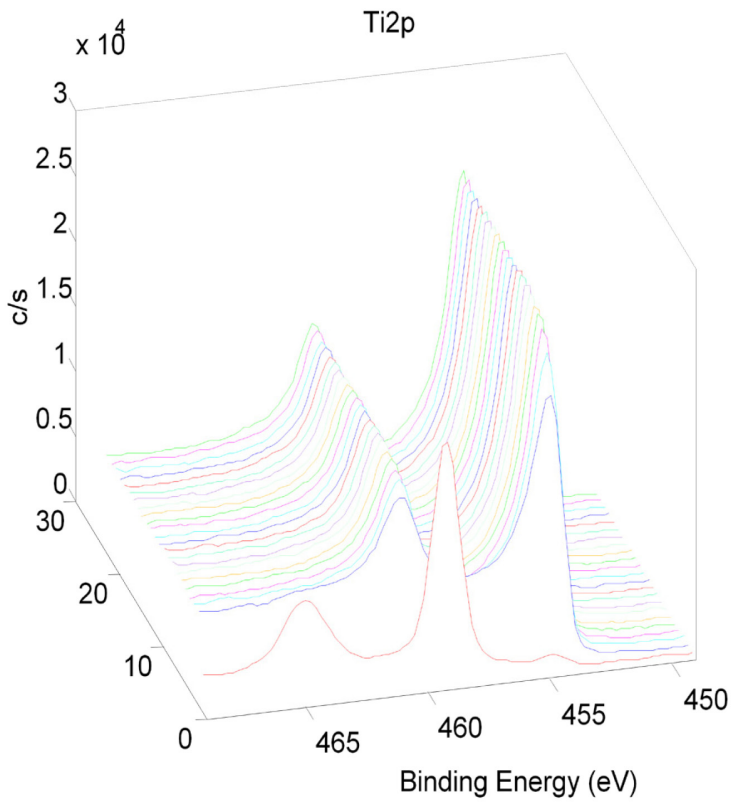

Figure 5-44 Ti montage plot for NiTi10TaMEP 


\section{Nickel}

A peak at $852.8 \mathrm{eV}$ was assigned to nickel in the metallic state, $\mathrm{Ni}^{0}$. The $\mathrm{Ni}$ montage plots in Figures 5-45 to 5-58 exhibited that $\mathrm{Ni}^{0}$ peak was weak or absent on the Nitinol surfaces. The Ni $2 p$ peak was a doublet consisting of the $2 p_{1 / 2}$ and $2 p_{3 / 2}$ peaks whose binding energies were 870.4 and $853.3 \mathrm{eV}$ respectively. The position of the two peaks at 854.7 and $856.4 \mathrm{eV}$, if any, were assigned to $\mathrm{Ni}^{+2}(\mathrm{NiO})$ and $\mathrm{Ni}^{+3}\left(\mathrm{Ni}_{2} \mathrm{O}_{3}\right)$ respectively.
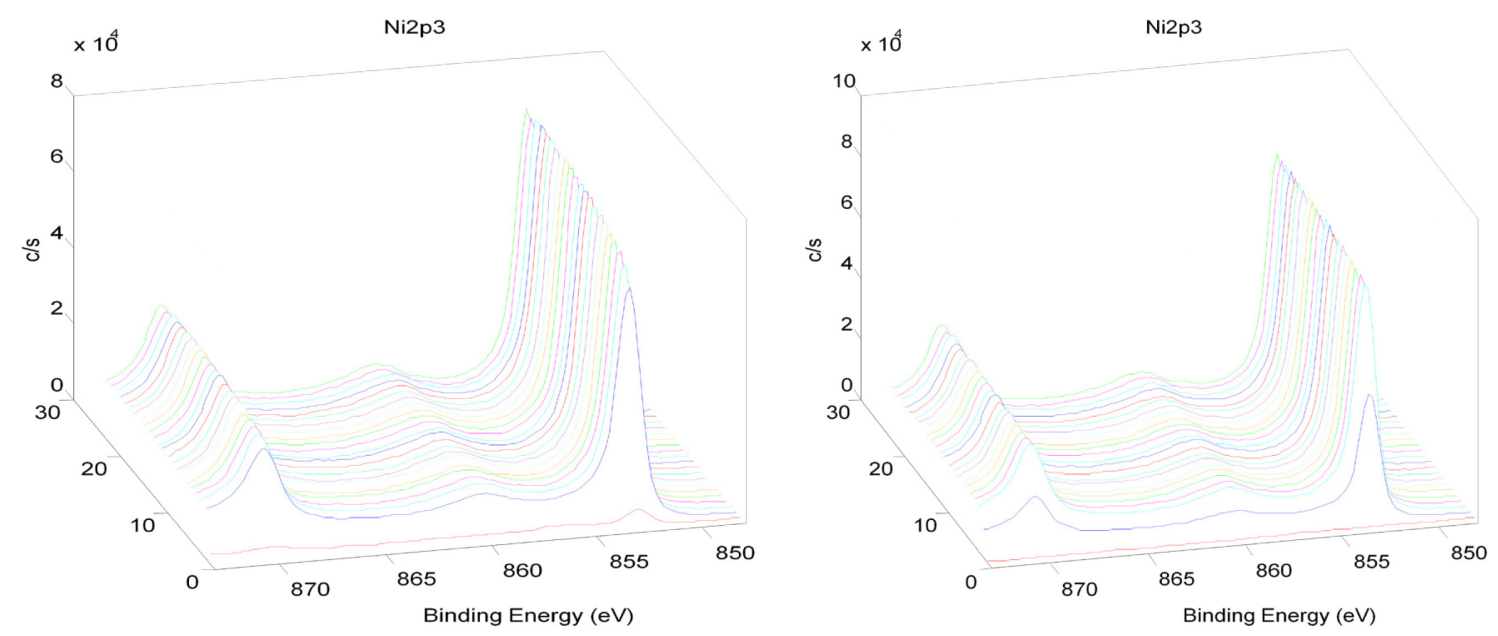

Figure 5-45 Ni montage plot for NiTi- Figure 5-46 Ni montage plot for NiTiuntreated

EP

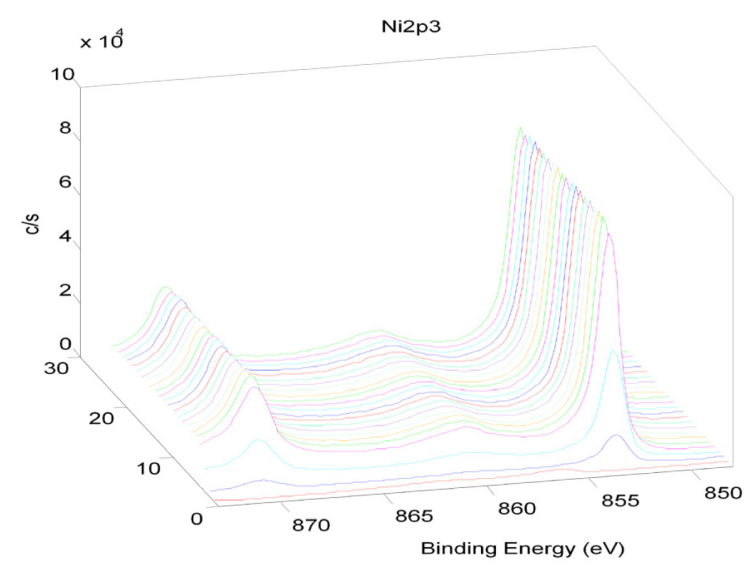

Figure 5-47 Ni montage plot for NiTi-MEP 

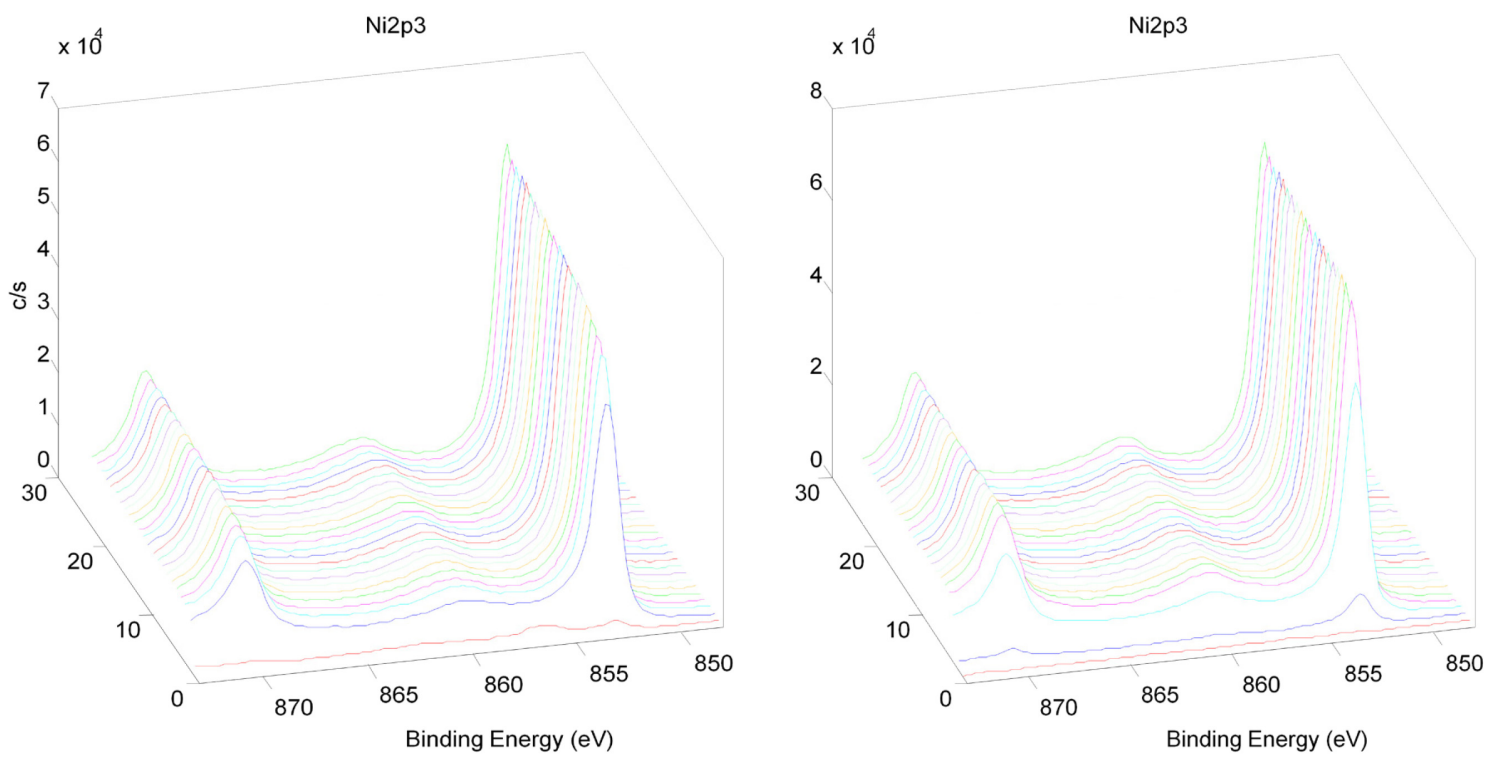

Figure 5-48 Ni montage plot for NiTi10Cr- Figure 5-49 $\mathrm{Ni}$ montage plot for untreated

\section{NiTi10Cr-EP}
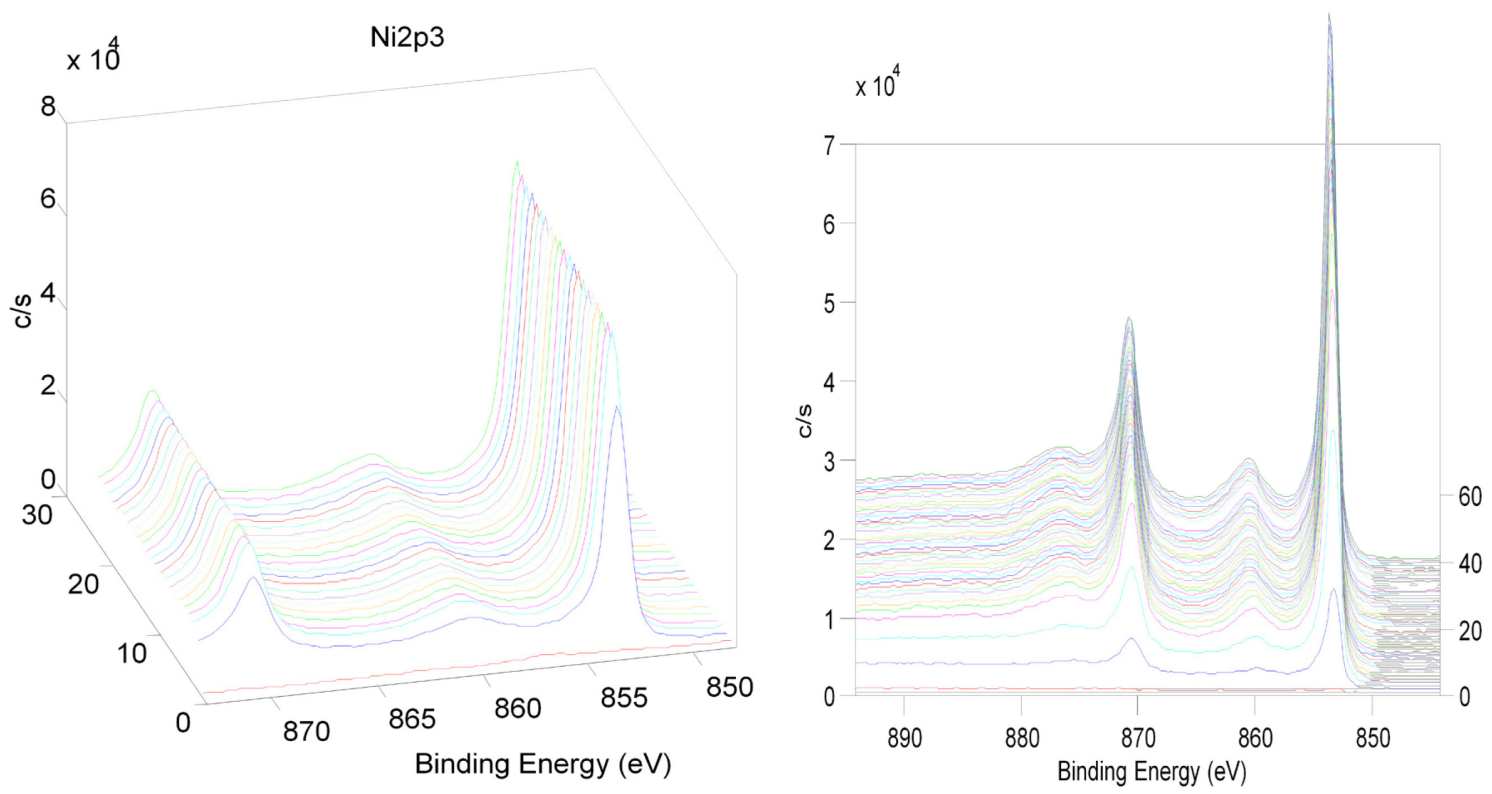

Figure 5-50 Ni montage plot for NiTi10Cr- Figure 5-51 Ni montage plot for MEP NiTi10Cr-W\&P 

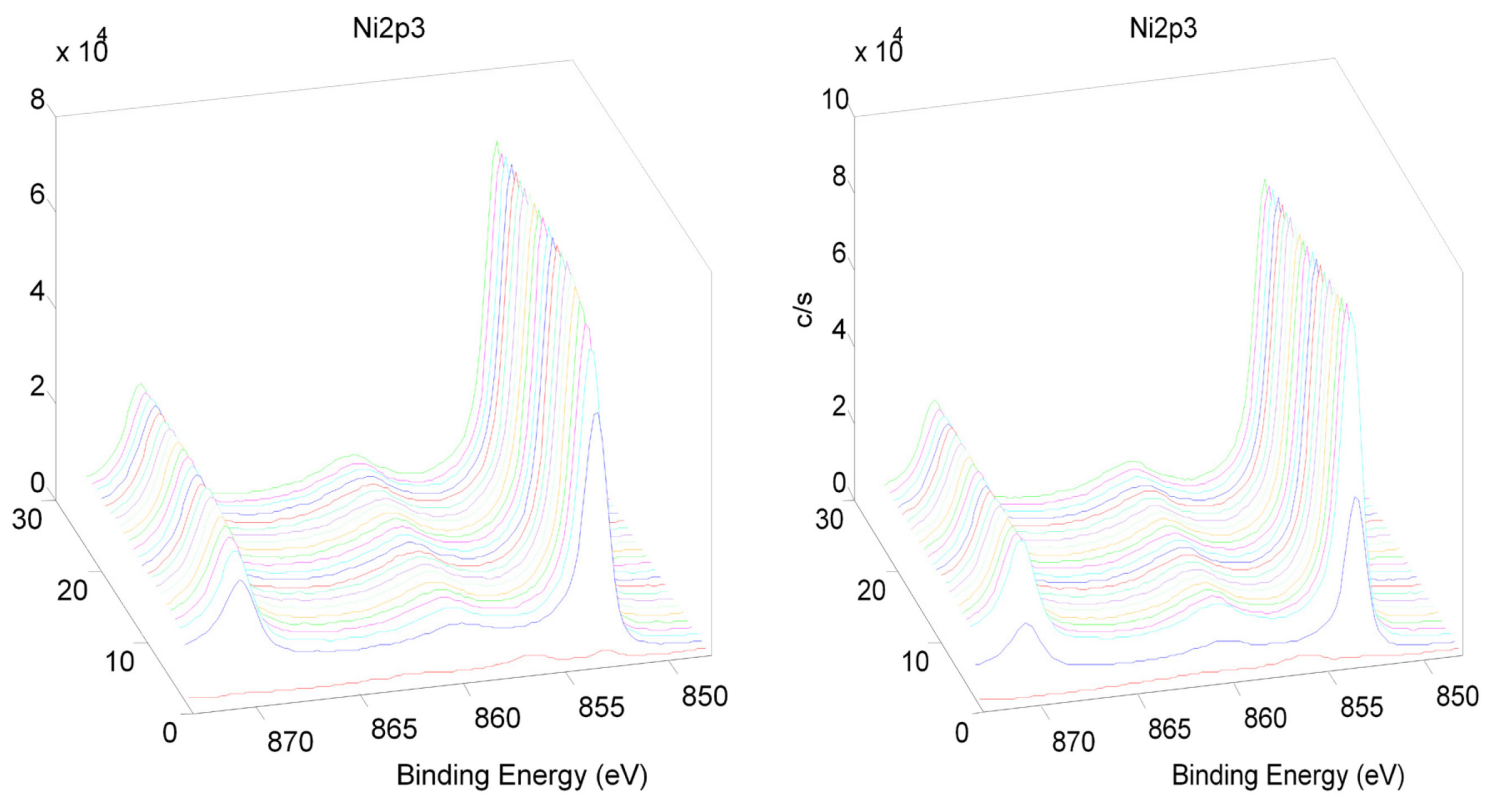

Figure 5-52 Ni montage plot for NiTi10Cu- Figure 5-53 Ni montage plot for untreated NiTi10Cu-EP
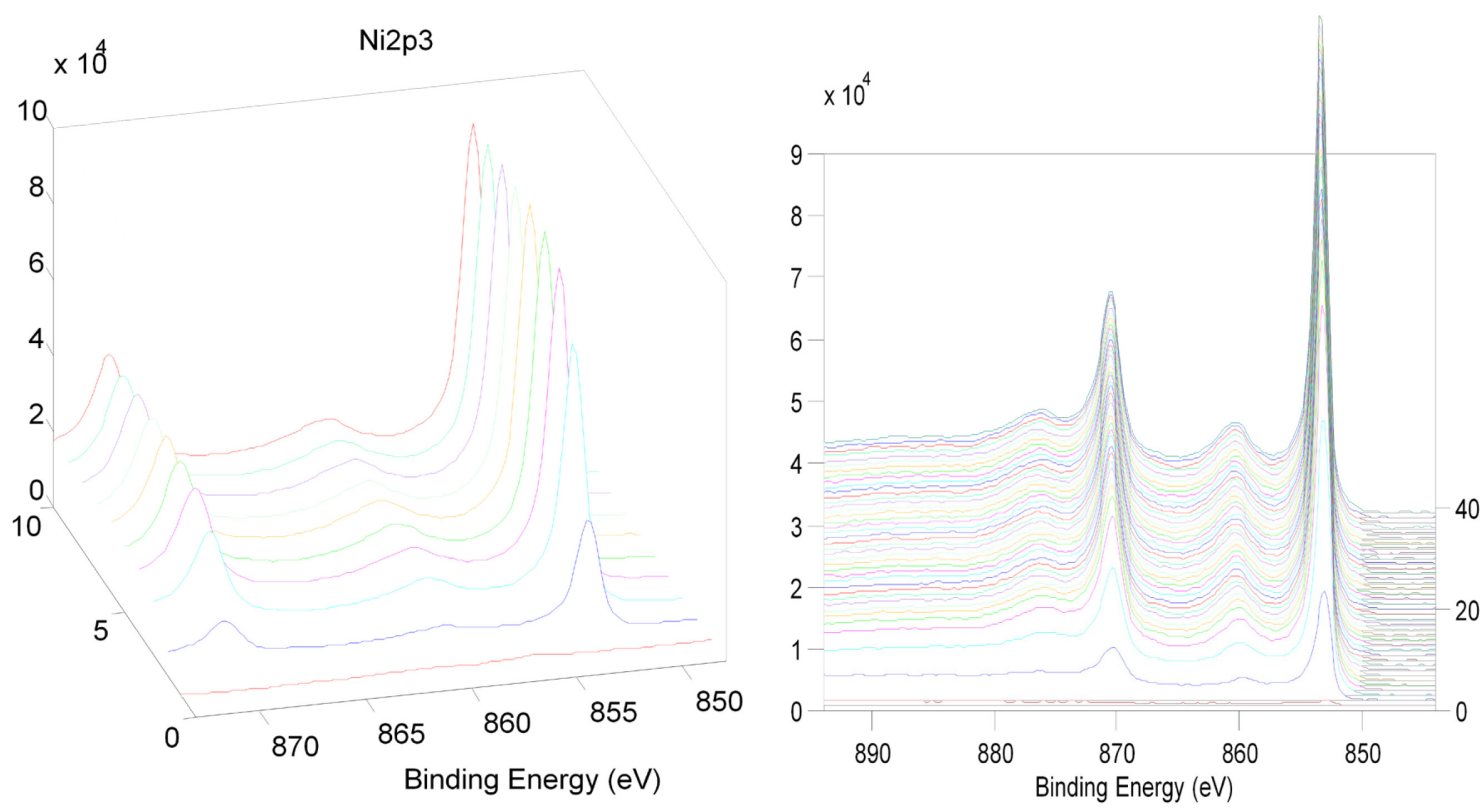

Figure 5-54 Ni montage plot for NiTi10Cu- Figure 5-55 Ni montage plot for MEP NiTi10Cu-W\&P 

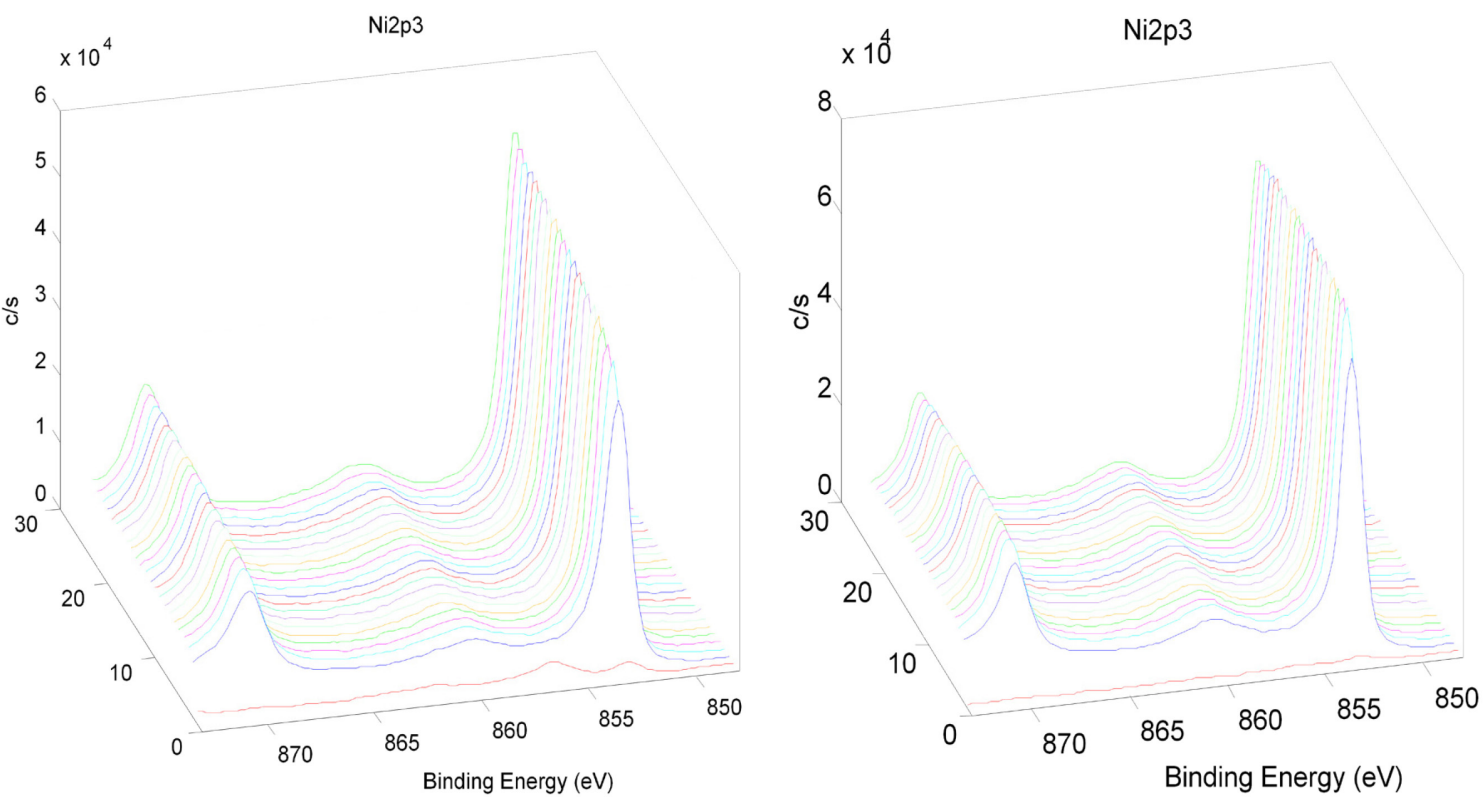

Figure 5-56 Ni montage plot for NiTi10Tauntreated

Figure 5-57 Ni montage plot for NiTi10Ta-EP

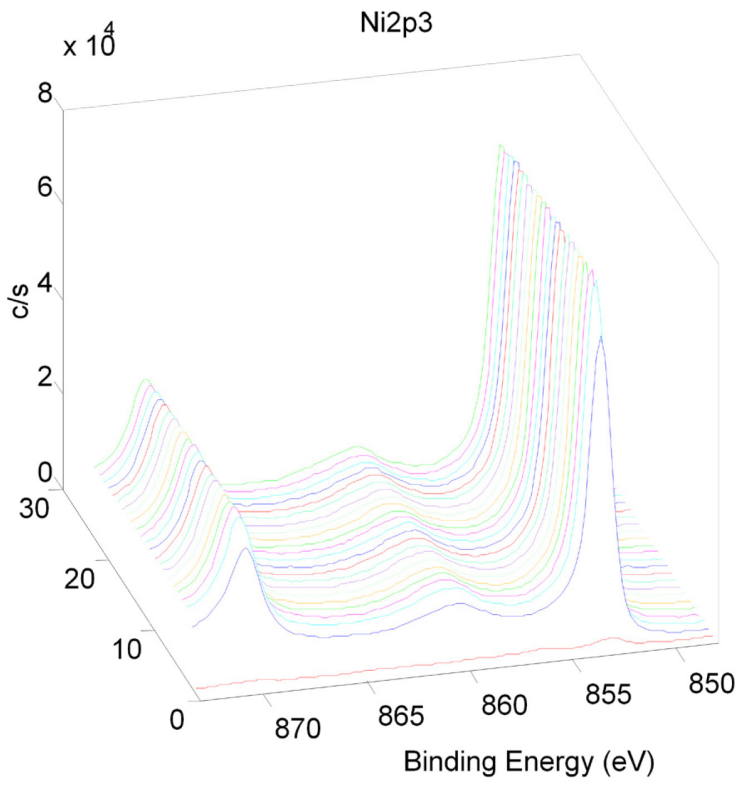

Figure 5-58 Ni montage plot for NiTi10TaMEP 
The Ni montage plot shown in Figure 5-45 for NiTi-untreated alloy illustrated a distinct elemental nickel peak at $852.8 \mathrm{eV}$. However, no nickel was detected on the surface of NiTi-EP alloy, which was consistent with the results obtained by Michiardi (A. Michiardi 2005). Similarly, no nickel peak was observed on the top surface layer of NiTiMEP. However, subsurface layers revealed a comparatively weak nickel peak when compared with its bulk. On the other hand, a weak peak of $\mathrm{Ni}^{+3}\left(\mathrm{Ni}_{2} \mathrm{O}_{3}\right)$ was detected on the top surface NiTi-MEP.

It is worth mentioning here that $\mathrm{Ni}$ concentration in PBS after corrosion tests conducted on NiTi-untreated as displayed in Table 20 was mainly due to relatively high $\mathrm{Ni}$ concentration in the top surface and sub-surface layers as shown in Figure 5-45. The first etching cycle on NiTi-untreated revealed a $\mathrm{Ni}^{0}$ peak while that of NiTi-EP and NiTiMEP revealed no $\mathrm{Ni}^{0}$ peak. Similarly, $\mathrm{Ni}^{0}$ enriched sub-surface layers were more pronounced on NiTi-untreated surface when compared with NiTi-EP and NiTi-MEP as shown in Figure 5-46 \& 5-47. It has been reported that elemental nickel from the subsurface layers can diffuse through the porous $\mathrm{TiO}_{2}$ layer and become released into the surrounding environment (J. A. S. Shabalovskaya 2008) (Christine Trépanier 1999). Nickel oxides are known to be less mobile in the $\mathrm{TiO}_{2}$ lattice than metallic nickel (David A. Armitage 2003). It should be noted that it is not only the amount of nickel present at the surface that governs platelet activation but also its oxidative state (David A. Armitage 2003).

Untreated NiTi10Cr, NiTi10Cu and NiTi10Ta displayed weak but distinct $\mathrm{Ni}^{0}$ and $\mathrm{Ni}^{+3}$ peaks as shown in Figures 5-48, 5-52 and 5-56, respectively. However, no elemental nickel was detected on the top surface layer of NiTi10Cr-EP, NiTi10Cu-EP and 
NiTi10Cu-MEP alloys as depicted in Figures 5-49, 5-53 and 5-54 respectively, but subsurface layers showed comparatively weak nickel peaks when compared with that in its bulk.

\section{Chromium}

The Cr-2p3 peak was a doublet consisting of the $2 \mathrm{p}_{1 / 2}$ and $2 \mathrm{p}_{3 / 2}$ peaks, with binding energies of 583.6 and $574.4 \mathrm{eV}$ respectively. The peak at $576.9 \mathrm{eV}$ was assigned to trivalent chromium $\left(\mathrm{Cr}_{2} \mathrm{O}_{3}\right)$ on the surface layer. The $\mathrm{Cr}^{3+}$ and $\mathrm{Cr}^{0}$ peaks were weak on all untreated and treated NiTi10Cr alloys as shown in Figures 5-59 to 5-62.

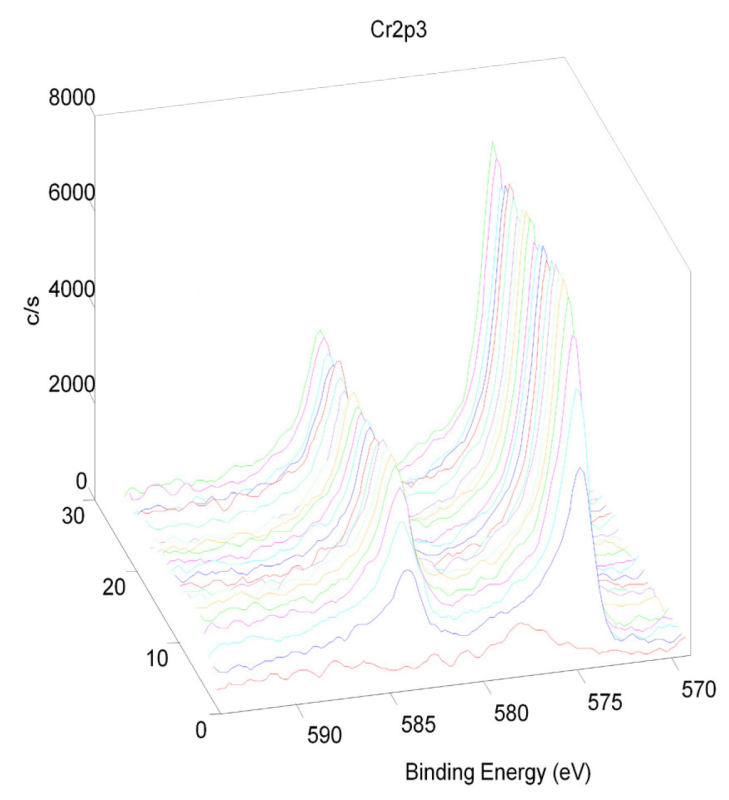

Figure 5-59 $\mathrm{Cr}$ montage plot for

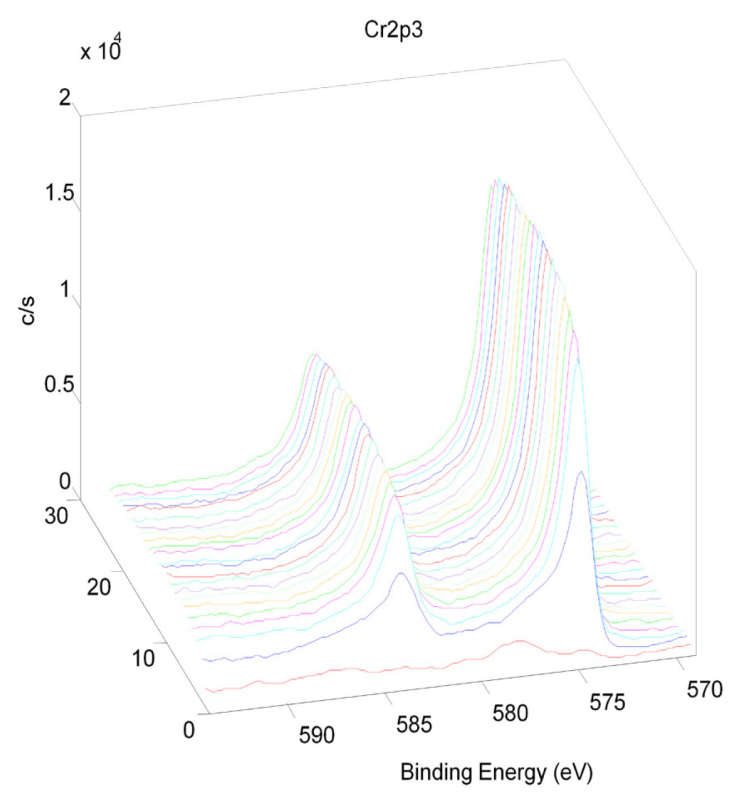

Figure 5-60 $\mathrm{Cr}$ montage plot for 

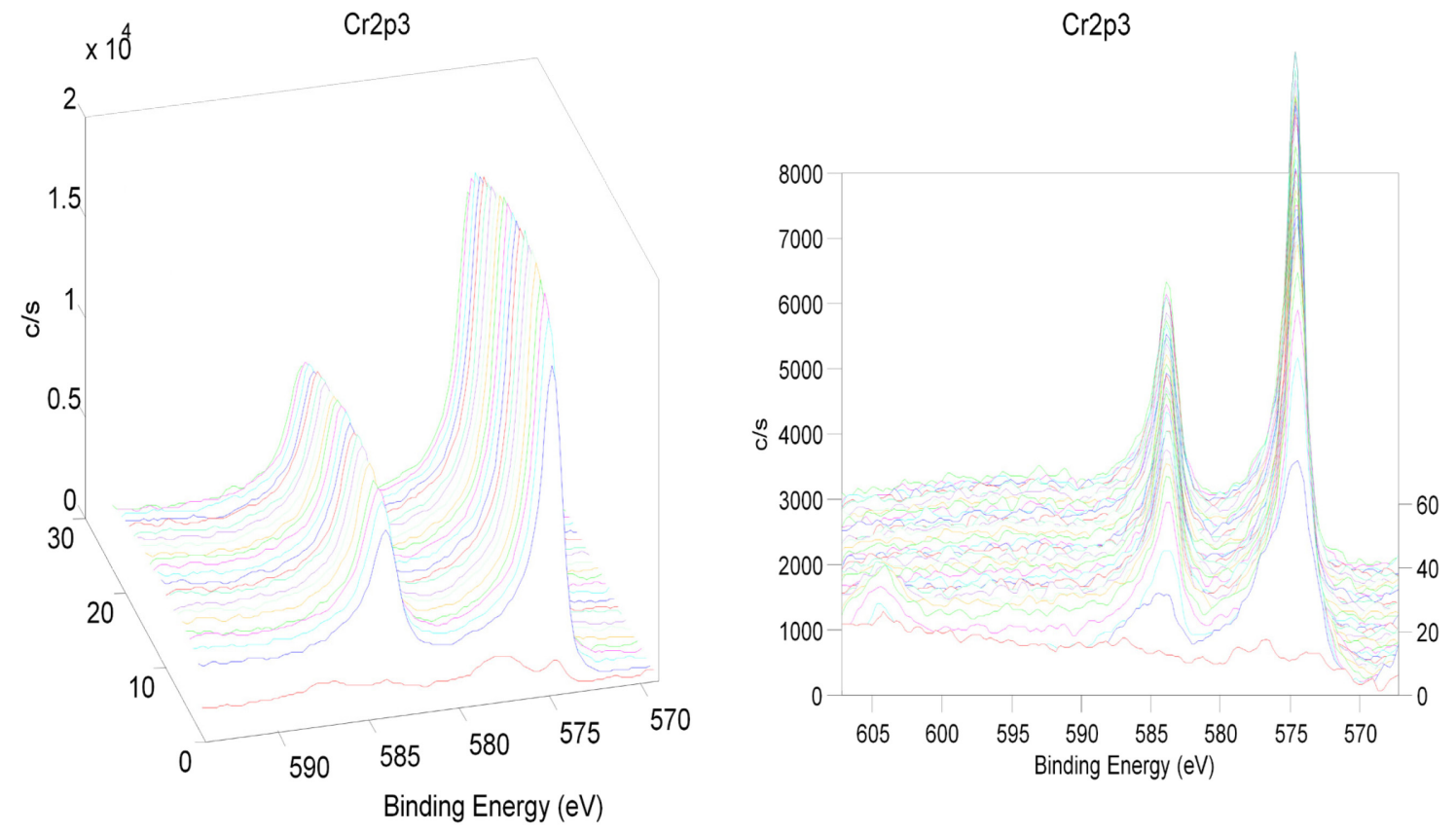

Figure 5-61 $\mathrm{Cr}$ montage plot for Figure 5-62 Cr montage plot for NiTi10CrNiTi10Cr-MEP

W\&P

\section{Copper}

The $\mathrm{Cu}-2 \mathrm{p} 3$ montage plot was shown in Figures 5-63 to 5-66 with a binding energy of $932.7 \mathrm{eV}$. All the copper was present in its elemental form and no Copper oxide peak was detected on the surface of $\mathrm{NiTi10Cu}$ alloys. Strong $\mathrm{Cu}^{0}$ peaks on NiTi10Cu-MEP suggested $\mathrm{Cu}$ enriched sub-surface layers as depicted in Figure 5-65. 

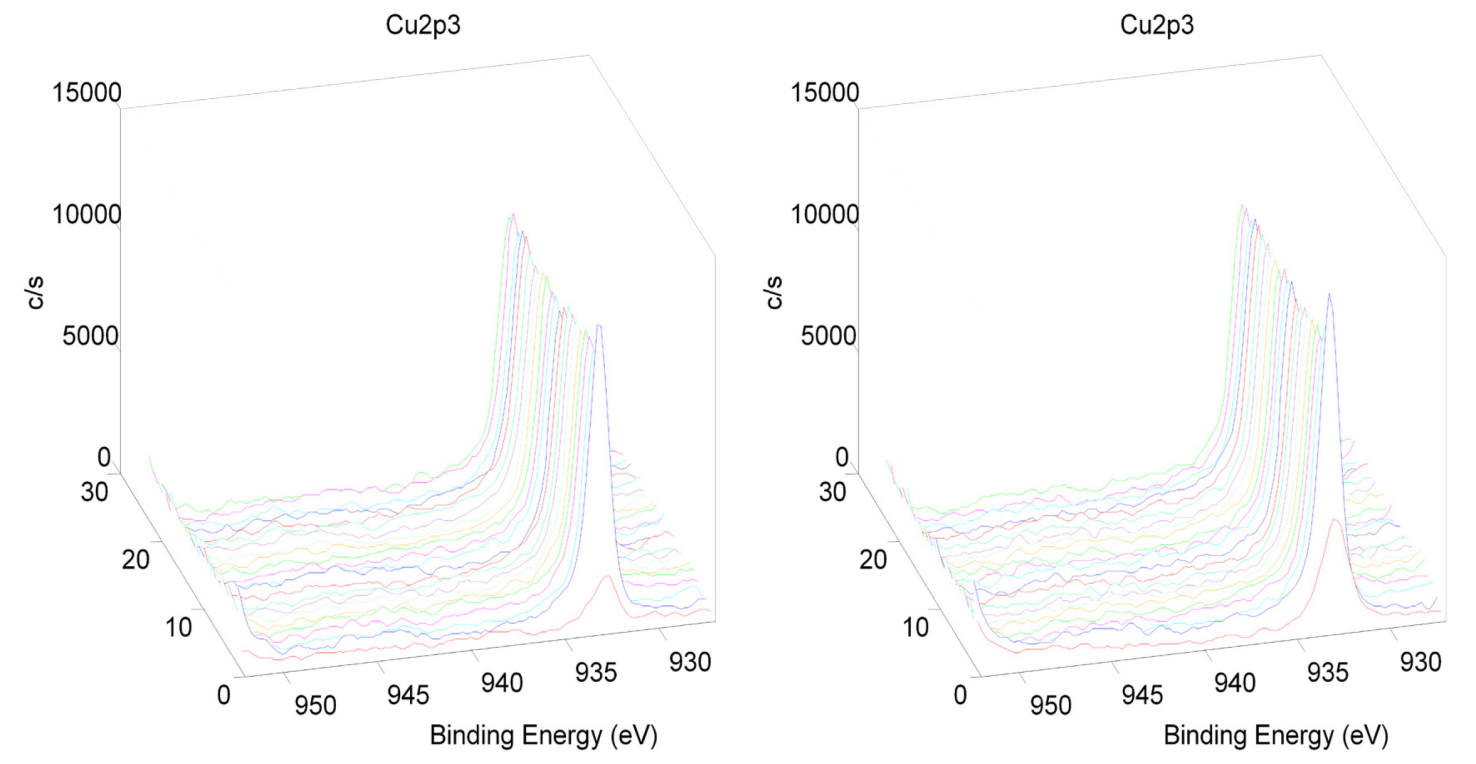

Figure 5-63 $\mathrm{Cu}$ montage plot for Figure 5-64 $\mathrm{Cu}$ montage plot for NiTi10Cu-

NiTi10Cu-untreated

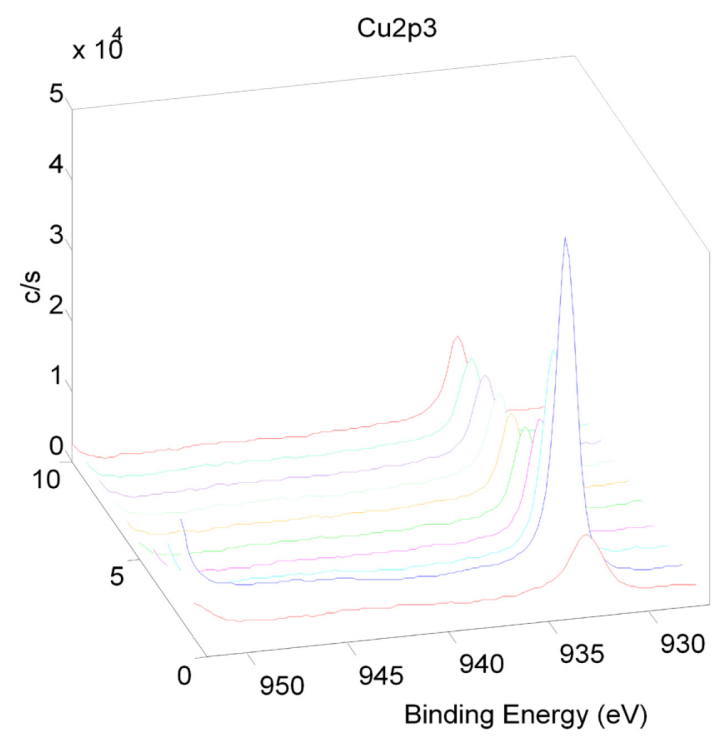

EP

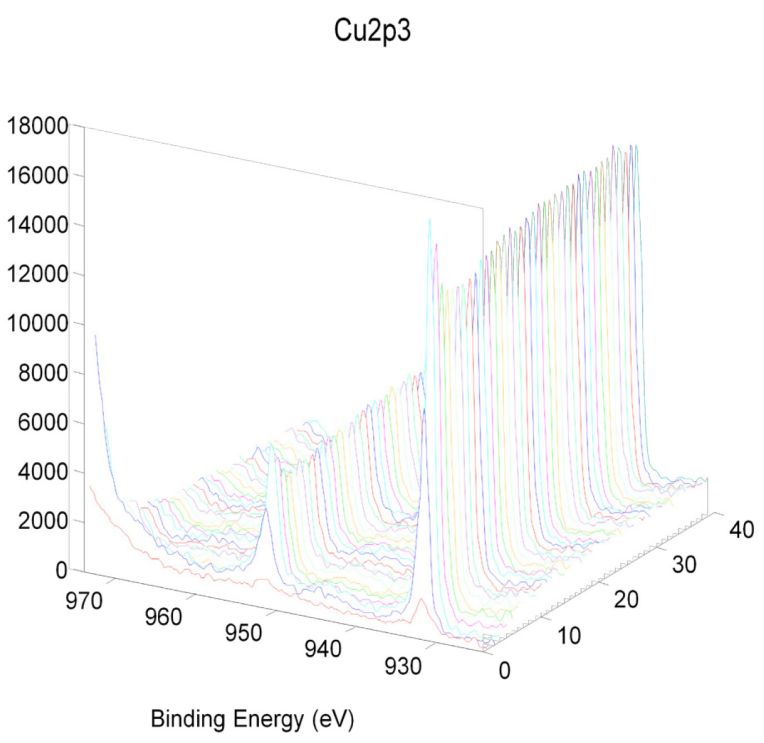

Figure 5-65 $\mathrm{Cu}$ montage plot for Figure 5-66 $\mathrm{Cu}$ montage plot for NiTi10CuNiTi10Cu-MEP W\&P 


\section{Tantalum}

The Ta-4f peak was a doublet consisting of the $4 \mathrm{f}_{5 / 2}$ and $4 \mathrm{f}_{7 / 2}$ peaks with binding energies of 23.8 and $21.9 \mathrm{eV}$ respectively. The Ta $5 \mathrm{p}_{3 / 2}$ peak had the binding energy of $32.9 \mathrm{eV}$. The doublet consisting of the $4 \mathrm{f}_{5 / 2}$ and $4 \mathrm{f}_{7 / 2}$ peaks whose binding energies were 26.4 and $28.2 \mathrm{eV}$ respectively, belong to $\mathrm{Ta}^{+5}\left(\mathrm{Ta}_{2} \mathrm{O}_{5}\right)$. This oxide peak was present on all untreated and treated NiTi10Ta alloys owing to Tantalum's high affinity for oxygen.
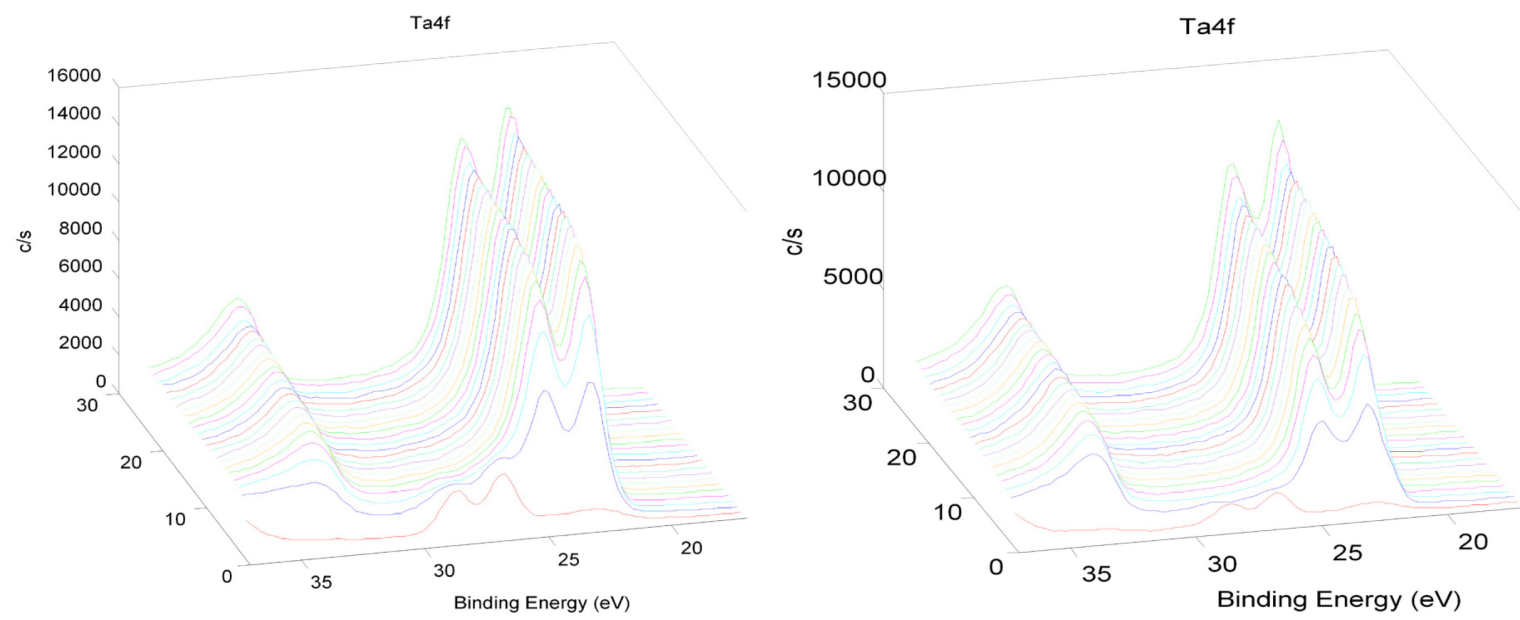

Figure 5-67 Ta montage plot for Figure 5-68 Ta montage plot for NiTi10TaNiTi10Ta-untreated EP

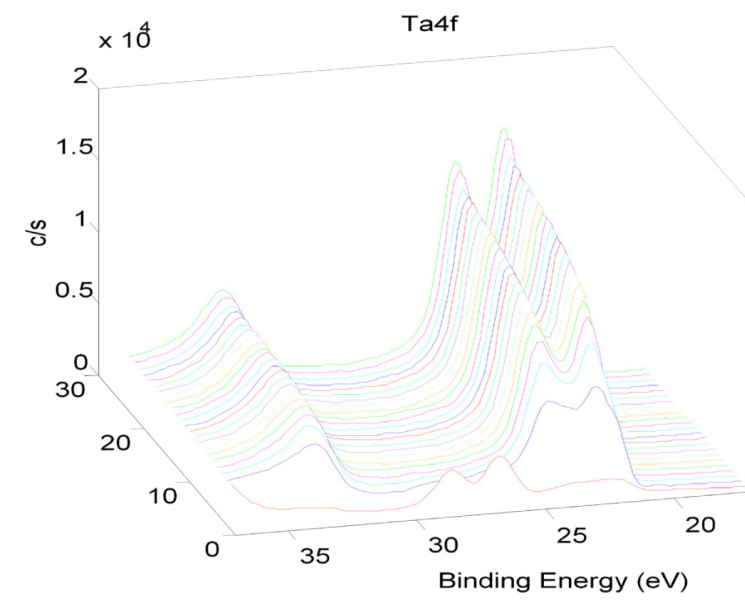

Figure 5-69 Ta montage plot for

NiTi10Ta-MEP 


\subsubsection{Composition of Nitinol Surfaces}

Since the information on the surface chemistry is important for understanding its biological behavior, elemental surface concentrations and $\mathrm{Ti} / \mathrm{Ni}$ ratios are given in Table 5-1, whereas, various oxide concentrations and oxide thicknesses are given in Table 5-2. The detailed XPS survey spectra are shown in Appendix A. The oxide thickness was estimated by marking the sputtering time at which the oxygen signal dropped to $50 \%$ in depth profile plots as described in previous studies (C.L. Chu 2008). This time was then used to calculate the thickness of the oxide layer using the sputter rate of $6.5 \mathrm{~nm} / \mathrm{minute}$. Although the oxide layer formed after surface treatments was thin, it appeared to be effective in blocking $\mathrm{Ni}$ ion release as indicated by the low nickel concentration, determined by ICP-MS analysis, shown in Tables 3-21 to 3-24.

In general, $\mathrm{Ni}$ concentration on the surface decreased as a result of most surface treatments performed on the Nitinol alloys. No Ni was observed on NiTi-EP and NiTi10Cr-EP. In the case of NiTi10Cr and NiTi10Ta alloys, the Ti/Ni ratio was increased after MEP and W\&P surface treatments when compared with that of the untreated alloys. However, NiTi and NiTi10Cu alloys showed mixed trends.

The oxide thickness of NiTi-untreated was $22.7 \mathrm{~nm}$ but it decreased to $16.2 \mathrm{~nm}$ after electropolishing and to $18.2 \mathrm{~nm}$ after magnetoelectropolishing. Addition of the ternary element into NiTi had significantly increased the oxide thickness; it increased to $29.2 \mathrm{~nm}, 30.5 \mathrm{~nm}$ and $32.5 \mathrm{~nm}$ after the addition of tantalum, chromium and copper respectively. The oxide thicknesses of ternary Nitinol alloys also decreased after surface

treatments as displayed in Table 5-2. These thin oxide layers were very effective in inhibiting nickel release. 
Table 5-1 Elemental concentrations (at. \%) on the surfaces of Nitinol alloys detected using XPS

\begin{tabular}{|l|c|c|c|c|c|c|c|c|c|}
\hline Alloys & $\mathbf{C}$ & $\mathbf{O}$ & $\mathbf{N}$ & $\mathbf{T i}$ & $\mathbf{N i}$ & $\mathbf{C r}$ & $\mathbf{C u}$ & $\mathbf{T a}$ & $\mathbf{T i} / \mathbf{N i}$ \\
\hline NiTi-untreated & 45.8 & 37.6 & 1.9 & 10.2 & 3.8 & & & & 2.68 \\
\hline NiTi-EP & 72.1 & 19.2 & 4.0 & 2.8 & & & & & \\
\hline NiTi-MEP & 51.0 & 34.8 & 3.6 & 5.9 & 2.7 & & & & 2.18 \\
\hline NiTi10Cr- untreated & 45.1 & 37.4 & 2.6 & 5.2 & 3.2 & 0.4 & & & 1.62 \\
\hline NiTi10Cr-EP & 45.9 & 37.9 & 4.3 & 7.4 & & 1.5 & & & \\
\hline NiTi10Cr-MEP & 59.5 & 28.9 & 2.3 & 5.0 & 1.5 & 2.2 & & & 3.33 \\
\hline NiTi10Cr-W\&P & 63.0 & 25.8 & 2.0 & 5.2 & 0.7 & 0.4 & & & 7.42 \\
\hline NiTi10Cu- untreated & 54.1 & 30.7 & 3.5 & 5.9 & 1.8 & & 0.8 & & 3.27 \\
\hline NiTi10Cu-EP & 63.3 & 24.3 & 1.7 & 3.8 & 4.2 & & 1.6 & & 0.90 \\
\hline NiTi10Cu-MEP & 68.8 & 22.7 & & 2.0 & 1.1 & & 5.5 & & 1.81 \\
\hline NiTi10Cu-W\&P & 67.7 & 22.5 & 1.6 & 4.3 & 0.3 & & 0.4 & & 14.3 \\
\hline NiTi10Ta- untreated & 38.2 & 39.8 & 1.9 & 7.1 & 4.0 & & & 2.4 & 1.77 \\
\hline NiTi10Ta-EP & 56.5 & 29.1 & 5.2 & 6.8 & 1.0 & & & 1.4 & 6.80 \\
\hline NiTi10Ta-MEP & 41.4 & 39.8 & 4.9 & 10.2 & 1.2 & & & 2.4 & 8.50 \\
\hline
\end{tabular}

Table 5-2 Oxides concentration and thickness on the surfaces of Nitinol alloys detected using XPS

\begin{tabular}{|l|c|c|c|c|c|}
\hline Alloys & $\mathrm{TiO}_{2}$ (at.\%) & $\mathrm{Ni}_{2} \mathrm{O}_{3}$ (at.\%) & $\mathrm{Cr}_{2} \mathrm{O}_{3}$ (at.\%) & $\begin{array}{l}\mathrm{Ta}_{2} \mathrm{O}_{5} \\
\text { (at.\%) }\end{array}$ & $\begin{array}{l}\text { Oxide } \\
\text { Thickness } \\
\text { (nm) }\end{array}$ \\
\hline NiTi-untreated & 11 & & & & 22.7 \\
\hline NiTi-EP & 3.5 & & & & 16.2 \\
\hline NiTi-MEP & 6.5 & 1.1 & & & 18.2 \\
\hline NiTi10Cr & 5.5 & 1.0 & 1.8 & & 30.5 \\
\hline NiTi10Cr-EP & 7.2 & 0.5 & 1.8 & & 16.2 \\
\hline NiTi10Cr-MEP & 6.0 & 1.7 & 2.0 & & 11.0 \\
\hline NiTi10Cr-W\&P & 3.5 & & 0.3 & & 9.5 \\
\hline NiTi10Cu & 6.0 & 1.2 & & & 32.5 \\
\hline NiTi10Cu-EP & 4.0 & 3.0 & & & 12.3 \\
\hline NiTi10Cu-MEP & 2.5 & 1.2 & & & 16.9 \\
\hline NiTi10CuW\&P & 7.5 & & & & 8.2 \\
\hline NiTi10Ta & 8.0 & 3.1 & & 2.2 & 29.2 \\
\hline NiTi10Ta-EP & 7.0 & 0.2 & & 2.4 & 1.0 \\
\hline NiTi10Ta-MEP & 11.7 & & & & 10.4 \\
\hline
\end{tabular}


Nickel was detected in the oxide form $\left(\mathrm{Ni}_{2} \mathrm{O}_{3}\right)$ in all of the alloys except NiTiuntreated, NiTi10Cr-W\&P and NiTi10Cu-W\&P. Since nickel oxides are known to be less mobile in the $\mathrm{TiO}_{2}$ lattice than metallic nickel (David A. Armitage 2003), it has significantly reduce the Ni leaching during the corrosion tests as explained in Section 3.5.

\subsection{Contact Angle Measurement}

In order to assess the biological response of Nitinol alloys, both wettability and surface energy were determined by measuring the contact angle of droplets of different solvents. Thse measurements were conducted by Ebatco ${ }^{\circledR}$ (Eden Prairie, MN, USA) on NiTi, NiTi10Cr-MEP and NiTi10Ta-MEP. It was reported that Nitinol's wettability and surface energy had significant influence on its biological response (J. A. S. Shabalovskaya 2008) (Gopinath Mani 2007). The Kyowa contact angle meter (model DM-CE1) used for this analysis is shown in Figure 5-70.

Tables 5-3 to 5-5 summarized the results of contact angle and surface energy measurements while images of a water droplet on Nitinol alloys are depicted in Figures 5-71 to 5-73.

Contact angles and surface energies were calculated using three different liquids: distilled water, ethylene glycol and diiodomethane, whose surface tensions were known as described in previous studies (V. Muhonen 2008). Single sample was tested for each type of Nitinol alloy, a total of five values were obtained by measuring the contact angle at different locations on the surface (V. Muhonen 2008). Tests were conducted on each specimen at locations with sufficient spacing, so as to prevent any influence of the previous tests. 


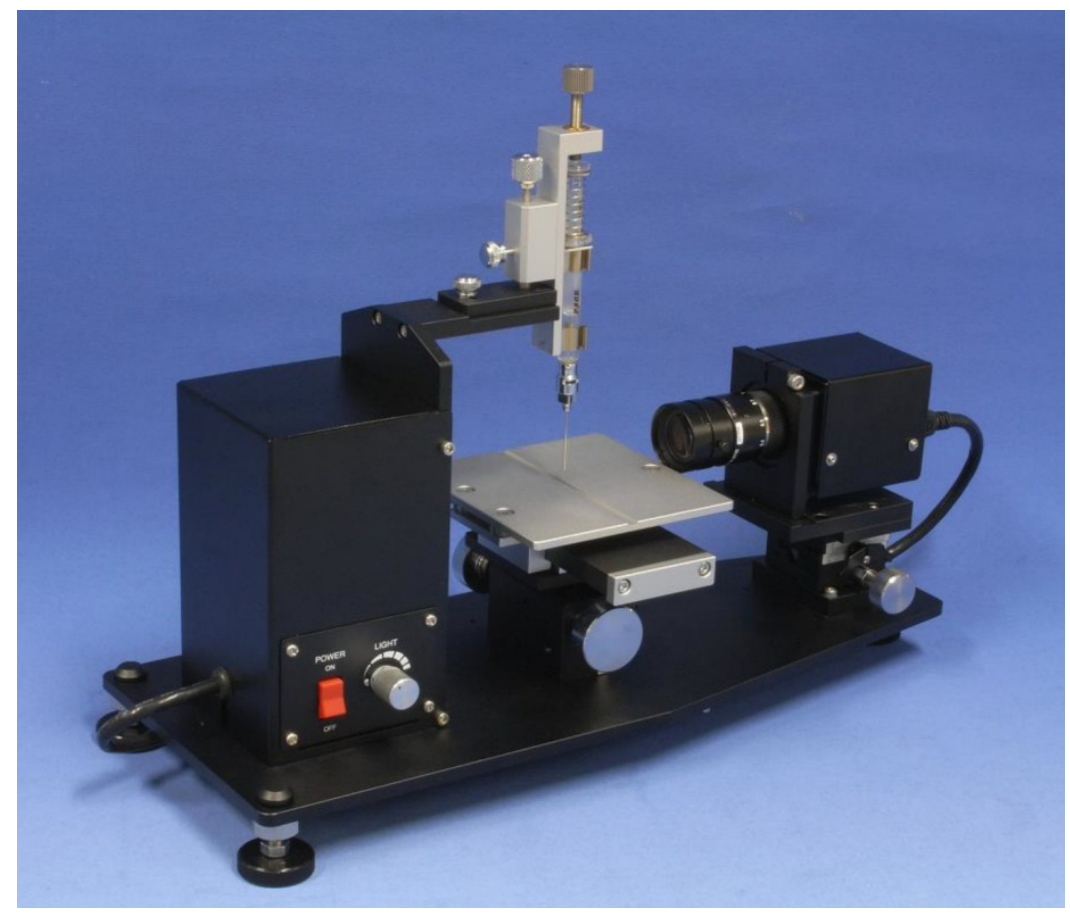

Figure 5-70 The Kyowa Contact Angle Meter

The results of the measurements of contact angles of various liquids on selected Nitinol alloys surfaces revealed that NiTi-untreated surfaces had contact angles less than $90^{\circ}$ and hence were hydrophilic. However, alloying and surface treatment of Nitinol increased the contact angle of the surfaces. The magnetoelectropolished surfaces were more hydrophobic (exhibited a higher contact angle) than the untreated NiTi-untreated surface. 
Table 5-3 Contact Angle Test Results for Distilled Water

\begin{tabular}{|c|c|c|c|c|c|c|c|}
\hline Test No. & 1 & 2 & 3 & 4 & 5 & Average & S.D. \\
\hline Specimen & $\begin{array}{c}\text { C.A. } \\
\text { (Deg) }\end{array}$ & $\begin{array}{c}\text { C.A. } \\
\text { (Deg) }\end{array}$ & $\begin{array}{c}\text { C.A. } \\
\text { (Deg) }\end{array}$ & $\begin{array}{c}\text { C.A. } \\
\text { (Deg) }\end{array}$ & $\begin{array}{c}\text { C.A. } \\
\text { (Deg) }\end{array}$ & $\begin{array}{c}\text { C.A. } \\
\text { (Deg) }\end{array}$ & $\begin{array}{c}\text { C.A. } \\
\text { (Deg) }\end{array}$ \\
\hline $\begin{array}{c}\text { NiTi-untreated } \\
\text { NiTi10Cr- } \\
\text { MEP }\end{array}$ & 64.2 & 64.8 & 66.6 & 64.3 & 63.6 & 64.7 & 1.1 \\
\hline $\begin{array}{c}\text { NiTi10Ta- } \\
\text { MEP }\end{array}$ & 103.8 & 103.7 & 109.4 & 106.1 & 106.6 & 105.9 & 2.3 \\
\hline
\end{tabular}

Table 5-4 Contact Angle Test Results for Ethylene Glycol

\begin{tabular}{|c|c|c|c|c|c|c|c|}
\hline Test No. & 1 & 2 & 3 & 4 & 5 & Average & S.D. \\
\hline $\begin{array}{c}\text { Specimen } \\
\text { C.A. }\end{array}$ & $\begin{array}{c}\text { C.A. } \\
\text { (Deg) }\end{array}$ & $\begin{array}{c}\text { C.A. } \\
\text { (Deg) }\end{array}$ & $\begin{array}{c}\text { C.A. } \\
\text { (Deg) }\end{array}$ & $\begin{array}{c}\text { C.A. } \\
\text { (Deg) }\end{array}$ & $\begin{array}{c}\text { C.A. } \\
\text { (Deg) }\end{array}$ & $\begin{array}{c}\text { C.A. } \\
\text { (Deg) }\end{array}$ \\
\hline $\begin{array}{c}\text { NiTi-untreated } \\
\text { NiTi10Cr- } \\
\text { MEP }\end{array}$ & 69.0 & 69.2 & 68.4 & 69.3 & 70.7 & 64.7 & 0.8 \\
\hline $\begin{array}{c}\text { NiTi10Ta- } \\
\text { MEP }\end{array}$ & 85.6 & 83.8 & 83.7 & 84.2 & 85.6 & 84.6 & 0.9 \\
\hline
\end{tabular}

Table 5-5 Contact Angle Test Results for Diiodomethane

\begin{tabular}{|c|c|c|c|c|c|c|c|}
\hline Test No. & 1 & 2 & 3 & 4 & 5 & Average & S.D \\
\hline Specimen & $\begin{array}{c}\text { C.A. } \\
\text { (Deg) }\end{array}$ & $\begin{array}{c}\text { C.A. } \\
\text { (Deg) }\end{array}$ & $\begin{array}{c}\text { C.A. } \\
\text { (Deg) }\end{array}$ & $\begin{array}{c}\text { C.A. } \\
\text { (Deg) }\end{array}$ & $\begin{array}{c}\text { C.A. } \\
\text { (Deg) }\end{array}$ & $\begin{array}{c}\text { C.A. } \\
\text { (Deg) }\end{array}$ & $\begin{array}{c}\text { C.A. } \\
\text { (Deg) }\end{array}$ \\
\hline NiTi-untreated & 46.7 & 45.7 & 45.4 & 46.9 & 48.2 & 46.6 & 1.1 \\
\hline $\begin{array}{c}\text { NiTi10Cr- } \\
\text { MEP }\end{array}$ & 69.7 & 66.0 & 68.6 & 63.0 & 71.0 & 67.7 & 3.2 \\
\hline $\begin{array}{c}\text { NiTi10Ta- } \\
\text { MEP }\end{array}$ & 69.3 & 68.9 & 68.6 & 65.6 & 70.1 & 68.5 & 1.7 \\
\hline
\end{tabular}




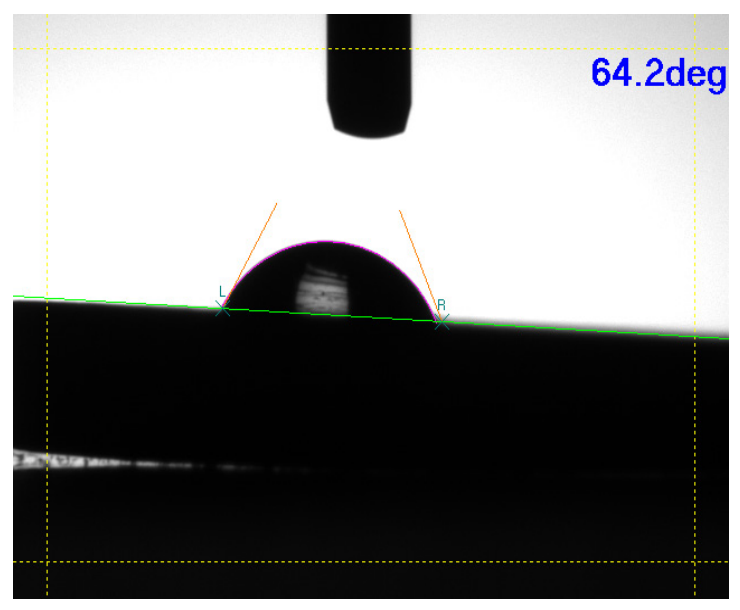

Figure 5-71 Image of a water droplet for contact angle analysis on NiTi-untreated

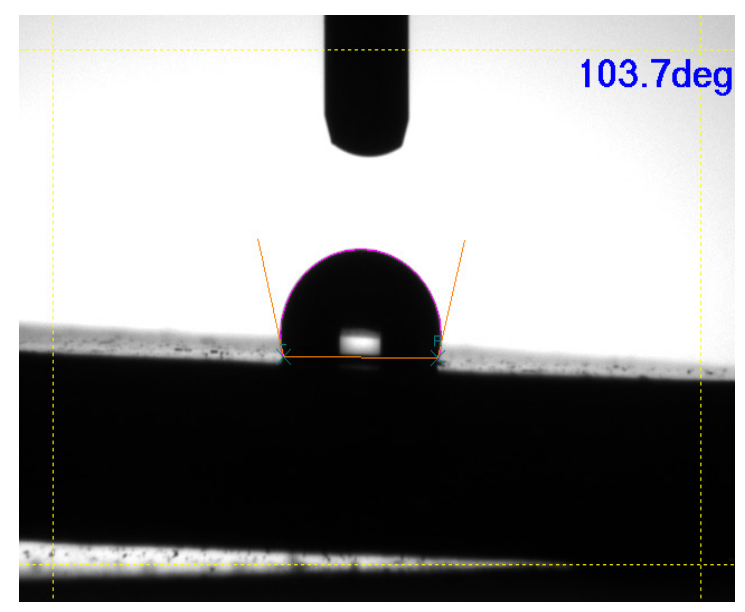

Figure 5-72 Image of a water droplet for contact angle analysis on NiTi10Cr-MEP

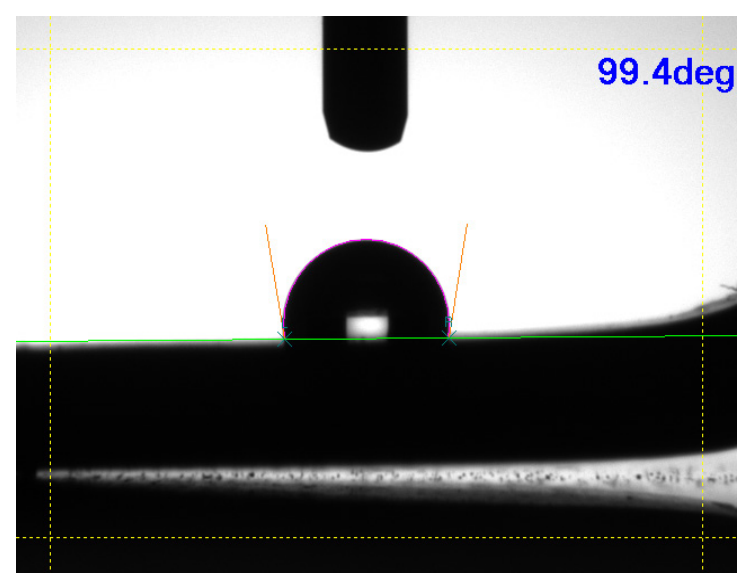

Figure 5-73 Image of a water droplet for contact angle analysis on NiTi10Ta-MEP

\subsubsection{Work of Adhesion}

Work of adhesion is a very useful measure of strength of adhesion between the liquid and the solid. It reflects the ease with which cells adhere to a solid substrate within a given medium. When blood is exposed to a biomaterial surface, adhesion of cells (red 
blood cells and platelets) occurs and the extent of adhesion determines the life of the implant material, as cellular adhesion could activate coagulation, which results in cascades formation. Cellular adhesion therefore, has a direct bearing on the thrombogenicity of a biomaterial and thus, dictates their biocompatibility (K. Vijayanand 2005). Therefore, studies on adhesion are a great importance for characterizing biomaterials from a cell adhesion point of view.

Table 5-6 lists interfacial free energy and work of adhesion for Nitinol alloys measured by contact angle meter. NiTi10Cr-MEP and NiTi10Ta-MEP exhibited lower values of work of adhesion suggesting that the extent of cell adhesion on them would be relatively lower than that on the NiTi-untreated surface when exposed to blood (K. Vijayanand 2005).

Table 5-6 Kitazaki-Hata Surface Interaction

\begin{tabular}{|c|c|c|c|c|c|c|}
\hline & \multicolumn{3}{|c|}{ Interfacial Free Energy (mJ/m^2) } & \multicolumn{3}{c|}{ Work of Adhesion (mJ/m^2) } \\
\hline Alloy & Water & $\begin{array}{c}\text { Ethylene } \\
\text { Glycol }\end{array}$ & Diiodomethane & Water & $\begin{array}{c}\text { Ethylene } \\
\text { Glycol }\end{array}$ & $\begin{array}{c}\text { Diiodo } \\
\text { methane }\end{array}$ \\
\hline NiTi-untreated & 100.1 & 114.4 & 96.4 & 103.9 & 64.5 & 85.6 \\
\hline $\begin{array}{c}\text { NiTi10Cr- } \\
\text { MEP }\end{array}$ & 42.8 & 19.6 & 5.1 & 53.8 & 51.9 & 69.5 \\
\hline $\begin{array}{c}\text { NiTi10Ta- } \\
\text { MEP }\end{array}$ & 33.5 & 15.7 & 6.1 & 64.0 & 56.7 & 69.4 \\
\hline
\end{tabular}

\subsubsection{Surface Energy}

The thrombogenicity of a material's surface increases with increasing surface energy (Gopinath Mani 2007). The bare metal surfaces are electropositive (i.e. have a 
negative charge) (Gopinath Mani 2007). Therefore, coating of a metal surface with polymers having low surface energy is a common trend, which has resulted in a significant reduction of thrombosis. One drawback of these thromboresistant coatings (hydrophobic polymers) is that they not only prevent the adherence of platelets but also endothelial cells. This problem has now been alleviated by coating the polymer surface with fibronectin (Gopinath Mani 2007).

Michiardi et al. investigated protein adsorption on NiTi alloys and deduced that albumin adsorption was directly proportional to the polarity of the surface energy and inversely proportional to the concentration of $\mathrm{Ni}$ in the bulk alloy (Alexandra Michiardi 2006). Fibronectin is one of the key proteins involved in cell adhesion mechanisms. The hydrophobic surfaces (MEP) can induce irreversible adsorption of fibronectin (F.J. Jing 2007). Polar (p), disperation (d) and hydrogen bonding (h) components of surface free energy of Nitinol alloys, measured by contact angle meter, are presented in Table 5-7. The untreated Nitinol had the high surface energy while MEP surfaces had the lowest. These surfaces will probably be effective in reducing thrombogenicity.

Table 5-7 Kitazaki-Hata Surface Free Energy Components $\left(\mathrm{mJ} / \mathrm{m}^{2}\right)$

\begin{tabular}{|c|c|c|c|c|}
\hline & $\mathrm{d}$ & $\mathrm{p}$ & $\mathrm{h}$ & Total \\
\hline NiTi- untreated & 10.3 & 108.7 & 12.2 & 131.2 \\
\hline NiTi10Cr-MEP & 22.4 & 1.4 & 0.0 & 23.8 \\
\hline NiTi10Ta-MEP & 20.5 & 3.5 & 0.7 & 24.7 \\
\hline Distilled Water & 29.1 & 1.3 & 42.4 & 72.8 \\
\hline Ethylene Glycol & 30.1 & 0.0 & 17.6 & 47.7 \\
\hline Diiodomethane & 46.8 & 4.0 & 0.0 & 50.8 \\
\hline
\end{tabular}




\subsection{Roughness Analysis}

Roughness analysis is an important feature for the materials biocompatibility. Surface roughness allows characterization of the potential for cellular adhesion and protein adsorption. It has been shown that a smoother surface had higher blood compatibility than rougher surfaces (W. Zingg 1982). Similarly, thrombogenicity and neointimal hyperplasia were usually higher for rougher surfaces (Gopinath Mani 2007).

The surface roughness of Nitinol alloys was analyzed using a Veeco Multimode Nanoscope IIIa Atomic Force Microscope (AFM). Scan areas of $10 \mu \mathrm{m}$ x $10 \mu \mathrm{m}$ were analyzed for varying characteristics in three randomly selected regions on a Nitinol alloy. The mean roughness $(\mathrm{Ra})$ was then summarized in Table 5-8. AFM plot data from the different roughness analyses were also shown in Figures 5-74 to 5-80.

NiTi-untreated and NiTi10Cr-EP had the highest surface roughness, $127.8 \mathrm{~nm}$ and $119.76 \mathrm{~nm}$ respectively. The alloys that were subjected to magnetoelectropolishing had the smoothest surfaces as described in previous studies by Hryniewicz et al. (T. Hryniewicz 2009). NiTi-MEP had the lowest surface roughness $(13.85 \mathrm{~nm})$. The electropolished NiTi surface was also relatively smooth $(20.03 \mathrm{~nm})$.

Table 5-8 Mean surface roughness (Ra) for Nitinol alloys

\begin{tabular}{|l|c|}
\hline \multicolumn{1}{|c|}{ Treatment } & $\mathrm{Ra}(\mathrm{nm})$ \\
\hline NiTi-untreated & 127.8 \\
\hline NiTi-EP & 20.0 \\
\hline NiTi-MEP & 13.8 \\
\hline NiTi10Cr-EP & 119.7 \\
\hline NiTi10Cr-MEP & 76.2 \\
\hline NiTi10Cr-WP & 28.4 \\
\hline NiTi10Cu-EP & 59.2 \\
\hline
\end{tabular}



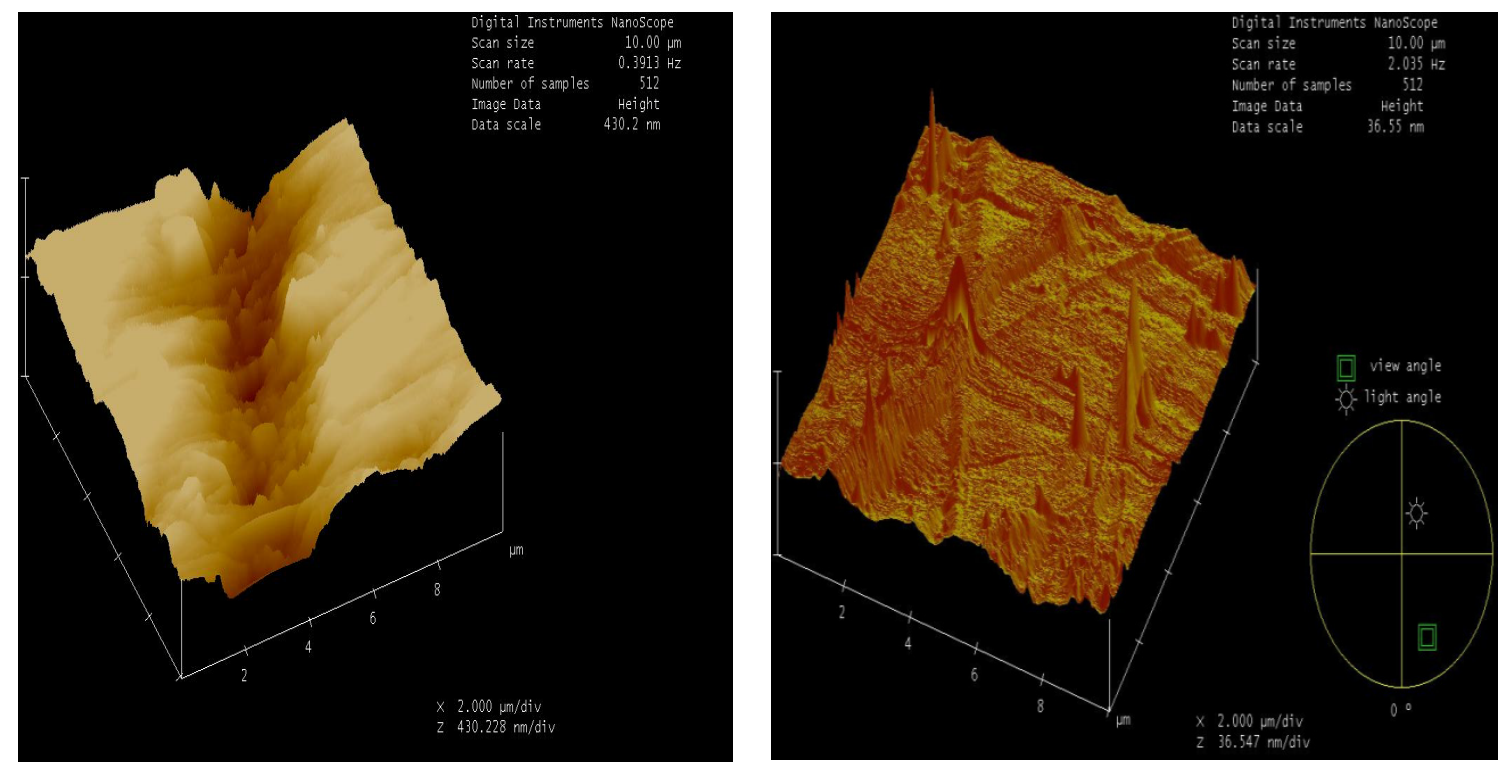

Figure 5-74 Typical AFM image of NiTi- Figure 5-75 Typical AFM image of NiTiuntreated EP
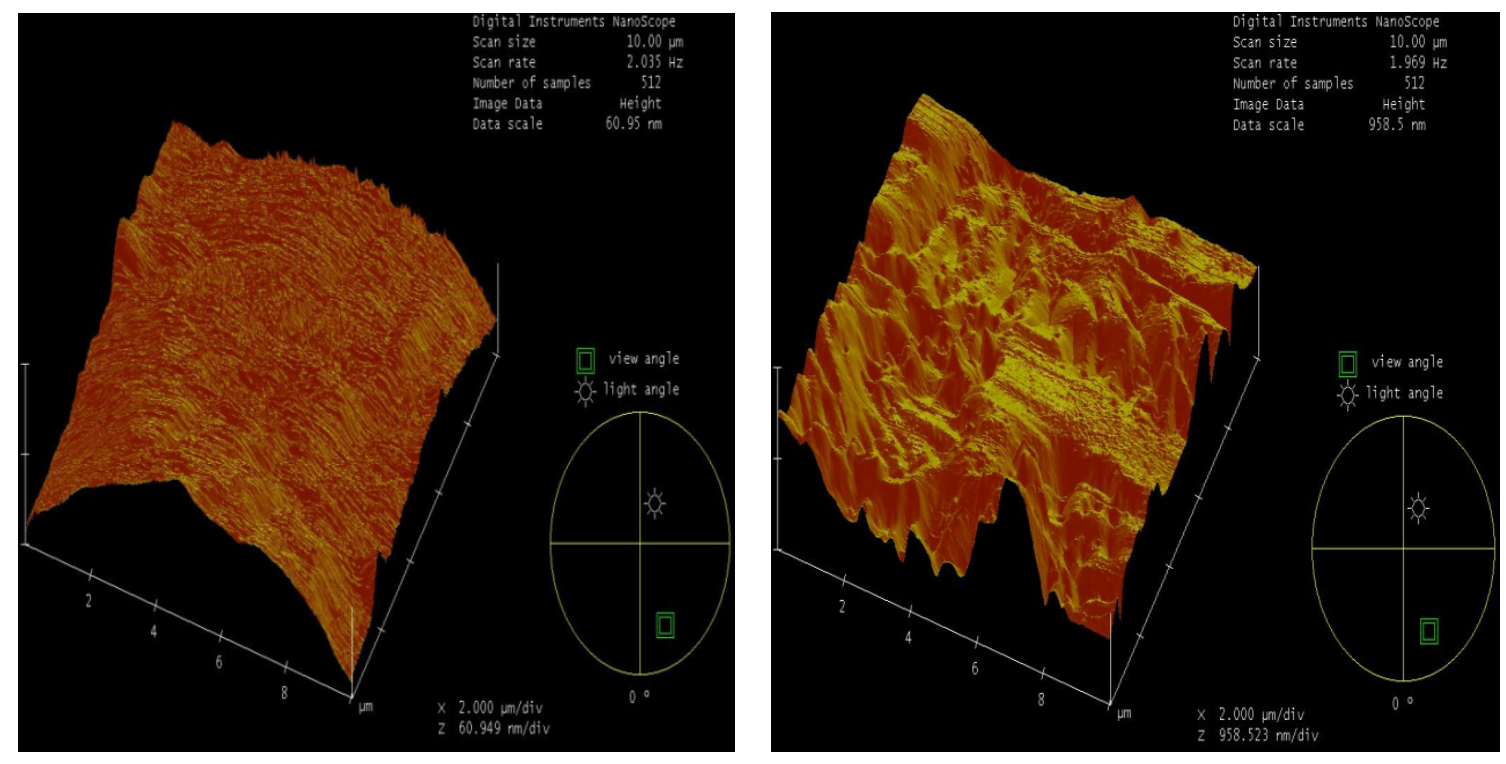

Figure 5-76 Typical AFM image of NiTi- Figure 5-77 Typical AFM image of MEP

NiTi10Cr-EP 

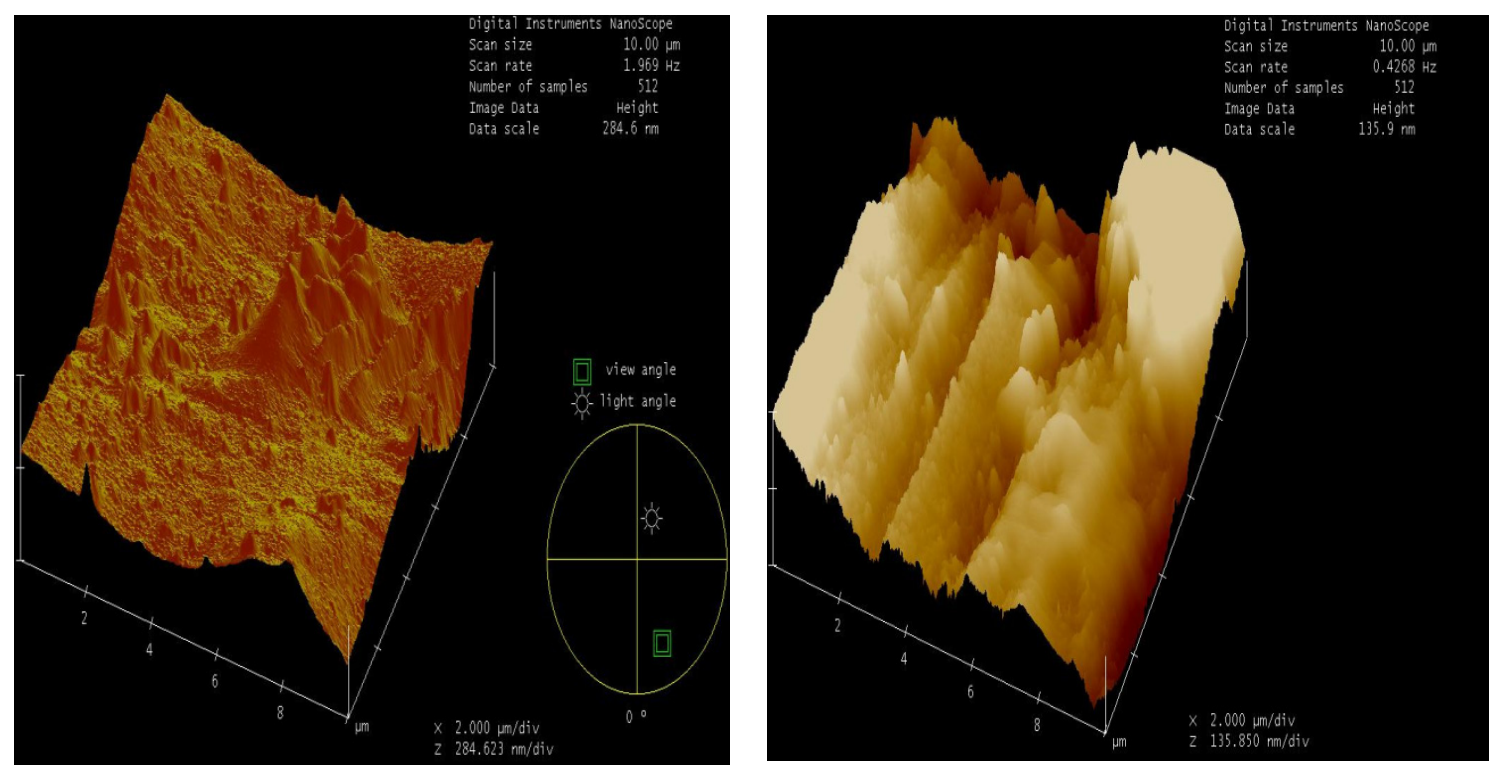

Figure 5-78 Typical AFM image of Figure 5-79 Typical AFM image of NiTi10Cr-MEP

NiTi10Cr-W\&P

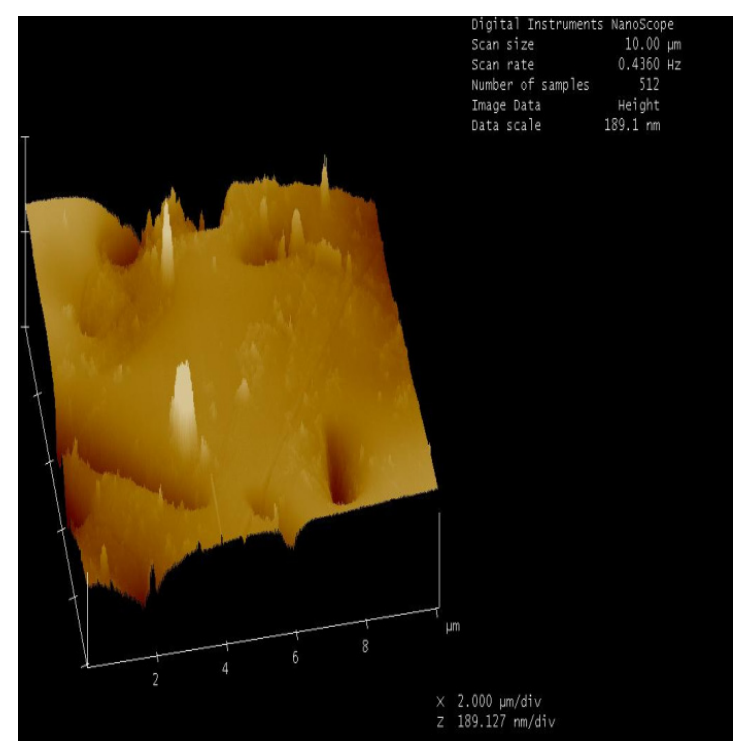

Figure 5-80 Typical AFM image of NiTi10Cu-EP 


\section{CHAPTER 6}

\section{DISCUSSION}

\subsection{Biocompatibility of Nitinol alloys}

Biocompatibility is defined as, "the ability of a material to perform with an appropriate host response in a specific application" (D. F. Williams 1992). In this investigation emphasis was placed on Nitinol's resistance to corrosion and human umbilical vein endothelial cells (HUVEC) response to Nitinol and its corrosion products. The biocompatibility of Nitinol is mainly dependent on some of its basic characteristics such as composition, nature and thickness of the oxide layer, surface morphology, surface charge and surface chemistry. Alloying and surface treatments result in changes of the aforementioned surface properties, which in turn affect the biocompatibility of Nitinol.

\subsubsection{Corrosion Analysis of Nitinol alloys}

Cyclic potentiodynamic polarization curves for Nitinol alloys depicted in Figures 3-4 to 3-9 revealed two distinct features - a positive and a negative hysteresis. NiTi, $\mathrm{NiTiCu}$, NiTiTa alloys and Nitinol stents displayed a positive hysteresis (reverse scan looped in a clockwise direction). NiTiCr alloys sometimes displayed a negative hysteresis (reverse scan looped in an anti-clockwise direction) or no hysteresis although the reverse scan still looped in an anti-clockwise direction.

The corrosion resistance of alloys and stents that exhibited a positive hysteresis, were evaluated by the difference between the breakdown and rest potentials $\left(E_{b}-E_{r}\right)$. NiTiCr was the only alloy that exhibited a negative or no hysteresis and its corrosion resistance was evaluated by the vertex potential $\mathrm{E}_{\mathrm{v}}$. 
The addition of ternary elements, copper, chromium and tantalum improved Nitinol's resistance to pitting and crevice corrosion. This may be attributed to the development of a thicker oxide layer on the ternary Nitinol alloys as depicted in Table 52. Indeed, passive metals like titanium, chromium and tantalum develop stable oxide layers on their surfaces, which contribute to their corrosion resistance in physiological conditions. This passivity can be enhanced by modifying the thickness, topography, and chemical composition of this oxide layer via various surface treatments.

The oxide layer thickness of the binary Nitinol alloy was estimated at $22.7 \mathrm{~nm}$, whereas that of the NiTi10Cu, NiTi10Cr and NiTi10Ta was $32.5 \mathrm{~nm}, 30.5$ and $29.2 \mathrm{~nm}$ respectively. $\mathrm{Ni}$ and $\mathrm{Cu}$ produced substitutional solid solutions, where the two elements are completely soluble in each other at all proportions. This enhanced the tendency for titanium to diffuse towards the surface to produce a more stable and thicker oxide layer. The reason for NiTi10Cu alloy having a thicker oxide layer was attributed to the fact that more titanium atoms relatively close to the surface diffuse towards the surface to produce a thermodynamically stable oxide as compared with remaining in the bulk $\mathrm{Ni}-\mathrm{Cu}$ solid solution matrix. In the case of NiTi10Cr and NiTi10Ta, both $\mathrm{Cr}$ and $\mathrm{Ta}$ compete with $\mathrm{Ti}$ to diffuse towards the surface to form the respective oxides.

In this study, the Ni released during corrosion correlated well with its distribution in the depth profile at the surface of the alloys. For example, a Ni concentration of approximately 3.8 at.\% was detected on the surface of NiTi-untreated, which is relatively low as compared with the bulk concentration. Whereas, for NiTi-EP and NiTi-MEP, the Ni concentration was non-detectable and 2.7 at.\% respectively, with the Ni concentration of the latter being primarily in the form of nickel oxide. Therefore, the relative depletion 
of Ni concentration on the surface of EP and MEP alloys and the formation of nickel oxide were primary reasons for their enhanced resistance to corrosion.

The elemental nickel from the surface layers can diffuse through the porous $\mathrm{TiO}_{2}$ layer and become released into the surrounding environment (J. A. S. Shabalovskaya 2008) (Christine Trépanier 1999). The surface chemistry of the implant plays an important role in platelet activation. It should be noted that the amount of elemental nickel and nickel oxides present at the surface of an implant governs platelet activation and thus the blood cascade formation (David A. Armitage 2003).

Surface treatments of the Nitinol alloys resulted in an enhancement of their corrosion resistance, mainly due to the formation of nickel oxide in addition to oxides of the other passsivating elements on the surface instead of elemental nickel. Among all the surface treated Nitinol alloys, the resistance to pitting corrosion $\left(E_{b}-E_{r}\right)$ indicated a decrease in the following order: NiTi10Ta-W\&P $>$ NiTi10Ta-EP $>$ NiTi-EP $>$ NiTi-MEP $>$ NiTi-W\&P $>$ NiTi10Ta-MEP $>$ NiTi10Cu-W\&P $>$ NiTi10Cu-MEP $>$ NiTi10Cu-EP. However, the resistance to crevice corrosion $\left(\mathrm{E}_{\mathrm{p}}\right)$ indicated a decrease in the following order: NiTi10Ta-MEP $>$ NiTi10Ta-W\&P $>$ NiTi10Ta-EP $>$ NiTi10Cu-W\&P $>$ NiTiW\&P $>$ NiTi10Cu-MEP $>$ NiTi-EP $>$ NiTi10Cu-EP $>$ NiTi-MEP.

\subsubsection{Endothelialization of Nitinol Alloys}

Endothelialization of vascular stents can prevent the proliferation and migration of smooth muscle cells (J. A. S. Shabalovskaya 2008) and significantly reduce the risk of In-Stent Restenosis (ISR). In this investigation, approximately $50 \times 10^{3}$ endothelial cells were seeded in each of the 24-well culture plate and incubated for 72 hours to assess 
proliferation. Hoechst dye highlighted the nuclei of the cells and Mitotracker Red dye highlighted the mitochondria of the cells. Upon observation using a fluorescent microscope, a confluent monolayer of endothelial cells exhibiting cell-to-cell contact was indicative of a non-cytotoxic response. Healthy endothelial cells were observed on the surface of all of the Nitinol alloys used in this investigation and their growth was prolific. The number of cells observed on the ternary Nitinol alloys appeared to be greater than that on the binary Nitinol alloy. Furthermore, the average diameter of the nuclei of endothelial cells on the binary NiTi was greater than that of cells on the ternary Nitinol alloys. However, further studies should be conducted to confirm this preferential growth of cells on the ternary alloys as well as the significance of endothelial cell nuclei size.

\subsubsection{Cytotoxicity Assessment of Nitinol Alloys}

Immersion tests of Nitinol alloys in cell culture media revealed that titanium, nickel and copper were the primary elements leached from the surface. This release was due to the partial dissolution of the oxide surface layers and the exposure of the nickel and copper enriched sub-layers. Cytotoxicity assays (SRB) conducted by using the cell culture media from the immersion tests, indicated that $\mathrm{Ni}$ and $\mathrm{Cu}$ ions were relatively toxic to Human Umbilical Vein Endothelial Cells (HUVEC) as compared with $\mathrm{Ti}, \mathrm{Cr}$ and Ta. It is the known fact that $\mathrm{Ni}$ can destroy cell organelles and even decrease cell numbers (Chun-Che Shih 2000). Moreover, $\mathrm{Ni}^{+2}$ can act as an antagonist to $\mathrm{Mg}^{+2}, \mathrm{Ca}^{+2}$ and $\mathrm{Zn}^{+2}$ and disturb the biological processes (J. W. S. A. Shabalovskaya 1995). Similarly, $\mathrm{Cu}^{+2}$ ions also induce oxidative stress within the cell, which result in severe loss of cell viability (Anna Eckers 2009). 
The binary Nitinol alloy exhibited a significant amount of Ni release after one day of immersion under static $(12.43 \mu \mathrm{g} / \mathrm{L})$ and dynamic $(23.47 \mu \mathrm{g} / \mathrm{L})$ conditions. Low SRB values were obtained after one day of immersion under static (0.742) and dynamic (0.695) conditions. However, after 42 days of immersion the SRB values increased under static (0.933) and dynamic (0.836) conditions as a result of a lower concentration of metal ions released.

Exogeneous addition of metal ions to cell culture media also exhibited very interesting results during cytotoxicity studies. In general, as the relative proportion of dissolved metal ion increased, the greater was the degree of toxicity. As shown in Figures 4-25 to 4-28 the SRB values at the metal ion concentration of $0.1 \mu \mathrm{g} / \mathrm{L}$ were highest in the case of $\mathrm{Ti}(0.982)$ followed by $\mathrm{Cu}(0.963), \mathrm{Cr}(0.962) \mathrm{Ni}(0.952)$. Furthermore, at the metal ion concentration of $10000 \mu \mathrm{g} / \mathrm{L}$, the SRB values were highest in the case of $\mathrm{Ti}$ (0.833), followed by $\mathrm{Cr}(0.790), \mathrm{Cu}(0.673)$ and $\mathrm{Ni}(0.643)$. These cytotoxicity assays also indicated that $\mathrm{Ni}$ and $\mathrm{Cu}$ ions were relatively more toxic to HUVEC cells as compared with $\mathrm{Ti}$ and $\mathrm{Cr}$.

\subsection{Surface Characterization of Nitinol Alloys}

\subsubsection{Scanning Electron Microscopy}

SEM micrographs for binary and ternary Nitinol alloys are shown in Figures 5-1 to 5-16. It was revealed that EP and MEP surface treatments resulted in a uniform and smooth surface layer as compared with that of the untreated and W\&P alloys. MEP surface treatment produced nano-structured features. This textured surface is conducive of high corrosion resistance and minimal nickel release. However, water boiled and 
passivated (W\&P) surfaces were rough and highly pitted because of nitric acid passivation.

\subsubsection{X-Ray Photoelectron Spectroscopy}

The elemental composition, speciation and depth profile on the surface of Nitinol alloys were determined by XPS. The dominant surface elements were always oxygen and carbon. The presence of carbon on all of the samples can be attributed to surface contamination by carbon-containing molecules absorbed from the atmosphere. In the depth profile analysis, the oxygen concentration profile exhibited a peak close to the surface, which then decreased sharply. However, Ni, Ti $\mathrm{Cr}, \mathrm{Cu}$ and $\mathrm{Ta}$ concentration profiles were low near the surface but increased sharply to a steady state value in the bulk of the alloy. This implied the presence of metallic oxides on the surface of the alloys. Moreover, different metal oxides exhibited maximum concentrations near the surface, which then decreased to zero.

Surface concentration ratios of $\mathrm{Ti} / \mathrm{Ni}$ were determined by XPS and the results displayed in Table 5-1 indicate a decrease in the following order: NiTi10Cu-W\&P > NiTi10Ta-MEP $>$ NiTi10Cr-W\&P $>$ NiTi10Ta-EP $>$ NiTi10Cr-MEP $>$ NiTi10Cuuntreated $>$ NiTi-untreated $>$ NiTi-MEP $>$ NiTi10Cu-MEP $>$ NiTi10Ta-untreated $>$ NiTi10Cr-untreated $>$ NiTi10Cu-EP. It should be noted that no Ni was detected on the surface in the cases of NiTi-EP and NiTi-Cr-EP and thus, no Ti/Ni ratio was determined.

XPS depth profiles indicated that the thickness of the mixed oxides of the surface

treated Nitinol alloys $(8.2-18.2 \mathrm{~nm})$ was less than that of the untreated Nitinol alloys 
$(22.7-32.5 \mathrm{~nm})$. It should be noted that this thin oxide layer was still sufficiently effective in blocking Ni release during corrosion.

\subsubsection{Contact Angle Measurement}

A Kyowa contact angle meter was used to measure the contact angles of selected Nitinol alloys using three different solvents: distilled water, ethylene glycol and diiodomethane. Several other parameters such as work of adhesion, interfacial energy and surface energy were calculated from the contact angles. NiTi-untreated surfaces had contact angles less than $90^{\circ}$ and hence were hydrophilic. However, NiTiCr-MEP and NiTiTa-MEP had contact angles greater than $90^{\circ}$ and hence were hydrophobic. Based on the results obtained, it can be concluded that the addition of the ternary elements $\mathrm{Ta}, \mathrm{Cr}$ and $\mathrm{Cu}$ to NiTi resulted in increased hydrophobicity of the alloy. Additionally surface treatment of the ternary Nitinol by MEP also resulted in increase hydrophobicity.

The adhesion of different biological species on the surface of a biomaterial is strongly influenced by its wettability. Hydrophobic surfaces generally possess a low work of adhesion, which is a useful measure of the strength of adhesion between an implant and biological species. The adhesion of various proteins and platelets on an implant could activate coagulation, which results in cascade formation and thrombogenicity. The higher

the work of adhesion, the greater is the disposition of the implant to cause a thrombogenic response. Therefore, cellular adhesion has a direct effect on thrombogenicity of an implant and thus, dictates its biocompatibility (K. Vijayanand 2005). The work of adhesion of Nitinol alloys studied in this investigation decreased in the following order: NiTi-untreated $>$ NiTiCr-MEP $>$ NiTiTa-MEP. This implies that the 
addition of the ternary elements $\mathrm{Ta}$ and $\mathrm{Cr}$ to NiTi and MEP surface treatment result in enhanced anti-thrombogenicity.

Surface energy is also factor in the assessment of a biomaterial's thrombogenic response. A high surface energy of an implant material is conducive to the formation of thrombosis. The surface energy of Nitinol alloys studied in this investigation decreased in the following order: NiTi-untreated $>$ NiTiTa-MEP $>$ NiTiCr-MEP. Therefore, it can again be concluded that the addition of the ternary elements Ta and $\mathrm{Cr}$ to NiTi and MEP surface treatment result in enhanced anti-thrombogenicity.

\subsubsection{Atomic Force Microscopy}

The surface roughness of Nitinol alloys was determined by AFM and the results are displayed in Table 5-8. MEP surface treated alloys had a relatively smooth surface with nano-structured features. The low surface roughness of MEP treated alloys correlated well with a high resistance to pitting and crevice corrosion. Although EP surface treated alloys were relatively less smooth than their MEP counterparts, both surface treatments resulted in comparable corrosion resistance. Furthermore, the smooth surfaces of MEP surface treated alloys had the additional benefit of having low surface energy, which was particularly observed in the case of NiTiTa-MEP and NiTiCr-MEP. The combination of a relatively smooth, nano-structured and low surface energy alloy surface has been considered advantageous for excellent hemocompatibility and antithrombogenecity (Gopinath Mani 2007).

These results obtained on the biocompatibility of surface treated Nitinol alloys suggested that MEP and EP surface treatments render good biocompatibility 
characteristics in terms of corrosion resistance, surface morphology, roughness, surface chemistry and surface charge. Additionally, the alloys were conducive to cell viability and proliferation. However, it should be noted that these tests were conducted on as received alloys, the properties of which can be expected to change during fabrication and sterilization of medical devices made from them. Nevertheless, it is believed that the results obtained in this study would be useful in predicting the behavior of implant devices made from the alloys. 


\section{CONCLUSIONS}

This work presents a novel approach to enhancing the corrosion resistance and biocompatibility of Nitinol alloys. Enhancing the biocompatibility of a medical device implies a seamless integration into the body with increased health and longevity of the patient. In this investigation, Nitinol alloys have been subjected to various surface treatments, such as electropolishing, magnetoelectropolishing, water boiling and passivation. MEP and EP eliminated the chemical heterogeneity on Nitinol alloys and provided stable oxides of $\mathrm{TiO}_{2}$, and in some cased mixed oxides of $\mathrm{Cr}_{2} \mathrm{O}_{3}, \mathrm{NiO}_{2}$ and $\mathrm{Ta}_{2} \mathrm{O}_{5}$ coating on the Nitinol surface, which significantly improved the corrosion resistance and biocompatibility of the alloy.

Surface characteristics, such as morphology, surface chemistry, surface charge, wettability and depth profile have been assessed and the release of metal ions in biological media was measured after corrosion tests. Important aspects of biocompatibility of Nitinol were performed such as the monitoring of cell viability as a function of Ni release from Nitinol alloys.

All surface treated Nitinol alloys were more resistant to localized corrosion when compared with untreated Nitinol alloys. Furthermore, the corrosion resistance of the alloys displaying a negative hysteresis (NiTiCr alloys) was evaluated in terms of $\mathrm{E}_{\mathrm{v}}$, whereas, that of alloys displaying a positive hysteresis (NiTi, NiTiCu and NiTiTa) was

evaluated by the difference between the breakdown and rest potentials $\left(E_{b}-E_{r}\right)$. In general, the pitting corrosion resistance $\left(\mathrm{E}_{\mathrm{b}}-\mathrm{E}_{\mathrm{r}}\right)$ of surface treated Nitinol alloys was higher than untreated ones. 
High corrosion resistance is one of the main prerequisites for enhanced biocompatibility because it minimizes $\mathrm{Ni}$ ion release. The surface treated Nitinol alloys offered the best corrosion resistance, possessed very low Ni content on the surface and negligible Ni release.

ICP-MS analysis of the PBS solution after each corrosion test revealed that the amount of nickel release appeared to be directly related to the nickel content on the surface of the alloy. Moreover, Nickel release was strongly dependent on surface treatment. The results indicated that untreated Nitinol may have a toxic effect as the amount of nickel being released is quite high.

Surface-induced thrombosis is known to be the one of the reasons for the failure of cardiovascular stents and is only reduced when the surface is rendered suitable for endothelialization. Endothelial cell spreading and proliferation was observed on untreated binary and ternary Nitinol Alloys. Additionally, the growth and viability of endothelial cells were prolific.

Static and dynamic immersion tests were performed by immersing the untreated binary and ternary Nitinol alloys in cell culture media and measuring the amount of metal ions released in solution. The binary Nitinol alloys released a large amount of Ni after 1 day of immersion in cell culture media under static and dynamic conditions as compared with ternary Nitinol alloys. The SRB assay revealed that as the relative proportion of dissolved metal ions in the cell culture media increased, the greater was the degree of toxicity. 
Comparative cytotoxicity studies were performed by conducting SRB assays in the presence of exogenously added metal ions. It was observed that $\mathrm{Ni}$ and $\mathrm{Cu}$ ions exhibited greater toxicity on HUVEC cells as compared with Ti and $\mathrm{Cr}$ ions.

XPS data illustrated mostly carbon and oxygen on the surfaces of Nitinol alloys. The concentration of nickel was extremely low or non-existent on the upper surface and was relatively depleted in the titanium oxide layer after surface treatments of Nitinol alloys, which could significantly improve their biocompatibility. Similarly, chemical composition of passive layers and particularly the high $\mathrm{Ti} / \mathrm{Ni}$ ratio indicated good prospects for the improvement of cardiovascular stents. Moreover, nickel, titanium, chromium and tantalum were mainly present as oxides on the surface treated samples. These oxides have higher biotolerance in the environment of human physiological fluids.

Magnetoelectropolishing (MEP) appeared to be a promising technique for improved corrosion resistance with negligible nickel release, low surface energy and low surface roughness. This is attributed to nickel oxides on its surface instead of elemental nickel, minimal surface roughness and micro-patterned surfaces as revealed by SEM. As a consequence, this new surface treatment (MEP) might reduce the risk of sensitization to Ni allergies, and might improve the cytotoxicity, biocompatibility of Nitinol alloys. This surface treatment might be a new successful candidate for different biomedical applications.

These findings will be useful for improving the biocompatibility of materials used to manufacture medical devices and will facilitate the emergence of a new age of cardiovascular stents with greater efficacy for treating patients than those currently available. Although this study was conducted on as-received Nitinol alloys, it is believed 
that the results presented in this dissertation are useful in predicting the behavior of implant devices made from these alloys.

The studies presented in this dissertation are preliminary and further research need to be conducted to elucidate platelet adhesion etc. for understanding thrombosis as well as in vivo studies. The results obtained are very promising, however, further investigation, especially in blood environment will determine the usefulness of the suggested techniques (EP, MEP and W\&P) for improving the surface of stent materials. The research should be carried out in designing and developing new alloys and should include essential features such as hemocompatibility, anti-inflammatory response and adhesion of platelets, leukocytes and smooth muscle cells. 


\section{REFERENCES}

A. Balamurugan, S. Rajeswari, G. Balossier,A. H. S. Rebelo, J. M. F. Ferreira. "Corrosion aspects of metallic implants - An overview." Materials and Corrosion 59, no. 11 (2008): 855-869.

A. Michiardi, C. Aparicio, J. A. Planell, F. J. Gil. "New oxidation treatment of NiTi shape memory alloys to obtain Ni-free surfaces and to improve biocompatibility." Journal of Biomedical Materials Research Part B: Applied Biomaterials 77B, no. 2 (2005): 249-256.

A. Ölander, Z. Krist. "The crystal structure of AuCd." 1932: 145.

Alexandra Michiardi, Conrado Aparicio, Buddy D. Ratner, Josep A. Planell, Javier Gil. "The influence of surface energy on competitive protein adsorption on oxidized NiTi surfaces." Biomaterials 29 (2006): 586-594.

Anna Eckers, Kerstin Reiman, Lars-Oliver Klotz. "Nickel and copper ion-induced stress signaling in human hepatoma cells: analysis of phosphoinositide 3'-kinase/Akt signaling." Biometals 22 (2009): 307-316.

Anne Gry Hemmersam, Morten Foss, Jacques Chevallier, Flemming Besenbacher. "Adsorption of fibrinogen on tantalum oxide, titanium oxide and gold studied by the QCM-D technique." Colloids and Surfaces B: Biointerfaces 43 (2005): 208-215.

Arash Shahryari, Fereshteh Azari, Hojatollah Vali, Sasha Omanovic. "The response of fibrinogen, platelets, endothelial and smooth muscle cells to an electrochemically modified SS316LS surface: Towards the enhanced biocompatibility of coronary stents." Acta Biomaterialia 6 (2010): 695-701.

ASTM F 2129. "Standard test method for conducting cyclic potentiodynamic polarization measurements to determine the corrosion susceptibility of small implant devices." Annual Book of Standards. ASTM, 2008.

ASTM F 86. "Standard Practice for Surface Preparation and Marking of Metallic Surgical Implants." Annual Book of Standards. ASTM, 2009.

B. Clarke, W. Carroll, Y. Rochev, M. Hynes, D. Bradley, D. Plumley. "Influence of Nitinol wire surface treatment on oxide thickness and composition and its subsequent effect on corrosion resistance and nickel ion release." Journal of Biomedical Materials Research A 79, no. 1 (2006): 61-70. 
B. O' Brien, W. M. Carroll, M. J. Kelly. "Passivation of nitinol wire for vascular implants - a demonstration of the benefits." Biomaterials 23 (2002): 1739-1748.

B. Thierry, M. Tabrizian, C. Trepanier, O. Savadogo, L. H. Yahia. "Effect of surface treatment and sterilization processes on the corrosion behavior of NiTi shape memory alloy." Journal of Biomedical Materials Research Part A 51, no. 4 (2000): 685-693.

B. Thierry, M. Tabrizian, O. Savadogo, L. H. Yahia. "Effects of sterilization processes on NiTi alloy: Surface characterization." Journal of Biomedical Materials Research 49, no. 1 (2000): 88-98.

Barry O'Brien, William Carroll. "The evolution of cardiovascular stent materials and surfaces in response to clinical drivers: A review." Acta Biomaterialia 5 (2009): 945958.

Bhat, Sujata V. Biomaterials. 2nd. Alpha Science International Ltd., 2005.

Brian Lin, Ken Gall, Hans J. Maier, Robbie Waldron. "Structure and thermomechanical behavior of NiTiPt shape memory alloy wires." Acta Biomaterialia 5 (2009): 257-267.

Buddy D. Ratner, Allan S. Hoffman, Frederick J. Schoen, Jack E. Lemons, ed. Biomaterials Science: An introduction to materials in medicine. 2nd. Elsevier Academic Press, 2004.

C. Cabrera, F. Lloris, R. Gimenez, M. Olalla, M. C. Lopez. "Mineral content in legumes: Contribution to the Spainish dietary intake." The Science of the Environment 308 (2003): $1-14$.

C. L. Chu, C. Guo, X. B. Sheng, Y. S. Dong, P. H. Lin, K. W. K. Yeung, P. K. Chu. "Microstructure, nickel suppression, and mechanical characteristics of electropolished and photoelectrocatalytically oxidized biomedical nickel titanium shape memory alloy." Acta Biomaterialia 5 (2009): 2238-2245.

C. L. Chu, R. M. Wang, L. H. Yin, Y. P. Pu, P. H. Lin, Y. S. Dong, C. Y. Chung, K. W. K. Yeung, P. K. Chu. "Effects of anodic oxidation in H2SO4 electrolyte on the biocompatibility of NiTi shape memory alloy." Materials Letters 62 (2008): 3512-3514.

C. Liu, D. Hu, J. Xu, D. Yang, M. QI. "In vitro electrochemical corrosion behavior of functionally graded diamond-like carbon coatings on biomedical Nitinol alloy." Thin Solid Films 496 (2006): 457-462.

C.L. Chu, R.M. Wang, T. Hu, L.H. Yin, Y.P. Pu, P.H. Lin, S.L. Wu, C.Y. Chung, K.W.K. Yeung, Paul K. Chu. "Surface structure and biomedical properties of chemically 
polished and electropolished NiTi shape memory alloys." Materials Science and Engineering C 28 (2008): 1430-1434.

Christine Trépanier, Maryam Tabrizian, L'Hocine Yahia, Luc Bilodeau, Dominique L. Piron,. "Effect of modification of oxide layer on NiTi stent corrosion resistance." Journal of Biomedical Materials Research Part B: Applied Biomaterials 43, no. 4 (1999): 433440.

Chun-Che Shih, Shing-Jong Lin, Yuh-Lien Chen, Yea-Yang Su, Shiau-Ting Lai, Gaston J. Wu, Ching-Fai Kwok, Kwok-Hung Chung. "The cytotoxicity of corrosion products of Nitinol stent wire on cultured smooth muscle cells." Journal of Biomedical Materials Research A 52, no. 2 (2000): 395-403.

D. C. Paschal, B. G. Ting, J. C. Morrow, J. L. Prikle, R. J. Jackson, E. J. Sampson, D. T. Miller, K. L. Caldwell. "Trace metals in the urine of United States residents:reference range concentration." Environmental Research 76 (1998): 53-59.

D. F. Williams, J. Black \& P.J. Doherty. Biomaterials-Tissue Interfaces. Edited by R.L. Williams, D.F. Williams, A.J.C. Lee P.J. Doherty. Vol. 10. Amsterdam: Elsevier, 1992.

D. O. Flamini, S. B. Saidman. "Electrodeposition of polypyrrole onto NiTi and the corrosion behavior of the coated alloy." Corrosion Science 52 (2010): 229-234.

D. Vojtech, L. Joska, J. Leitner. "Influence of a controlled oxidation at moderate temperatures on the surface chemistry of Nitinol wire." Applied Surface Science 254 (2008): 5664-5669.

D. Zhang, W. Zeng, Z. Zi, P. K. Chu. "Corrosion resistance of TiN coated biomedical nitinol under deformation." Materials Science and Engineering C 29 (2009): 1599-1603.

David A. Armitage, Terry L. Parker, David M. Grant. "Biocompatibility and hemocompatibility of surface-modified NiTi alloys." Journal of Biomedical Materials Research A 66, no. 1 (2003): 129-137.

Davis, J. R. Handbook of materials for medical devices. Edited by J. R. Davis. ASM International, 2003.

E. McLuas, Y. Rochev, W. M. Carroll, T. J. Smith. "Analysis of the effects of surface treatments on nickel release from Nitinol wires and their impact on candidate gene expression in endothelial cells." Journal of Materials Science: Materials In Medicine 19, no. 3 (2008): 975-980. 
F. J. Gil, E. Solano, A. Mendoza, J. Pena. "Inhibition of Ni release from NiTi and NiTiCu orthodontic archwires by nitrogen diffusion treatment." Journal of Applied Biomaterials \& Biomechanics 2 (2004): 151-155.

F. J. Gil, E. Solano, J. Pena, E. Engel, A. Mendoza, J. A. Planell. "Microstructural, mechanical and citotoxicity evaluation of different NiTi and NiTiCu shape memory alloys." Jornal of Materials Science: Materials in Medicine 15 (2004): 1181-1185.

F. Sun, K. N. Sask,J. L. Brash, I. Zhitomirsky. "Surface modifications of Nitinol for biomedical applications." Colloids and Surfaces B: Biointerfaces 67 (2008): 132-139.

F. T. Cheng, K. H. Lo, H. C. Man. "An electrochemical study of the crevice corrosion resistance of NiTi in Hanks' solution." Journal of Alloys and Compounds 437 (2007): 322-328.

F.J. Jing, N. Huang, L. Wang, R.K.Y. Fu, Y.F. Mei, Y.X. Leng, J.Y. Chen, X.Y. Liu, Paul K. Chu. "Behavior of human umbilical vein endothelial cells on micro-patterned amorphous hydrogenated carbon films produced by plasma immersion ion implantation \& deposition and plasma etching." Diamond \& Related Materials 16 (2007): 550-557.

Fontana, Mars G. Corrosion Engineering. Edited by 3rd. McGraw Hill, 1986.

G. S. Firstov, R. G. Vitchev, H. Kumar, B. Blanpain, J. V. Humbeeck. "Surface oxidation of NiTi shape memory alloy." Biomaterials 23 (2002): 4863-4871.

G. Tepe, J. Schmehl, H. P. Wendel, S. Schaffner, S. Heller, M. Gianotti, C. D. Claussen, S. H. Duda. "Reduced thrombogenicity of Nitinol stents-In vitro evaluation of different surface modifications and coatings." Biomaterials 27 (2006): 643-650.

Gopinath Mani, Marc D. Feldman, Devang Patel, C. Mauli Agrawal. "Coronary stents: A materials perspective." Biomaterials 28 (2007): 1689-1710.

Gurappa, I. "Development of appropriate thickness ceramic coatings on $316 \mathrm{~L}$ stainless steel for biomedical applications." Surface and Coatings Technology 161 (2002): 70-78.

J. C. Wataha, P. E. Lockwood, M. Marek, M. Ghazi. "Ability of Ni-containing biomedical alloys to activate monocytes and endothelial cells in vitro." Journal of Biomedical Materials Research Part B: Applied Biomaterials 45, no. 3 (2000): 251-257.

J. L. Xu, F. Liu, F. P. Wang, D. Z. Yu, L. C. Zhao. "Formation of Al2O3 coatings on NiTi alloy by micro-arc oxidation method." Current Applied Physics 9 (2009): 663-666.

J. S. Temenoff, A. G. Mikos. Biomaterials: The interaction of biology and materials science. Pearson Prentice Hall, 2008. 
Jae-hwa Lee, Tae-hyun Nam, Hyo-jun Ahn, Yeon-wook Kim. "Shape memory characteristics and suoperelasticity of Ti-45Ni-5Cu alloy ribbons." Materials Science and Engineering A 438-440 (2006): 691-694.

K. Detre, M. L. Murphy, H. Hultgren. "Effect of coronary bypass surgery on longevity in high and low risk patients. Report from the V.A. Cooperative Coronary Surgery Study." Lancet. 19772 (1977): 1243-1245.

K. H. Wu, J. L. Ma. "Effects of Ta addition on Microstructure and Transformation Behavior of Ni-Ti Alloys." Journal of Materials Science and Technology 70, no. 1 (2001): 5-6.

K. Linnainmaa, P. Kivipensas and H. Vainio. "Toxicity and cytogenetic studies of ultrafine titanium dioxide in cultured rat liver epithelial cells." Toxicity in Vitro, 1997: 329-335.

K. Otsuka, X. Ren. " Physical metallurgy of Ti-Ni-based shape memory alloys." Progress in Materials Science 50 (2005): 511-678.

K. Vijayanand, Deepak K. Pattanayak, T. R. Rama Mohan and R. Banerjee. "Interpreting blood-biomaterial interactions from surface free energy and work of adhesion." Trends in Biomaterials and Artificial Organs 18 (2005): 73-83.

Lawrence E. Eiselstein, Duane Steffey, Andrew Nissan, Nigel Corlett, Roberto Dugnani, Esra Kus and Sarah G. Stewart. "Acceptance criteria for corrosion resistance of medical devices: statistical analysis of Nitinol pitting in In Vivo environments." Journal of Materials Engineering and Performance 5-6 (2009): 768-780.

M. C. Chen, S. K. Wu. "Surface analyses and biocompatibility study of $500{ }^{\circ} \mathrm{C}$ oxidized Ni50Ti50 and Ni40Ti50Cu10 shape memory alloys." Surface and Coating Technology 203 (2009): 1715-1721.

M. Diaz, P. Sevilla, A. M. Galan, G. Escolar, E. Engel, F. J. Gil. "Evaluation of ion release, cytotoxicity, and platelet adhesion of electrochemical anodized $316 \mathrm{~L}$ stainless steel cardiovascular stents." Journal of Biomedical Materials Research Part B: Applied Biomaterials 87B, no. 2 (2008): 555 - 561.

M. Es-Souni, M. Es-Souni, H. F. Brandies. "On the transformation behaviour, mechanical properties and biocompatibility of two NiTi-based shape memory alloys: NiTi42 and NiTi42Cu7." Biomaterials 22 (2001): 2153-2161.

M. Frotscher, J. Burow, M.F.X Wagner, K. Neuking, G. Eggeler, P. Schön, R. Böckmann. "Thermo-mechanical processing, microstructure and bending rotation fatigue 
of ultra-fine grained NiTiCr-wires." The International Conference for Shape Memory and Superelastic technologies. Tsukuba: ASM International, 2007. 149-158.

M. Frotscher, J. Burow, P. Schon K. Neuking, R. Bockmann, G. Eggeler. "Characterization of the mechanical properties of ultra-fine grained NiTiCr-wires." Materialwissenschaft und Werkstofftechnik 40, no. 1-2 (2009): 17-22.

Mohammed Es-Souni, Martha Es-Souni, Helge Fischer-Brandies. "Assessing the biocompatibility of NiTi shape memory alloys used for medical applications." Analytical Bioanalytical Chemistry 381, no. 3 (2005): 557-567.

N. Balakrishnan, B. Uvelius, P. Zaszczurynski, D. L. Lin, M. S. Damaser. "Biocompatibility of Nitinol and stainless steel in the bladder: An experimental study." The Journal of Urology 173 (2005): 647-650.

N. D. Munroe, C. Pulletikurthi, W. Haider. "Enhanced biocompatibility of porous Nitinol." Journal of Materials Engineering and Performance 18, no. 5 (2009): 765-767.

N. Munroe, W. Haider, H. S. Wu, A. Datye. "Corrosion behavior of cardiovascular stent materials." The International Conference for Shape Memory and Superelatic Technologies. Tsukuba, 2007. 299-306.

Nicolas Schiff, Mickaël Boinet, Laurent Morgon, Michèle Lissac, Francis Dalard, Brigitte Grosgogeat. "Galvanic corrosion between orthodontic wires and brackets in fluoride mouthwashes." European Journal of Orthodontics 28 (2006): 298-304.

P. I. Branemark, R. Adell, U. Breine, B.O. Hansson, J. Lindstrom \& A. Ohlsson. "Intraosseous anchorage of dental protheses. I. Experimental Studies." Scandinavian Journal of Plastic and Reconstructive Surgery 3 (1969): 81-100.

Pound, Bruce G. "Susceptibility of Nitinol to localized corrosion." Journal of Biomedical Materials Research 77A, no. 1 (2006): 185-191.

R. A. Yankov, N. Shevchenko, A. Rogozin, M. F. Maitz, E. Richter, W. Möller, A. Donchev, M. Schütze. "Reactive plasma immersion ion implantation for surface passivation." Surface and Coatings Technology 201 (2007): 6752-6758.

Rahul Bhola, Shaily M. Bhola, Brajendra Mishra, and David L. Olson. "Electrochemical behavior of Titanium and its alloys as dental implants in normal saline." Research Letters in Physical Chemistry, 2009: 1-4.

Revie, R. Winston. Uhlig's Corrosion Handbook. Edited by 2nd. Wiley Interscience, 2000 . 
Ryhänen, Jorma. "Biocompatibility evaluation of nickel-titanium shape memory metal alloy." Oulun Yliopisto, Oulu: PhD Thesis, 1999.

S. A. Shabalovskaya, J. Anderegg, F. Laab, P. A. Thiel, G. Rondelli. "Surface conditions of Nitinol wires, tubing, and as-cast alloys. The effect of chemical etching, aging in boiling water, and heat treatment." Journal of Biomedical Materials Research Part B: Applied Bioamterials 65, no. 1 (2003): 193-203.

S. A. Shabalovskaya, J. W. Anderegg. "Surface spectroscopic characterization of TiNi nearly equiatomic shape memory alloys for implants." The Journal of Vacuum Science and Technology A 13, no. 5 (1995): 2624-2632.

S. Alavi, S. H. Raji, A. A. Ghorbani. "Effects of steam and dry-heat sterilization on bending properties of NiTi wires." Orth wav 68, no. 3 (2009): 123-128.

S. F. Hsieh, S. L. Chen, H. C. Lin, M. H. Lin, S. Y. Chiou. "The machining characteristics and shape recovery ability of $\mathrm{Ti}-\mathrm{Ni}-\mathrm{X}(\mathrm{X}=\mathrm{Zr}, \mathrm{Cr})$ ternary shape memory alloys using the wire electro-discharge machining." International Journal of Machine Tools \& Manufacture 49, no. 6 (2009): 509-514.

S. Mändl, J. W. Gerlach, B. Rauschenbach. "Surface modification of NiTi for orthopaedic braces by plasma immersion ion implantation." Surface and Coatings Technology 196 (2005): 293-297.

S. Mändl, R. Sader, G. Thorwarth, D. Krause, H. F. Zeilhofer, H. H. Horch, B. Rauschenbach. "Biocompatibility of titanium based implants treated with plasma immersion ion implantation." Nuclear Instruments and Methods in Physics Research B 206 (2003): 517-521.

S. Shabalovskaya, J. Anderegg, G. Rondelli, W. Vanderlinden, S. D. Feyter. "Comparative in vitro performances of bare Nitinol surfaces." Biomedical Materials Engineering 18 (2008): 1-14.

S. Shabalovskaya, J. Anderegg, J. Van Humbeeck. " Critical overview of Nitinol surfaces and their modifications for medical applications." Acta Biomaterialia 4 (2008): 447-467.

S. Shabalovskaya, J. V. Humbeeck. "'Shape Memory Alloys for Biomedical Applications." Chap. 9, edited by S. Miyazaki T. Yoneyama. Woodhead Pub., 2008.

S. Trigwell, G. Selvaduray. "Effect of Surface treatment on the surface characteristics of AISI 316L stainless steel." Materials and Processes for Medical Devices. Boston: ASM International, 2007. 208-213. 
S. Trigwell, R.D. Hayden, K.F. Nelson \& G. Selvaduray. "Effects of surface treatment on the surface chemistry of NiTi alloy for biomedical applications." Surface and Interface Analysis 26 (1998): 483-489.

S. Virtanen, I. Milošev, E. Gomez-Barrena, R. Trebše, J. Salo, Y.T. Konttinen. "Special modes of corrosion under physiological and simulated physiological conditions." Acta Biomaterialia 4 (2008): 468-476.

Schroeder, Valeska. "Evolution of the passive film on mechanically damaged Nitinol." Journal of Biomedical Materials Research Part A 90A (2008): 1-17.

Sevtlana A. Shabalovskaya, K. Hauch, J. Wataha, J. Anderegg, P. Poncet, J. Cunnick. "Effects of surface chemistry on biocompatiability of NiTi." Proceedings of the International Conference on Shape Memory and Superelastic Technologies. Kurhaus Baden-Baden: ASM International, 2004. 367-373.

Shabalovskaya, S. A. "Surface, corrosion and biocompatibility aspects of Nitinol as an implant material." Bio-Medical Materials and Engineering 12 (2002): 69-109.

Shabalovskaya, S. "On the nature of the biocompatibility and on medical applications of NiTi shape memory and superelastic alloys." Biomedical Materials and Engineering 6 (1996): 267-289.

Shabalovskaya, Sevtlana. "Physicochemical and biological aspects of Nitinol as a biomaterial." International Materials Review 46, no. 4 (2001): 230-250.

Silverman, D. C. "Tutorial on cyclic potentiodynamic polarization technique." Proceedings of the Corrosion/98 Research Topical Symposia. San Diego: NACE international, 1998.

Stoeckel, Dieter. "The Shape memory effect - phenomenon, alloys and applications." Shape Memory Alloys for Power Systems EPRI. 1995. 1-13.

Svetlana A. Shabalovskaya, Gianni C. Rondelli, Andreas Undisz, James W. Anderegg, T. David Burleigh, Markus Rettenmayr. "The electrochemical characteristics of native Nitinol surfaces." Biomaterials 30 (2009): 3662-3671.

Svetlana A. Shabalovskaya, He Tian, James W. Anderegg, Dominique U. Schryvers, William U. Carroll, Jan Van Humbeeck. "The influence of surface oxides on the distribution and release of nickel from Nitinol wires." Biomaterials 30 (2009): 468-477.

T. B. Massalski, H. Okamoto, P. R. Subramanian, L. Kacprzak, ed. Binary alloy phase diagrams. 2. Vol. 3. Materials Park, OH: ASM International, 1990. 
T. Duerig, A. Pelton, D. Stöckel. "An overview of Nitinol medical applications." Materials Science and Engineering A273-275 (1999): 149-60.

T. Goryczka, J. Lelatko, and P. Ochin. "Nanocrystalline platinum layer deposited on NiTiCu shape memory strip." The European Physical Journal Special Topics 158 (2008): 33-38.

T. Hryniewicz, R. Rokicki, K. Rokosz. "Corrosion and surface characterization of titanium biomaterial after magnetoelectropolishing." Surface and Coatings Technology 203 (2009): 1508-1515.

Tomasz Goryczka, Jan Van Humbeeck. "NiTiCu shape memory alloy produced by powder metallurgy." Journal of Alloys and Compounds 456 (2008): 194-200.

U.S. Census Bureau. Vers. U.S. Interim Projections by Age, Sex, Race, and Hispanic. 2004. http://www.census.gov/ipc/www/usinterimproj/.

Uhlig, J. Horvath and H. H. "Critical potentials for pitting corrosion of $\mathrm{Ni}, \mathrm{Cr}-\mathrm{Ni}$, $\mathrm{Cr}-\mathrm{Fe}$, and related stainless steels." Journal of Electrochemical Society 115 (1968): 791-795.

V. C. Dinca, S. Soare, A. Barbalat, C. Z. Dinu, A. Moldovan, I. Stoica, T. Vassu, A. Purice,N. Scarisoareanu, R. Birjega, V. Craciun, V. Ferrari DeStefano, M. Dinescu. "Nickel-titanium alloy: Cytotoxicity evaluation on microorganism culture." Applied Surface Science 252 (2006): 4619-4624.

V. Muhonen, C. Fauveaux, G. Olivera, P. Vigneron, A. Danilov, M.-D. Nagel, J. Tuukkanen. "Fibronectin modulates osteoblast behavior on Nitinol." Journal of Biomedical Materials Research A 88A, no. 3 (2008): 787-796.

W. Haider, N. Munroe, C. Pulletikurthi, P. S. K. Gill, S. Amruthaluri. "A comparative biocompatibility analysis of ternary Nitinol alloys." Journal of Materials Engineering and Performance 18 (2009): 760-764.

W. Zingg, A. W. Neumann, A. B. Strong, O. S. Hum and D. R. Absolom. "Effect of surface roughness on platelet adhesion under static and under flow conditions." Canadian Journal of Surgery 25 (1982): 16.

Warner, Clifford P. "The effect of exposure to simulated body fluids on breakdown potentials." Journal of Materials Engineering and Performance 18, no. 5-6 (2009): 754759. 
Wojciech Chrzanowski, Ensanya Ali Abou Neel, David Andrew Armitage, Jonathan Campbell Knowles. "Effect of surface treatment on the bioactivity of nickel-titanium." Acta Biomaterialia 4 (2008): 1969-1984.

Wu, M. H. "Fabrication of Nitinol Materials and Components." The International Conference on Shape Memory and Superelastic Technologies. Kunming, 2001. 285-292.

X. M. Liu, S. L. Wu, P. K. Chu, C. Y. Chung, C. L. Chu, K. W. K. Yeung, W. W. Lu, K. M. C. Cheung, K, D. K. Luk. "Effects of water plasma immersion ion implantation on surface electrochemical behavior of NiTi shape memory alloys in simulated body fluids." Applied Surface Science 253 (2007): 3154-3159.

X. Wen, N. Zhang, X. Li, Z. Cao. "Electrochemical and histomorphometric evaluation of the TiNiCu shape memory alloy." Bio-Medical Materials and Engineering 7, no. 1 (1997): 1-11.

X.-Y. Li, E. Akiyama, H. Habazaki, A. Kawashima, K. Asami, K. Hashimoto. "Spontaneously passivated films on sputer-deposited Cr-Ti alloys in 6M Hcl solution." Corrosion Science 39 (1997): 935-948.

Y. Cheng, W. Cai, H. T. Li, Y. F. Zheng. "Surface modification of NiTi alloy with tantalum to improve its biocompatibility and radiopacity." Journal of Materials Science 41 (2006): 4961-4964.

Y. Shen, G. Wang, L. Chen, H. Li, P. Yu, M. Bai, Q. Zhang, J. Lee, Q. Yu. "Investigation of surface endothelialization on biomedical nitinol (NiTi) alloy: Effects of surface micropatterning combined with plasma nanocoatings." Acta Biomaterialia 5 (2009): 3593-3604.

Zhijun Bai, M.J. Filiaggi, J.R. Dahn. "Fibrinogen adsorption onto 316L stainless steel, Nitinol and titanium." Surface Science 603 (2009): 839-846. 
APPENDICES 


\section{APPENDIX A}

\section{XPS Survey Spectra}

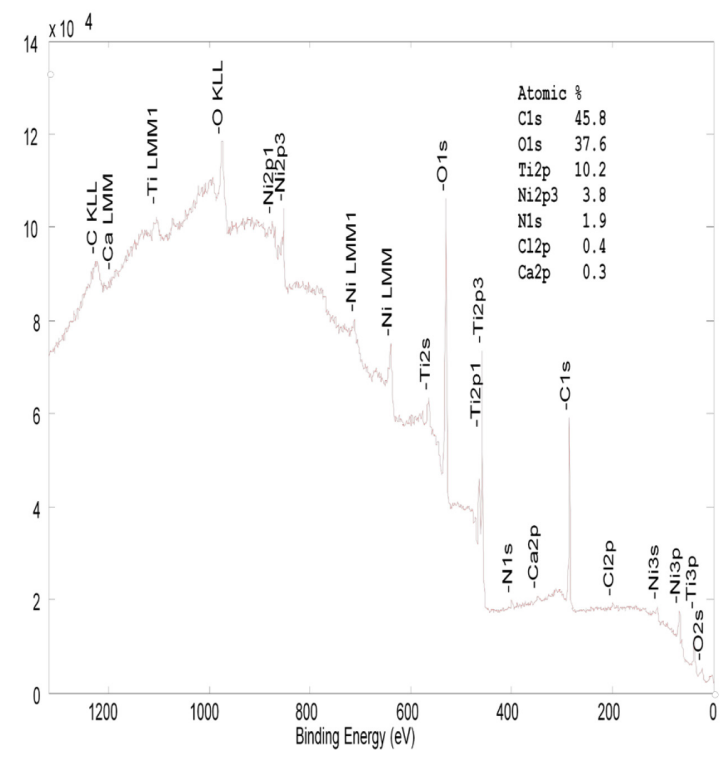

NiTi-untreated

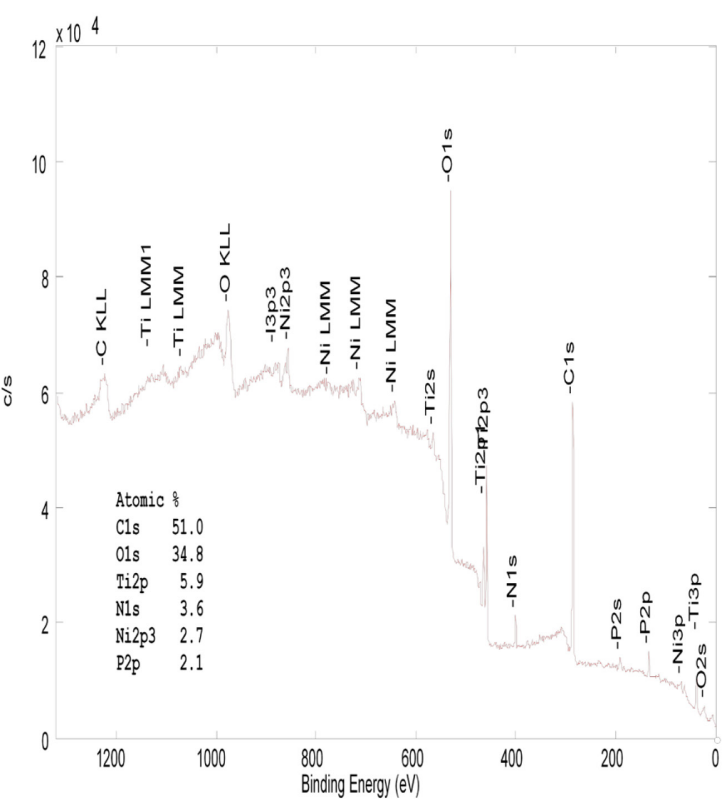

NiTi-MEP

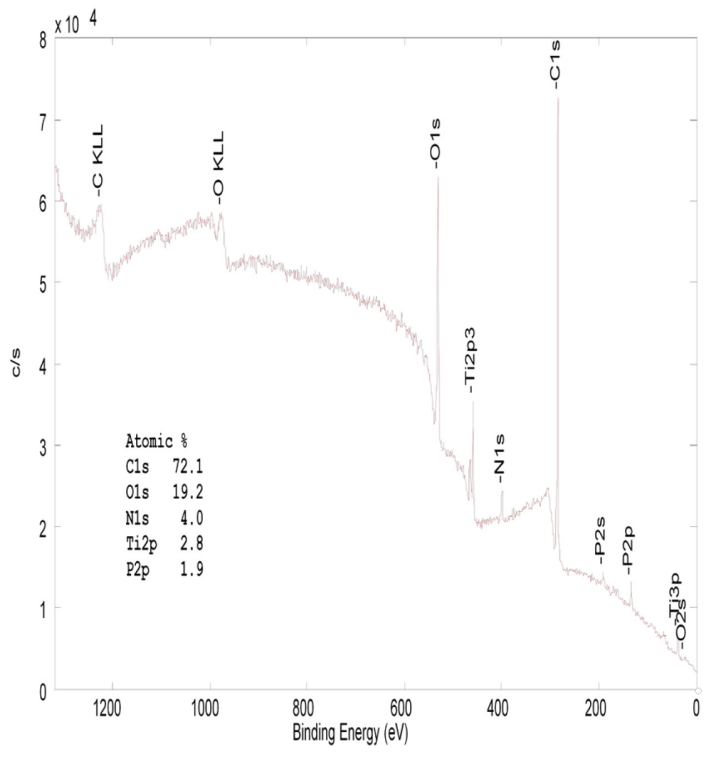

NiTi-EP

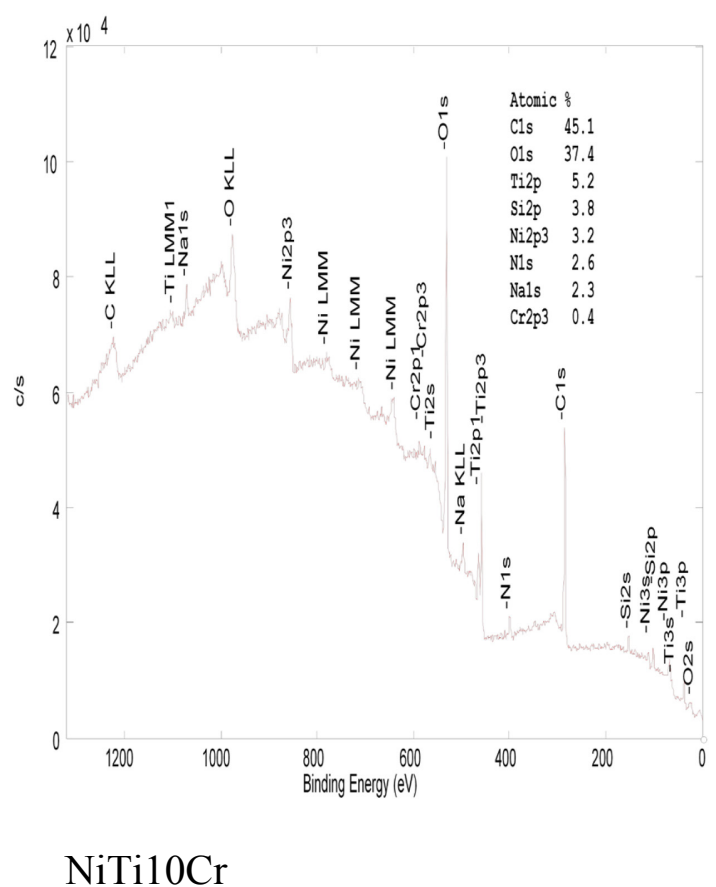




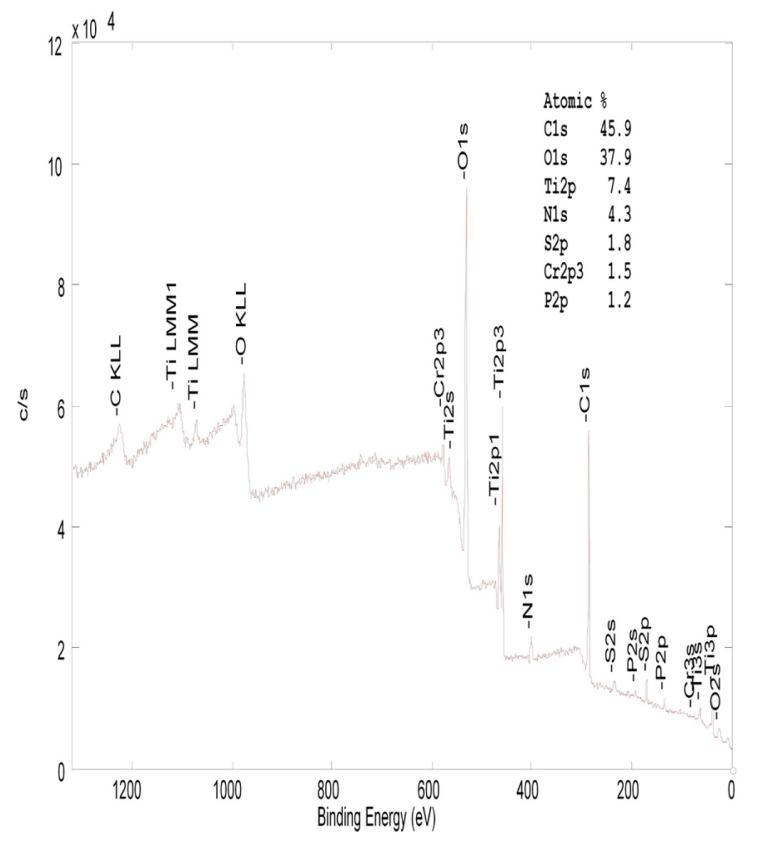

NiTi10Cr-EP

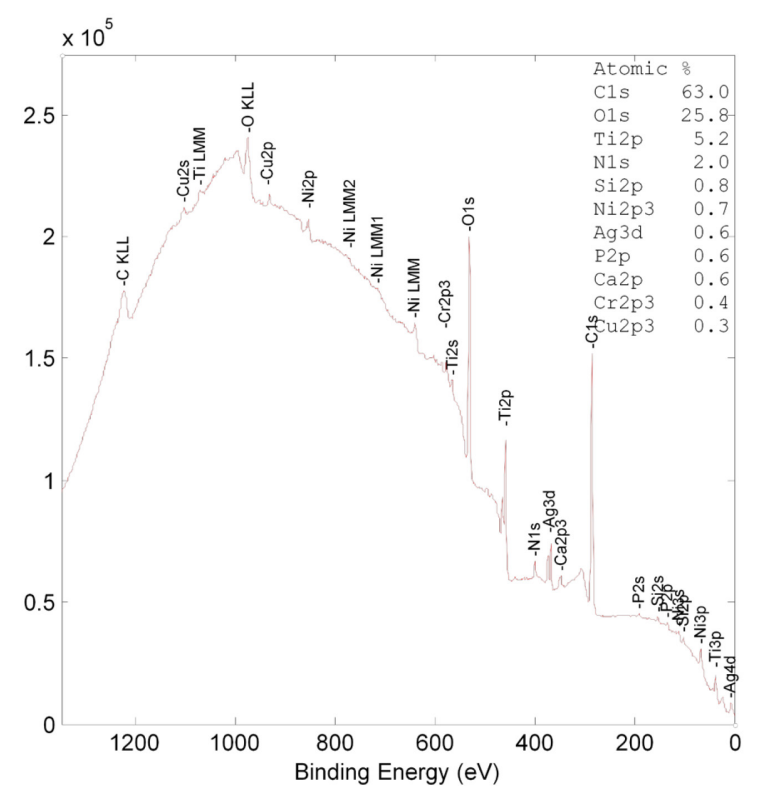

NiTi10Cr-W\&P

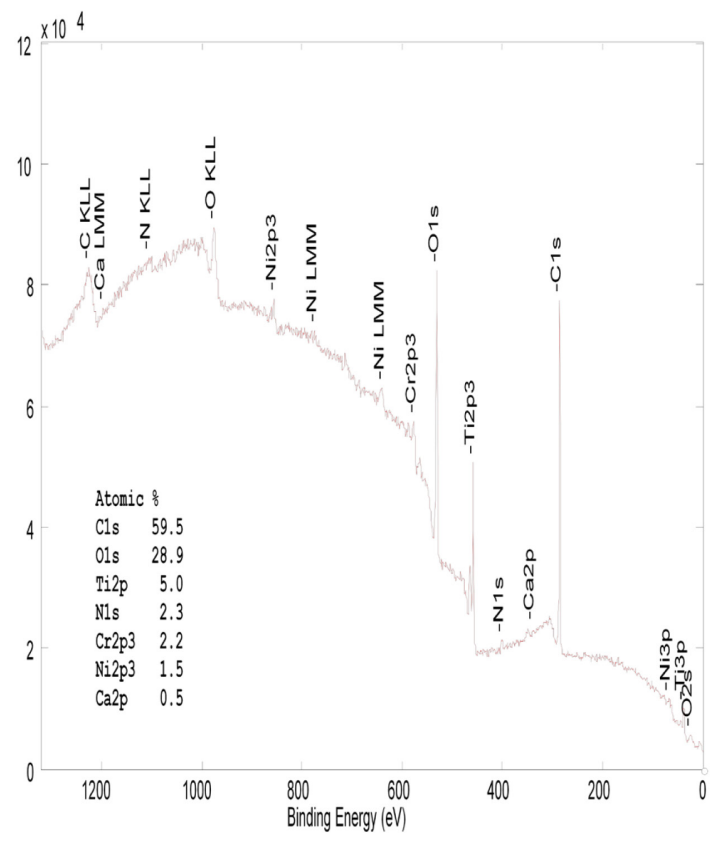

NiTi10Cr-MEP

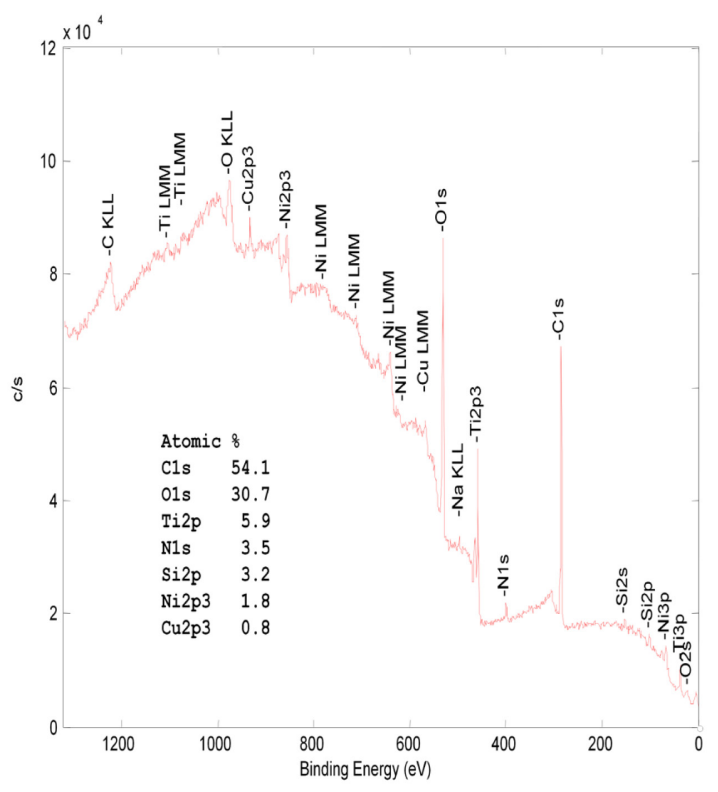

NiTi10Cu-untreated 


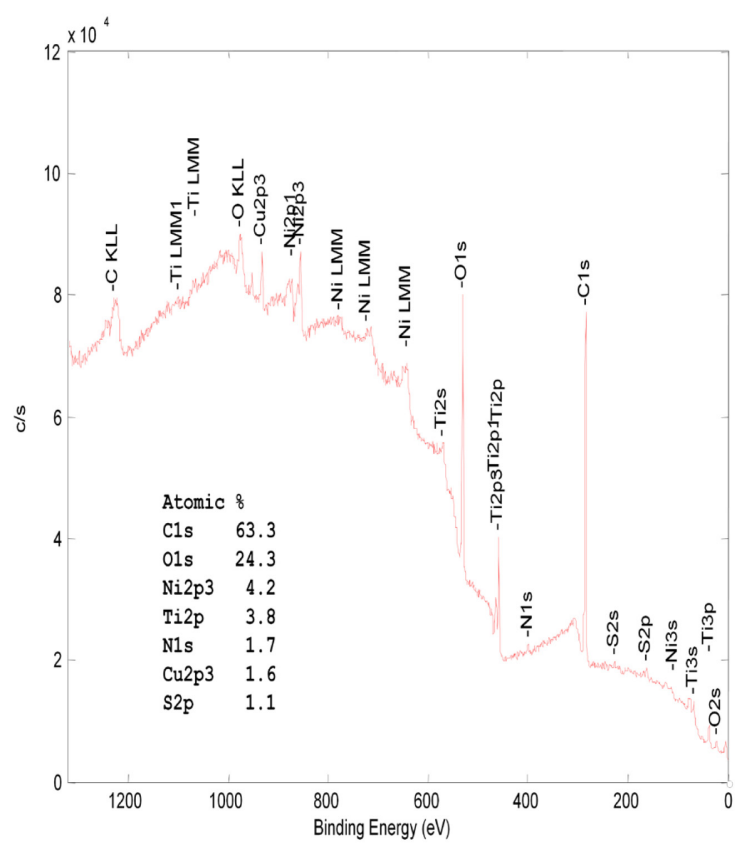

NiTi10Cu-EP

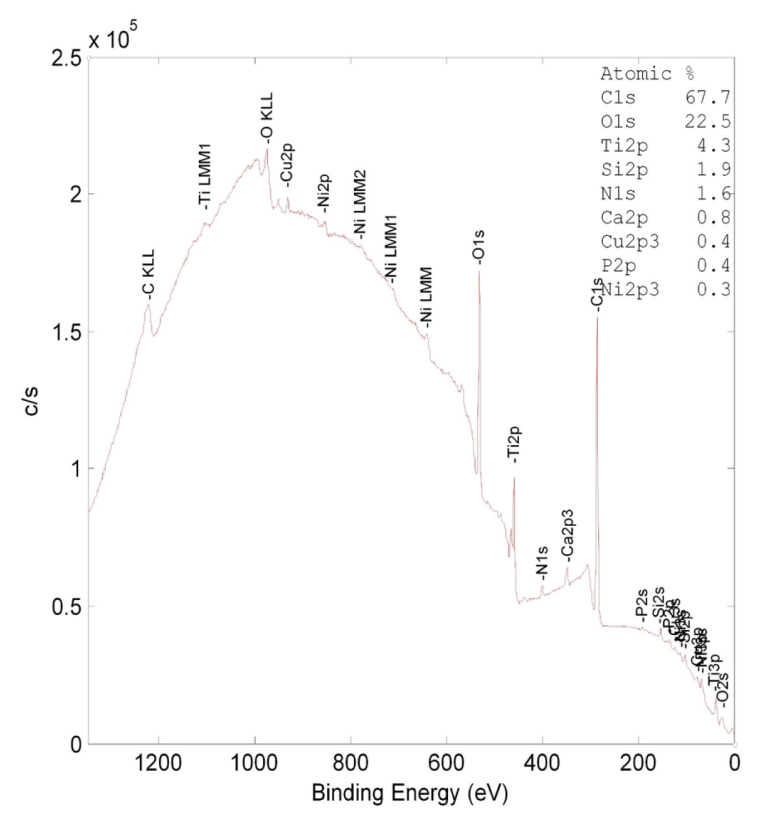

NiTi10Cu-W\&P
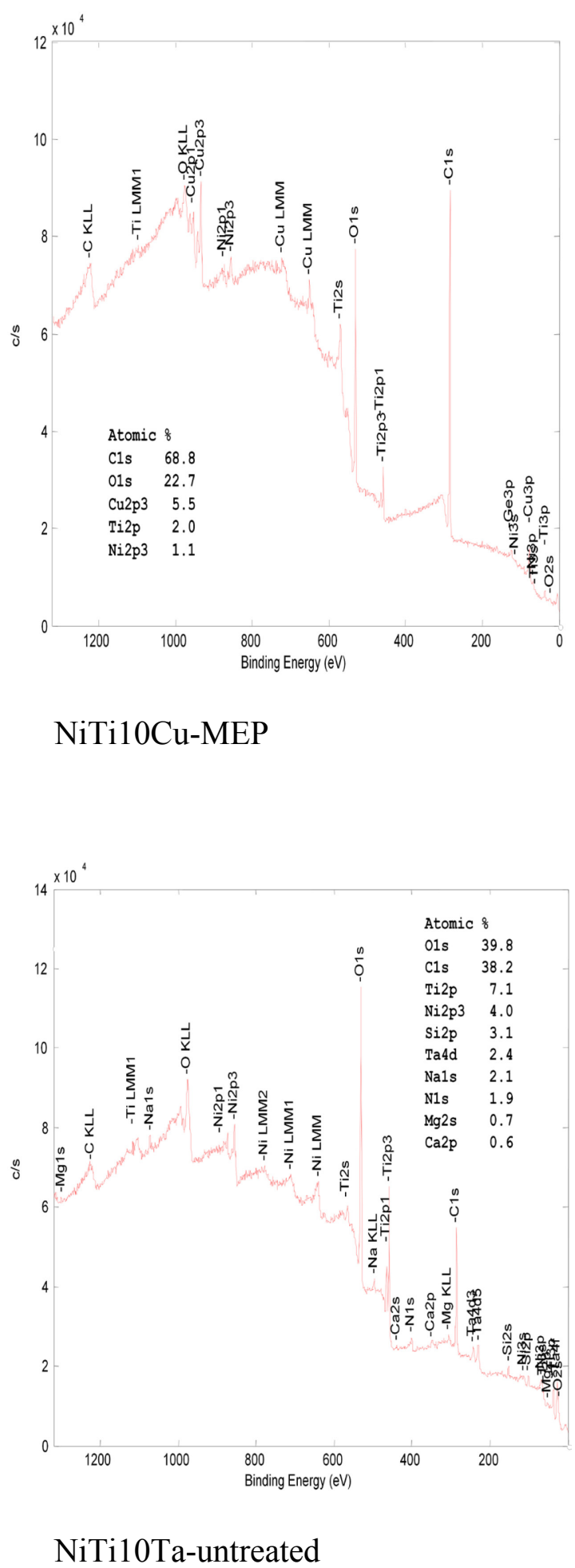


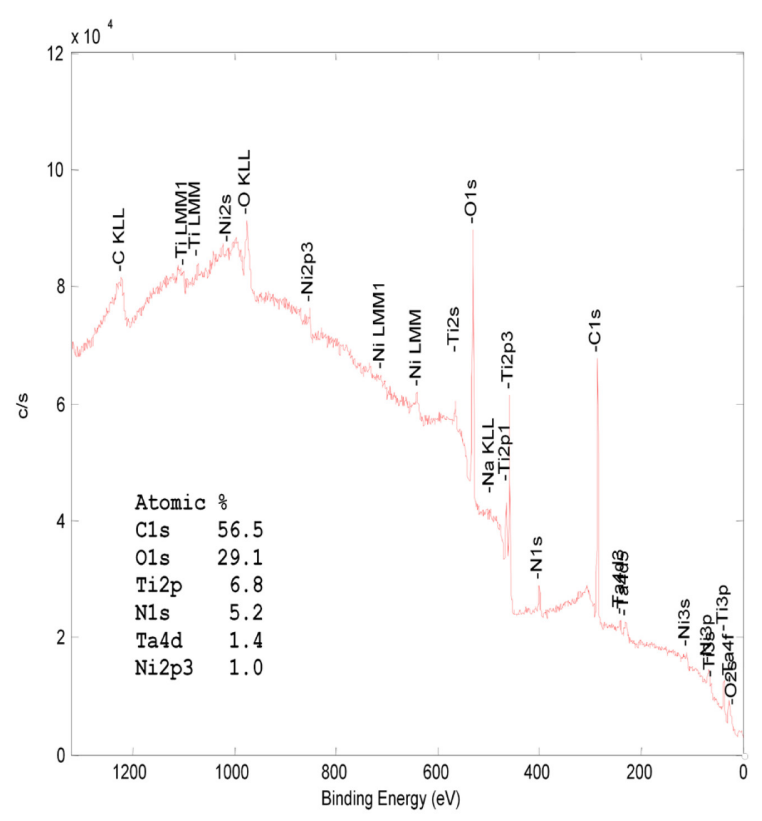

NiTi10Ta-EP

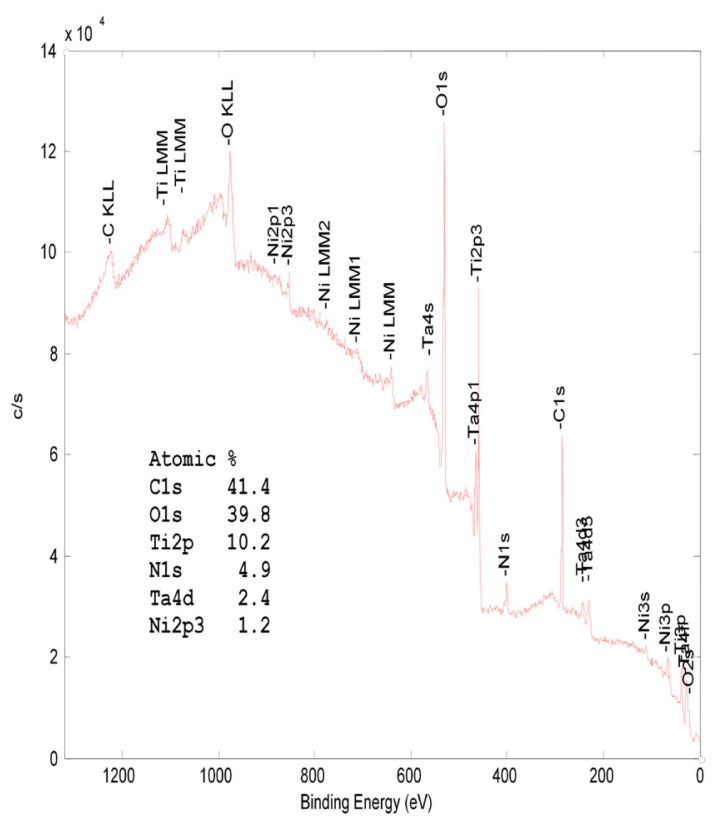

NiTi10Ta-MEP 


\section{APPENDIX B}

\section{Carbon Montage Plots}
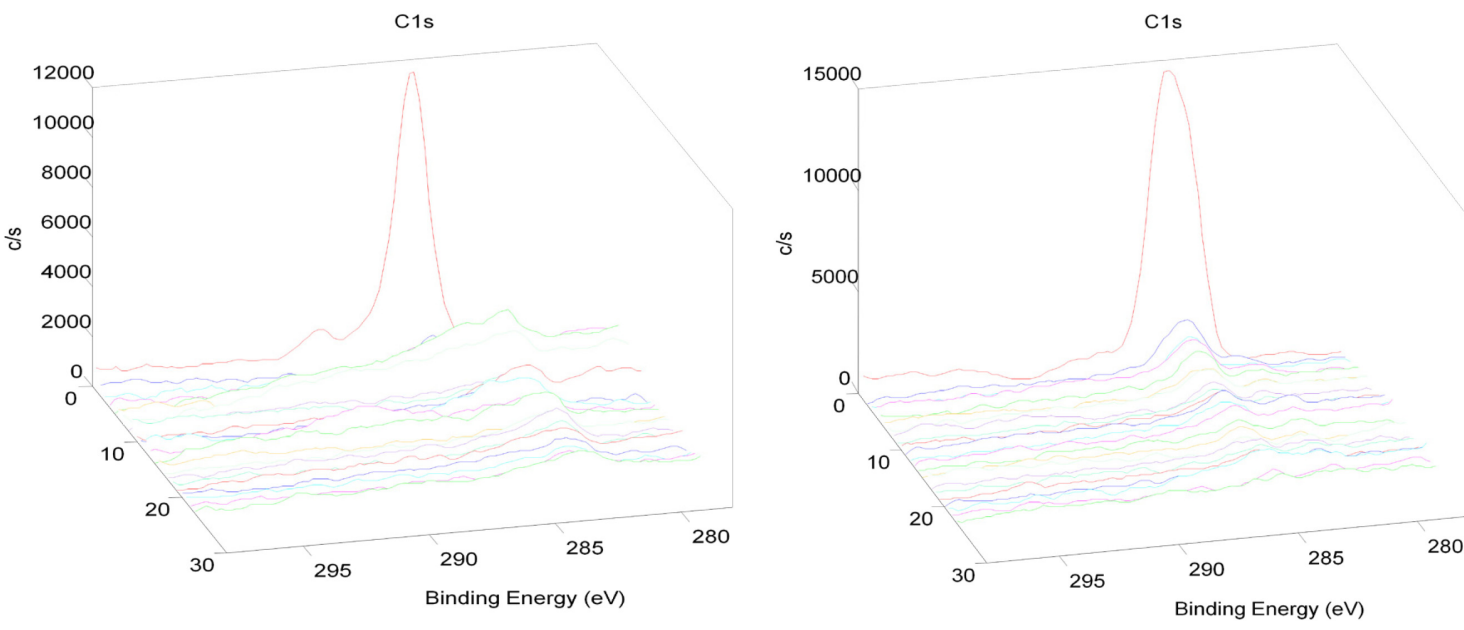

\section{NiTi-untreated}

\section{NiTi-EP}
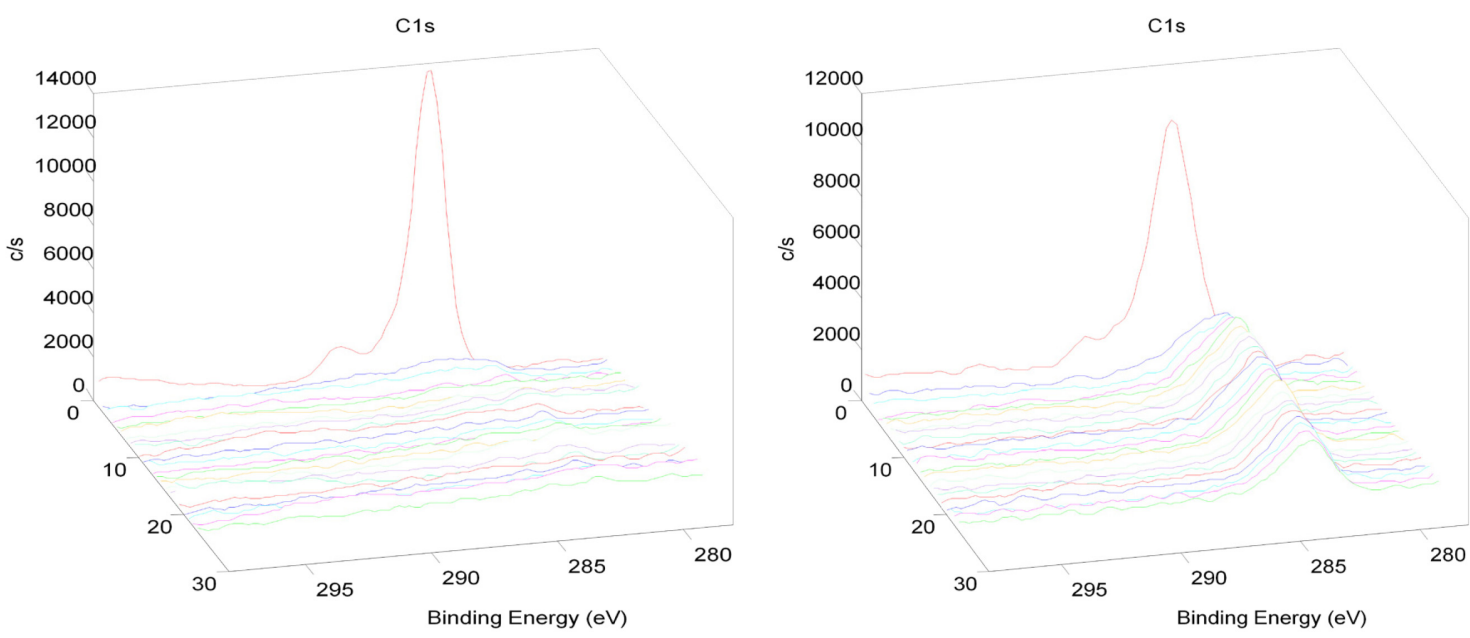

NiTi-MEP

NiTi10Cr-untreated 


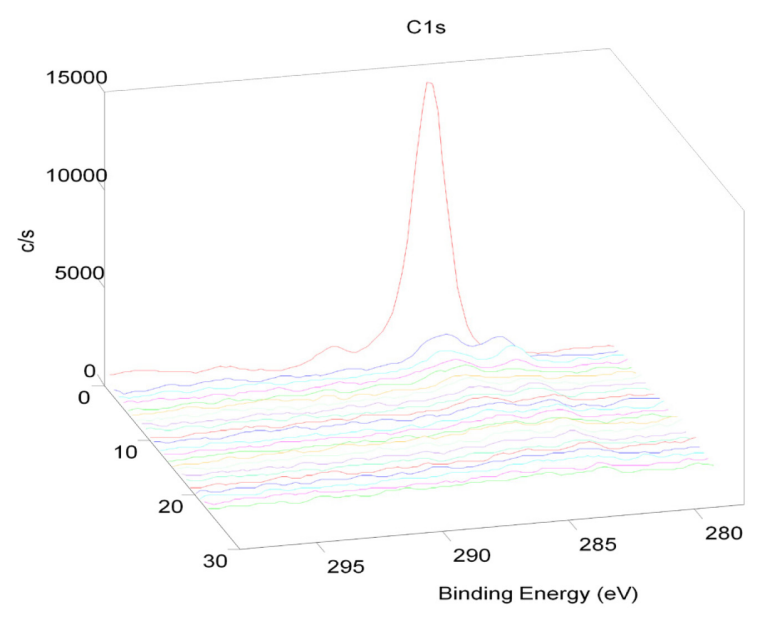

\section{NiTi10Cr-EP}

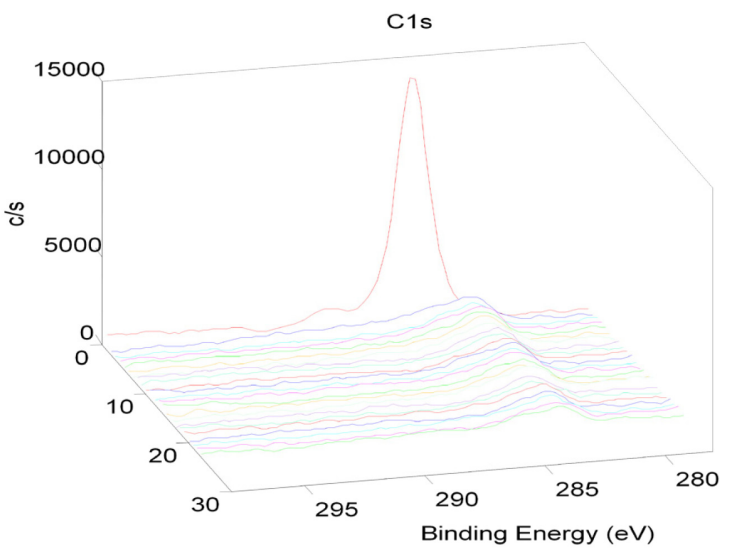

\section{NiTi10Cu-untreated}

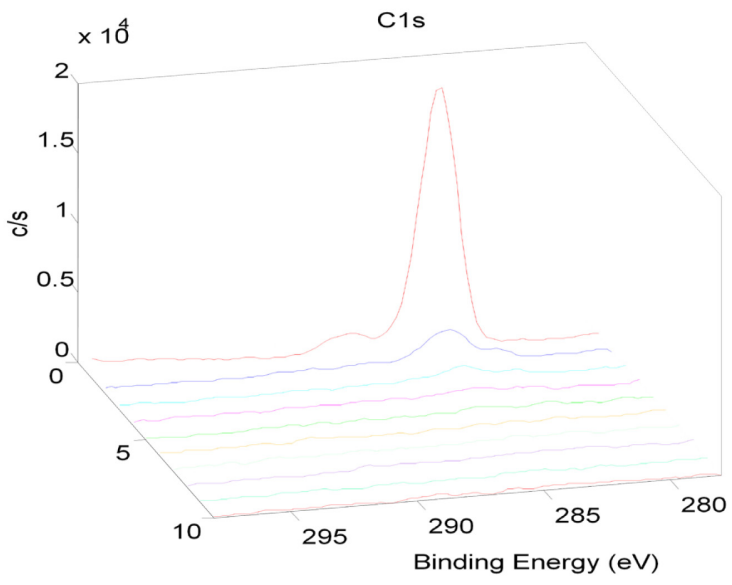

NiTi10Cu-MEP

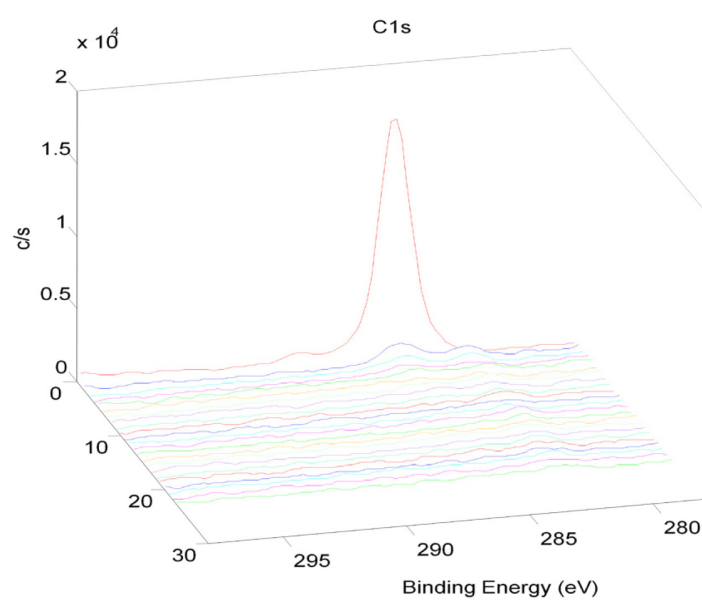

NiTi10Cr-MEP

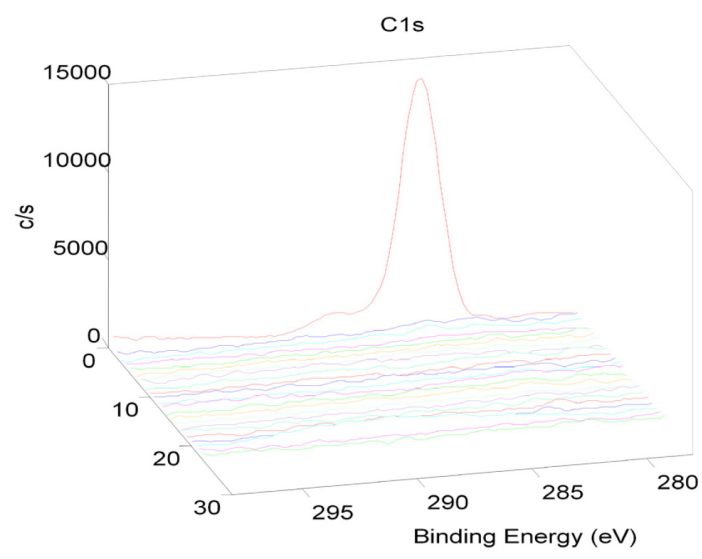

\section{NiTi10Cu-EP}

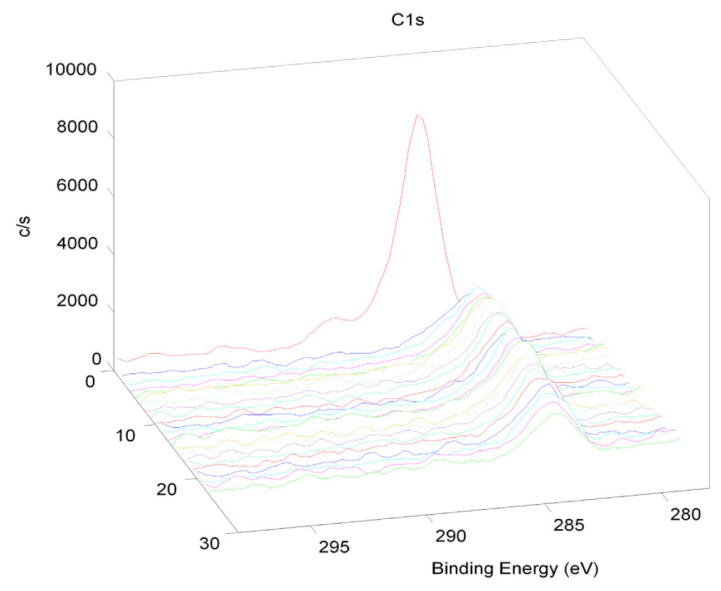

NiTi10Ta-untreated 


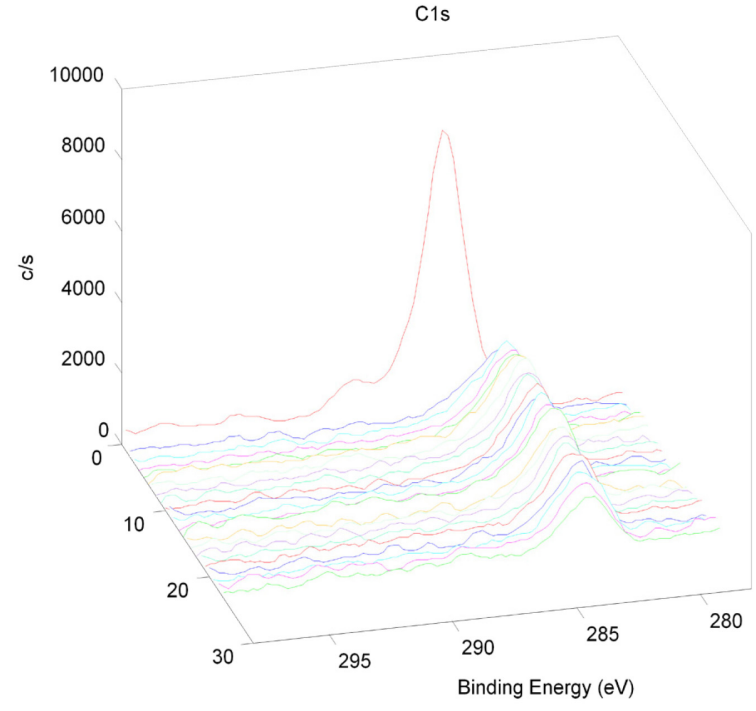

NiTi10Ta-EP

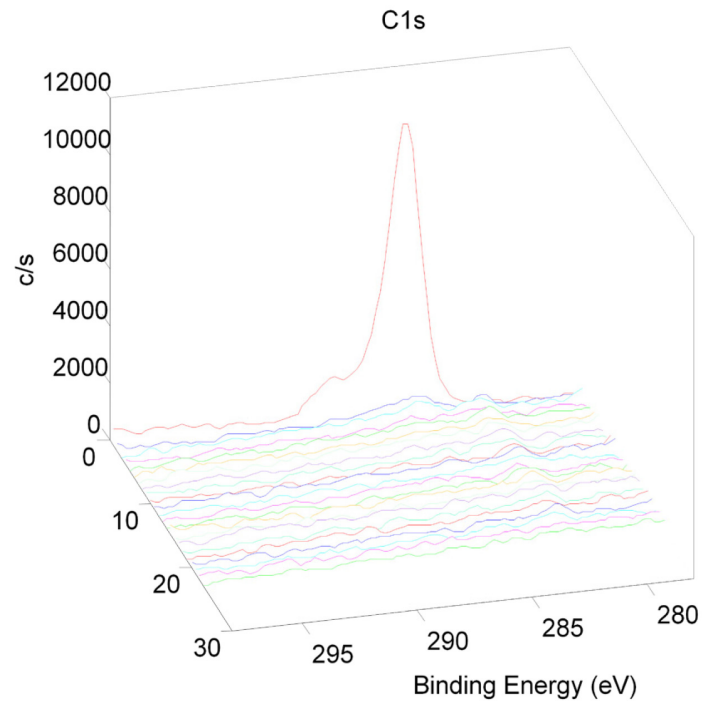

NiTi10Ta-MEP 


\section{APPENDIX C}

\section{Oxygen Montage Plots}

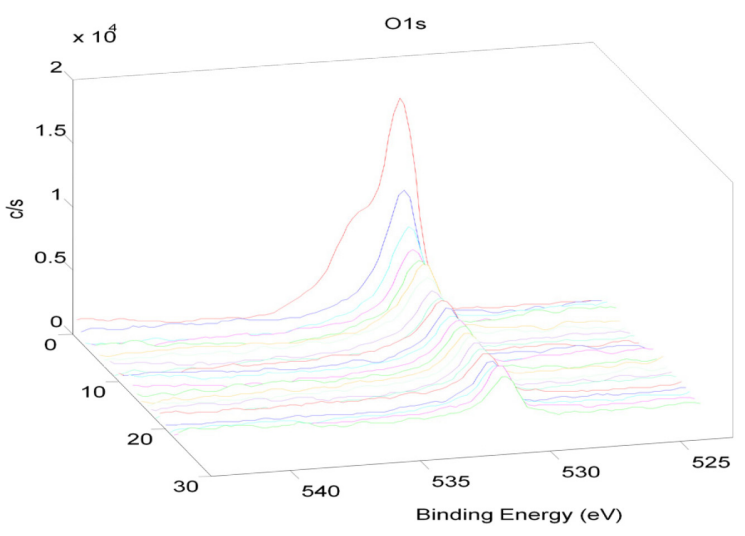

NiTi-untreated

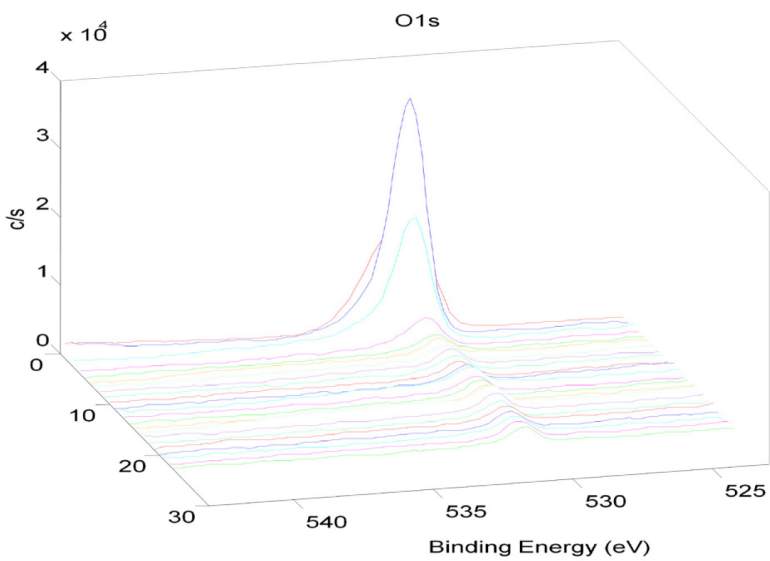

NiTi-MEP

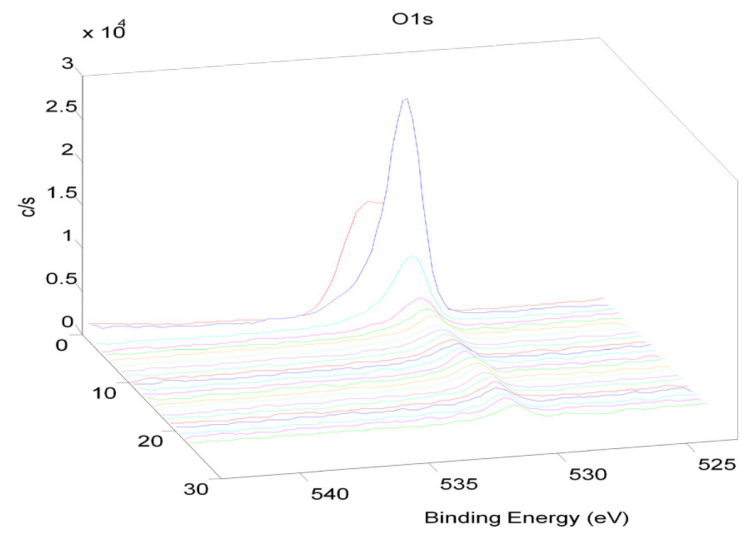

NiTi10Cr-EP

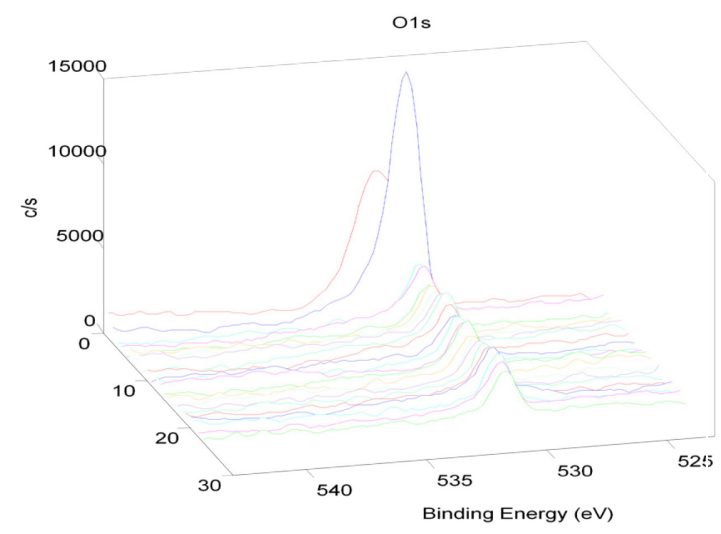

NiTi-EP
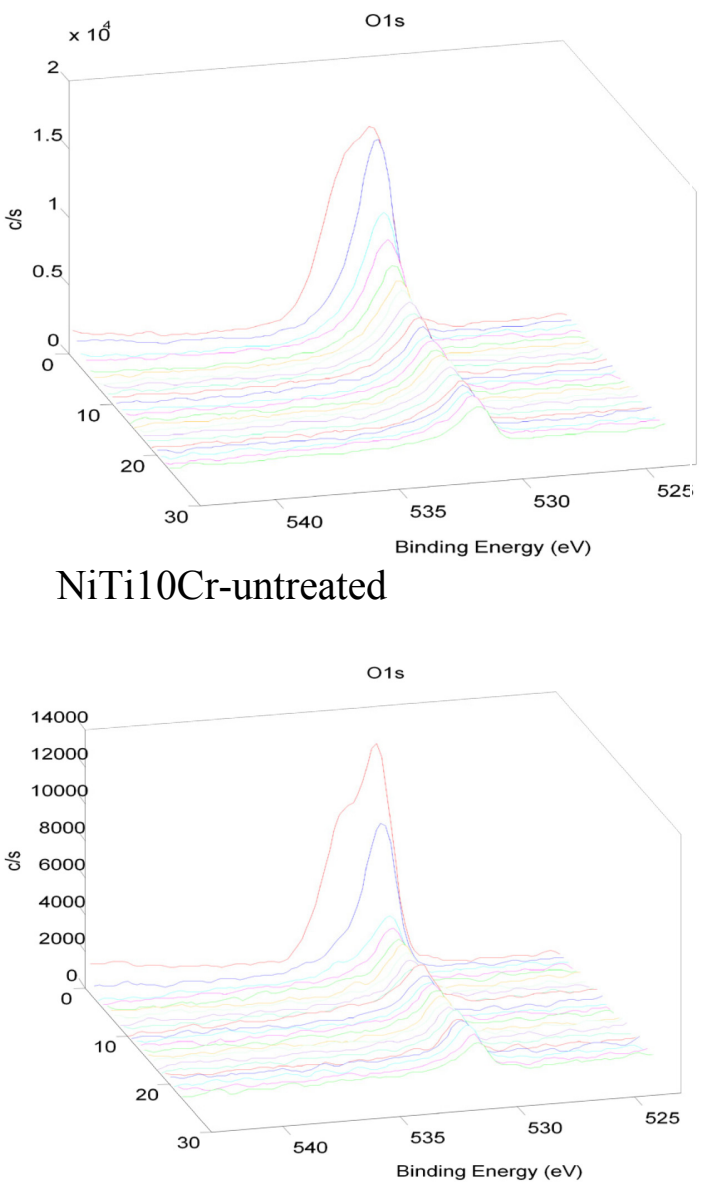

NiTi10Cr-MEP 


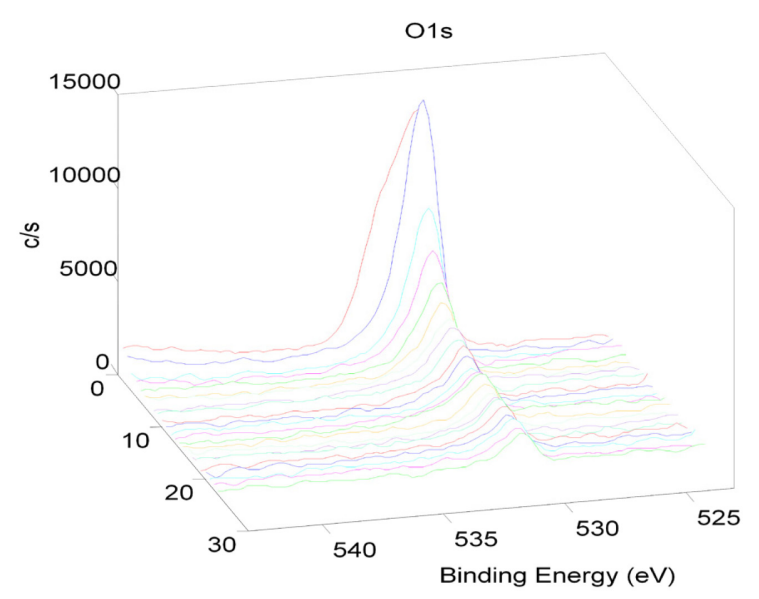

NiTi10Cu-untreated

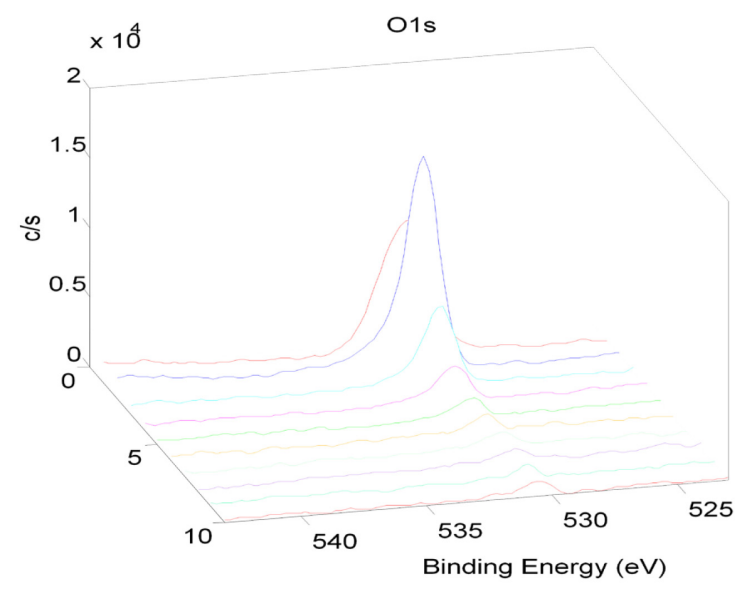

\section{NiTi10Cu-MEP}

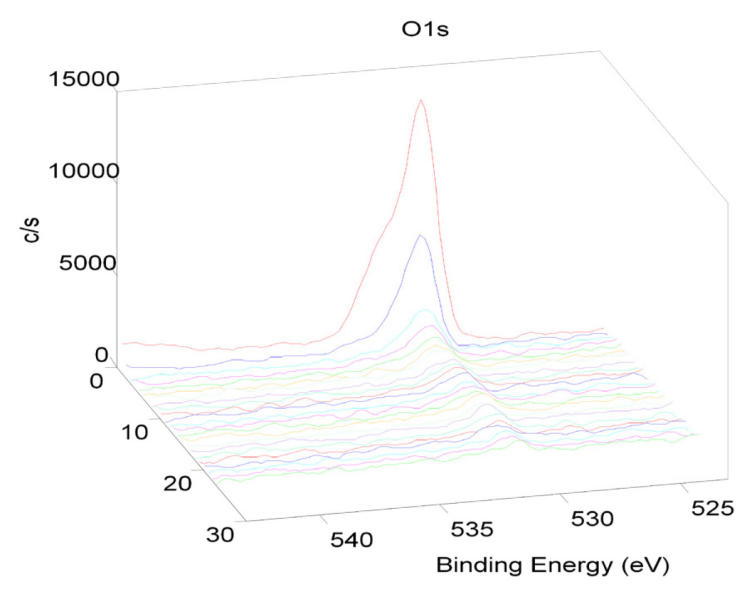

NiTi10Ta-EP

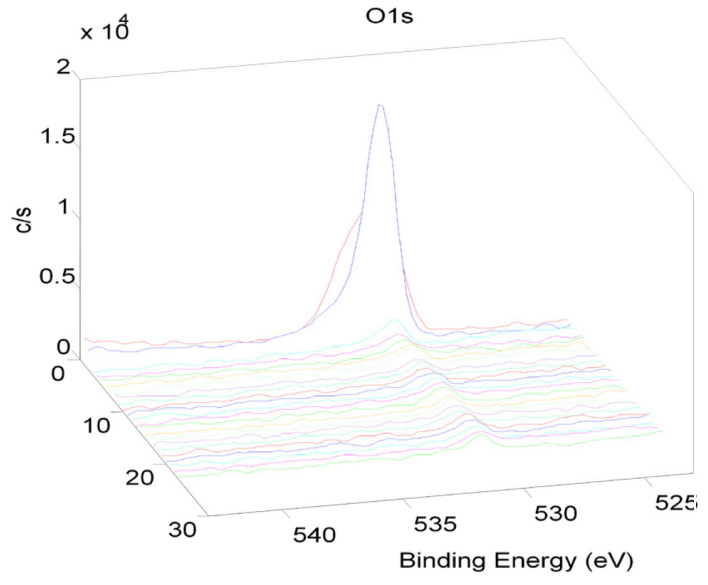

NiTi10Cu-EP

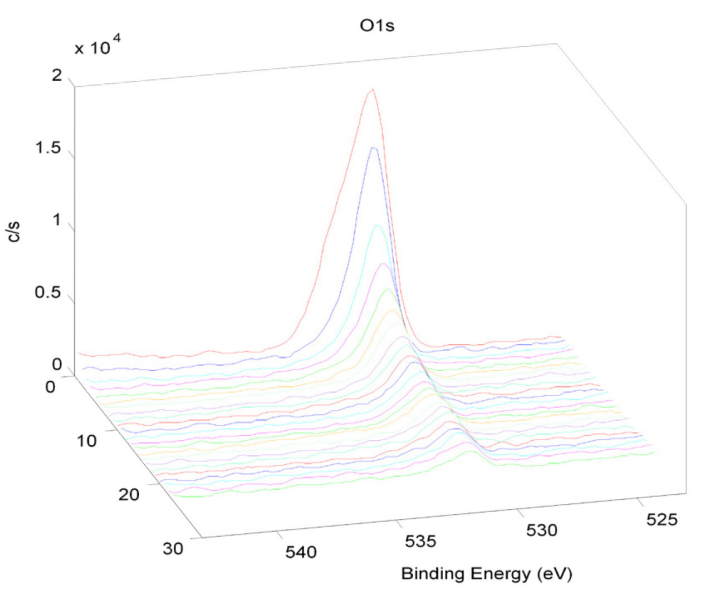

NiTi10Ta-untreated

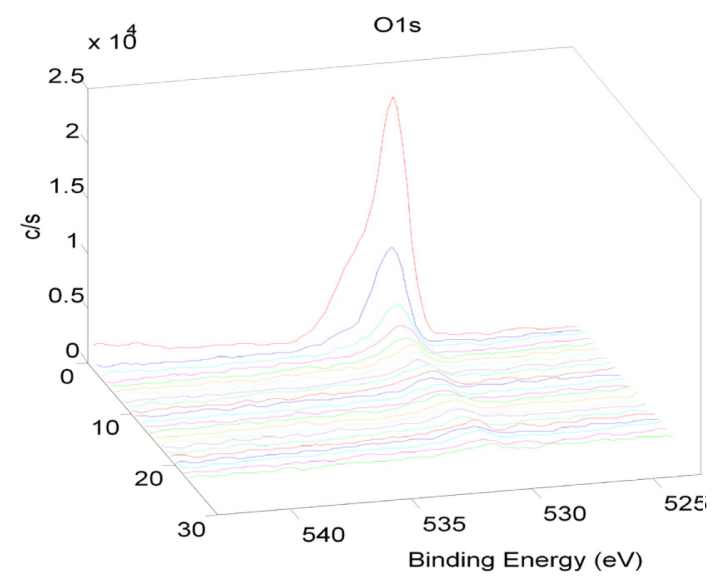

NiTi10Ta-MEP 
VITA

\section{WASEEM HAIDER}

1998

2003

2006
B.Sc. Biological and Chemical Sciences

University of the Punjab

Lahore, Pakistan

B.Sc. Metallurgical and Materials Engineering Middle East Technical University

Ankara, Turkey

M.Sc. Materials Engineering

Tampere University of Technology

Tampere, Finland

\section{PUBLICATIONS AND PRESENTATIONS}

W. Haider, N. Munroe, V. Tek, C. Pulletikurthi, Puneet K. S Gill, S. Pandya, "Review on Surface Modifications of Nitinol". Journal of Long Term Effects of Medical Implants: Volume 9, Issue 2 (2010).

W. Haider, N. Munroe, C. Pulletikurthi, Puneet K. S Gill, S. Amruthaluri, "A Comparative Biocompatibility Analysis of Ternary Nitinol Alloys". Journal of Materials Engineering and Performance: Volume 18, Issue 5 (2009) pp. 760-764.

N. Munroe, C. Pulletikurthi, W. Haider, "Enhanced Biocompatibility of Porous Nitinol". Journal of Materials Engineering and Performance: Volume 18, Issue 5 (2009) pp. 765-767.

W. Haider, N. Munroe, V. Tek, A. J. McGoron, P. K. S. Gill, C. Pulletikurthi, S. Pandya, “An assessment of metal ions release from ternary Nitinol alloys under static and dynamic conditions", SMST 2010 The International Conference for Shape Memory and Super elastic Technologies, May 16-20, 2010, Pacific Grove, California (Under preparation)

W. Haider, N. D. Munroe, P. K. S. Gill, C. Pulletikurthi, "The electrochemical characteristics of surface treated Nitinol alloys", NACE-Corrosion 2010 conference, March 14-18, 2010 San Antonio, Texas. (In press)

W. Haider, N. Munroe, S. Shah, A. J. McGoron, C. Pulletikurthi, P. K. S. Gill, "Cytotoxicity Assessment of Corrosion Products of Nitinol Alloys", Materials and Processes for medical devices-Conference and Exhibition, August 10-12, 2009, Minneapolis, Minnesota. (In Press) 
W. Haider, N. D. Munroe, C. Pulletikurthi, P. K. S. Gill, "Corrosion Behavior of Electropolished and Non-electropolished Ternary Nitinol Alloys", 25th Southern Biomedical Engineering Conference 2009, The International Federation for Medical and Biological Engineering (IFMBE) Proceedings 24, pp. 33-34, 2009.

N. Munroe, Puneet K. S. Gill, S. Amruthaluri, W. Haider, "Highly conductive Nanostructure Cu-Cr-MWCNT Composite". Materials Science \& Technology (MS\&T) 2008 Conference, pp. 2309-2318, October 5-9, 2008, Pittsburgh, Pennsylvania.

P. K. S. Gill, N. D. Munroe, W. Haider, C. Pulletikurthi, S. Pandya, V. Tek, Biocompatibility Assessment of a Conductive Ni-Ti-CNT Composite, MRS Fall Meeting, November 30 December 4, 2009, Boston, Massachusetts.

W. Haider, N. Munroe, V. Tek, Y. Tang, A. J. McGoron C. Pulletikurthi, P. K. Singh Gill, S. Pandya, Comparing the Biocompatibility of Electropolished and Magnetoelectropolished Nitinol, Biointerface, October 26-28, 2009, San Mateo, California.

C. Pulletikurthi, N. Munroe, W. Haider, V. Tek, P. K. S Gill and S. Pandya, The Effect of Electropolishing and Magnetoelectropolishing on the Biocompatibility of Porous Nitinol Implant, Biointerface, October 26-28, 2009, San Mateo, California.

P. K. S. Gill, N. Munroe, W. Haider, C. Pulletikurthi, Mechanical and Bio-compatibility Studies on MWCNT based ternary alloys, Nanotech India 2009, 14-16 August, 2009, Kochi, India.

W. Haider, N. Munroe, Y. Tang, A. J. McGoron, C. Pulletikurthi, P. K. S. Gill, Endothelialization of Ternary Nitinol Alloys, Materials and Processes for medical devicesConference and Exhibition, August 10-12, 2009, Minneapolis, Minnesota.

W. Haider, N. Munroe, C. Pulletikurthi, P. K. S. Gill, S. Amruthaluri, Corrosion and Biocompatibility of Ternary Nitinol Alloys, ASEAN Pakistan Conference on Materials Science, December 15-16, 2008, Islamabad, Pakistan.

N. D. Munroe, W. Haider, C. Pulletikurthi, Puneet K.S Gill, S. Amruthaluri, S. Kanchibhotla, Phase Transformation and Energy Absorption of Nitinol Alloys, Proceedings, SMST 2008, The International Conference for Shape Memory and Superelastic Technologies, September 21-25, 2008, Stresa, Italy.

N. Munroe, W. Haider, A. Datye, K. H. Wu "Corrosion Behavior of Electropolished Implant Alloys". Proceedings, SMST 2007, The International Conference for Shape Memory and Superelastic Technologies, pp. 307-314, December 3-5, 2007, Tsukuba, Japan.

N. Munroe, W. Haider, K. H. Wu, A. Datye, "Corrosion Behavior of Cardiovascular Stent Materials". Proceedings, SMST 2007, The International Conference for Shape Memory and Superelastic Technologies, pp. 299-306, December 3-5, 2007, Tsukuba, Japan.

Reviewer: Journal of Materials Engineering and Performance 